\title{
Redes Bayesianas para Extração de Conhecimento de Bases de Dados, Considerando a Incorporação de Conhecimento de Fundo e o Tratamento de Dados Incompletos ${ }^{1}$
}

\section{Cláudio Alex Jorge da Rocha}

Orientação: Profa. Dra. Solange Oliveira Rezende

Dissertação apresentada ao Instituto de Ciências Matemáticas e de Computação - USP, como parte dos requisitos para a obtenção do título de Mestre em Ciências - Área de Ciências de Computação e Matemática Computacional.

USP - São Carlos

Março de 1999

\footnotetext{
${ }^{1}$ Trabalho realizado com auxílio da FIDESA e PICDT-CAPES.
} 
Este documento foi preparado com o formatador de textos IATEX. O sistema de citações de referências bibliográficas utiliza o padrão Chicago do sistema BibTeX.

(C) Copyright 1999 por Cláudio Alex Jorge da Rocha.

Todos os Direitos Reservados. 


\section{Dedicatória}

À Cleise, a pessoa mais importante do mundo, e a quem eu tenho o maior amor do mundo. 


\section{Agradecimentos}

A Deus, simplesmente, por tudo.

Aos Meu Pais, Francisco e Gláucia, pela educação, amor, repeito e por fazeram tudo para que eu pudesse realizar um sonho. O simples sonho de estudar, em um país que, para a grande maioria das pessoas, estudar ainda não passa de um sonho.

Aos meus irmãos, que apesar de parecermos tão desligados, mostramo-nos sempre unidos por um ideal - a felicidade de todos nós.

Ao Ivan e ao Renato, pela sólida amizade que nos une a tanto tempo. O I.R.A é eterno.

À Regiane e ao Amigo Hulk, por toda amizade que nos faz pensar na construção imediata do RHIRA.

À Aletéia, Andrezza, Caldas, Daniel, Jorge, Paulo e Thereza, que, apesar do pouco tempo de convívio, mostraram-me que fazemos parte de um só grupo, ou como diríamos, um só cluster.

À Prof. Dra. Maria Carolina Monard, pelo incentivo e o carinho pelo qual sempre me tratou.

Ao Prof. Dr. Raysildo Lôbo, pela atenção e valiosas contribuições para a realização deste trabalho.

Ao Luiz Fernando, pela colaboração e dedicação a este trabalho.

À Jaqueline e Chandler, que além da amizade, doaram o seu precioso tempo na revisão desta dissertação. No LABIC, temos versões em português e inglês do nosso corretor ortográfico, sintâtico, semântico, etc.

Aos amigos (Antônio, Naiara, Luis Carlos, Marisa, Ernesto, Cláudia, Robson, Marco, Mirla, Silmara, Márcia, Walter, Huei, Fábio, Andrea, Hélio, Luciana, Telma, Tatiana, Nilda, Mayb, Flávia, Jusane, Edmar, entre tantos outros), pelos bons e inesquecíveis momentos compartilhados.

À todos os amigos do LABIC, pelo companherismo, e por fazer sempre desse labo- 
ratório um ambiente de muita harmonia.

Aos professores do CEFET e da UNAMA, especialmente o José Ricardo, Afonso, Robson, Cláudio Roberto, Cláudio Lima, Andracir, Rômulo, Avelino, Edgar, Ricardo, Takemura, Paulo e Júnior, pelo companheirismo e rico aprendizado de nosso convívio.

À Beth, Laura, Marília, às funcionárias da biblioteca, ao Paulinho, ao Jacques e à todos os funcionários do ICMC, pela maneira prestativa e educada que sempre me atenderam.

A CAPES, pelo apoio financeiro. Infelizmente, aqueles que outrora receberam tanto incentivo, são os mesmos que querem acabar com esse elemento tão fundamental para sucesso de qualquer pesquisa.

À FIDESA, pelo apoio financeiro e pronto atendimento dos pleitos de seus professores bolsistas.

Àqueles que, de um modo ou de outro, contribuíram para a realização deste trabalho.

Finalmente, permitam-me contar uma história...

Quando cheguei em São Carlos, em 21 de fevereiro de 1997, e adentrei pela primeira vez (pelo portão da Arquitetura) na USP - São Carlos, uma frase chamou-me a atenção - "USP - Educação para o Brasil". Primeiramente, causou-me espécie, de certa forma a considerei até opulenta. A partir do momento que comecei a entender e conhecer as pessoas que fazem a "Educação para o Brasil", pude verificar a magnitude desse, muito mais que slogan - um Princípio. Na construção de minha formação acadêmica ainda não havia conhecido argamassas tão sólidas. Pessoas que se dedicam com veemência àquilo que fazem, e que estabelecem mecanismos, mesmo com tantos estorvos impostos pelo governo, para oferecer todos os meios possíveis para que façamos muito mais que seis disciplinas e uma dissertação; mas para que tenhamos uma formação digna, de profissionais que possam disseminar, em qualquer canto desse imenso país, a semente da "Educação para o Brasil". Vários são aqueles que personificam esse Princípio. Eu tive a honra de conhecer e trabalhar com uma delas - a Prof. Dra. do Brasil, Solange Oliveira Rezende, que não poupou esforços para oferecer os melhores subsídios para minha formação. À Solange, um agradecimento muito especial pela orientação, incentivo, dedicação e amizade. 
"Cada um hospeda dentro de si uma águia.

Sente-se portador de um projeto infinito.

Quer romper os limites apertados de seu arranjo

existencial. Há movimentos na educação,

na política e no processo de mundialização

que pretendem reduzir-nos a simples galinhas, confinadas

aos limites do terreiro. Devemos equilibrar estes

dois pólos, impedindo que a cultura da

homogeneização afogue a águia e nos tolha de voar."

Leonardo Boff 


\section{Sumário}

1 Introdução 1

2 Processo de Extração de Conhecimento de Bases de Dados 6

2.1 Considerações Iniciais . . . . . . . . . . . . . . . . . 6

2.2 Aquisição de Conhecimento em Bases de Dados . . . . . . . . . 7

2.3 Etapas do Processo de Extração de Conhecimento de Bases de Dados . . . . 8

2.3.1 Compreensão do Domínio da Aplicação . . . . . . . . . . . . . 11

2.3.2 Seleção e Preparação dos Dados . . . . . . . . . . . . . . . 12

2.3 .3 Data Mining. . . . . . . . . . . . . . . . . 13

2.3.4 Avaliação do Conhecimento Extraído . . . . . . . . . . . . 21

2.3.5 Consolidação e Utilização do Conhecimento Extraído . . . . . . . . 21

2.4 Elementos que Apoiam o Processo de Extração de Conhecimento de Bases de Dados . . . . . . . . . . . . . . . . . . . 22

2.4 .1 Data Warehouse . . . . . . . . . . . . . . . 22

2.4 .2 Ferramentas de Visualização . . . . . . . . . . . . . . . 24

2.4 .3 Técnicas Estatísticas . . . . . . . . . . . . . . . . . . 24

2.5 Problemas Relacionados ao Processo de Extração de Conhecimento de Bases de Dados . . . . . . . . . . . . . . . . . . . . . . . . 25

2.5.1 Definição dos Objetivos da Aplicação . . . . . . . . . . . 25

2.5 .2 Ruído nos Dados . . . . . . . . . . . . . . . . 26

2.5 .3 Dados Incompletos . . . . . . . . . . . . . . . . . . 26

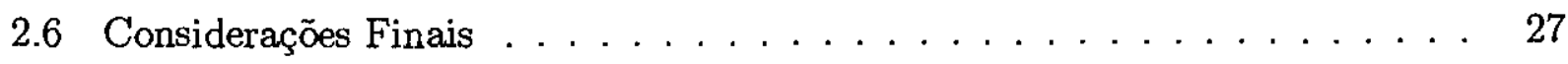

3 Redes Bayesianas para Extração de Conhecimento de Bases de Dados 28

3.1 Consideraçōes Iniciais . . . . . . . . . . . . . . . . . . 28 
3.2 Manipulação de Incerteza . . . . . . . . . . . . . . . . . . . . . . 29

3.3 Teoria das Probabilidades . . . . . . . . . . . . . . . 30

3.4 Aprendizado Bayesiano e Aprendizado de Máquina . . . . . . . . . . 36

3.5 Redes Bayesianas . . . . . . . . . . . . . . . . . . 39

3.6 Aprendizado de Redes Bayesianas . . . . . . . . . . . . . . . . 44

3.6.1 Aprendizado das Probabilidade em Redes Bayesianas . . . . . . . . 45

3.6.2 Aprendizado da Estrutura de Redes Bayesianas . . . . . . . . . . 49

3.7 Inferência em Redes Bayesianas . . . . . . . . . . . . . . . . . . 52

3.8 Considerações Finais . . . . . . . . . . . . . . . . 55

4 Tratamento de Dados Incompletos $\quad 58$

4.1 Considerações Iniciais . . . . . . . . . . . . . . . . . 58

4.2 Mecanismos de Geração dos Valores Ausentes . . . . . . . . . . . . . 59

4.3 Métodos para o Tratamento de Dados Incompletos . . . . . . . . . . . . 60

4.3.1 Classificadores para Dados Incompletos . . . . . . . . . . . . . 62

4.3.2 Aprendizado de Classificadores para Dados Incompletos . . . . . . . 65

4.3.3 Manipulação de Valores Ausentes em Exemplos de Testes . . . . . . . 66

4.4 Estimativa de Dados Incompletos . . . . . . . . . . . . . . 68

4.4.1 Critério de Complexidade Estocástica para Estimativa de Dados Incompletos .......................... 68

4.4.2 Algoritmos Expection Maximization e Simulated Annealing . . . . . . 70

4.5 Aprendizado de Redes Bayesianas a partir de Conjuntos de Dados com Valores Ausentes . . . . . . . . . . . . . . . . . . 71

4.5.1 Método Gibbs Sampling . . . . . . . . . . . . . 72

4.5.2 Bound e Collapse . . . . . . . . . . . . . 73

4.6 Considerações Finais . . . . . . . . . . . . . . . . . 76

5 Incorporação de Conhecimento de Fundo $\quad 77$

5.1 Consideraçōes Iniciais . . . . . . . . . . . . . . . . . . . . 77

5.2 Incorporação de Conhecimento de Fundo no Aprendizado Simbólico . . . . . 78

5.2.1 Representação do Conhecimento de Fundo no Aprendizado Simbólico 79

5.2.2 Combinação de Conhecimento de Fundo com Dados no Aprendizado Simbólico . . . . . . . . . . . . . . . . 80 
5.3 Incorporação de Conhecimento de Fundo em Redes Bayesianas . . . . . . . 82

5.3.1 Representação do Conhecimento de Fundo em Redes Bayesianas . . . 82

5.3.2 Combinação de Conhecimento de Fundo com Dados em Redes Bayesianas 83

5.4 Considerações Finais . . . . . . . . . . . . . . . . . . 85

6 Ferramentas Utilizadas $\quad \mathbf{8 7}$

6.1 Considerações Iniciais $\ldots \ldots$. . . . . . . . . . . . . . . . 87

6.2 Ferramentas Utilizadas na Etapa de Seleção e Preparação dos Dados . . . 87

6.3 Ferramentas Utilizadas na Etapa de Data Mining . . . . . . . . . . . . 88

6.3.1 Mineset M $^{T M} \ldots \ldots \ldots \ldots \ldots$

6.3.2 Bayesian Knowledge Discoverer . . . . . . . . . . . . . . . . 90

6.3 .3 Hugin System . . . . . . . . . . . . . . . . . 91

6.4 Considerações Finais . . . . . . . . . . . . . . . . . . 95

7 Estudo de Caso - Base de Dados do Programa de Melhoramento Genético $\begin{array}{ll}\text { da Raça Nelore } & \mathbf{9 7}\end{array}$

7.1 Considerações Iniciais $\ldots \ldots \ldots 7$

7.2 Compreensão do Domínio da Aplicação . . . . . . . . . . . . . . . . 98

7.3 Seleção e Preparação dos Dados . . . . . . . . . . . . . . . . . . 100

7.4 Data Mining . . . . . . . . . . . . . . . . . . . 103

7.4.1 Redução de Atributos e Instâncias . . . . . . . . . . . . . . . . . 104

7.4 .2 Extração de Padrões . . . . . . . . . . . . . . . . 106

7.4 .3 Pré-Avaliação dos Resultados . . . . . . . . . . . . . . 118

7.5 Considerações Finais . . . . . . . . . . . . . . . . . . . . 122

8 Estudo de Caso - Base de Dados da Swiss Life 125

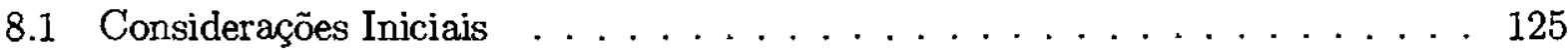

8.2 Descrição do Conjunto de Dados . . . . . . . . . . . . . . . 126

8.3 Preparação dos Dados . . . . . . . . . . . . . . . . . . 128

8.4 Data Mining . . . . . . . . . . . . . . . . . . 128

8.4.1 Redução de Atributos e Instâncias . . . . . . . . . . . . . . . 129

8.4 .2 Extração de Padrões . . . . . . . . . . . . . . . . . 130

8.4.3 Tratamento de Dados Incompletos . . . . . . . . . . . . . 131 
8.5 Considerações Finais . . . . . . . . . . . . . . . . . . 133

9 Conclusão

Referências 


\section{Lista de Figuras}

2.1 Pirâmide do Processo de Conhecimento. . . . . . . . . . . . 7

2.2 Etapas do Processo de Extração de Conhecimento de Bases de Dados. . . . . 10

2.3 Sistema de aprendizado típico (Batista, 1997) . . . . . . . . . . . 18

3.1 Probabilidade Condicional $P(A \mid B)$ (Soares et al., 1991) . . . . . . . 33

3.2 Generalização da probabilidade condicional (Soares et al., 1991) . . . . . . . 35

3.3 Exemplo de independência condicional. . . . . . . . . . . . . . . . . . 41

3.4 Exemplo de rede Bayesiana para deteç̧ão de fraude em compras com cartão de crédito (Heckerman, 1997) . . . . . . . . . . . . . . . . . 42

3.5 Parâmetros de uma rede Bayesiana (Ramoni and Sebastiani, 1997c). . . . . 47

3.6 Algumas estruturas possíveis de redes Bayesianas para as variáveis A, B e C. 50

3.7 Exemplo de inferência utilizando o Hugin. . . . . . . . . . . . . . 54

3.8 Exemplo do cálculo da configuração mais provável. . . . . . . . . . . . . 55

3.9 Aspectos qualitativo e quantitativo das redes Bayesianas. . . . . . . . . . 56

3.10 Aprendizado de redes Bayesianas. . . . . . . . . . . . . . . . . 57

4.1 Exemplo de um conjunto de dados, desconsiderando os exemplos com valores ausentes. . . . . . . . . . . . . . . . . . . . . 59

4.2 Representação da estratégia Regras Default para um CDI. . . . . . . . . . 64

4.3 Representação da estratégia Classificador Lattice para um CDI. . . . . . . . 65

4.4 Possíveis cenários para o conjunto de dados $D\left(M=D_{c 1}\right.$ e $\left.D_{c 2}\right) \ldots \ldots$. . 69

4.5 Exemplo da estrutura de uma rede Bayesiana fornecida como entrada para o Bound e Collapse. . . . . . . . . . . . . . . . . . . 74

4.6 Freqüências virtuais de $n *\left(x_{3 k} \mid x_{1}, x_{2}\right)$ consistentes com a base de dados in-

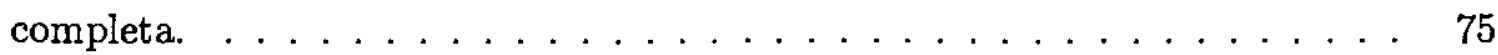




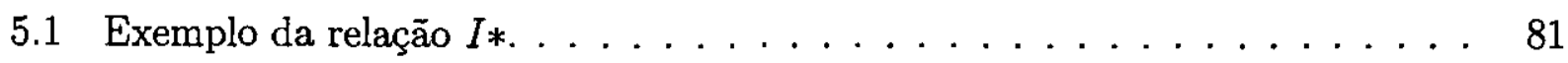

5.2 Esquema básico da combinação de conhecimento de fundo com dados em redes Bayesianas. . . . . . . . . . . . . . . . . . . . 85

6.1 Exemplo de uma rede Bayesiana gerada pelo BKD. . . . . . . . . . . . . 92

6.2 Exemplo da aplicação do Algoritmo de Propagação do BKD. . . . . . . . . . 93

6.3 Exemplo de uma rede bayesiana criada no Hugin System. . . . . . . . . . . . 94

6.4 Exemplo da aplicação do Algoritmo de Propagação do Hugin. . . . . . . . . 95

6.5 Exemplo do método de propagação $\max$ normal. . . . . . . . . . . . . 96

7.1 Nova base de dados gerada a partir do cruzamento dos dados dos animais e de seus pais. . . . . . . . . . . . . . . . . . . . . . . . 104

7.2 Distribuição dos valores nas faixas discretizadas pelo Mineset $^{T M}$, para os atributos do conjunto de dados Crescimento_1991. . . . . . . . . . . . 110

7.3 Indicadores estatísticos, levantados pelo Mineset $^{T M}$ para o conjunto de dados Fertilidade_1991. . . . . . . . . . . . . . . . . . 111

7.4 Rede Bayesiana gerada pelo BKD a partir do conjunto de dados Hab_Materna_1994.112

7.5 Rede Bayesianas gerada pelo BKD, a partir do conjunto de dados Hab_Materna_1994 discretizado pelo Mineset $^{T M}$. Sendo $0=(\mathrm{m},-0.45], 1=(-0.45,0.15], 2=(0.15,0.85]$

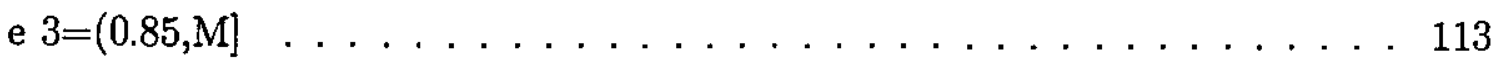

7.6 Exemplo de inferência, via algoritmo de propagação, sobre redes Bayesianas geradas pelo BKD. . . . . . . . . . . . . . . . . . . . . . . . 114

7.7 Rede Bayesiana gerada pelo BKD a partir do conjunto de dados Hab_Materna_1994, retirando-se $20 \%$ de seus valores. . . . . . . . . . . . . . 115

7.8 Rede Bayesiana gerada pelo BKD a partir do conjunto de dados Hab_Materna_.1994, retirando-se $40 \%$ de seus valores. . . . . . . . . . . . . . 116

7.9 Atualização dos parâmetros da rede Bayesiana gerada pelo BKD a partir do conjunto de dados Hab_Materna_1994, com 20\% dos valores de seus atributos ausentes .

7.10 Atualização dos parâmetros da rede Bayesiana gerada pelo BKD a partir do conjunto de dados Hab_Materna_.1994, com 40\% dos valores de seus atributos ausentes 
7.11 Rede Bayesiana gerada pelo BKD a partir de Hab_Materna_1994, considerando o conhecimento a priori de que há dependência entre a DDPP240_P e a DMPP120.................................. 119

7.12 Rede Bayesiana criada no Hugin System a partir da rede gerada pelo BKD da base de dados Hab_Materna_1994. . . . . . . . . . . . . . . . . . . 122

7.13 Exemplo da aplicação do Algoritmo de Propagação do Hugin. . . . . . . . . . 123

7.14 Exemplo da aplicação do Algoritmo de Propagação do Hugin usando o método $\max$ normal. . . . . . . . . . . . . . . . . . . . . . 124

8.1 Indicadores estatísticos, levantados pelo Mineset ${ }^{T M}$, para o conjunto de dados da relação HHOLD. . . . . . . . . . . . . . . . . . . . . . . . 130

8.2 Distribuição dos valores nas faixas discretizadas pelo Mineset $^{T M}$, para os atributos do conjunto de dados HHOLD_comp. . . . . . . . . . . . . . . . 131

8.3 Rede Bayesianas gerada pelo BKD, a partir do conjunto de dados HHOLD_comp discretizado pelo Mineset ${ }^{T M}$. . . . . . . . . . . . . . . . . . . . . 132

8.4 Rede Bayesiana gerada pelo BKD a partir do conjunto de dados HHOLD_comp.133

8.5 Rede Bayesiana gerada pelo BKD a partir do conjunto de dados HHOLD. . . 134 


\section{Lista de Tabelas}

2.1 Um modo de classificação dos algoritmos para Data Mining (Félix, 1998). . . 19

3.1 Distribuição de probabilidade conjunta para duas variáveis booleanas (Russell and Norvig, 1995). . . . . . . . . . . . . . . . . . 34

3.2 Conjunto de dados D. . . . . . . . . . . . . . 47

6.1 Propriedades e recursos implementados pelo BKD e Hugin System. . . . . . . 97

7.1 Descrição da base de dados do PMGRN. . . . . . . . . . . . . . 101

7.2 Descrição dos principais atributos da base de dados do PMGRN. . . . . . . . 102

7.3 Resumo dos aspectos a serem considerados para compreensão do PMGRN. . 103

7.4 Distribuição dos animais em relação ao cadastro dos dados de seus pais. . . . 103

7.5 Relação de atributos de DEPs considerados para a análise dos grupos con-

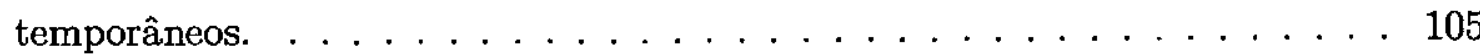

7.6 Conjuntos de dados criados a partir dos grupos contemporâneos de 1991, 1994,

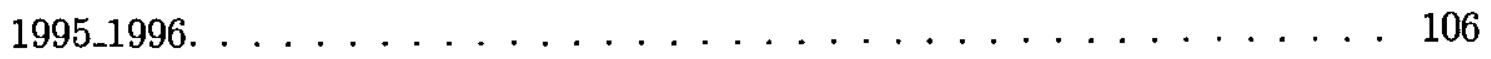

7.7 Atributos de DEPs e o sexo dos animais considerados para cada funcionalidade. 106

7.8 Conjuntos de dados criados a partir dos conjuntos de dados Animais_1991, Animais_1994 e Animais_1995_1996, considerando as funcionalidades sugeridas pelo especialista. . . . . . . . . . . . . . . . . . 107

7.9 Faixas de valores das discretizações realizadas pelo Mineset $^{T M}$ para o conjunto de dados Crescimento_1991. . . . . . . . . . . . . 108

7.10 Faixas de valores das discretizações realizadas pelo BKD para o conjunto de dados Crescimento_1991. . . . . . . . . . . . . . . . 109 
7.11 Configuração mais provável para que um animal possua valores de DMPP120 entre $[0,9,3,6)$, dadas as evidências $\left(2,1 \leq D D P P 120 \_P \leq 4,3\right)$, e $(-4,2 \leq$

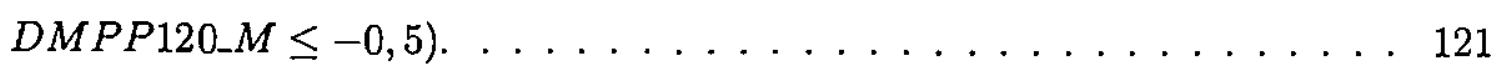

8.1 Distribuição dos registros da base de dados da Swiss Life, por relação. . . . 128

8.2 Relação HHOLD. . . . . . . . . . . . . . . . . . . . . . . . . . . . . 129

8.3 Conjuntos de dados utilizados para extração de redes Bayesianas. . . . . . 129 


\section{Resumo}

O interesse cada vez maior das empresas em adquirir novas tecnologias de processamento e armazenamento de dados, além de visualizar a informação como seu maior patrimônio, tem direcionado várias pesquisas para o estudo do processo de transformação desses dados em conhecimento, o que pode proporcionar um auxílio efetivamente inteligente à tomada de decisão. Nesse contexto, o processo de Extração de Conhecimento de Bases de Dados (KDD - Knowledge Discovery in Database) desponta como uma tecnologia capaz de cooperar amplamente na busca do conhecimento embutido nos dados. Essa busca pode ser realizada utilizando métodos estatísticos e/ou técnicas de Inteligência Artificial, especialmente as que manipulam incerteza, que são amplamente aplicados na análise de dados com objetivo de encontrar relações de interesse. As redes Bayesianas representam um dos modelos mais proeminentes para encontrar essas relações. Este trabalho envolve a investigação dos conceitos, técnicas, métodos e ferramentas Bayesianas para auxiliar o processo de extração de conhecimento de bases de dados, considerando a incorporação de conhecimento de fundo, bem como o tratamento de dados incompletos. 


\begin{abstract}
The fact that companies are becoming more and more interested in acquiring new technologies for processing and storing data, as well as the view that information is their largest asset, has led to much research about the process of transforming this data into knowledge, which can make it possible to aid decision-making in an effective and intelligent manner. In this context, the Knowledge Discovery in Databases (KDD) process has emerged as a technology well suited to searching for knowledge that is embedded in the data. This search can be made using statistical methods and/or Artificial Intelligence techniques, especially those that manipulate uncertainty, which are widely used to analyze data and find interesting relations. Bayesian networks represent one of the more proeminent models for finding these relations. This work involves the investigation of Bayesian concepts, techniques, methods and tools to aid the process of extracting knowledge from databases, considering the inclusion of background knowledge, as well as treatment of incomplete data.
\end{abstract}




\section{Capítulo 1}

\section{Introdução}

Vive-se a era da informação. A popularização da principal e maior rede de computadores do planeta - internet, os avanços ocorridos na coleta e armazenamento de dados, o constante desenvolvimento das empresas no que concerne a seu parque tecnológico e, principalmente, a evolução das necessidades de informação, fazem com que qualquer esforço para facilitar a manipulação e o entendimento humano em relação a esse grande leque de informações ganhe importância de mesma proporção.

A preocupação cada vez maior das empresas públicas e privadas em adquirir novas tecnologias de processamento e armazenamento, além de visualizar a informação e o conhecimento como seu maior patrimônio, tem direcionado várias pesquisas para o estudo do processo de transformação desses dados em conhecimento, o que pode proporcionar um auxílio efetivamente inteligente à tomada de decisão.

A transformação de dados em conhecimento tem utilizado métodos eminentemente manuais para análise e interpretação de dados, o que torna o processo de extração de padrões em bases de dados muitas vezes caro, lento e altamente subjetivo, além de inviável em se tratando de grandes volumes de dados.

O interesse em automatizar o processo de análise de grandes volumes de dados tem fomentado várias pesquisas em um campo emergente chamado Extração de Conhecimento de Bases de Dados (KDD - Knowledge Discovery in Database) (Fayyad et al., 1996).

KDD é o processo de extração de conhecimento de grandes bases de dados com o objetivo de compreender esses dados, adquirindo relações de interesse não observadas pelo especialista do domínio, bem como auxiliando a validação de conhecimento extraído por 
esse especialista. Esse processo é bastante complexo, pois consiste de uma tecnologia composta de um conjunto de modelos matemáticos e técnicas de software que são usados para encontrar padrões e regularidades nos dados (Decker and Focardi, 1995), além de ser um processo centrado na interação entre usuários, especialistas do domínio e responsáveis pela aplicação do processo KDD. Essa busca de padrões pode ser realizada utilizando métodos estatísticos e/ou técnicas de Inteligência Artificial, especialmente os que manipulam incerteza, que são amplamente aplicados na análise de dados com objetivo de encontrar relações e dependências entre esses dados. Este trabalho focalizará um dos métodos mais proeminentes para encontrar essas relações - as redes Bayesianas (Heckerman, 1997).

$\mathrm{O}$ uso de redes Bayesianas está se tornando cada vez mais um alvo de pesquisa por parte da comunidade de KDD (Ramoni and Sebastiani, 1997c). As redes Bayesianas são modelos gráficos que codificam relacionamentos probabilísticos entre variáveis de interesse. Quando usadas em conjunto com outras técnicas estatísticas, essas redes apresentam uma série de vantagens para modelagem de dados, entre as quais destacam-se: incorporação de conhecimento de fundo e tratamento de dados incompletos ${ }^{1}$.

A importância da combinação de conhecimento de fundo com dados merece ser destacada, principalmente, por proporcionar uma diminuição do esforço computacional no processo de KDD, uma vez que conhecimentos prévios do domínio podem ser incorporados a esse processo. Enquanto o tratamento dos dados incompletos é de relevante interesse, basicamente. por razão das bases de dados comerciais apresentarem, com muita freqüência, valores de atributos ausentes.

O objetivo principal deste trabalho é investigar os métodos Bayesianos para extração de conhecimento a partir de dados, destacando as suas aplicações no processo KDD no que concerne a extração de padrões, tratamento de dados incompletos, incorporação de conhecimento de fundo e pré-avaliação desses padrões. Para o pleno cumprimento desse objetivo, dois estudos de casos foram realizados. O primeiro utiliza uma base de dados do Programa de Melhoramento Genético da Raça Nelore (Lobo et al., 1998), enquanto o segundo faz uso da base de dados de seguros da Swiss Life - uma das maiores empresas do ramo em toda a Europa (Kietz and Staudt, 1998).

Como metas a serem atingidas no primeiro estudo de caso, podem ser destacadas:

\footnotetext{
${ }^{1}$ Neste trabalho, a expressāo "dados incompletos" será utilizada para denotar a ausência de alguns valores de atributos de uma base de dados.
} 
- Executar as fases do Processo de Extração de Conhecimento de Base de Dados, efetuando desde o levantamento das necessidades dos criadores e especialista do Programa de Melhoramento Genético da Raça Nelore (PMGRN), até as avaliações preliminares dos resultados obtidos.

- Analisar os métodos Bayesianos para extração de padrões de acasalamento dos animais do PMGRN, com o propósito de obter animais de maior produtividade.

- Verificar as dependências, utilizando ferramentas Bayesianas, entre as características econômicas (e.g. peso) dos pais e de seus filhotes. Sendo essas dependências codificadas na forma de redes Bayesianas.

- Efetuar inferências nas redes Bayesianas geradas a partir dos dados do PMGRN, a fim de quantificar, em termos probabilísticos, a influência que determinada característica de um animal exerce sobre a mesma ou até outra característica do filhote. Por exemplo, qual a probabilidade de um animal apresentar uma boa característica de perímetro escrotal, dado que o seu pai apresenta uma ótima característica de perímetro escrotal e sua mãe apresenta uma característica de peso apenas regular.

- Investigar o tratamento de dados incompletos, verificando as alterações ocorridas entre as características do pai e do filho, de acordo com o volume de valores ausentes.

- Potencializar os resultados (conhecimentos) obtidos no processo KDD, via interação direta com os especialistas do domínio, por intermédio da incorporação de conhecimento de fundo.

- Utilizar mecanismos de visualização para simplificar, principalmente para o especialista, o entendimento e, conseqüentemente, a avaliação dos resultados obtidos.

Quanto ao estudo de caso de seguros, cabe ressaltar que, apesar de não ser um caso eminente de aplicação do processo KDD, visto que não há a intervenção direta de especialistas no domínio, este estudo de caso foi utilizado com o objetivo precípuo de encontrar relações de dependências entre os atributos da base de dados de seguros. Vale destacar que a motivação maior dessa busca decorre do fato dessa base de dados possuir um número razoável de atributos (43), o que dificulta sobremaneira a análise manual destes dados. A seguir são 
listados os objetivos específicos da aplicação do processo KDD, utilizando a base de dados de Seguro da Swiss Life:

- Extrair relações de dependência entre os atributos da base de dados de seguros utilizando redes Bayesianas.

- Efetuar inferências nas redes Bayesianas geradas a partir dos dados desse estudo de caso, a fim de quantificar, em termos probabilísticos, a influência que determinado atributo tem sobre os demais.

- Utilizar mecanismos de visualização para simplificar a pré-avaliação das redes Bayesianas obtidas, bem como da inferência sobre elas.

- Visto que a base de dados contém um número elevado de valores de atributos ausentes, investigar o uso de redes Bayesianas para o tratamento desses dados incompletos.

Para um melhor entendimento, esta dissertação foi dividida conforme é apresentado a seguir.

No Capítulo 2, são apresentados os conceitos relacionados ao Processo de Extração de Conhecimento de Bases de Dados, tais como, as etapas que o compõe, os elementos de suporte, bem como os problemas mais frequentes quando da aplicação desse processo.

No Capítulo 3, são focalizadas as redes Bayesianas no contexto do processo de extração de conhecimento de bases de dados, considerando, principalmente, o aprendizado de redes Bayesianas a partir de dados, bem como a inferência sobre essas redes.

No Capítulo 4, são explorados os principais aspectos relacionados à ocorrência de valores de atributos ausentes nos dados, enfatizando a utilização da abordagem Bayesiana no tratamento desses valores ausentes.

No Capítulo 5, com ênfase no uso de redes Bayesianas, é apresentada a incorporação de conhecimento de fundo no processo KDD.

No Capítulo 6, são mostradas as ferramentas de software utilizadas neste trabalho.

No Capítulo 7, são apresentados os resultados obtidos no estudo de caso da base de dados do Programa de Melhoramento Genético da Raça Nelore. Neste capítulo são focalizadas todas as etapas do processo KDD, bem como a lincorporação de conhecimento de fundo e o tratamento de dados incompletos, utilizando redes Bayesianas. 
No Capítulo 8, é apresentado o estudo de caso utilizando a base de dados de seguros da Swiss Life, focalizando as redes Bayesianas para a extração de conhecimento e o tratamento de dados incompletos a partir dessa base de dados.

No Capítulo 9, são apresentadas as conclusões, contribuições e algumas sugestões de trabalhos futuros.

Finalmente, é apresentada a bibliografia que foi utilizada para que a realização deste trabalho fosse possível. 


\section{Capítulo 2}

\section{Processo de Extração de}

\section{Conhecimento de Bases de Dados}

\subsection{Considerações Iniciais}

O constante avanço dos mecanismos de coleta e armazenamento de dados, bem como o inexorável processo de automação do mundo das ciências, negócios e governo, têm ocasionado a necessidade de novas técnicas e ferramentas capazes de automatizar o processo de análise e entendimento dos dados. Portanto, sem uma forte ênfase em pesquisas de técnicas de extração de conhecimento de bases de dados, corre-se o risco de estar privado do "valor" de grande parte dos dados armazenados nessas bases.

Como forma de solucionar esse problema, KDD desponta como uma tecnologia capaz de cooperar amplamente na busca do conhecimento embutido nos dados. Desta forma, o principal objetivo do processo KDD é encontrar padrões válidos e potencialmente úteis nos dados.

Na literatura são encontradas várias nomenclaturas para o processo de KDD, entre elas destacam-se: Data Mining, processamento de padrões de dados, arqueologia de dados, coleta de informações, garimpagem de dados e siftware (Li, 1996), (Silberschatz et al., 1996), (Mannila, 1997b). Porém, segundo Fayyad, Data Mining pode ser visto como parte de um processo maior de extração de conhecimento de bases de dados ${ }^{1}$, que consiste de um

\footnotetext{
${ }^{1}$ Apesar de alguns autores usarem indistintamente os termos KDD e Data Mining, neste trabalho, Data Mining é visto como sendo parte do processo KDD.
} 
processo não trivial de identificação de padrões compreensíveis, válidos e potencialmente úteis embutidos nos dados (Fayyad et al., 1996).

Para um bom entendimento das características, etapas e problemas relacionados à aplicação do processo KDD, este capítulo é dividido da seguinte forma. Na próxima seção, são apresentados alguns problemas relacionados a aquisição de conhecimento em bases de dados, além de alguns conceitos importantes para o entendimento do processo KDD. Em seguida, na seção 2.3, é apresentado o processo de extração de conhecimento de bases de dados, detalhando cada uma de suas etapas. Na seção 2.4, são destacados alguns dos elementos que apoiam esse processo. Na seção 2.5, são enfatizados os principais problemas relacionados à aplicação do processo KDD. Por último, na seção 2.6, são realizadas as considerações finais a respeito dos assuntos relacionados a esse processo.

\subsection{Aquisição de Conhecimento em Bases de Dados}

De uma forma geral, os dados podem ser vistos como a matéria-prima do processo KDD. No momento em que o usuário atribui algum significado especial aos dados, estes passam a ser entendidos como uma informação. Quando os especialistas de um domínio de aplicação estabelecem, por exemplo, uma regra, a interpretação de confronto entre esse fato (informação) e essa regra constitui conhecimento adquirido a respeito dos dados. A relação hierárquica entre os dados, a informação e o conhecimento existentes em uma base de dados, considerando o volume e o valor que os usuários de níveis decisórios atribuem a cada um dos elementos dessa hierarquia, pode ser visualizado na Figura 2.1.

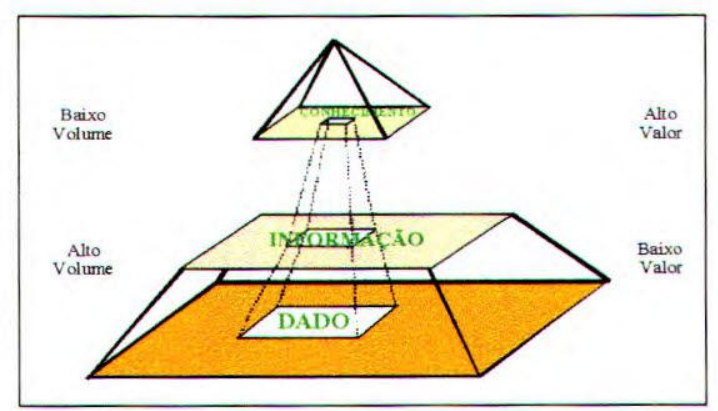

Figura 2.1: Pirâmide do Processo de Conhecimento.

Dessa forma o conhecimento pode ser visto como uma abstração ou um nível de in- 
formação acima dos dados. Segundo Carbonel, conhecimento pode ser definido como uma informação interpretada, categorizada, aplicada, revisada e que possui um determinado valor para o usuário (Carbonel and Langley, 1987).

A aquisição de conhecimento representa um dos principais problemas relacionados ao desenvolvimento de sistemas inteligentes. Isso se deve, principalmente, à grande quantidade de procedimentos, relaçōes e técnicas que interagem nesse processo. Além disso, o conhecimento adquirido nem sempre é apropriado para uso efetivo, visto que o mesmo pode possuir propriedades indesejáveis como, por exemplo, grande volume e difícil representação (Rich and Knight, 1993).

O processo de aquisição de conhecimento pode ser realizado de forma explícita, na qual a extração do conhecimento é feita por intermédio do engenheiro de conhecimento, utilizando técnicas convencionais, como por exemplo, estudo de casos e entrevista a especialistas do domínio (Rezende and Pugliesi, 1998); ou implícita, que é geralmente feita utilizando sistemas de aprendizado de máquina para extrair conhecimento a partir de dados.

Dessa forma, o processo KDD se apresenta como um conjunto de técnicas e ferramentas capazes de contribuir amplamente para o problema de aquisição de conhecimento implícito em grandes massas de dados. A seguir são apresentadas as etapas que compõem esse processo.

\subsection{Etapas do Processo de Extração de Conhecimento de Bases de Dados}

A extração de conhecimento a partir de grande massas de dados deve ser vista como um processo interativo e iterativo, e não como um sistema de análise automática. Dessa forma, não se pode esperar a extração de conhecimento útil simplesmente submetendo um conjunto de dados a uma "caixa preta" (Mannila, 1997a).

A interatividade do processo KDD é pautada no amplo entendimento, por parte dos usuários desse processo, sobre o domínio da aplicação. Esse entendimento envolve a seleção de um subconjunto representativo dos dados, ferramentas adequadas para extração de padrões e bons critérios para avaliá-los. Para um melhor entendimento das funções dos usuários que utilizam o processo KDD, neste trabalho, eles são divididos em três classes:

- Especialista do domínio, que deve possuir amplo entendimento do domínio da apli- 
cação.

- Analista, que executa o processo KDD e, portanto, deve possuir amplo conhecimento das etapas que compõem esse processo.

- Usuário final, o qual pode não possuir amplo conhecimento do domínio, e é freqüentemente aquele que utiliza o conhecimento extraído no processo KDD para auxiliá-lo em um processo de tomada de decisão.

Vale ressaltar que estes usuários podem até não possuir funções disjuntas no processo KDD, desse modo, pode haver situaçōes, por exemplo, em que o especialista também é o usuário final ou que o especialista auxilie e/ou execute funções pertinentes ao analista.

O sucesso do processo KDD depende, em parte, da interação entre esses usuários. É pouco provável que o analista encontre conhecimento útil a partir dos dados sem o aval do especialista sobre o que seria útil para um domínio específico. Além disso, a interatividade do processo requer a participação efetiva do usuário final e do especialista nas escolhas e decisões ao longo do processo (Fayyad et al., 1996).

A extração de conhecimento a partir de dados pode ser entendida como um processo contendo, pelo menos, os seguintes passos:

\section{Compreensão do domínio da aplicação.}

2. Seleçāo e preparação dos dados.

\section{Data Mining.}

\section{Avaliação do conhecimento extraído.}

\section{Consolidação e utilização do conhecimento extraído.}

Um esquema representativo contendo todos esses passos é ilustrado na Figura 2.2. O processo KDD inicia com o entendimento do domínio da aplicação, considerando aspectos como os objetivos dessa aplicação e as fontes de dados (bases de dados da qual se pretende extrair conhecimento). Em seguida, é realizado uma seleção de dados a partir dessas fontes, de acordo com os objetivos da aplicação do processo KDD. Os conjuntos de dados resultantes dessa seleção são, então, pré-processados e submetidos aos métodos e ferramentas da etapa 
de Data Mining ${ }^{2}$ com o objetivo de encontrar padrões/modelos (conhecimento) a partir dos dados. Após esta etapa, esse conhecimento é avaliado quanto a sua qualidade e/ou utilidade para que, em caso positivo, seja utilizado para apoio a algum processo de tomada de decisão. Vale acentuar que, apesar das ferramentas de visualização serem mais utilizadas na etapa de avaliação do conhecimento extraído, elas são de grande relevância para facilitar o entendimento e avaliação, principalmente do usuário final, dos resultados de cada etapa, conforme pode ser observado na parte inferior da Figura 2.2.

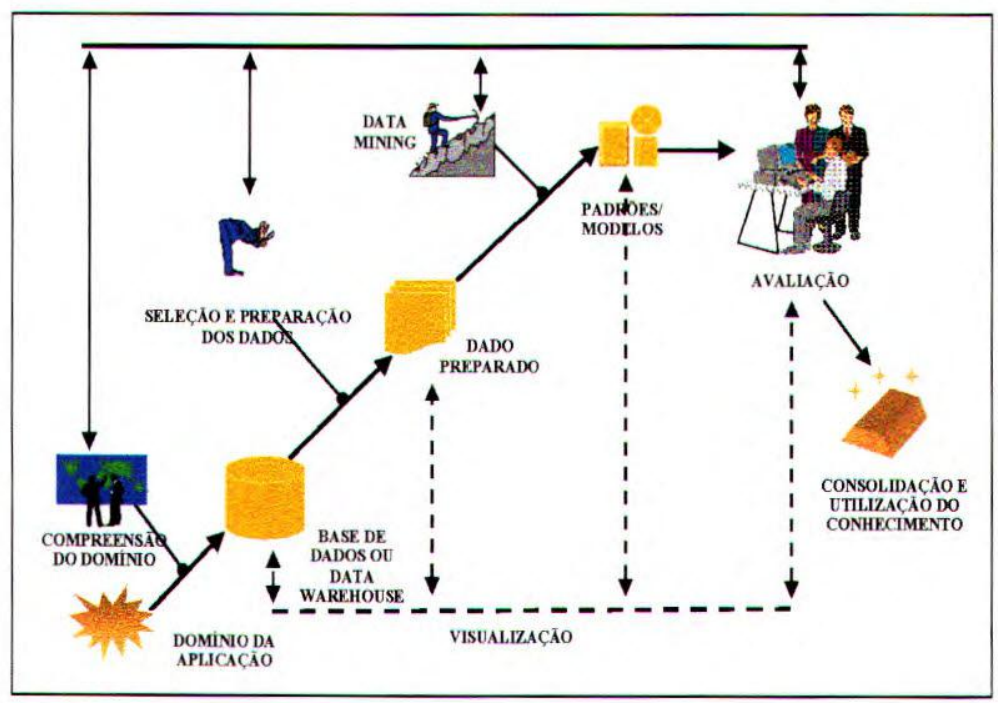

Figura 2.2: Etapas do Processo de Extração de Conhecimento de Bases de Dados.

É importante notar que, por ser um processo eminentemente iterativo, as etapas do processo KDD não são estanques, ou seja, a correlação entre as técnicas e métodos utilizados nas várias etapas é considerável, a ponto da ocorrência de pequenas mudanças em uma delas afetar substancialmente o sucesso de todo o processo. Desta forma, os resultados de um determinada etapa pode acarretar mudanças a quaisquer das etapas anteriores ou ainda, o recomeço de todo o processo (Fayyad, 1996).

Um detalhamento maior dos objetivos de cada etapa será apresentado a seguir.

\subsubsection{Compreensão do Domínio da Aplicação}

Nesta etapa, procura-se o completo entendimento do domínio da aplicação, considerando aspectos como:

\footnotetext{
${ }^{2}$ Os métodos e ferramentas de Data Mining também serão chamados de algoritmos ao longo desse trabalho
} 
- Estudo de viabilidade e custos da aplicação do processo.

- Verificação da quantidade e tipo do conhecimento disponível antes do início do processo de KDD.

- Condições e metas do usuário final/especialista.

A sinergia usuário final/especialista do domínio/analista deve ser bastante acentuada nessa etapa. O produto dessa interação deve ser uma documentação completa do domínio, considerando entre outros fatores:

- Identificação das fontes dos dados: internas (e.g. bases de dados da empresa) e externas (e.g. internet).

- Identificação dos gargalos do domínio, considerando, entre outros aspectos:

- bases de dados com valores de atributos ausentes;

- bases de dados com um grande volume de dados, por exemplo, em grandes aplicações de vendas a varejo as bases de dados têm em média $10^{5}$ a $10^{7}$ registros e 5000 campos;

- tipos de dados armazenados nas bases de dados, como por exemplo: dados multimídia (e.g. imagens digitalizadas, áudio, etc.), gráficos, combinação de dados discretos e contínuos, etc.

- Estabelecimento de critérios para avaliação dos resultados do processo, verificando a relação entre a facilidade de entendimento com a qualidade (utilidade) do conhecimento a ser extraído.

- Especificação do modo como o conhecimento extraído deverá ser utilizado. Por exemplo, para classificação, visualização, exploração, etc.

\subsubsection{Seleção e Preparação dos Dados}

A extração direta de conhecimento a partir de grandes bases de dados pode se tornar uma tarefa inviável. Grandes volumes de dados podem gerar um espaço de busca de padrões combinatorialmente explosivo. Além disso, a maioria dos algoritmos para extração de padrōes possuem limitaçōes quanto ao volume de dados que podem manipular. A busca de 
conhecimento em grandes bases de dados pode ocasionar, ainda, o aumento das chances de encontrar-se padrões pouco significativos e até mesmo espúrios. Possíveis soluções para esse problema envolve a tentativa de selecionar amostras significativas (e.g. utilizando técnicas estatísticas) e/ou selecionar conjuntos de dados, a partir de interações com o especialista do domínio, da base de dados da aplicação.

Segundo Mannila, a seleção e preparação dos dados consome cerca de $80 \%$ de todo o tempo gasto no processo KDD (Mannila, 1997a). Esta etapa envolve a seleção de conjuntos de dados representativos da base de dados e o pré-processamento e redução desses conjuntos, a fim de adequá-los aos padrões de entrada dos métodos para Data Mining. Essas duas subetapas serão apresentadas a seguir.

\section{Seleção dos Conjuntos de Dados}

A escolha de conjuntos de dados que reflitam com a maior fidelidade possível os objetivos da aplicação do processo KDD (subseção 2.3.1), além da própria base de dados, é de suma importância para as demais etapas do processo KDD. Seleções de conjuntos de dados pouco significativos podem produzir resultados (padrões extraídos) imprecisos ou sem valia. Além disso, pequenos conjuntos podem levar a conclusões incorretas, por outro lado, grandes quantidades de dados podem tornar o processamento lento e até mesmo inviável devido às limitações dos algoritmos para Data Mining. Portanto, entre outros aspectos, devem ser considerados:

- O tamanho dos conjuntos de dados.

- As estratégias para obtenção dos conjuntos de dados, de acordo com os objetivos do especialista e/ou usuário final (técnicas estatísticas também podem ser utilizadas).

- A homogeneidade dos dados.

- A dinâmica dos dados (e.g. mudanças de valores de atributos ao longo do tempo).

\section{Preparação e Redução dos Conjuntos de Dados}

Após a etapa de seleção, é necessário o pré-processamento dos conjuntos de dados, a fim de atender as exigências e limitações dos formatos de entrada dos algoritmos para Data Mining. 
Esse pré-processamento inclui a preparação e redução dos dados observando, observando fatores como os que se seguem:

- Verificação das características da base de dados, como tipos de dados, padronização do conteúdo dos registros (e.g. no caso do sexo das pessoas, é comum que seja especificado através de valores $\mathrm{M}$ ou' $\mathrm{F}, 0$ ou 1, Mas ou Fem).

- Eliminação dos registros duplicados, lixo nos dados produzidos pelas migrações, etc.

- Tratamento de ruídos nos dados.

- Avaliação do grau de representatividade dos atributos.

- Manipulação de valores de atributos ausentes (dados incompletos).

- Representação dos dados de acordo com os objetivos da tarefa.

- Utilização de métodos para reduzir efetivamente o número de variáveis a serem consideradas ou encontrar representação fixa para os dados.

É importante destacar que se a base de dados estiver em um data warehouse (apresentado na seção 6.4), problemas como padronização e limpeza nos dados podem ser em grande parte resolvidos, pois o data warehouse provê métodos que, entre outros, permitem a integração, padronização e sumarização de dados (Inmon, 1996).

\subsubsection{Data Mining}

Mesmo depois de observados todos os aspectos envolvidos na seleção e preparação de dados, esses conjuntos de dados podem, ainda, ser substancialmente grandes para serem submetidos aos algoritmos para Data Mining. Dessa forma, antes de se realizar a extração de padrões, pode ser necessário submeter esses conjuntos, dentro da etapa de Data Mining, a um processo de redução de instâncias e/ou atributos (features).

\section{Redução de Instâncias e/ou Atributos}

Essa sub-etapa do processo de Data Mining é responsável pela redução dos elementos (instâncias e atributos) que compõem os conjuntos de dados que serão submetidos aos algoritmos 
para Data Mining. O fornecimento de um volume muito grande desses elementos pode levar a um processo de extração de conhecimentos muito complexo, posto que esses algoritmos podem encontrar um número muito grande de relações embutidas nos dados, dificultando o entendimento do que foi extraído e tornando a aplicação desses conhecimentos inviável. Além disso, a maioria dos algoritmos para Data Mining possuem, como já foi visto na subseção 2.3.2, limitações quanto ao volume de instâncias e atributos que podem manipular. Em adição a redução de instâncias (ou exemplos) e a redução de atributos, pode-se classificar as reduções em mais dois tipos, a saber:

- Redução de features por combinação de atributos: consiste na criação de um ou mais atributos a partir da combinação de outros atributos já existentes. Um atributo, analisado isoladamente, pode não possuir "valor" preditivo muito elevado, mas, em combinação com outro(s) atributos, pode representar muito mais o que se deseja aprender a partir dos dados.

- Redução dos valores discretizando atributos contínuos: alguns algoritmos não trabalham com valores contínuos para o atributo-classe (ou atributo-meta), outros apenas manipulam valores contínuos para todos os atributos. Assim, como a maioria das bases de dados reais possuem valores contínuos para grande parte de seus atributos, as vezes torna-se indispensável a aplicação de métodos de discretizações a fim de "adaptar" os valores dos atributos (ou simplesmente do atributo-classe) às exigências dos algoritmos para Data Mining. Embora alguns pesquisadores considerem a discretização como uma tarefa da etapa de Seleção e Preparação dos Dados, neste trabalho é considerada como uma tarefa de Data Mining. Essa consideração é justificada pelo interesse em melhorar o desempenho dos algoritmos, via métodos de discretização "híbridos" (aglutinando técnicas estatísticas, sugestões dos especialistas do domínio e métodos de discretização que interajam com os algoritmos para Data Mining). Além disso, alguns métodos oferecem mecanismos de discretização embutidos.

Após a observação dos fatores envolvidos na redução de instâncias e/ou atributos, a extração de padrões pode, finalmente, ser realizada. 


\section{Extração de Padrões}

Data Mining (DM) envolve a criação de modelos apropriados de representação dos padrões e relações identificados a partir dos dados. O resultado desses modelos, depois de avaliados pelo analista, especialista e/ou usuário final, são empregados para predizer os valores de atributos definidos pelo usuário final baseados em novos dados (Kerber et al., 1995), (Fayyad, 1996).

Os modelos gerados por DM seguem geralmente os padrões estatísticos, neurais ou simbólicos. Um modelo estatístico típico é gerado pelo método de regressão (e.g. regressão linear) e é representado por um sistema de equaçōes. Um modelo neural é representado como uma arquitetura (e.g. rede feedforward) de nós e conexōes (com pesos) entre eles, além de uma função de aprendizado (e.g. regra delta). Já os modelos simbólicos são geralmente representados por regras do tipo IF...THEN ou árvores de decisão. Existe uma vasta gama de algoritmos referenciados na literatura que seguem esses modelos (Kerber, 1991), (Quinlan, 1993), (Haykin, 1994).

Em particular, algoritmos para DM consistem da combinação de três componentes básicos: Modelo, Critério de Preferência e Algoritmo de Busca (Fayyad et al., 1996). Um algoritmo, portanto, é freqüentemente uma instanciação de um Modelo/Critério de Preferência/Algoritmo de busca. Por exemplo, um modelo de classificação baseado em uma representação qualquer, o critério de preferência baseado em probalidade de dados e usando uma determinada heurística de busca. Para um melhor entendimento dos principais componentes de um algoritmo para DM, eles serão descritos a seguir.

\section{Modelo}

O modelo de um algoritmo para DM considera dois fatores: a função do modelo e a representação do modelo.

As funções do modelo, também conhecidas como técnicas de DM, especificam o modo como o conhecimento deverá ser utilizado. Entre as funções mais comuns e aceitas pela comunidade de KDD, destacam-se (Li, 1996), (Fayyad et al., 1996), (Félix, 1998):

- Previsāo: novos casos são generalizados a partir do aprendizado sobre experiências passadas com respostas conhecidas (essas respostas recebem frequentemente o nome de rótulo ou classe). A previsão pode ser dividida em dois tipos de problema: Classificação 
e Regressão. $\mathrm{Na}$ Classificação, rótulos possuem valores discretos, enquanto que na Regressão, os rótulos são valores contínuos.

- Regras de Associação: determinam as relações entre os campos de uma base de dados (e.g. regras de associação podem descrever que itens são comumente comprados juntamente com outros em um supermercado).

- Caracterização: é a abstração de um conjunto de dados com tarefas relevantes em uma relação, propiciando uma descrição compacta desse conjunto (e.g. os sintomas de uma determinada doença podem ser resumidos em um conjunto de características).

- Clustering (segmentação): cria partições (clusters) nos dados, no qual os membros de cada partição são similares de acordo com algumas medidas de similaridades ou modelos de densidade probabilísticas (e.g. um conjunto de novas doenças podem ser agrupadas em várias categorias baseadas nos seus sintomas).

- Evolução: modela padrões seqüenciais (e.g. em dados com dependência de tempo, assim como análise de séries temporais). O objetivo é modelar os estados do processo gerando a seqüência ou relatando as tendências do processo ao longo do tempo.

Para que essas técnicas sejam aplicadas é necessário que os algoritmos para DM possuam uma linguagem para representar os conceitos (padrões) obtidos a partir de dados. Essa linguagem, chamada de representação do modelo, descreve o estado interno desse algoritmo. Esta representação geralmente determina a flexibilidade do modelo em representar os dados e a interpretabilidade do modelo em termos humanos. Na literatura pode-se encontrar vários tipos de representação, entre as quais destacam-se: árvores e regras de decisão (Kẹber, 1991), (Quinlan, 1993), modelos não lineares (e.g. redes neurais) (Haykin, 1994), instance-based (e.g. métodos nearest-neighbor (Ling and Wang, 1997) e raciocínio baseado em casos (Aamodt and Plaza, 1994)), modelos de dependência gráfica probabilística (e.g. redes Bayesianas) (Heckerman, 1997).

\section{Critério de Preferência}

O critério de preferência verifica a qualidade do modelo e seus parâmetros, considerando, por exemplo, mecanismos para evitar overfitting, ol seja, evitar que o algoritmo "decore". 
Há dois critérios a serem considerados: o explícito, embutido nos algoritmos de busca, como os critérios de probabilidade máxima de encontrar os parâmetros que maximizam a probabilidade dos dados observado; e, o implícito, utilizado principalmente na etapa de seleção e preparação dos dados, e que refletem o bias subjetivo do analista em termos de quais modelos devem ser considerados (Fayyad et al., 1996).

\section{Algoritmo de Busca}

O algoritmo de busca especifica um método para encontrar modelos e parâmetros particulares a partir dos dados. Entre os algoritmos de busca encontrados na literatura, destacam-se: ID3 (Quinlan, 1986), CN2 (Clark and Niblett, 1989), (Clark and Boswell, 1991), Perceptron (Hertz et al., 1991), Naive-Bayes (Langley et al., 1992), C4.5, C4.5-rules (Quinlan, 1993), Nearest-neighbor (Ling and Wang, 1997), Autoclass (Cheeseman and Stutz, 1990) e o BKD (Ramoni and Sebastiani, 1997b). A maioria desses algoritmos, também chamados de sistemas de aprendizado, foram desenvolvidos e são largamente aceitos e utilizados pela comunidade de Aprendizado de Máquina.

O Aprendizado de Máquina (AM) representa uma das partes centrais do processo KDD (etapa de Data Mining), e pode ser definido como uma sub-área de Inteligência Artificial que pesquisa métodos computacionais relacionados à aquisição de novos conhecimentos, novas habilidades e novas formas de organizar o conhecimento já existente. Esses métodos podem ser entendidos como sistemas de aprendizado que tomam decisões baseadas em experiências acumuladas contidas em casos resolvidos com sucesso (Weiss and Kulikowski, 1991).

Conforme ilustrado na Figura 2.3, um sistema de aprendizado típico trabalha sob algum paradigma tentando extrair conhecimento, em uma linguagem de descrição de conceitos, a partir de um conjunto de exemplos ${ }^{3}$.

Desta forma, estes sistemas aprendem por meio da seleção ou adaptação do modelo, no paradigma escolhido, de modo que esse modelo classifique corretamente os exemplos conhecidos bem como novos exemplos (Batista, 1997).

A escolha do melhor algoritmo para DM é freqüentemente crítica, pois é sabido que nenhum deles tem desempenho ótimo em todos os domínios de aplicação (Batista, 1997), (Salzberg, 1997). A seleção desses algoritmos é realizada pelo analista e deve ser pauta-

\footnotetext{
${ }^{3}$ Estes exemplos são obtidos a partir dos dados de um domínio, e são representados em alguma linguagem de descrição de exemplos.
} 


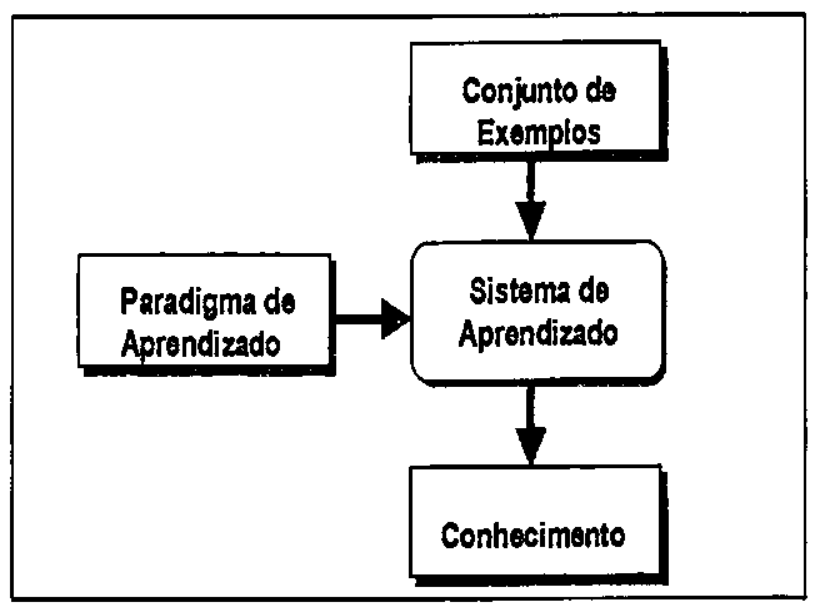

Figura 2.3: Sistema de aprendizado típico (Batista, 1997).

da nas restrições do domínio e/ou nas preferências do usuário final (e/ou especialista no domínio). Considerando essas restrições, o analista pode selecionar o algoritmo baseado em alguns parâmetros como, por exemplo, o tipo de aprendizado, paradigmas de aprendizado, linguagens de descrição e como novos exemplos serão integrados. O modo de classificação de algoritmos por intermédio desses parâmetros é ilustrado na Tabela 2.1.

Essa classificação considera desde o modo como os indutores aprendem, paradigma de aprendizado de máquina, linguagem utilizada para descrever o aprendizado, até o modo em que podem ser integrados novos exemplos a esses sistemas. Esses parâmetros são brevemente explicados a seguir.

O processo de aprendizado pode ser realizado de dois modos: via aprendizado supervisionado ou aprendizado não-supervisionado. No aprendizado supervisionado, os padrões nos dados são encontrados explorando um conjunto de casos conhecidos que mostram ou implicam em padrões bem definidos; e baseados nestes casos, as generalizações são realizadas. No aprendizado não-supervisionado, os padrões nos dados são encontrados a partir de alguma caracterização lógica de regularidade nos mesmos (Decker and Focardi, 1995).

Com relação aos paradigmas, os sistemas de aprendizado podem ser classificados em:

- Paradigma Simbólico: aprendem construindo representações simbólicas de um conceito através da análise de exemplos e contra-exemplos desse conceito.

- Paradigma Estatístico: os classificadores estatísticos freqüentemente assumem que valores de atributos estão normalmente distribuídos, e então podem usar os dados forne- 


\begin{tabular}{|c|c|c|c|}
\hline $\begin{array}{c}\text { Tipo de } \\
\text { Aprendizado }\end{array}$ & $\begin{array}{c}\text { Paradigmas de } \\
\text { Aprendizado }\end{array}$ & $\begin{array}{c}\text { Linguagens de } \\
\text { Descrição }\end{array}$ & $\begin{array}{c}\text { Modo que os } \\
\text { Novos Exemplos } \\
\text { são Integrados }\end{array}$ \\
\hline Não Supervisionado & $\begin{array}{c}\text { Estatístico } \\
\text { Instance-Based } \\
\text { Conexionista } \\
\text { Genético }\end{array}$ & $\begin{array}{c}\text { Exemplo ou } \\
\text { Instâncias } \\
\text { Hipóteses ou } \\
\text { Conceitos Aprendidos } \\
\text { Teoria de Domínio } \\
\text { ou Conhecimento de } \\
\text { Fundo }\end{array}$ & Não Incremental \\
\hline
\end{tabular}

Tabela 2.1: Um modo de classificação dos algoritmos para Data Mining (Félix, 1998).

cidos para determinar média, variância e co-variância da distribuição, entre outros.

- Paradigma Instance-based: os sistemas instance-based classificam casos nunca vistos através de casos similares conhecidos.

- Paradigma Conexionista: as redes neurais são construções matemáticas relativamente simples que utilizam o mecanismo de paralelismo, no qual são conectados um grande número de pequenas unidades de processamento (neurônios) ligadas em rede.

- Paradigma Genético: um classificador genético consiste de uma população de elementos de classificação que competem para realizar uma predição. Elementos que possuem um desempenho fraco são descartados, enquanto os elementos mais fortes proliferam, produzindo variações de si mesmos.

Em um sistema de aprendizado é necessário utilizar linguagens para representar exemplos ou instâncias e a teoria de domínio previamente conhecida. Estas linguagens são chamadas de linguagens de descrição, e podem ser divididas em:

- Linguagem de descrição de exemplos ou instâncias: descreve os exemplos utilizados pelo programa para aprender conceitos, estabelecendo limites sobre os tipos de padrões que o sistema pode aprender. 
- Linguagem de descrição de hipóteses ou conceitos aprendidos: descreve o estado interno de um programa de aprendizado, correspondente a teoria dos conceitos ou padrões que existem nos dados, estabelecendo limites sobre o que pode ou não pode ser aprendido.

- Linguagem de descrição da teoria de domínio ou conhecimento de fundo: descreve todo oconhecimento prévio que o programa possui a respeito do domínio.

Finalmente, os algoritmos de aprendizado podem ser classificados de duas formas segundo o modo em que podem ser integrados novos exemplos: não incremental e incremental. No modo não incremental é necessário que todos os exemplos de treinamento estejam simultaneamente disponíveis para que um conceito seja induzido. Enquanto que o modo incremental revê a definição do conceito corrente, se necessário, em resposta a cada nova instância de treinamento observada. Vale ressaltar que, além da observação desses parâmetros, as avaliações experimentais desempenham um papel fundamental na seleção de um algoritmo, uma vez que não existem métodos formais para decidir qual o melhor algoritmo para um determinado domínio de aplicação (Kliber et al., 1988).

Após a escolha e execução do método de aprendizado utilizado na etapa de Data Mining, os resultados obtidos sāo preliminarmente avaliados pelo o analista do processo KDD.

\section{Pré-Avaliação dos Resultados Obtidos}

Antes dos resultados serem fornecidos para o especialista do domínio avaliar e, em caso positivo, utilizar efetivamente em algum processo decisório, torna-se imperativa a avaliação preliminar do conhecimento extraído. Isso é realizado pelo analista do processo KDD com intuito de eliminar padrões espúrios, sem valor algum ou em situações óbvias guiadas pelo senso comum (e.g. "as vacas dão leite"). Nesta etapa é realizada uma avaliação prévia da qualidade do conhecimento extraido considerando principlamente taxa de acerto e compreensibiliade do conhecimento extraido.

Vale ressaltar que as próprias ferramentas para Data Mining fornecem mecanismos para efetuar pré-avaliações de resultados. Alguns exemplos desses mecanismos são mostrados a seguir:

- Facilidade de compreensão da linguagem de descrição de conceitos. 
- Precisão dos algoritmos de aprendizado.

- Recursos de visualização.

- Ferramentas Estatísticas.

- Análise exploratória dos resultados.

\subsubsection{Avaliação do Conhecimento Extraído}

O processo KDD não termina quando os padrōes nos dados de entrada são extraídos. É preciso que o usuário entenda e possa julgar a utilidade do conhecimento extraído contrastando-o com o conhecimento do especialista do domínio. Nesta etapa é avaliado especialmente a compreensibiliade e o grau de surpresa do conhecimento extraído. Essa interação pode facilitar a busca das causas de possíveis erros ocorridos ao longo de todo esse processo.

A avaliação do conhecimento extraído é uma tarefa bastante difícil que envolve, entre outros aspectos, a utilização de métodos (geralmente estatísticos) para "filtrar" o conhecimento extraído, removendo padrōes redundantes e/ou irrelevantes (Fayyad, 1996). Esses métodos devem ser acompanhados de técnicas de visualização para auxiliar os usuários e especialistas do domínio na filtragem dos padrões, bem como na decisão sobre a utilidade do conhecimento extraído. Além disso, devem ser observados os critérios de desempenho do processo, considerando fatores como a precisão e a representação do conhecimento extraído. Por exemplo, um algoritmo para DM pode possuir uma elevada capacidade preditiva mas pouca capacidade descritiva (simplicidade de representação do conhecimento).

\subsubsection{Consolidação e Utilização do Conhecimento Extraído}

A consolidação do conhecimento extraído pressupōe a verificação e a solução de potenciais conflitos com o conhecimento existente antes do processo ser iniciado. $O$ conhecimento pode, então, ser organizado pelo analista dentro de um modelo, usado para refinar o modelo existente na aplicação ou simplesmente documentado e informado ao usuário.

A maioria das etapas do processo $\mathrm{KDD}$, vistas na seção 2.3 , envolvem a utilização de ferramentas de suporte a execução das tarefas pertinentes a essas etapas. Na próxima seção são apresentados os principais elementos de apoio a execução do Processo KDD. 


\subsection{Elementos que Apoiam o Processo de Extração de Conhecimento de Bases de Dados}

Nesta seção serão abordados três dos principais elemento de apoio ao processo KDD: data warehouse, técnicas estatísticas e visualização de dados. Esse elementos podem ser considerados ferramentas de auxílio para a extração de conhecimento devido a otimização dos recursos e tempo gastos nesse processo, bem como o maior controle dos dados, no que concerne ao armazenamento e recuperação. Além disso, a compreensão do domínio é acentuadamente facilitada, posto que as técnicas estatísticas, em conjunto com as ferramentas de visualização, têm um papel fundamental em todas as etapas do processo KDD, sobretudo nas etapas de seleção e preparação dos dados, Data Mining e avaliação do conhecimento extraído.

\subsubsection{Data Warehouse}

Data Warehouse (DW) congrega várias tecnologias, tais como, plataformas de hardware, ferramentas de gerenciamento de dados distribuídas, bases de dados voltadas para consultas complexas e ferramentas inteligentes de análise de dados. Seu uso como modelo de infraestrutura para o suporte à tomada de decisão tem como objetivos fundamentais (Inmon, 1996):

- Prover um ambiente de informação bem administrado e protegido contra acessos indiscrimidados de usuários, haja visto o grande ativo que representam essas informações para uma empresa.

- Construir um modelo de dados corporativo que permita uma padronização da manipulaçāo das informações, tanto nos sistemas de produçāo quanto nos de tomada de decisão.

- Manter a independência entre os processos dos usuários e os da administração.

Algumas das aplicações mais freqüentes de DW são: análise de vendas e marketing, otimização de rotas e análise de riscos em transportes, análise de lucros e riscos em empreendimentos bancários, e análise de reclamações ou detecção de fraudes em seguradoras. 
Criar um DW não é uma simples questão de tecnologia de bases de dados ou processadores paralelos, envolve planejamento e modelagem (aspectos muitas vezes deixados em segundo plano), integração de vários softwares e uma contínua atualização e refinamento.

Uma solução bem projetada de DW visa a satisfação das necessidades de análise de informações dos usuários, como monitorar o histórico das operações, além de prever situaçōes futuras. Ao transformar, consolidar e racionalizar as informações dispersas em diferentes bases de dados e plataformas, um DW permite que sejam realizadas análises estratégicas bastantes eficazes em informações antes inacessíveis ou subaproveitadas. Um das tecnologias mais populares para análise de DW é conhecido como OLAP (On-Line Analytical Processing) (Codd, 1993). Essa tecnologia focaliza a manipulação e análise de dados por meio de métodos multidimensionais, com o objetivo de suprir as limitações impostas pelas linguagens de consultas (e.g. SQL) e pelos esquemas de bancos de dados relacionais para armazenamento e acesso a dados. O OLAP oferece suporte às atividades de análise e navegação do usuário final, tais como: cálculos e modelagens aplicadas ao longo de dimensões e hierarquias, análises temporais sobre períodos seqüencias, separação de subconjuntos de informações para visualização em tela, e navegação em níveis mais profundos de detalhes dos dados.

Vale destacar que as ferramentas oferecidas pelo binômio DW e OLAP (e.g. OLAM - On-Line Analytical Mining (Han, 1998)) podem facilitar sobremaneira aplicação do Processo KDD, visto que grande parte do pré-processamento dos dados para Data Mining já é realizado por estas tecnologias. Sendo neste pré-processamento frequentemente observados a integridade, consistência e limpeza dos dados. Num DW, a maior parte dessa preparação normalmente já foi realizada. Além disso, a integração de OLAP com funções de Data Mining permite ao usuário investigar diferentes tarefas de extração de padrões de forma interativa.

\subsubsection{Ferramentas de Visualização}

As ferramentas de visualização de dados estão se tornando cada vez mais importantes no processo KDD, pois permitem, entre outros, o aumento da capacidade de análise e de interpretação dos resultados obtidos (Rezende et al., 1998).

Geralmente, a visualização de dados pode ser utilizada como uma ferramenta exploratória na análise desses dados. Um especialista em visualização pode construir diferentes 
tipos de gráficos onde o especialista do domínio e o analista do processo KDD podem verificar tendências a partir dos dados, analisando quais os atributos mais significativos para um determinado padrão descoberto e, principalmente, mostrar ao usuário final ou ao próprio especialista do domínio, de maneira mais clara e concisa, o conhecimento extraído.

Os principais tipos de ferramentas usadas para realizar as aplicações de visualização são: as linguagens de programação especializadas e as ferramentas Graphic User Interface (GUI). As linguagens de programação exigem geralmente habilidades de programação necessárias para criação de gráficos (e.g. C++). Essa linguagens são voltadas, particularmente, para os casos em que se exigem gráficos especializados, não disponíveis no mercado. As ferramentas GUI são apropriadas às situações em que as necessidades de visualização dos dados não excede a própria capacidade dessas ferramentas.

Vale ressaltar que é freqüente o uso de ferramentas avançadas de visualização de dados no processo KDD, principalmente as que envolvem análise estatística. Nesse caso são também necessários conhecimentos estatísticos para uma plena utilização dessas ferramentas.

\subsubsection{Técnicas Estatísticas}

A estatística tem desenvolvido uma vasta infra-estrutura (teoria) como suporte de seus próprios métodos e uma linguagem (cálculo probabilístico) para descrever suas abordagens para quantificar incerteza associada às inferências a partir dos dados. Estes métodos permitem descrever relações entre variáveis para predição, quantificando efeitos, ou sugerindo caminhos (Glymour et al., 1997).

A relação entre o processo KDD e estatística é bastante estreita. Embora com enfoques diferentes, ambas as áreas objetivam a localização de padrões e regularidade nos dados. Em geral, o processo KDD, particularmente na etapa de Data Mining, enfatiza mais a facilidade de entendimento do conhecimento adquirido que basicamente a precisão. Além disso, a maioria dos algoritmos para DM estão mais voltados à produção de conjuntos de declaraçōes sobre dependências locais entre variáveis de interesse (e.g. na forma de regras) do que propriamente na construção de modelos globais que incluam todas as variáveis de interesse do problema (Glymour et al., 1997).

Além da etapa de DM, as técnicas estatísticas têm um papel fundamental em mais três etapas do processo KDD. Na etapa de seleção e preparação dos dados, por exemplo, 
tentando extrair amostras enxutas e representativas dos dados; e na etapa de avaliação do conhecimento extraído, especialmente no que concerne a utilização de técnicas de visualização (Fayyad, 1996).

Além disso, técnicas estatísticas, juntamente com técnicas de Inteligência Artificial, especialmente as que manipulam incerteza (Heckerman, 1997), provêem mecanismos para evitar overfitting, tratar ruídos, manipular conjuntos de dados incompletos (missing values), e combinar conhecimento de fundo (do domínio ou a priori) com os dados. Na próxima são destacados alguns dos principais problemas relacionados ao processo KDD.

\subsection{Problemas Relacionados ao Processo de Extração de Conhecimento de Bases de Dados}

Nesta seção são abordados alguns dos principais problemas relacionados ao processo KDD e algumas das principais medidas que podem ser adotadas para evitá-los.

\subsubsection{Definição dos Objetivos da Aplicação}

A clareza das metas a serem alcançadas influencia sobremaneira o êxito ou fracasso do processo KDD. Faz-se necessário, portanto, ter um profundo conhecimento da base de dados do domínio de aplicação para, dentre outras coisas, determinar a forma com que o conhecimento pode ser representado e de que maneira os resultados (conhecimentos) vão ser empregados.

Objetivos bem claros e discutidos a partir da interação analista/especialista/usuário final podem evitar que, ao longo do processo, sejam especificados muitos outros objetivos (não previsto na etapa de Compreensão do Domínio), o que pode acarretar um desperdício de tempo e recursos na tentativa de encontrar "às cegas" o que se pretende obter por intermédio do processo KDD.

\subsubsection{Ruído nos Dados}

Assumir que todos os valores de um conjunto de dados estão totalmente corretos não representa uma hipótese sustentável, em se tratando de dados reais. A maioria dos algoritmos para Data Mining trabalham com a suposição de que os registros de uma base de dados podem incluir valores de atributos baseados nas medidas subjetivas e/ou de juízo, o que 
pode significar que esses valores representam erros. Os erros não sistemáticos deste tipo, em determinados valores dos atributos, são normalmente chamados de ruído.

O tratamento de ruído se dá geralmente pela consideração ou não da parte dos dados que apresentam ruídos. Os ruídos nos dados são geralmente identificados por intermédio da excepcionalidade (ou variação acentuada) de valores do conjunto de dados, mediante as técnicas estatísticas. Vale ressaltar que alguns pesquisadores, como Quinlan, consideram que não vale a pena destinar esforços para eliminar ruídos do conjunto de dados se é bastante provável que o conhecimento seja aplicado, na prática, em outros conjuntos de dados com ruído (Quinlan, 1993).

\subsubsection{Dados Incompletos}

Em bases de dados reais é muito freqüente a ausência de alguns valores de atributos (dados incompletos), especialmente em bases de dados comerciais. Esse problema ocorre por muitos motivos, entre os quais, destacam-se (Fayyad et al., 1996), (Ramoni and Sebastiani, 1997b):

- Armazenamento de dados impuros.

- Perda de dados (e.g. causada por problemas físicos de armazenamento).

- Revisão dos dados armazenados (e.g. novos atributos são considerados, quando há alguns meses atrás não o foram).

- Falta de observação de atributos preditivos ou que, apesar de aparentemente irrelevantes, em conjunto com outros atributos tenham elevado poder preditivo.

- Falhas na medição dos valores dos atributos.

Os métodos de tratamento de dados incompletos (missing values) em bases de dados têm recebido atenção especial em pesquisas relacionadas a KDD, especialmente aqueles que envolvem soluções estatísticas (e.g. redes Bayesianas) (Ramoni and Sebastiani, 1997b).

\subsection{Considerações Finais}

Na última década, três fatores importantes nortearam o crescimento de nossa capacidade de gerar e colecionar dados: primeiro, a disponibilidade de tecnologias que oferecem um grande 
poder de armazenamento e processamento de dados a baixo custo; segundo, pelo acúmulo de dados a uma razão crescente; e por último, a introdução de novos conjuntos de métodos desenvolvidos pela comunidade de informática para o processamento de dados (Decker and Focardi, 1995), (Li, 1996).

Atualmente, as bases de dados já estão sendo medidas em terabytes, e as potencialidades de hardware estão crescendo exponencialmente. Desta forma, tecnologias como KDD são cada vez mais utilizadas para auxiliar analistas em seu trabalho de investigação e análise desses enormes conjunto de dados a fim de se extrair conhecimento.

O processo de extração de conhecimento de bases de dados combina métodos e ferramentas de estatística, aprendizado de máquina e banco de dados para encontrar uma descrição matemática e/ou lógica, eventualmente complexa, de padrões e regularidades nos dados (Fayyad et al., 1996), (Mannila, 1997a).

Neste capítulo foram enfatizadas as principais etapas do processo KDD, bem como a importância da interação entre os usuários para o êxito desse processo. Além disso, foram apresentados os principais elementos que auxiliam a realização das tarefas pertinentes a essas etapas, bem como os principais problemas encontrado para realizá-las.

No próximo capítulo, são apresentados os principais conceitos relacionados às redes Bayesianas, pilar do entendimento dos métodos de aprendizado utilizados neste trabalho. 


\section{Capítulo 3}

\section{Redes Bayesianas para Extração de Conhecimento de Bases de Dados}

\subsection{Considerações Iniciais}

Durante a última década, as redes Bayesianas (RBs) tornaram-se um método bastante utilizado pela comunidade de Inteligência Artificial para manipular incerteza em sistemas especialistas (Heckerman et al., 1995), (Russell and Norvig, 1995). Mais recentemente, as atividades de pesquisa têm focalizado métodos de aprendizado de RBs a partir de dados, o que tem atraído sobremaneira a atenção da comunidade de KDD (Heckerman, 1997), (Ramoni and Sebastiani, 1997b).

Apesar de já existirem várias representações (e.g. árvores de decisão e regras de produção) e técnicas (e.g. classificação e clustering) para análise de dados, as RBs têm sido alvo de pesquisas especialmente por quatro razōes (Heckerman, 1997), que serão apresentadas a seguir.

Primeiro, manipulação efetiva de conjuntos de dados incompletos. Por exemplo, o problema da classificação, utilizando técnicas de aprendizado supervisionado padrão, em um contexto em que duas variáveis de um conjunto de dados são fortemente correlacionadas é particurlamente simples quando todos os valores dessas variáveis são observadas nesse conjunto. Entretanto, quando uma dessas variáveis não é observada, essas técnicas podem perder muito da precisão na classificação de novos exemplos, pois não codificam a correlação entre as variáveis. As redes Bayesianas oferecem um modo natural de codificação dessas 
correlação (por meio de dependências entre variáveis de um conjunto de dados).

Segundo, o aprendizado sobre relacionamentos causais entre variáveis do domínio. Essa forma de aprendizado facilita o entendimento do domínio (e.g. em análise exploratória de dados), bem como permite efetuar previsões na presença de intervenções de especialistas de um domínio de aplicação (e.g. um analista de marketing pode desejar saber se deve ou não aumentar a exposição de um anúncio para elevar a venda de um determinado produto).

Terceiro, as RBs, em conjunto com outras técnicas de estatísticas Bayesianas, facilitam a combinação do conhecimento do domínio com os dados. As RBs possuem uma semântica causal que faz com que a codificação do conhecimento de fundo (causal) seja realizada de maneira direta.

Finalmente, os métodos Bayesianos associados às RBs e a outros tipos de modelos oferecem uma eficiente abordagem para evitar overfitting dos dados.

Para um melhor entendimento da representação e extração de conhecimento usando RBs, este capítulo foi dividido da seguinte forma. Na próxima seção é focalizado o problema da manipulação de conhecimento incerto. Na seção 3.3 é apresentada uma introdução à Teoria das Probabilidades. Na seção 3.4 é mostrada a importância da abordagem Bayesiana para o Aprendizado de Máquina. Em seguida, na seção 3.5 são enfatizados os conceitos relacionados às $\mathrm{RBs}$, bem como a construção dessas redes a partir do conhecimento a priori (conhecimento de fundo) do especialista. Na seção 3.6 é focalizado o aprendizado das probabilidades e da estrutura de uma RB, a partir da combinação do conhecimento de fundo e dados. Na seção 3.7 são apresentados alguns algoritmos de inferência em RBs. Por último, na seção 3.8 são feitas algumas considerações finais acerca da extração de conhecimento de bases de dados usando RBs.

\subsection{Manipulação de Incerteza}

Um dos principais problemas da aquisição de conhecimento é quando ela é realizada em domínios com incerteza. Essa incerteza geralmente advém da falta de conhecimento categórico das propriedades de um domínio, ou seja, não é possível especificar todas as possíveis situações desse domínio por existirem muitas condições a serem observadas ou por elas serem desconhecidas (e.g. em um domínio médico não são conhecidas todas as possíveis causas do câncer). 
Para um melhor entendimento da manipulação de incerteza, considere o exemplo de um domínio odontológico. Se todas as possíveis causas de dor de dente fossem especificadas utilizando, por exemplo, lógica de 1 ordem, como é mostrado a seguir:

$\forall p \operatorname{sintoma}(p$, dor.de_dente $) \rightarrow$ doenca $(p$, cárie $) \vee$ doenca $(p, g$ engivite $) \vee \ldots$

Essa representação seria impraticável para este problema, posto que nāo haveria como detalhar todas essas causas através das regras dessa lógica (Russell and Norvig, 1995).

Assim, a manipulação de incerteza utilizando lógica de 1 ordem falharia devido, principalmente, a três razões: a grande quantidade de regras a serem manipuladas, a falta de conhecimento (ignorância teórica) do próprio especialista sobre todos os possíveis termos das regras (e.g. todas as possíveis causas dos índices que fazem a bolsa de valores caírem); e a ignorância prática, isto é, por mais que sejam conhecidos todos os possíveis termos dessa regra, em certas situações de um domínio particular, esses termos não teriam validade (e.g. um mesmo tratamento para uma determinada doença poderia ter efeito diferenciado para pacientes diferentes) (Russell and Norvig, 1995). Dessa forma, o máximo que o especialista poderia fornecer é um grau de crença das sentenças relevantes. Por exemplo, um dentista pode, baseado em seus estudos, "crer" que, em $80 \%$ dos casos, um paciente que apresenta dor de dente, tem cárie.

A principal ferramenta para manipular graus de crença advém da Teoria das Probabilidades, a qual associa um grau de crença entre 0 e 1 para uma determinada sentença. A probabilidade 0 (zero) para uma dada sentença, corresponde a uma inequívoca crença de que essa sentença é falsa, enquanto a probabilidade 1 (um) corresponde à inequívoca crença de que a sentença é verdadeira. Probabilidades entre 0 e 1 correspondem ao grau de crença intermediário no qual a sentença é verdadeira. A seguir é apresentada uma introdução da Teoria das Probabilidades, que é de grande valia para o entendimento dos conceitos relacionados às $\mathrm{RBs}$.

\subsection{Teoria das Probabilidades}

O conceito de grau de crença está relacionado à definição subjetiva de probabilidade, que pode ser entendida como a medida de crença que um observador possui na ocorrência de 
um evento. Enquanto a probabilidade freqüentista se baseia no valor do qual se aproxima a freqüência relativa de ocorrências desse evento em um grande número de repetiçōes (e.g. probabilidade de cair cara no lançamento $n+1$ de uma moeda, considerando os $n$ lançamentos anteriores), a probabilidade subjetiva é uma propriedade da pessoa que determina a probabilidade (e.g. o grau de crença de uma pessoa para determinar a probabilidade de um paciente ficar bom se ele for submetido a um novo tratamento) (Dantas, 1997). Para o aprendizado de redes Bayesianas serão considerados os dois conceitos de probabilidades - freqüentista (quando a rede for induzida a partir dos dados) e a subjetiva (quando as probabilidades da rede for especificada com apoio do especialista).

Uma crítica comum à definição de probabilidade subjetiva é com relação à aparente arbitrariedade das medidas de probabilidade, pois, como saber qual deve ser o grau de crença que satisfaz as regras de probabilidades? Em que escala essas probabilidades devem ser medidas?

No que concerne à primeira questão, muitos pesquisadores sugerem diferentes conjuntos de propriedades que devem ser satisfeitos pelos graus de crença. O fato da grande maioria desses conjuntos de propriedades levarem às mesmas regras - as regras de probabilidade -" reforça o argumento do uso da teoria da probabilidade para a medida de crença (Russell and Norvig, 1995), (Heckerman, 1997).

Com relação à questão da escala de probabilidades, a medida do grau de crença é comumente referida como uma atribuição de probabilidades por parte de um determinado observador. Por exemplo, um especialista em sismologia compara sua "opiniāo" sobre a ocorrência de um terremoto com a ocorrência de bolas brancas retiradas de uma urna contendo $m$ bolas brancas e $n$ bolas pretas. Sua probabilidade para ocorrência de terremoto seria então $\frac{m}{n+m}$ (Dantas, 1997).

No cálculo da probabilidade de um determinado evento ocorrer devem ser consideradas as percepções (evidências) obtidas a partir do domínio. Por exemplo, na ausência de qualquer outra evidência, a probabilidade de um determinado paciente ter cárie é de 0,1. Entretanto, se é sabido que o paciente apresenta dor de dente, a probabilidade desse mesmo paciente ter cárie será bem maior, 0,8. Portanto, se uma pessoa declara a probabilidade de um evento ocorrer, esta declaração deve considerar todas as informações que dizem respeito a esse evento. Caso novas percepçōes sejam obtidas, a avaliação deve ser atualizada para refletir essas novas evidências. Antes das evidências serem obtidas tem-se a probabilidade a priori 
ou incondicional, após a obtenção das evidências, tem-se a probabilidade condicional ou a posteriori.

A probabilidade a priori, denotada por $P(A)$ é a probabilidade de uma proposição $A$ ser verdadeira, desde que não seja fornecida nenhuma evidência. Por exemplo, se cárie denota a proposição de que um determinado paciente tem cárie, $P($ cárie $)=0,1$ significa que, na ausência de qualquer outra evidência, a probabilidade desse paciente ter cárie é de $10 \%$.

Uma vez obtida alguma evidência a partir do domínio, a probabilidade condicional, denotada por $P(A \mid B)$, deve ser aplicada. Por exemplo, $P$ (cárie $\mid$ dor_de_dente $)=0,8$ indica que se um determinado paciente tem dor de dente e não há outra evidência disponível, então a probabilidade do paciente ter cárie será de $80 \%$. É importante notar que a probabilidade a priori $P(A)$ pode ser vista como um caso especial da probabilidade condicional $P(A \mid)$, onde a probabilidade é condicionada a nenhuma evidência.

Para ilustrar o cálculo das probabilidades condicionais, considere o exemplo do lançamento de dois dados equilibrados. Deseja-se saber a probabilidade da soma dos dois dados ser igual a 8, se sabemos que o resultado do primeiro dado é 3 . Como o resultado do primeiro dado é 3, existem apenas seis resultados possíveis nesse experimento:

$$
(3,1)(3,2)(3,3)(3,4)(3,5)(3,6)
$$

A condição de que o primeiro dado apresenta a face 3 restringiu o espaço amostral de 36 para apenas 6 pontos, dos quais apenas um interessa - aquele cujos números têm a soma 8. Logo, a probabilidade procurada é $1 / 6$.

Se näo fosse informado a priori o resultado do primeiro dado como sendo igual a 3, a probabilidade de se obter a soma 8 seria então de $5 / 36$.

Através deste exemplo é possível observar que a probabilidade de um evento $A$ se modifica quando se dispöe da evidência de outro evento associado $B$. A probabilidade do evento $A$, quando se sabe que o evento $B$ ocorreu $(P(A \mid B))$ é calculada por:

$$
P(A \mid B)=\frac{P(A \cap B)}{P(B)}, P(B)>0
$$

Para entender a Equação 3.1 basta considerar que o espaço amostral ficou reduzido ao evento $B$, conforme ilustrada na Figura 3.1. 


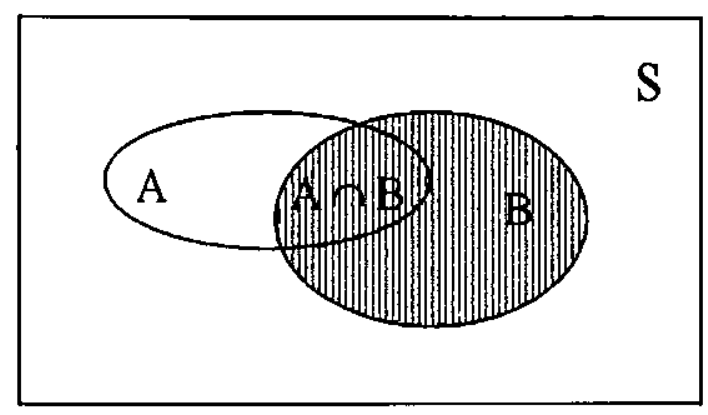

Figura 3.1: Probabilidade Condicional $P(A \mid B)$ (Soares et al., 1991).

A presença da interseção no numerador é facilmente justificada considerando que a ocorrência de $A$, quando se sabe que $B$ ocorreu, corresponde à ocorrência de $A$ e de $B$, ou seja, de sua interseção, ilustrada no diagrama da Figura 3.1.

A Equação 3.1 pode ser escrita como:

$$
P(A \cap B)=P(A \mid B) P(B)
$$

Aplicando-a ao exemplo dos dados, seja $A$ o evento "soma 8" e $B$ o evento "3 no primeiro dado". O espaço amostral tem 36 pontos. O evento $B$ tem 6 pontos. O evento $A$ tem 1 ponto. E o evento $A \cap B$ tem apenas 1 ponto. Logo, $P(A \mid B)=1 / 6$.

A Equação 3.2, chamada de regra da multiplicação, pode ser entendida como: "para que $A$ e $B$ sejam verdadeiros é necessário que $B$ também o seja e, então, $A$ ser verdadeiro dado $B$ ". A regra da multiplicação também pode ser representada conforme é mostrada na Equação 3.3:

$$
P(A \cap B)=P(B \mid A) P(A)
$$

Em geral, se há interesse em encontrar a probabilidade de um evento $A$ e tem-se acumulado as evidências $B$, basta calcular $P(A \mid B)$. Entretanto, algumas vezes não se tem esta probabilidade diretamente disponível. Neste caso, deve-se recorrer a alguma forma de inferência probabilística para calcular tal probabilidade.

Essa inferência pode ser feita sobre a distribuição de probabilidade conjunta (DPC) das variáveis envolvidas no domínio da aplicação. A DPC representa a especificação completa do domínio, ou seja, assinala valores de probabilidades a todas as variáveis desse domínio. A DPC pode ser entendida como uma tabela n-dimensional ( $n$ é o número de variáveis 
do domínio), onde cada célula representa a probabilidade de ocorrência de um determinado estado. Por exemplo, na Tabela 3.1 é mostrada a DPC de um domínio odontológico bastante simples constituído de duas variáveis booleanas: dor_de_dente e cárie.

\begin{tabular}{|c|c|c|}
\hline & dor_de_dente & $\neg$ dor_de_dente \\
\hline cárie & 0,04 & 0,06 \\
\hline cárie & 0,01 & 0,89 \\
\hline
\end{tabular}

Tabela 3.1: Distribuição de probabilidade conjunta para duas variáveis booleanas (Russell and Norvig, 1995).

Dessa forma, o cálculo de $P(A \mid B)$, considerando por exemplo $A=$ cárie e $B=$ dor_de_dente, pode ser realizado, a partir da DPC da Tabela 3.1, utilizando a Equação 3.1:

$$
P(A \mid B)=\frac{P(A \cap B)}{P(B)}=\frac{0,04}{0,04+0,01}=0,80
$$

Naturalmente, em problemas reais deve ser considerada a possibilidade do tratamento de um número maior de variáveis, e não apenas duas, como no exemplo odontológico. Por esta razão seria inviável manipular, computacionalmente falando, por exemplo, todas as $2^{n}$ entradas da DPC sobre as $n$ variáveis booleanas de um determinado domínio. Em geral, sistemas de aprendizado probabilístico, ao invés da DPC, trabalham diretamente com probabilidades condicionais para encontrar qualquer probabilidade de interesse a partir das variáveis. A regra de Bayes representa a teoria básica utilizada por esses sistemas para efetuar essa tarefa (Russell and Norvig, 1995).

A regra de Bayes (lei de Bayes ou teorema de Bayes) pode ser definida da seguinte forma. Dado um espaço amostral $S$ (formado por $E$ eventos), $A$ representa um ou mais eventos arbitrários de $S$, com $P(A)>0$. Considerando $E_{k}$ e $E_{i}$ dois eventos quaisquer de $S$, então a regra de Bayes pode ser dada pela Equação 3.4:

$$
P\left(E_{k} \mid A\right)=\frac{P\left(E_{k} \cap A\right)}{P(A)}=\frac{P\left(E_{k} \cap A\right)}{\sum P\left(E_{i} \cap A\right)}=\frac{P\left(E_{k}\right) P\left(A \mid E_{k}\right)}{\sum P\left(E_{i}\right) P\left(A \mid E_{i}\right)}
$$

Esta regra pode ser vista como uma generalização da probabilidade condicional ao caso de mais de dois eventos. Para ilustrá-la, considere o diagrama mostrado na Figura 3.2. 


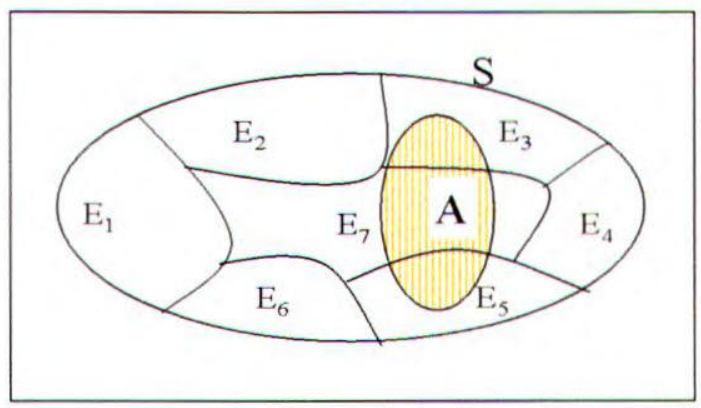

Figura 3.2: Generalização da probabilidade condicional (Soares et al., 1991).

Como os $E_{i}$ formam uma partição de $S$, temos que $A=\left(E_{1} \cap A\right) \cup\left(E_{2} \cap A\right) \cup \ldots \cup\left(E_{n} \cap A\right)$. Considerando que os eventos $E_{i} \cap A$ são mutuamente exclusivos (não podem ocorrer ao mesmo tempo), então:

$$
P(A)=P\left(E_{1} \cap A\right)+P\left(E_{2} \cap A\right)+\ldots+P\left(E_{n} \cap A\right)=\sum_{1}^{n} P\left(E_{i} \cap A\right)
$$

Dessa forma, pela definição de probabilidade condicional, tem-se que:

$$
P\left(E_{k} \mid A\right)=\frac{P\left(E_{k} \cap A\right)}{P(A)}=\frac{P\left(E_{k} \cap A\right)}{\sum P\left(E_{i} \cap A\right)}
$$

donde

$$
P\left(E_{k} \mid A\right)=\frac{P\left(E_{k}\right) P\left(A \mid E_{k}\right)}{P(A)}=\frac{P\left(E_{k}\right) P\left(A \mid E_{k}\right)}{\sum P\left(E_{i}\right) P\left(A \mid E_{i}\right)}
$$

Sendo $B$ um evento qualquer $E_{k}$ e $A$ o conjunto de evidências, a Regra de Bayes pode ser expressa, de forma simplificada, do seguinte modo:

$$
P(B \mid A)=\frac{P(A \mid B) P(B)}{P(A)}
$$

Assim, essa regra estabelece um modo para calcular a probabilidade de uma proposição $B$ (dado o conjunto de evidências $A$ ) baseado na sua probabilidade a priori - $P(B)$, a probabilidade das várias evidências observadas, $A$, dada a proposição $B-P(A \mid B)$, e a probabilidade das próprias evidências observadas $-P(A)$. Por exemplo, considere um problema de diagnóstico mecânico em que o especialista (mecânico) sabe que problemas no alinhamento de direção de um automóvel causam, em $60 \%$ dos casos, desgaste irregular de pneus. O mecânico também conhece alguns fatos incondicionais: a probabilidade a priori de um automóvel 
apresentar desgaste irregular de pneus é de 0,03 e de ter problemas de alinhamento de direção é de 0,01 . Considerando $A$, a hipótese de um automóvel ter problemas de alinhamento e $B$ de apresentar desgaste irregular de pneus, qual seria a probabilidade do automóvel ter algum problema de alinhamento sabendo que ele apresenta desgaste irregular de pneus?

Utilizando a Equação 3.6, obtém-se:

$$
P(A \mid B)=\frac{P(B \mid A) P(A)}{P(B)}=\frac{0,6 * 0,01}{0,03}=0,2
$$

Em outras palavras, é esperado que $20 \%$ dos carros tenham problema de desgaste irregular de pneus quando apresentarem problemas de alinhamento.

Em razão da regra de Bayes poder ser aplicada sobre qualquer conjunto mutuamente exclusivo e coletivamente exaustivo de eventos, cuja a soma das probabilidades é igual a 1. Por exemplo, em um conjunto de dados com duas classes A e B, um exemplo não pode pertencer as duas classes (mutuamente exclusivo) e a soma das probabilidades de um exemplo pertencer a classe A e a classe B é igual a 1 (coletivamente exaustivo). Além disso, em função da utilidade da abordagem Bayesiana para o Aprendizado de Máquina e, consequentemente, ao processo de extração de conhecimento de bases de dados, é importante sublinhar a aplicação dessa regra em sistemas de Aprendizado de Máquina.

\subsection{Aprendizado Bayesiano e Aprendizado de Máquina}

Segundo Michell, métodos de aprendizado Bayesianos são importantes para o Aprendizado de Máquina, principalmente por duas razões: (1) sistemas de aprendizado Bayesiano (e.g. Naive Bayes (Langley et al., 1992)) estão entre os mais práticos e eficientes métodos para certos tipos de problemas de aprendizado e (2) métodos Bayesianos estabelecem uma perspectiva útil para o entendimento de algoritmos que não manipulam probabilidades explicitamente (Michell, 1997).

Sobre a perspectiva de Aprendizado de Máquina, deseja-se freqüentemente determinar a melhor hipótese $h$, a partir de algum espaço $H$ de hipóteses, considerando um conjunto de dados (ou de exemplos) de treinamento $D$. Por exemplo, um determinado banco precisa saber se concede ou não crédito (hipóteses) a uma pessoa de acordo com seus atributos (e.g. sexo, idade, renda, tipo de moradia, bens, etc.), considerando um conjunto de dados contendo valores destes atributos e, geralmente, a hipótese associada a esses valores. 
Um possível modo de especificar a "melhor hipótese" é encontrar a hipótese "mais provável" (de máxima verossimilhança), dado um conjunto de dados $D$ e mais o conhecimento inicial sobre a probabilidade a priori das várias hipóteses em $H$. A hipótese mais provável, representada por $h_{\text {MAP }}$ (Maximum a Posteriori), pode ser determinada pela regra de Bayes, usada para calcular a probabilidade condicional de cada hipótese candidata a mais provável, da seguinte forma:

$$
\begin{gathered}
h_{M A P} \equiv \operatorname{argmax}_{h \in H} P(h \mid D) \\
h_{M A P} \equiv \operatorname{argmax}_{h \in H} \frac{P(D \mid h) P(h)}{P(D)}
\end{gathered}
$$

Como o termo $P(D)$ é uma constante independente de $h$, ele pode ser desconsiderado. Desta forma, obtém-se a Equação 3.7 a seguir:

$$
h_{M A P} \equiv \operatorname{argmax}_{h \in H} P(D \mid h) P(h)
$$

Além disso, em alguns casos, pode-se assumir que qualquer hipótese candidata é, a priori, igualmente provável, ou seja, $P\left(h_{i}\right)=P\left(h_{j}\right)$ para todo $h_{i}$ e $h_{j}$ pertencente a $H$. Deste modo, para o cálculo da hipótese mais provável, pode-se considerar apenas o termo $P(D \mid h)$ - probabilidade dos dados de treinamento $D$ dado $h$, representada pela hipótese de Máxima Verossimilhança (Maximum Likelihood) $h_{M L}$ na Equaçāo 3.8 abaixo:

$$
h_{M L} \equiv \operatorname{argmax}_{h \in H} P(D \mid h)
$$

Para ilustrar o cálculo da hipótese mais provável, considere um problema de diagnóstico médico em que sāo consideradas duas hipóteses: (1) o paciente tem câncer e (2) o paciente não tem câncer. Os dados do paciente são obtidos a partir de um teste de laboratório, com apenas dois resultados possíveis: positivo ou negativo. É também sabido um fato incondicional de que apenas 0,008 da população sofre dessa doença. Além disso, os testes de laboratório apresentam acerto em $98 \%$ dos casos positivos e $97 \%$ dos casos negativos de câncer. Esta situaçāo pode ser resumida pelas probabilidades abaixo (Michell, 1997):

- Probabilidades incondicionais:

$$
P(\text { câncer })=0,008 \quad P(\neg \text { câncer })=0,992
$$


- Probabilidades condicionais:

$$
\begin{array}{ll}
P(\text { positivo } \mid \text { âncer })=0,98 & P(\text { negativo } \mid \text { câncer })=0,02 \\
P(\text { positivo } \mid \neg \text { câncer })=0,03 & P(\text { negativo } \mid \neg \text { câncer })=0,97
\end{array}
$$

Baseado nessas probabilidades, qual seria o diagnóstico para um paciente cujo teste de laboratório deu positivo?

A $h_{M A P}$ pode ser calculada através da Equação 3.7 do seguinte modo:

$P($ positivo|câncer $) P($ câncer $)=0,98 * 0,008=0,0078$

$P($ positivo| $\neg$ câncer $) P(\neg$ câncer $)=0,03 * 0,992=0,0298$

Portanto, $h_{M A P}=\neg c a ̂ n c e r$. Apesar de não ser informada diretamente, a probabilidade condicional de um paciente ter câncer, dado o resultado do teste positivo, também pode ser calculado por intermédio da Regra de Bayes (Equação 3.6). Assim, tem-se que:

$$
\begin{gathered}
P(\text { câncer } \mid \text { positivo })=\frac{P(\text { positivo } \mid \text { câncer }) P(\text { câncer })}{P(\text { positivo })} \\
P(\text { positivo })=P(\text { positivo } \mid \text { câncer }) P(\text { câncer })+P(\text { positivo } \mid \neg \text { câncer }) P(\neg \text { câncer })=0,0376 \\
P(\text { câncer } \mid \text { positivo })=\frac{0,0078}{0,0376} \approx 0,21
\end{gathered}
$$

Vale ressaltar que tanto o cálculo da $h_{M A P}$ quanto o da $h_{M L}$ são utilizados para o aprendizado de redes Bayesianas a partir de dados, e serão vistos na seção 3.6.

Um exemplo típico de métodos de aprendizado Bayesiano que fazem uso do cálculo da hipótese mais provável é o classificador Naive Bayes. Este classificador estima a hipótese (classe) mais provável a partir da suposição de que os valores dos atributos dos dados de treinamento são condicionalmente independentes dada a classe (atributo-classe) a que esses dados pertencem (Michell, 1997).

A partir dessa suposição, o Naive Bayes identifica a classe mais provável, $C_{M A P}$ (pertencentes a algum conjunto de classes possíveis $C$ ) de uma nova instância, dado os valores dos atributos $\left(a_{1}, a_{2}, \ldots, a_{n}\right)$ dessa instância, de acordo com a Equação 3.9 abaixo:

$$
C_{M A P}=\operatorname{argmax}_{c_{j} \in C} P\left(c_{j} \mid a_{1}, a_{2}, \ldots, a_{n}\right)
$$

Considerando a regra de Bayes (Equação 3.6), a $C_{M A P}$ pode ser entendida (calculada) como a $h_{M A P}$ de uma nova instância (com atributos $a_{1}, a_{2}, \ldots, a_{n}$ ) pertencer a uma classe $c_{j}$ $\left(c_{j} \in C\right)$ : 


$$
C_{M A P}=\operatorname{argmax}_{c_{j} \in C} P\left(a_{1}, a_{2}, \ldots, a_{n} \mid c_{j}\right) P\left(c_{j}\right)
$$

Como o Naive Bayes considera que todos os valores de atributos são independentes dada a classe a que eles pertencem, a probabilidade de se observar, a partir do conjunto de dados de treinamento, a conjunção $\left(a_{1}, a_{2}, \ldots, a_{n}\right)$ dada a classe $c_{j}$ a que eles pertencem, é o produto das probabilidades individuais dos atributos: $P\left(a_{1}, a_{2}, \ldots, a_{n} \mid c_{j}\right)=\prod_{i} P\left(a_{i} \mid c_{j}\right)$. Substituindo $P\left(a_{1}, a_{2}, \ldots, a_{n} \mid c_{j}\right)$ por $\prod_{i} P\left(a_{i} \mid c_{j}\right)$ na Equação 3.10 , obtém-se a Equação 3.11 a seguir:

$$
C_{M A P}=\operatorname{argmax}_{c_{j} \in C} P\left(c_{1}\right) \prod_{i} P\left(a_{i} \mid c_{j}\right)
$$

Desta forma, o método de aprendizado desse algoritmo envolve a estimativa dos vários termos $P\left(c_{j}\right)$ e $P\left(a_{i} \mid c_{j}\right)$ baseados na freqüência em que eles ocorrem nos exemplos de treinamento. $\mathrm{O}$ conjunto dessas estimativas correspondem a hipótese aprendida, que é então usada para classificar uma nova instância por intermédio da Equação 3.11.

Esta seção, bem como as seções 3.2 e 3.3 procuraram fornecer os insumos básicos para a compreensão do estudo de RBs. A seguir são apresentados os conceitos relacionados às RBs, bem como a construção das mesmas a partir do conhecimento a priori (de fundo) do especialista do domínio.

\subsection{Redes Bayesianas}

Na seção 3.3 , foi mostrado que a distribuição de probabilidade conjunta pode responder às questões de relacionamento probabilístico entre as variáveis do domínio. Entretanto, em problemas reais (e.g. Data Mining) essa tarefa pode se tornar inviável devido ao grande número de variáreis a serem manipuladas. As redes Bayesianas provêem representações apropriadas para essa tarefa, em função de poderem representar as dependências entre variáveis do domínio e proporcionarem uma concisa e eficiente especificação da DPC (Russell and Norvig, 1995). (Heckerman, 1997).

Lma rede Bayesiana ou rede de crença pode ser vista como um grafo que representa o relacionamento probabilístico entre o conjunto de variáveis de um domínio, consistindo de (Russell and Norvig, 1995): 
- Um conjunto de nós que representam as variáveis aleatórias $\mathbf{X}=\left\{X_{1}, X_{2}, \ldots, X_{n}\right\}$ do domínio.

- Um conjunto de ligações dirigidas ou setas conectando pares de nós. Essas setas representam a influência direta que um nó exerce sobre outro.

- Uma Tabela de Probabilidade Condicional (TPC) para cada nó, que quantifica os efeitos que os nós-pais $(P a)$ exercem sobre esse nó. Os nós-pais de um nó $n$ são todos aqueles que possuem setas apontando para $n$.

- Um grafo sem ciclos direcionados (DAG - Directed Aciclic Graphic).

Desta forma, uma rede Bayesiana provê uma completa descrição do domínio. Cada entrada na DPC pode ser calculada a partir das informações da rede. Uma entrada genérica da DPC é a probabilidade de uma conjunção de uma particular atribuição de valores para cada variável, assim como $P\left(X_{1}=x_{1} \cap \ldots \cap X_{n}=x_{n}\right)$. Abreviando esta notação para $P\left(x_{1}, \ldots, x_{n}\right)$, os valores das entradas da DPC podem ser obtidos por intermédio da Equação 3.12:

$$
P\left(x_{1}, \ldots, x_{n}\right)=\prod_{i=1}^{n} P\left(x_{i} \mid P a_{i}\right)
$$

Cada entrada da distribuição de probabilidades conjunta é representada pelo produto dos elementos apropriados (de acordo com o relacionamento entre as variáveis) das tabelas de probabilidades condicionais na rede Bayesiana, ou seja, as TPCs estabelecem uma representação simplificada da DPC.

Para que a representação da DPC seja possível, a rede Bayesiana especifica, juntamente com as probabilidades condicionais da TPC, a independência condicional entre um subconjunto de variáveis de $X$. Uma variável $X$ (ou um conjunto de variáveis $\left(X_{1}, X_{2}, \ldots, X_{n}\right)$ ) é condicionalmente independente de $Y$ (ou de um conjunto de variáveis $Y_{1}, Y_{2}, \ldots, Y_{n}$ ), dado uma variável $Z$ (ou $Z_{1}, Z_{2}, \ldots, Z_{n}$ ), se a distribuição probabilística de $X$ é independente do valor de $Y$, dado o valor de $Z$, ou seja:

$$
P(X \mid Y, Z)=P(X \mid Z)
$$

Estendendo este conceito para um conjunto de variáveis, tem-se:

$$
P\left(X_{1}, X_{2}, \ldots, X_{n} \mid Y_{1}, Y_{2}, \ldots, Y_{m}, Z_{1}, Z_{2}, \ldots, Z_{k}\right)=P\left(X_{1}, X_{2}, \ldots, X_{n} \mid Z_{1}, Z_{2}, \ldots, Z_{k}\right)
$$


A definição de independência condicional corresponde à ausência de arcos entre os nós de uma rede Bayesiana. Por exemplo, os nós $X$ e $Y$ da rede visualizada na Figura 3.3 são independentes condicionalmente, dado $Z$.

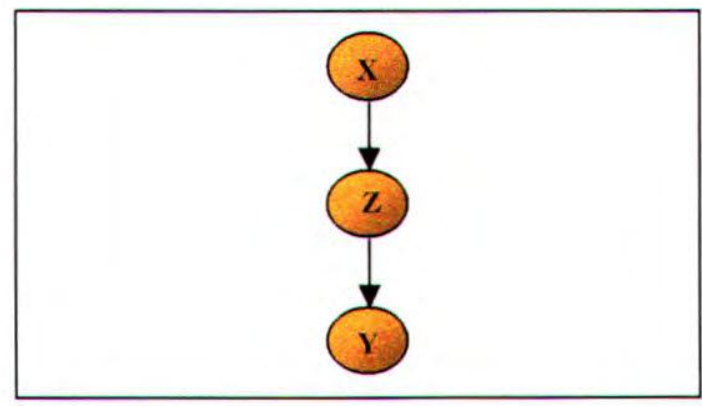

Figura 3.3: Exemplo de independência condicional.

A independência condicional entre as variáveis de um particular domínio podem auxiliar o processo de construção de uma rede Bayesiana para esse domínio. Uma forma de visualizar isso é baseada no seguinte:

- Reescrevendo $P\left(X_{i}\right)$ em termos da definição de probabilidade condicional (Equação 3.1) e reduzindo cada conjunção de probabilidades a uma probabilidade condicional e uma conjunção menor, obtém-se:

$$
\begin{gathered}
P\left(x_{1}, x_{2}, \ldots, x_{n}\right)=P\left(x_{n}, x_{n-1}, \ldots, x_{1}\right) P\left(x_{n-1} \mid x_{n-2}, \ldots, x_{1}\right) \ldots P\left(x_{2} \mid x_{1}\right) P\left(x_{1}\right) \\
P\left(x_{1}, x_{2}, \ldots, x_{n}\right)=\prod_{i=1}^{n} P\left(x_{i} \mid x_{i-1}, \ldots, x_{1}\right)
\end{gathered}
$$

- Comparando as equações 3.12 e 3.13, tem-se:

$$
P\left(x_{i} \mid x_{i-1}, \ldots, x_{1}\right)=P\left(x_{i} \mid P a_{i}\right)
$$

- A partir da Equação 3.14 é possível notar que $P a_{i} \subseteq\left\{x_{i-1}, \ldots, x_{1}\right\}$. Desse modo, para determinar a estrutura de uma rede Bayesiana deve-se (1) ordenar as variáveis de algum modo (geralmente de acordo com as observações do especialista do domínio) e (2) determinar o conjunto de variáveis que satisfazem a Equação 3.14.

Para ilustrar o processo de construção de uma rede Bayesiana, considere o problema da detecção de fraude em compras com cartões de crédito. Na Figura 3.4, esse exemplo é 
mostrado, na qual os arcos são desenhados da causa para o efeito, os quadros mostram a distribuição de probabilidade local associada a cada nó da rede Bayesiana, e os asteriscos representam a atribuição de quaisquer valores, dentre os possíveis, às variáveis. Desse modo, a estrutura da rede Bayesiana pode ser obtida seguindo os passos:

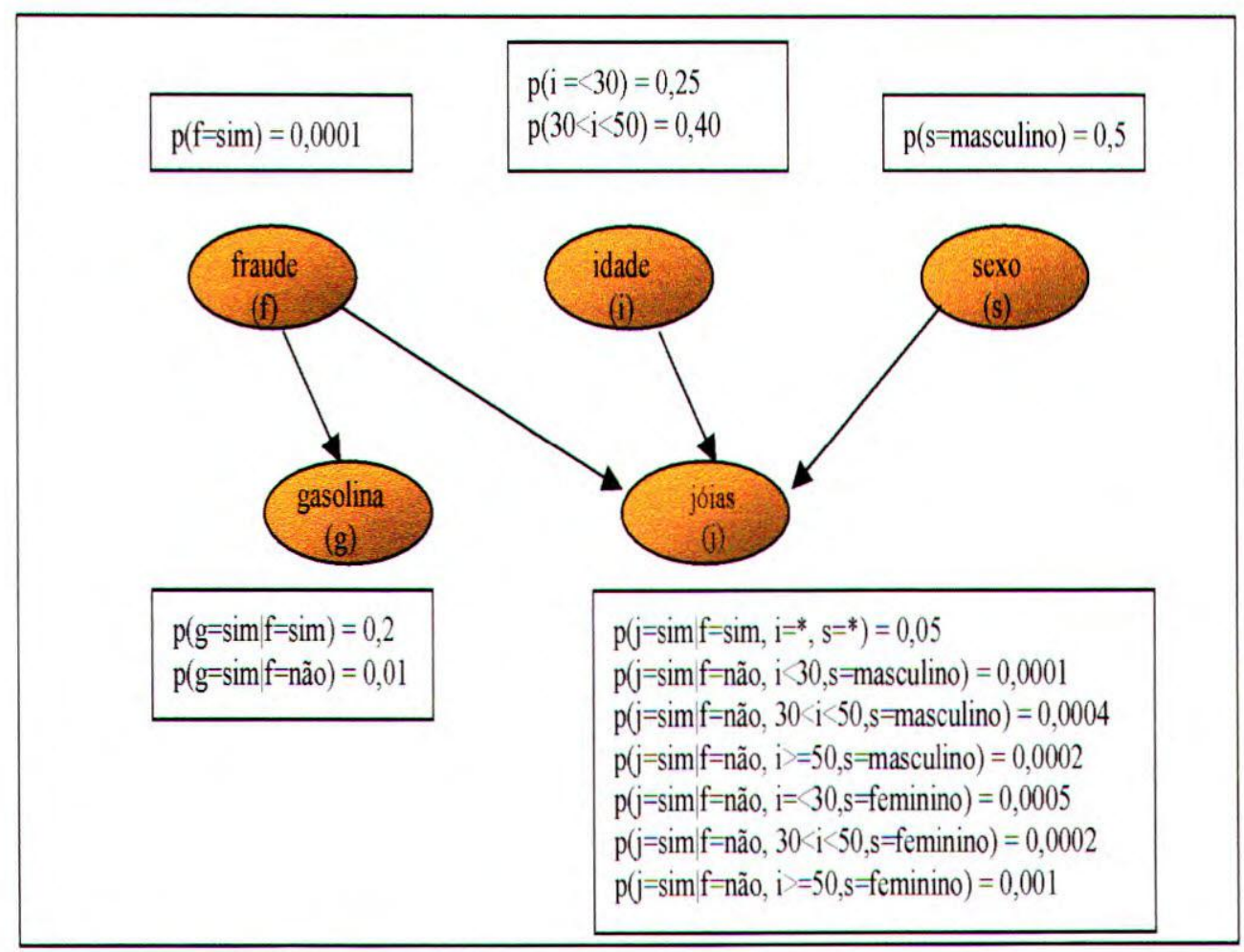

Figura 3.4: Exemplo de rede Bayesiana para deteç̧ão de fraude em compras com cartão de crédito (Heckerman, 1997).

1. Selecionar o conjunto de variáveis que descrevem o domínio. Uma possível escolha para o problema de detecção de fraude seria: fraude $(f)$, gasolina $(g)$, jóias $(j)$, idade $(i)$ e sexo $(s)$, representando se a compra é ou não fraudulenta, se houve ou não compra de gasolina nas últimas 24 horas, se houve ou não compra de jóias nas últimas 24 horas, o sexo e a idade do usuário do cartão de crédito, respectivamente.

2. Eleger uma ordem para essas variáveis. Uma possível ordem das variáveis para o problema de detecção de fraude seria: $f, i, s, g$ e $j$.

3. Enquanto houver variáveis a serem consideradas:

(a) Adicionar um nó a rede para cada variável $X_{i}$. 
(b) Estabelecer um conjunto de nós-pais de $X_{i}$ sobre o conjunto mínimo de nós já incluídos na rede que satisfazem a propriedade de independência condicional estabelecida pela Equação 3.14. No exemplo, utilizando a ordem $f, i, s, g$ e $j$, sugerida no passo 2, obtém-se:

$$
\begin{gathered}
P(i \mid f)=P(i) \\
P(s \mid f, i)=P(s) \\
P(g \mid f, i, s)=P(g \mid f) \\
P(j \mid f, i, s, g)=P(j \mid f, i, s)
\end{gathered}
$$

(c) Definir a TPC para $X_{i}$.

Vale ressaltar que, apesar de serem mostrados como uma seqüência simples, na prática, esses passos são geralmente interligados. Por exemplo, julgamentos de independência condicional e/ou causa e efeito podem influenciar na construção da rede Bayesiana. Além disso, alguns problemas, como os que serão tratados a seguir, devem ser considerados nesse processo de construção.

No passo 1, a seleção do conjunto de variáveis deve ser guiada pelos objetivos da aplicação (e.g. predição ou exploração). Para isso, é importante identificar um subconjunto das várias observações importantes para o domínio, a fim de organizá-las dentro de variáveis mutuamente exclusivas e coletivamente exaustivas. Na literatura alguns guias são oferecidos para resolução desse problema, por exemplo, por decisões estatísticas (Tukey, 1977) ou por decisões de especialistas (Howard and Matheson, 1983).

Nos passos 2 e 3, a seleção da ordem das variáveis pode ocasionar problemas no que concerne a relação de independência condicional entre elas. Por exemplo, a escolha da ordem $(j, g, s, i, f)$ para o problema de detecção de fraude resultaria em uma rede completamente conectada (pior caso), o que seria equivalente à manipulação da DPC das variáveis do domínio. Deste modo, a escolha deve ser baseada no relacionamento causal entre as variáveis, que corresponde a proposição de independência condicional (expressada pela Equação 3.14) entre elas. Em geral, a construção de uma rede Bayesiana se baseia no relacionamento de causa e efeito entre as variáveis (Heckerman, 1997). Por exemplo, dada a proposição de que a fraude é uma causa direta da compra de gasolina, e fraude. idade e sexo a causa direta da compra de jóias, obteve-se a rede da Figura 3.4. 
Esse processo de construção considera apenas o conhecimento prévio (ou de fundo) do domínio. Em outra palavras, a rede deve ser concebida por intermédio da interação com o especialista do domínio. Essa interação tem a finalidade de identificar os relacionamentos entre as variáveis de interesse, para em seguida codificá-los na rede. Por exemplo, o especialista no problema da deteç̧ão de fraude pode identificar a influência direta que a idade exerce sobre a aquisição de jóias e até mesmo quantificar essa dependência (através dos valores de probabilidades condicionais). A seguir será mostrado o aprendizado ${ }^{1}$ da estrutura e das probabilidades condicionais (TPCs) de uma rede Bayesiana a partir de dados.

\subsection{Aprendizado de Redes Bayesianas}

Segundo Dietterich, o processo de aprendizado de redes Bayesiana consiste de três passos: (1) seleção da estrutura da rede Bayesiana, (2) especificação da forma de distribuição de probabilidades de cada nó da rede, e (3) ajuste (atualização) dos valores dessas probabilidade a partir de um conjunto de dados de treinamento. Na maioria dos métodos (algoritmos) Bayesianos correntes os passos (1) e (2) são realizados pelos usuários desse método² (ou previamente estabelecido pelo algoritmo), e o passo (3) é realizado pelo método de aprendizado (Dietterich, 1997).

Para um melhor entendimento desse processo, considere o exemplo de detecção de fraude em compras com cartão de crédito mostrado na Figura 3.4. Primeiramente, a rede Bayesiana que representa as relações entre as variáveis desse problema é especificada, por exemplo, pelo usuário. Em seguida, é necessário que seja especificado como a distribuição de probabilidade de cada nó será representada. No caso do problema da detecção de fraude, as variáveis foram "discretizadas" em um pequeno número de valores para que cada distribuição de probabilidade possa ser representada em uma tabela (TPC), por exemplo, idade foi "discretizada" dentro dos valores $(\leq 30,30-50, \geq 50)$.

Finalmente, o algoritmo tenta estimar as probabilidades (parâmetros) da TPC baseado no conjunto de dados de treinamento. Por exemplo, a célula $P(i \leq 30)$ da TPC da variável

\footnotetext{
${ }^{1}$ Neste trabalho, o termo aprendizado será utilizado quando a construção da rede Bayesiana for realizada por intermédio de algum algoritmo de aprendizado, a partir de dados.

${ }^{2}$ Os usuários do método podem representar a interação entre o analista, usuário final e o especialista do domínio, no caso do processo de KDD.
} 
$i$ pode ser simplesmente calculada a partir do número de clientes do conjunto de dados de treinamento que tenham idade igual ou inferior a 30 anos. $O$ parâmetro $P(j=\operatorname{sim} \mid f=$ $\operatorname{sim}, i \leq 30, s=$ feminino) pode ser computado por intermédio da fração dos exemplos de treinamento onde a compra seja uma fraude, a idade do cliente seja igual ou inferior a 30 anos e o sexo seja feminino e que tenha comprado jóias nas últimas $24 \mathrm{~h}$. Tecnicamente estas são as estimativas de Máxima Verossimilhança de cada um dos parâmetros da rede Bayesiana.

Um ponto que merece ser destacado no processo de aprendizado de redes Bayesianas é se todos os valores de variáveis devem ser observadas (não há valores de atributos ausentes) no conjunto de dados de treinamento ou se algumas não devem ser consideradas (Michell, 1997). A seguir será apresentado o aprendizado de redes Bayesianas considerando dois aspectos. Primeiro que a estrutura da rede Bayesiana (com o conhecimento prévio do domínio) deve ser fornecida a priori e, segundo, que todos os valores de variáveis devem ser diretamente observados no conjunto de dados (os dados são completos).

\subsubsection{Aprendizado das Probabilidade em Redes Bayesianas}

No caso em que a estrutura da RB é dada, o aprendizado se resume à atualização das tabelas de probabilidades condicionais dos nós dessa rede, caso as variáveis que eles representem sejam discretas ${ }^{3}$ ou através de uma função de distribuição de probabilidade, no caso das variáveis serem contínuas (Buntine, 1996).

Para uma melhor compreensão do aprendizado das probabilidades das TPCs de uma rede Bayesiana qualquer, considere uma rede definida a partir de um conjunto de variáveis discretas $\mathrm{X}=\left\{X_{1}, X_{2}, \ldots, X_{n}\right\}$ e por um modelo (estrutura) $M$ (fornecido a priori) de rede Bayesiana, que especifica as dependências condicionais dos elementos de $\mathbf{X}$. Considere ainda que cada variável $X_{i}$ possui um conjunto finito de estados (valores) $c_{i}$ e que podem possuir um conjunto de variáveis pais (nós-pais) $P a_{i}$, as quais podem assumir valores $q_{i}$. $\mathrm{O}$ modelo $M$ produz, a partir da Equação 3.12, uma fatorização da DPC de um conjunto de valores (um exemplo do conjunto de dados) das variáveis de $\mathrm{X}\left(x_{k}=\left\{X_{i k}, \ldots, X_{n k}\right\}\right.$ ) do seguinte modo:

\footnotetext{
${ }^{3}$ Neste trabalho será enfatizado o aprendizado de redes Bayesianas com nós discretos.
} 


$$
P\left(X=x_{k}\right)=\prod_{i=1}^{n} P\left(X_{i}=x_{i k} \mid P a_{i}=p a_{i j}\right)
$$

no qual $p a_{i j}$ denota o estado de $P a_{i}$ em $x_{k}$.

Suponha agora que seja fornecido um conjunto de dados contendo $n$ exemplos (casos) $D=\left\{x_{i}, \ldots, x_{n}\right\}$. A tarefa básica de um método de aprendizado, dada uma estrutura de rede Bayesiana $M$, é estimar, a partir de $D$, as probabilidades condicionais das TPCs de cada um dos nós de $M$. Estas probabilidades condicionais serão consideradas como parâmetros desconhecidos $\theta=\left(\theta_{i j k}\right)$ (no qual $\theta_{i j k}=P\left(x_{i k} \mid p a_{i j}, \theta\right)$ ) e $\theta_{i j}=\left(\theta_{i j 1}, \ldots, \theta_{i j c_{i}}\right.$ ) é o vetor de parâmetros (probabilidades condicionais da TPC de um nó) associados com a distribuição condicional $X_{i} \mid p a_{i j}$, inferido a partir de $D$.

Na Figura 3.5 é mostrado um exemplo de uma rede Bayesiana definida por $X=$ $\left\{X_{1}, X_{2}, X_{3}\right\}$ e $c_{i}=2$ para $i=1,2,3$. O grafo, dado a priori, codifica a independência condicional de $X_{1}$ e $X_{2}$ e determina que ambos são pais de $X_{3}$. Desta forma, $P a_{3}$ possui quatro valores $p a_{i j}$ correspondente as quatro combinações de estados de $X_{1}$ e $X_{2}$ (para simplificar, esse valores serão denotados como $\left.p a_{31}=(1,1), p a_{32}=(1,2), p a_{33}=(2,1), p a_{34}=(2,2)\right)$. Assim, seis parâmetros (valores das TPCs) independentes $\theta=\left(\theta_{1}, \theta_{2}, \theta_{31}, \theta_{32}, \theta_{33}, \theta_{34}\right)$ quantificam a rede Bayesiana, no qual $\theta_{11}=P\left(x_{11} \mid \theta\right), \theta_{21}=P\left(x_{21} \mid \theta\right)$, e $\theta_{3 j 1}=P\left(x_{31} \mid p a_{3 j}, \theta\right)$ para $j=1,2,3,4$. A partir desses parâmetros e considerando que os valores para cada linha das TPCs são coletivamente exaustivos, cuja soma das probabilidades é igual a 1 , os seguintes vetores de parâmetros são obtidos: $\theta_{1}=\left(\theta_{11}, 1-\theta_{11}\right), \theta_{2}=\left(\theta_{21}, 1-\theta_{21}\right)$, e $\theta_{31}=\left(\theta_{311}, 1-\theta_{311}\right), \theta_{32}=\left(\theta_{321}, 1-\theta_{321}\right), \theta_{33}=\left(\theta_{331}, 1-\theta_{331}\right), \theta_{34}=\left(\theta_{341}, 1-\theta_{341}\right)$.

Vários métodos de estimativas dos parâmetros $\theta_{i j k}$ podem ser encontrados na literatura (Heckerman, 1997), (Buntine, 1996). Dentre os mais utilizados, destaca-se o da Máxima Verossimilhança (Maximum Likelihood). Para entender este método considere $n\left(x_{i k} \mid p a_{i j}\right)$ a freqüência de ocorrência de $\left(x_{i k}, p a_{i j}\right)$ em um conjunto de dados $D$, e $n\left(p a_{i j}\right)=\sum_{k} n\left(x_{i k} \mid p a_{i j}\right)$ a freqüência de $p a_{i j}$. A distribuição de probabilidade condicional de um exemplo (caso) $x_{k}$ de $D$ pode ser expressa como uma função de $\theta_{i j k}$ da seguinte forma:

$$
P\left(x_{k} \mid \theta\right)=\prod_{=1}^{n} \theta_{i j k}
$$

Dessa forma, considerando os exemplos de $D$ independentes, a distribuição de probabilidade conjunta de $D$ é 


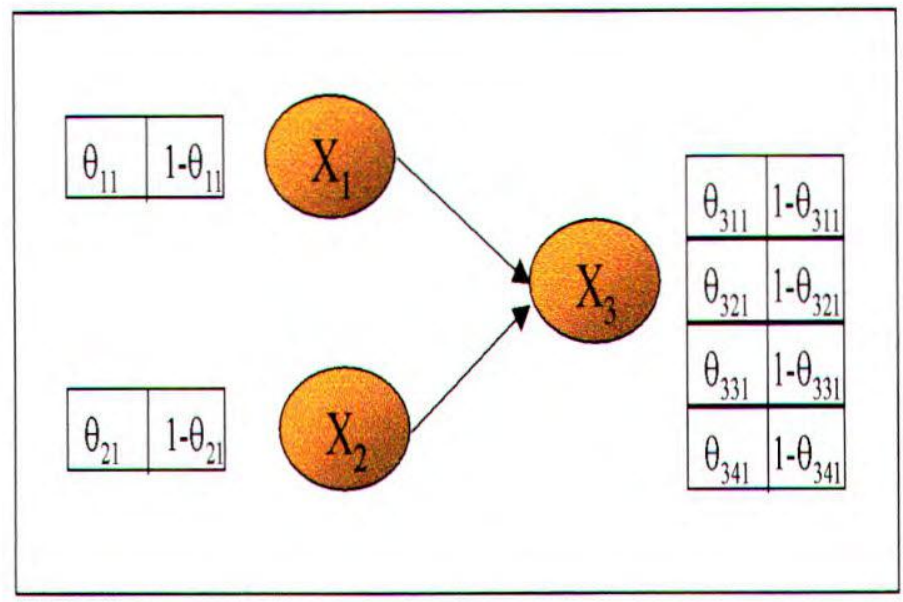

Figura 3.5: Parâmetros de uma rede Bayesiana (Ramoni and Sebastiani, 1997c).

$$
P(D \mid \theta)=\prod_{k=1}^{n} P\left(X_{k} \mid \theta\right)=\prod_{i=1}^{m} \prod_{j=1}^{q_{i}} \prod_{k=1}^{c_{i}} \theta_{i j k}^{x_{i} k \mid p a_{i j}}
$$

Esta equação é chamada de função de verossimilhança $l(\theta)$. A Máxima Verossimilhança representa, portanto, o cálculo dos valores dos parâmetros que maximizam $l(\theta)$. Geralmente, a estimativa de Máxima Verossimilhança para $\theta_{i j k}$ é representado pela freqüência dos casos relevantes do conjunto de dados: $\hat{\theta}_{i j k}=\frac{n\left(x_{i k} \mid p a_{i j}\right)}{n\left(p a_{i j}\right)}$.

O método da Máxima Verossimilhança pode apresentar dois problemas muito comuns, em se tratando de algoritmos de aprendizado: dados esparsos e overfitting. Para entender estes problemas considere um conjunto de dados $D$ (referente a rede Bayesiana da Figura 3.5), formado pelos exemplos mostrados na Tabela 3.2 .

\begin{tabular}{|c|c|c|c|}
\hline Exemplo & $X_{1}$ & $X_{2}$ & $X_{3}$ \\
\hline 1 & $\mathrm{~V}$ & $\mathrm{~F}$ & $\mathrm{~V}$ \\
\hline 2 & $\mathrm{~V}$ & $\mathrm{~V}$ & $\mathrm{~V}$ \\
\hline 3 & $\mathrm{~V}$ & $\mathrm{~V}$ & $\mathrm{~F}$ \\
\hline 4 & $\mathrm{~V}$ & $\mathrm{~F}$ & $\mathrm{~F}$ \\
\hline
\end{tabular}

Tabela 3.2: Conjunto de dados D.

O primeiro problema ocorre quando $\hat{\theta}_{i j k}=0$ se $n\left(x_{i k} \mid\right.$ paij $)=0$, por exemplo, $P\left(X_{3}=\right.$ $\left.V \mid X_{1}=F, X_{2}=V, \theta\right)$ não pode ser estimado, visto que não existe instâncias em $D$ cujo $X_{1}=F$. Segundo Buntine, para $n$ variáveis binárias e uma rede Bayesiana totalmente 
conectada (como no exemplo da Figura 3.5) são necessários mais do que $2^{n-1}$ exemplos em $D$ para que a Máxima Verossimilhança possa ser estimada (Buntine, 1996). Uma possível solução para o problema da manipulação de poucos exemplos no conjunto de dados é ajustar a probabilidade de uma determinada célula de acordo com suas "adjacentes" na TPC. Por exemplo, pode-se definir que $P\left(X_{3}=V \mid X_{1}=F, X_{2}=V\right)$ tenha um valor próximo de $P\left(X_{3}=V \mid X_{1}=V, X_{2}=V\right)$ da TPC do nó $X_{3}$. Além desse método, vários outros são propostos na literatura (Dietterich, 1997), (Michell, 1997).

Para entender o problema de overfitting, considere o cálculo da Máxima Verossimilhança para $P\left(X_{1}=V \mid \theta\right)$. O resultado será igual a 1,0 , pois em todos os exemplos $X_{1}=V$. Uma solução para esse problema seria imaginar que, como esse parâmetro $P\left(X_{1}=V \mid \theta\right)=$ 1,0 foi baseado em apenas 4 casos, parece razoável que o "verdadeiro" valor deva ser, por exemplo, em torno de 0,9 , e por acaso ocorreu de $X_{1}$ ser a igual a $V$ em todos os exemplos. Portanto, a estimativa 1, 0 deveria ser entendida como o limite superior de probabilidade. Por definição, o valor de Máxima Verossimilhança $\left(1,0^{4}\right)$ representa um valor superestimado da verdadeira verossimilhança dos dados $\left(0,9^{4}\right)$. Quando isso ocorre diz-se que ouve overfitting nos dados (Buntine, 1996). De acordo com a Teoria da Máxima Verossimilhança, à medida que a amostra de dados vai aumentando a superestimação vai gradualmente convergindo para o "verdadeiro" valor da verossimilhança dos dados (para um estudo mais aprofundado da Teoria de Máxima Verossimilhança veja (Casella and Berger, 1990)).

Vale ressaltar que as possíveis soluções para o problema de overfitting nos dados são muito estudadas pela comunidade de Aprendizado de Máquina, haja vista que se trata de um dos problemas mais comuns em se tratando de aprendizado supervisionado. Um exemplo dessas soluções seriam os métodos de poda para árvores de decisão (Quinlan, 1993).

Um outro modo de calcular os parâmetros das TPCs de uma rede Bayesiana é conhecida como Maximum a Posteriori (MAP) e representa uma extensão da Máxima Verossimilhança. A MAP, que é um dos métodos mais utilizados pelos algoritmos de aprendizado de redes Bayesianos, permite incorporar informações a priori (conhecimento de fundo) dos parâmetros $\theta_{i j k}$ antes dos exemplos de $D$ serem vistos. Dessa forma, o aspecto central desse método é considerar $\theta_{i j k}$ como uma variável randômica, cuja a probabilidade a priori representa o grau de crença do observador (especialista) sobre as probabilidades condicionais das TPCs da rede Bayesiana, desconsiderando os dados. O método de aprendizado de redes Bayesiana, então, usa esses dados para atualizar as crenças a priori usando a regra de Bayes, da seguinte forma: 


$$
P(\theta \mid D)=\frac{P(\theta) P(D \mid \theta)}{P(D)}
$$

No qual $P(D)$ é calculado do seguinte modo:

$$
P(D)=\int P(D \mid \theta) P(\theta) d \theta
$$

Um estudo deste método e algumas extensões do mesmo podem ser encontrados em (Ramoni and Sebastiani, 1997c), (Heckerman, 1997).

Nesta seção a estrutura da rede Bayesiana foi considerada a priori. Dessa forma, o aprendizado se resumiu ao cálculo das probabilidades das TPCs a partir dos dados. $\mathrm{Na}$ próxima seção será considerado o aprendizado de ambos - a estrutura e as probabilidades condicionais de um rede Bayesiana.

\subsubsection{Aprendizado da Estrutura de Redes Bayesianas}

O aprendizado da estrutura de redes Bayesianas pode ser entendido como encontrar uma estrutura que codifique a DPC para um conjunto de variáveis aleatórias $\mathbf{X}$, dado um conjunto de dados D. Isto é, encontrar uma estrutura, em um possível espaço de hipóteses de estruturas $S^{h}$, avaliando as probabilidades a priori das hipóteses $S^{h}-P\left(S^{h}\right)$. Então, dado um conjunto de dados $D$, calcular as probabilidades condicionais que maximizam $P\left(S^{h} \mid D\right)$ (estrutura) e $P\left(\theta_{i j k} \mid D, S^{h}\right)$ (probabilidade condicionais das TPCs dos nós da estrutura da rede Bayesiana $\left.S^{h}\right)$.

O cálculo de $P\left(\theta_{i j k} \mid D, S^{h}\right)$ pode ser realizado como foi descrito na subseção 3.6.1. O cálculo de $P\left(S^{h} \mid D\right)$ pode ser feito por intermédio da Regra de Bayes (Equação 3.6) da seguinte maneira:

$$
P\left(S^{h} \mid D\right)=\frac{P\left(S^{h}\right) P\left(D \mid S^{h}\right)}{P(D)}
$$

Sendo que $P(D)$ é independente da estrutura $S^{h}$. Dessa forma, para determinar a distribuição de probabilidade condicional das possíveis estruturas, é necessário calcular a verossimilhança marginal dos dados $\left(P\left(D \mid S^{h}\right)\right)$ para cada estrutura (considerando a probabilidade a priori $P\left(S^{h}\right)$ de cada uma das estruturas) e então determinar a estrutura que codifica a DPC para $\mathbf{X}$ baseado nos valores máximos de verossimilhança. Este método. conhecido como abordagem Bayesiana completa (por considerar todos as possíveis estruturas 
de rede Bayesiana do espaço de hipóteses), é freqüentemente inviável (Heckerman, 1997). Por exemplo, para se ter uma idéia, o espaço de hipóteses das estruturas das redes Bayesianas para um conjunto formado por apenas três variáveis $A, B$ e $C$ é formado por 25 diferentes estruturas. Na Figura 3.6 são mostradas algumas dessa estruturas.

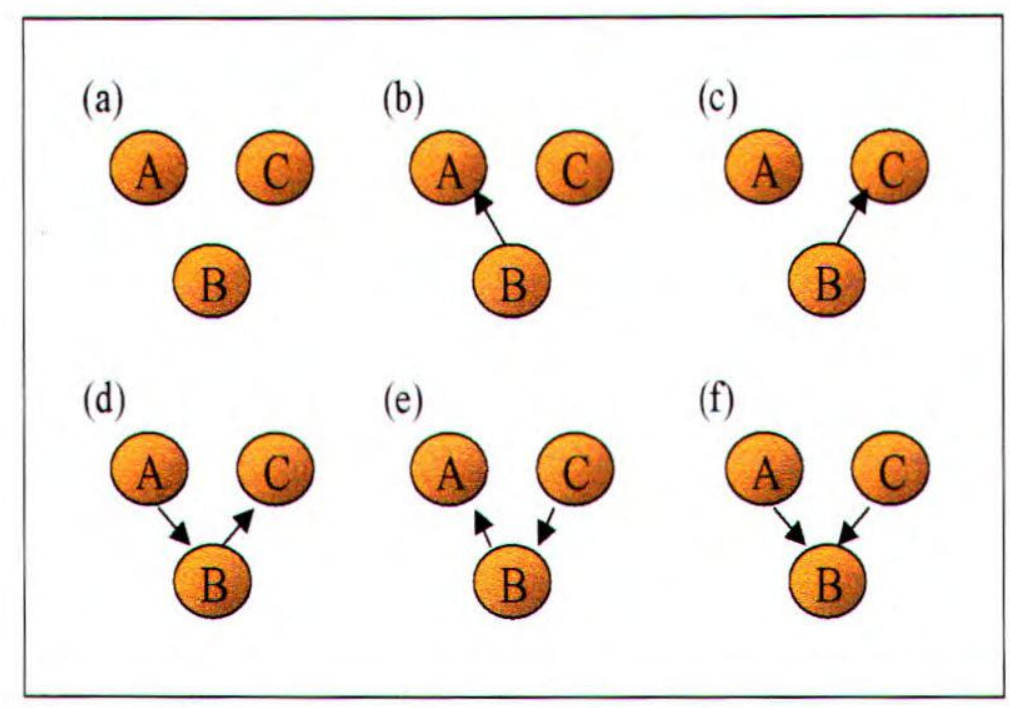

Figura 3.6: Algumas estruturas possíveis de redes Bayesianas para as variáveis A, B e C.

Em problemas com um grande número de variáveis a serem consideradas é necessário o uso de outras abordagens. Entre as mais referenciadas na literatura e mais utilizadas pelos métodos de aprendizado de redes Bayesianas, destaca-se a abordagem de Seleção do Modelo. Para o estudo de outras abordagens veja (Madigan and Raftery, 1994).

A tarefa básica da Seleção do Modelo é selecionar um modelo "bom" (i.e. uma "boa" hipótese de estrutura) a partir dos modelos possíveis e considerá-lo como se fosse o modelo "correto". Esta abordagem pode suscitar várias questões:

- É possível obter resultados precisos na seleção do modelo com essa abordagem?

- Como decidir se o modelo é "bom" ou não?

- Como encontrar modelos "bons"?

A questão da precisão é difícil de ser respondida. No entanto, várias pesquisas mostram experimentalmente que a seleção de um único modelo "bom" freqüentemente produz resultados bastante satisfatórios (Cooper and Herskovits, 1992), (Heckerman et al., 1995). 
Quanto a segunda questão, é necessário estabelecer algum critério para medir o grau em que uma determinada estrutura de rede Bayesiana combina adequadamente o conhecimento de fundo (estrutura da rede fornecida pelo especialista) com o conhecimento embutido nos dados. Um modelo bastante utilizado é o da probabilidade condicional relativa, calculada do seguinte modo:

$$
\log P\left(D, S^{h}\right)=\log P\left(S^{h}\right)+\log P\left(D \mid S^{h}\right)
$$

Como pode ser observado na Equação 3.21, esse critério possui dois componentes: o $\log$ a priori $\left(\log P\left(S^{h}\right)\right)$ e o log de verossimilhança marginal $\left(\log P\left(D \mid S^{h}\right)\right)$.

Várias métodos são encontrados na literatura para o cálculo de $\log P\left(S^{h}\right)$. O caso mais simples considera qualquer hipótese de $S^{h}$ igualmente comum (não considerando, portanto, o valor de $\log P\left(S^{h}\right)$ para o cálculo de $\log P\left(D, S^{h}\right)$ ). Um outro método, proposto por Heckerman, usa uma estrutura de rede dada a priori (conhecimento de fundo). A idéia básica deste método é penalizar a probabilidade $\left(P\left(S^{h}\right)\right)$ de cada estrutura de acordo com alguma medida de desvio entre uma determinada estrutura e a rede considerada a priori (Heckerman et al., 1995).

Segundo Dawid, o cálculo do $\log P\left(D \mid S^{h}\right)$ poderia ser feito utilizando a Equação 3.22:

$$
\log P\left(D \mid S^{h}\right)=\sum_{e=1}^{n} \log P\left(x_{e} \mid x_{1}, \ldots, x_{e-1}, S^{h}\right)
$$

O termo $P\left(x_{e} \mid x_{1}, \ldots, x_{e-1}, S^{h}\right)$ é a predição para $x_{e}$ feita para o modelo $S^{h}$. O modelo com maior log de verossimilhança marginal $\left(\log P\left(D \mid S^{h}\right)\right)$, considerando as probabilidades a priori das estruturas iguais, representa um "bom" modelo de estrutura para o conjunto de $\operatorname{dad}$ os $D$ (Dawid, 1984).

Finalmente, com relação a terceira pergunta, várias pesquisas têm sido direcionadas para o uso de algoritmos de busca heurística para encontrar uma boa estrutura a partir do espaço de hipótese de todas as possíveis estruturas de redes Bayesianas. Um exemplo desses algoritmos é o greedy search, que inicia com a escolha de uma estrutura qualquer de rede Bayesiana. Então, avalia o log de verossimilhança marginal (através, por exemplo, da Equação 3.22) para todas as possíveis mudanças $m$ (e.g. adicionar ou retirar uma seta da estrutura). Em seguida, realiza a mudança $m$ cujo o valor do log de verossimilhança marginal seja máximo. A busca é concluída quando não existe $m$ que proporcione um valor maior 
para o $\log$ de verossimilhança marginal. Este algoritmo é utilizado por vários métodos de aprendizado de redes Bayesianas como, por exemplo, o K2 (Cooper and Herskovits, 1992) e Bayesian Knowledge Discovery (Ramoni and Sebastiani, 1997c).

Para ilustrar o aprendizado da estrutura de redes Bayesiana, considere o exemplo do K2. Este método, proposto Cooper e Herskovits, aprende estruturas de redes Bayesianas a partir de um conjunto de dados completo, cuja ordem das variáveis deve ser fornecida pelo usuário desse método. O K2 adota um método para calcular (selecionar) a estrutura com máxima verossimilhança e um algoritmo de busca para encontrá-la (aproximadamente). Essa busca é iterativa e inicia com uma estrutura de rede bem simples, onde todas as variáveis são independentes uma das outras. Em seguida são avaliadas as verossimilhanças marginais de cada rede resultante de possíveis mudanças (e.g. adicionar uma nova ligação entre dois nós dessa rede), e então é aplicada a melhor das alterações antes de uma nova iteração. Esse processo continua até que o algoritmo não consiga encontrar nenhuma alteração simples que melhore (aumente) o valor de máxima verossimilhança (Cooper and Herskovits, 1992).

Os métodos discutidos nessa seção consideram o processo de aprendizado de redes Bayesianas a partir de um conjunto de dados completos, ou seja, todos os valores das variáveis utilizadas no processo devem ser observados. No próximo capítulo é mostrado o problema da manipulação de dados incompletos, bem como alguns métodos para tratar esse problema.

Após a construção da rede (a partir do conhecimento fundo do domínio, dos dados ou da combinação de ambos), são necessários mecanismos de inferência para computar as eventuais probabilidades de interesse. Na próxima seção são apresentados alguns tipos de inferência em redes Bayesianas.

\subsection{Inferência em Redes Bayesianas}

A tarefa básica de um sistema de aprendizado probabilístico é calcular a distribuição de probabilidade condicional de um conjunto de variáveis, dado o valor de um conjunto de variáveis de evidências. Por exemplo, no problema da detecção de fraude (Figura 3.4), podese desejar conhecer a probabilidade de ocorrer determinada fraude, dada as evidências de compra de gasolina nas últimas 24 horas e o sexo do comprador. Como essa probabilidade não está diretamente armazenada na rede Bayesiana, é necessário computá-la. O cálculo de probabilidades de interesse em uma rede Bayesiana é geralmente conhecida como inferência 
probabilística (Michell, 1997).

A princípio, uma rede Bayesiana pode ser usada para calcular a distribuição probabilística para qualquer subconjunto de variáveis, dado os valores ou distribuição de qualquer subconjunto das variáveis restantes. A razão disso, conforme já foi apresentado na seção 3.5, é que as redes Bayesianas determinam a distribuição de probabilidade conjunta de todas as variáveis representadas por ela.

Vários métodos de inferência probabilística têm sido propostos na literatura para redes Bayesianas com variáveis discretas. Por exemplo, Shatcher desenvolveu um algoritmo de propagação orientado a metas capaz de realizar uma absorção incremental de evidência. ou seja, dada uma ou mais evidências, o algoritmo atualiza as probabilidades de cada um dos nós restantes (que não sofreram evidências) da rede (Shatcher, 1988). Uma versão atualizada desse algoritmo é implementada pelo Bayesian Knowledge Discovery (Ramoni and Sebastiani, 1997b). Jensen criou um algoritmo que transforma a rede Bayesiana em uma lista de nós (chamada de árvore de junção), com os seus respectivos estados e probabilidades marginais (Jensen et al., 1990). Um exemplo desse tipo de inferência probabilística pode ser realizado por intermédio do Hugin (Andersen et al., 1989), que implementa esse algoritmo. Considerando a rede Bayesiana de detecção de fraude em compras com cartão de crédito da Figura 3.4, qual seria a probabilidade de ocorrer fraude dada a ocorrência da compra de jóias por uma pessoa que tenha menos de 30 anos? Na Figura 3.7 é apresentada essa situação, executada no ambiente Hugin.

Dessa forma, a probabilidade da ocorrência de fraude seria de 1,64\%. Outra extensão implementada no Hugin é a identificação da configuração mais provável dos valores das variáveis de uma rede Bayesiana (Jensen, 1994). Para entender esta tarefa, considere o exemplo anterior. Qual seria a máxima configuração das variáveis da rede Bayesiana de detecção fraude, dada a evidência de ocorrência da compra de jóias? Na Figura 3.8 é apresenta essa situação no Hugin.

Portanto, a máxima configuração (valores das variáveis que apresentam probabilidade igual a 100) para essa situação seria Fraude $=$ não, Gasolina $=$ não, Idade $\geq 50$ e Sexo $=$ Feminino.

Os métodos de inferência probabilística propostos na literatura para redes Bayesianas com variáveis contínuas incluem métodos exatos e aproximados de inferência. Métodos de inferência exatos que codificam a distribuição Gaussiana-Multivariada ou Combinação- 


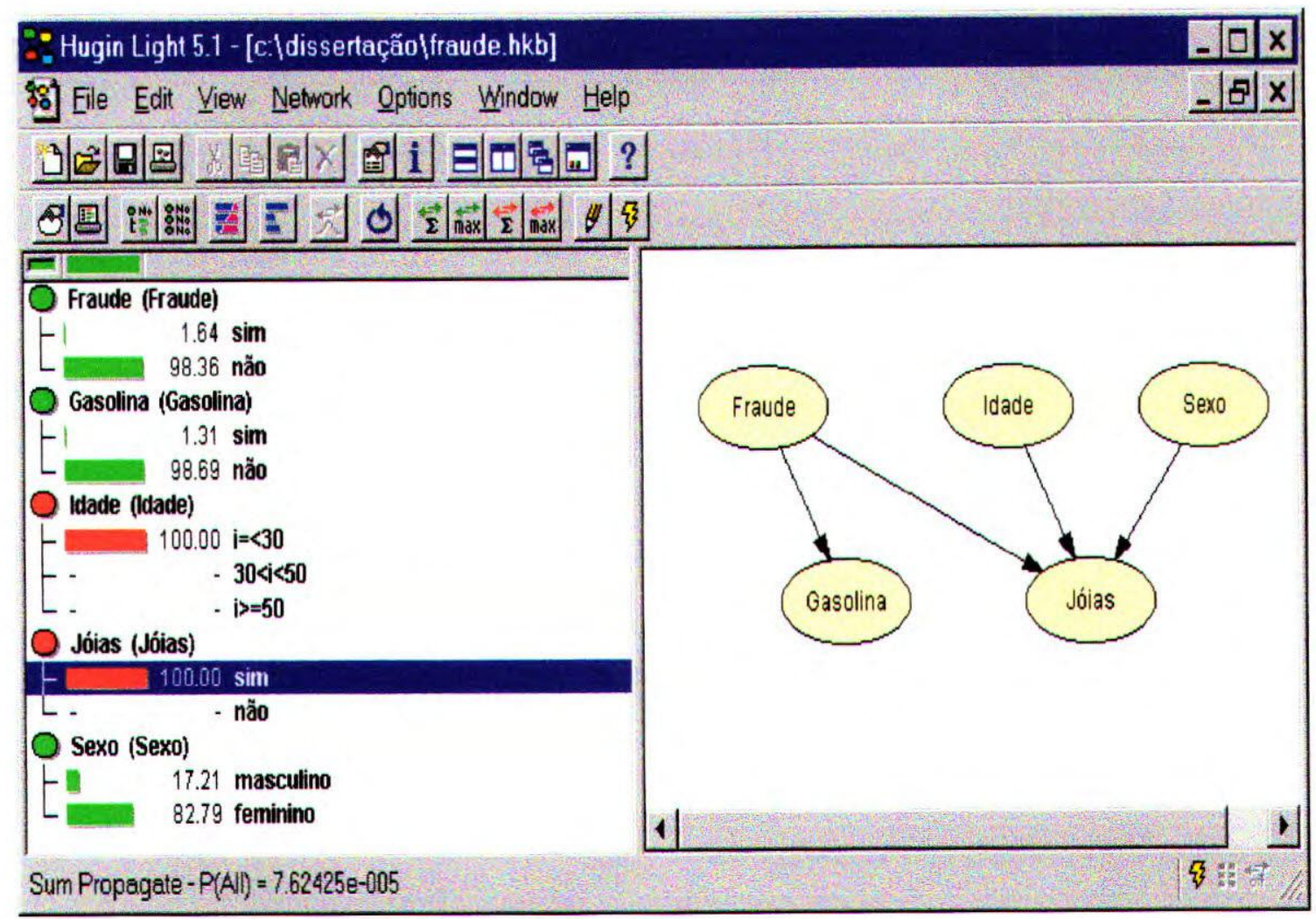

Figura 3.7: Exemplo de inferência utilizando o Hugin.

Gaussiana têm sido desenvolvidos por Shachter e Kenley (Shatcher and Andersen, 1989), e Lauritzen (Lauritzen, 1992), respectivamente. A maioria destes métodos usam o conceito de independência condicional para simplificar o cálculo de probabilidades de interesse.

Os métodos aproximados de inferência em uma rede Bayesiana sacrificam a precisão para poderem ganhar em eficiência. Por exemplo, o método Monte Carlo estabelece uma solução aproximada para amostragem randômica da distribuição de variáveis não observadas. 


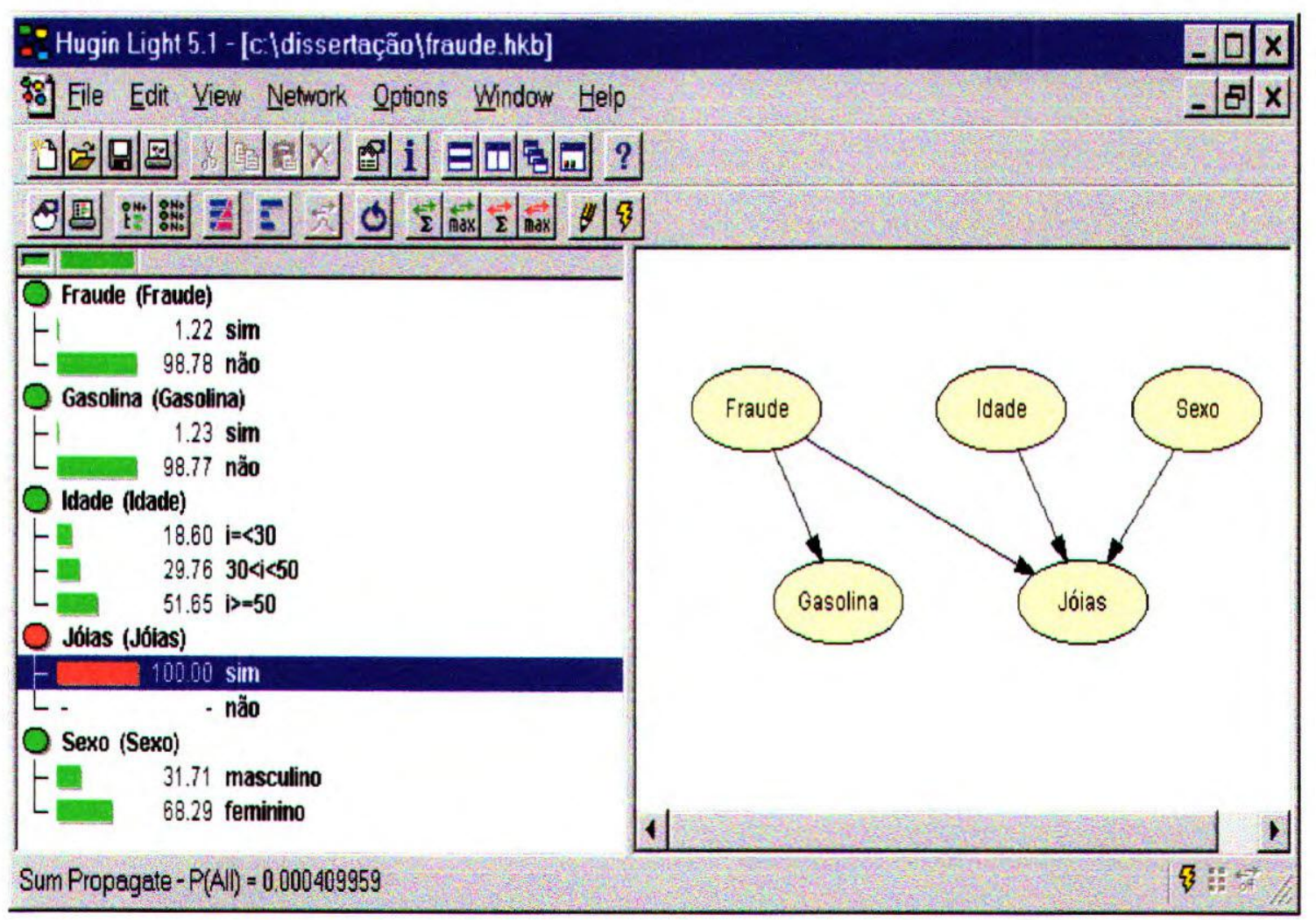

Figura 3.8: Exemplo do cálculo da configuração mais provável.

\subsection{Considerações Finais}

As redes Bayesianas podem ser entendidas como modelos que codificam os relacionamentos probabilísticos entre as variáveis que representam um determinado domínio. Esses modelos podem ser vistos como uma composição de dois aspectos: qualitativo e quantitativo. Na Figura 3.9 é mostrado um esquema geral dessa composição.

A observação desses dois aspectos propiciam uma representação eficiente da DPC do conjunto de variáveis de uma determinada aplicação. Isto se deve a redução substancial do número de probabilidades a serem manipuladas. Por exemplo, em uma rede com n nós (booleanos), onde cada um desses nós não possue mais que $k$ nós-pais, a ordem do número de valores de probabilidade a serem tratados pela rede Bayesiana seria $O\left(n 2^{k}\right)$, ao invés de $O\left(2^{n}\right)$ da DPC. Vale ressaltar que, apesar dessa redução, o número de valores de probabilidades é considerável em se tratanto de domínios com uma grande quantidade de variáveis a serem 


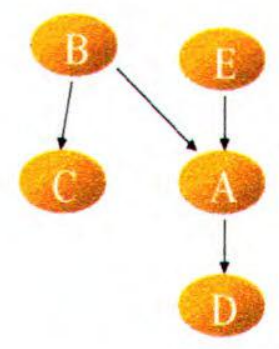

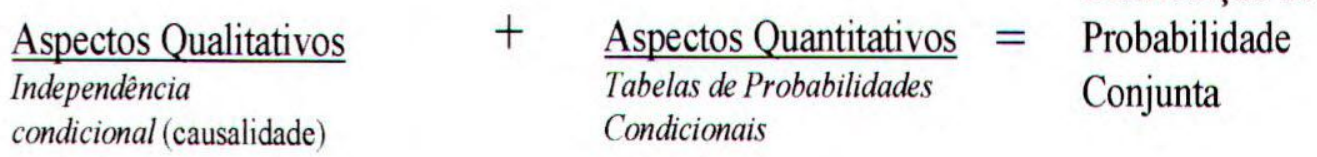

Grafo aciclico

- nós: variáveis randômicas (estados

mutuamente exclusivos e coletivamente

exaustivos)

- setas: influência direta (causal)

Figura 3.9: Aspectos qualitativo e quantitativo das redes Bayesianas.

manipuladas.

Vale lembrar que os aspectos que compõem a semântica das RBs facilitam, dada a inerente representação causal dessas redes, o entendimento e o processo de tomada de decisão, por parte dos usuários desses modelos. Isto se deve, principalmente, ao fato de que as relações (de dependência ou independência) entre as variáveis do domínio podem ser visualizadas graficamente, bem como a quantificação, em termos probabilísticos, dos efeitos dessas relações.

A construção (ou aprendizado) das redes Bayesianas pode ser realizada utilizando apenas o conhecimento prévio do domínio, a partir dos dados ou da combinação de ambos. Na Figura 3.10 pode ser visualizado um esquema ilustrativo do processo de aprendizagem de redes Bayesianas.

Uma das principais características desse processo de aprendizado é que o tratamento e/ou as inferências não são realizadas sobre as "classes", como ocorre, por exemplo, com o aprendizado supervisionado. Desse modo, é possível fazer qualquer tipo de inferência sobre as RBs, visto que as variáveis são tratadas de maneira indiscriminada. Essa inferência é 


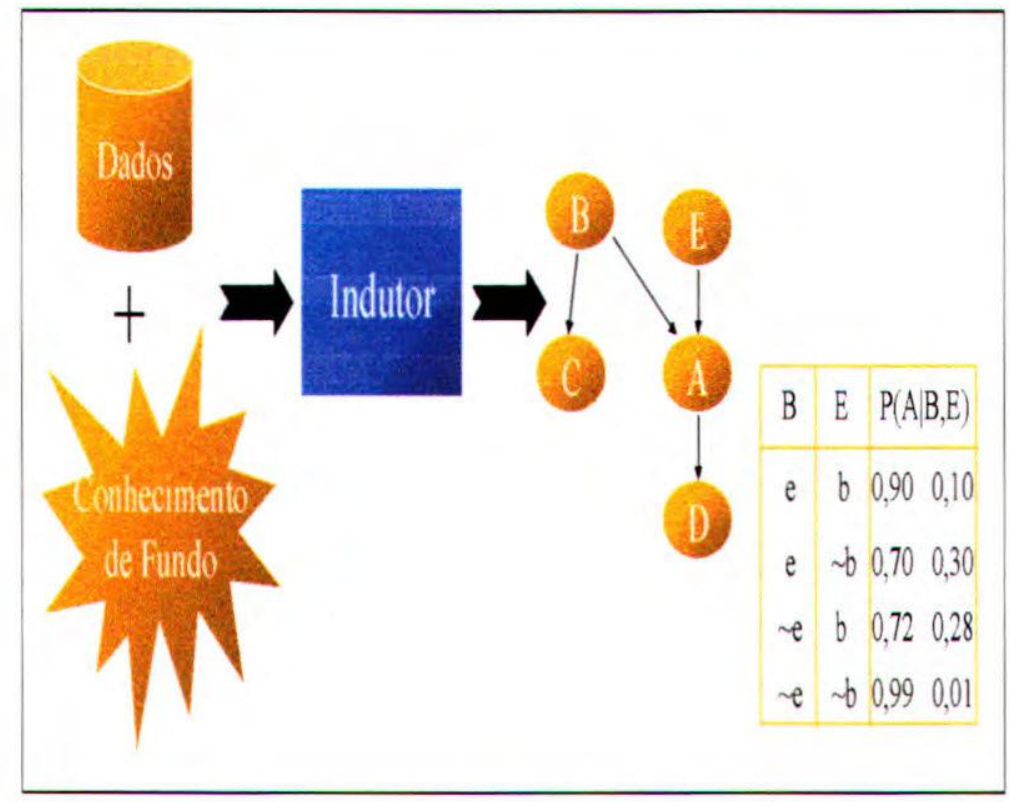

Figura 3.10: Aprendizado de redes Bayesianas.

freqüentemente realizada por intermédio de um algoritmo de propagação que, dada uma ou mais evidências, atualiza as probabilidades de cada uma das variáveis (nós) restantes da rede.

O fato de uma RB poder ser construída a partir, e tão somente, do conhecimento prévio do domínio mostra o potencial da semântica desse modelo para a incorporação de conhecimento de fundo. Além dessa propriedade, cabe destacar os mecanismos para evitar overfitting e o tratamento de dados incompletos, que será tratado no próximo capítulo. 


\section{Capítulo 4}

\section{Tratamento de Dados Incompletos}

\subsection{Considerações Iniciais}

Conforme foi visto na subseção 2.5.3, é muito freqüente a ausência de alguns valores de atributos (dados incompletos) em bases de dados reais. Para o tratamento desses valores devem ser considerados vários aspectos, entre os quais se destacam:

- Etapa do processo de KDD na qual o tratamento será realizado.

- Mecanismo de geração dos valores ausentes.

- Paradigma e tipo de aprendizado utilizados.

O tratamento de valores ausentes pode ser realizado tanto na etapa de Seleção e Preparação dos Dados quanto na etapa de Data Mining ${ }^{1}$. Na etapa de Seleção e Preparação dos Dados, os valores ausentes podem ser simplesmente desconsiderados (Figura 4.1) ou serem tratados através de técnicas estatísticas padrão para encontrar os valores ausentes com base nos valores conhecidos na base.

Vale ressaltar que os valores ausentes, tratados neste trabalho, são aqueles que não foram coletados quando os exemplos (registros) foram observados. Entretanto, há pelo menos mais dois tipos que, apesar de não serem manipulados nesse trabalho, é importante mencionar: Don't care - os valores não são observados porque eles são considerados irrelevantes para este caso e Informative Missing - o valor está ausente mas essa ausência representa uma informação importante (e.g. um número de telefone ausente pode indicar que a pessoa não

\footnotetext{
${ }^{1}$ Este trabalho enfatizará o tratamento de dados incompletos na etapa de Data Mining.
} 


\begin{tabular}{|c|c|c|c|c|c|c|c|}
\hline Paciente & Tenperative & Ibate & PesO & $\begin{array}{l}\text { Pressio do } \\
\text { Sangue }\end{array}$ & Sexo & $\begin{array}{l}\text { Tatede } \\
\text { Sargue }\end{array}$ & Diagnánstico \\
\hline 3060 & & 25 & & & & & fourtor \\
\hline 83877 & 36,7 & 62 & 62 & 145 & $F$ & Negatitio & Donap B \\
\hline 2344 & 37,4 & 4 & 102 & 161 & M & Negadivo & Sartioned \\
\hline 09362 & 39,5 & 50 & 65 & $|3|$ & $\mathrm{F}$ & Negativio & Doang A \\
\hline tasts & $\frac{61,2}{60,2}$ & & & 10 & & foustoro & Odautentit \\
\hline
\end{tabular}

Figura 4.1: Exemplo de um conjunto de dados, desconsiderando os exemplos com valores ausentes.

possui telefone). Assim, o valor ausente pode corresponder a um valor de atributo adicional (e.g. Fone $=$ sem_telefone).

O tratamento dos valores ausentes na etapa de Data Mining será apresentado ao longo deste capítulo, o qual está dividido do seguinte modo. Na próxima seção, são abordados os mecanismos de geração de valores ausentes. Na seção 4.3, são mostrados alguns métodos para o tratamento de dados incompletos, considerando o paradigma e o tipo de aprendizado de máquina utilizados na etapa de Data Mining. Na seção 4.4, são apresentados algoritmos para estimativa de dados incompletos. Na seção 4.5 , que representa a ênfase deste trabalho no tratamento de dados incompletos, são focalizados métodos para o aprendizado de redes Bayesianas. Por último, na seçāo 4.6, são feitas algumas considerações finais a respeito dos assuntos contemplados neste capítulo.

\subsection{Mecanismos de Geração dos Valores Ausentes}

O efeito dos valores ausentes sobre a representatividade de uma amostra pode assumir padrões de acordo como esses dados ausentes estão distribuídos nessa amostra. Esses padrões podem ser entendidos como mecanismos de geração dos valores ausentes (Ghahramani and Jordan, 1994), (Ramoni and Sebastiani, 1997a). Para entender os tipos desses mecanismos, que serão apresentados a seguir, considere um conjunto de dados composto pelos valores de duas variáveis discretas $X$ e $Y$, em que $X$ é sempre observada e $Y$ está sujeita a não assumir valores (missing values). Considere, ainda, um valor ausente denotado por $Y=$ ? e 
um exemplo incompleto por $\left(X=x_{i}, Y=\text { ? }\right)^{2}$.

O tipo dos mecanismos de geração dos valores ausentes é determinado pela probar bilidade de $Y=$ ? depender dos valores de $Y$ e/ou $X$. Se esta probabilidade depende de $X$, mas não depende de $Y$, então os dados ausentes são chamados de missing at random (MAR), e os valores observados de $Y$ não são representativos da amostra como um todo, mas o são quando considerados como categorias de $X$. Um caso especial desta situação é realizada quando a probabilidade de $Y=$ ? não é dependente de $Y$ nem de $X$. Nesse caso, os dados ausentes são gerados pelo mecanismos de missing completely at random (MCAR) e os valores observados de $Y$ são uma sub-amostra representativa da amostra completa, mas não conhecida na amostra original, já que entradas observadas, ou não, são geradas pelo mesmo mecanismo. Quando a probabilidade de $Y=$ ? depende de ambos, $X$ e $Y$, diz-se que o mecanismo de dados incompletos é não ignorável (NI), e a amostra incompleta não é mais representativa da amostra original (Ramoni and Sebastiani, 1997a).

A classificação dos mecanismos de geração de dados incompletos fornecem um poderoso meio de entender o comportamento de amostras incompletas mas, infelizmente, essa classificação deixa em aberto o problema de como manipular os valores ausentes, visto que, desconsiderar o mecanismo de dados incompletos não implica que os valores ausentes sejam ignorados. Algumas abordagens para o tratamento de dados incompletos serão apresentadas na próxima seção.

\subsection{Métodos para o Tratamento de Dados Incompletos}

Em muitos domínios de aplicação, as bases de dados são freqüentemente incompletas, ou seja, alguns valores de atributos estão ausentes. A falta desses valores pode causar uma série de problemas para programas de computadores cuja operação é baseada nessas bases de dados. Em particular, o tratamento desse problema é importante para a comunidade de Aprendizado de Máquina e Data Mining (Fayyad, 1996), as quais se propõem a construir programas para extrair conhecimento a partir de dados. Vale ressaltar que o problema de

\footnotetext{
${ }^{2}$ Este modelo com apenas duas variáveis pode facilmente ser estendido para casos mais gerais, em que um conjunto de variáveis sempre observadas afeta uma variável que apresente valores ausentes. Este cenário é bastante comum em algumas aplicações da estatística, como por exemplo, nos estudos prospectivos, experimentos controlados e aprendizado supervisionado em Aprendizado de Máquina.
} 
dados incompletos é também referenciado na literatura estatística (Little and Rubin, 1987).

Para o tratamento de dados incompletos, realizado na etapa de Data Mining, devem ser considerados, além do modo como esses dados ausentes ocorrem, o paradigma e o tipo de aprendizado que serão utilizados pelos algoritmos de DM. Neste trabalho, como forma de instanciar o problema do tratamento de dados incompletos, serão enfatizados o paradigma estatístico-Bayesiano (seção 4.5) e o paradigma simbólico, utilizando o aprendizado supervisionado, que será mostrado ao longo dessa seção.

Sob a luz do paradigma simbólico, o aprendizado de um classificador a partir de um conjunto de dados completos (que será chamado aqui de CDC) difere, fundamentalmente, do aprendizado de um classificador a partir de um conjunto de dados incompletos (referenciado nesse trabalho como CDI) pelo fato de os CDCs especificarem as condições necessárias e suficientes para cada classe. Dessa forma, os mesmos não são capazes de classificar categoricamente descrições (exemplo de um conjunto de dados) incompletas "ambiguas"3. Em contraste, CDIs podem propor "classificações default" para esses casos". Visto que essas "classificações default" podem mudar em função de informações adicionais desse objeto do domínio. Assim, os CDIs são capazes de exibir uma "classificação com comportamento não monotônico" (Reither, 1987). Esse tipo de "classificação com comportamento não monotônico" pode ser entendida como a não possibilidade do CDI classificar univocamente um objeto do domínio, visto que um valor de atributo ausente, desse objeto, pode assumir vários valores. Sendo assim, essa classificação não pode ser codificada em termos de um CDC (Schuurmans and Greiner, 1995).

Apesar da tarefa de aprendizado de um CDI ser considerada em vários estudos empíricos, os resultados dos mesmos têm demonstrado que há um vasto número de estratégias para a classificação de dados com valores ausentes, mas nenhuma tem sido largamente aceita como uniformemente superior as outras (Quinlan, 1989), (Porter et al., 1990).

Para entender estas estratégias, considere um domínio simples composto por um vetor de atributos booleanos $\vec{x}=\left(x_{1}, \ldots, x_{n}\right), x_{i} \in\{0,1\}$. Assim, o conjunto de objetos do domínio é dado por $X_{n}=\{0,1\}^{n}$. Considere, ainda, apenas duas classes para as quais um exemplo

\footnotetext{
${ }^{3}$ Uma descrição incompleta "ambígua" é uma descrição parcial que pode ser completada (e.g. pelo preenchimento dos valores de atributos não especificados correntemente) de diferentes modos, produzindo, assim, diferentes classificações.

"Os termos "exemplo", "caso" e "objeto" são usados indistintamente neste trabalho.
} 
possa ser classificado, sendo os objetos classificados como membros ou não membros desse "conceito" (classe) sobre o domínio. Um exemplo completo é especificado pelo par ( $\bar{x}$, classe), consistindo dos atributos do domínio e a classe classe $\in\{0,1\}$. Entretanto, nem sempre todos os valores dos atributos do domínio são observados. Dessa forma, especificando um valor desconhecido por $*$, o conjunto dos objetos do domínio é, agora, dado por $X_{n}^{*}=$ $\{0,1, *\}^{n}$. Logo, $x_{i}=0$ pode ser mapeado para $x_{i}^{*} \in\{0, *\}$, e $x_{i}=1$ para $x_{i}^{*} \in\{1, *\}$. Um exemplo $\left(\bar{x}^{*}\right.$, classe) consiste, então, de uma descrição (parcial) $\vec{x}^{*}$ de algum objeto do domínio $X^{*}$, juntamente com a classe $\in\{0,1\}$, sendo que o espaço de exemplos possíveis é dado por $X_{n}^{*} \times\{0,1\}$.

Um CDC é uma função $d c: X_{n} \rightarrow\{0,1\}$ que descreve algum conceito do domínio, isto é, $d c(\bar{x})=1$ se e somente se $\bar{x}$ pertence a este conceito. Um CDI, por outro lado, é uma função $d i: X_{n}^{*} \rightarrow\{0,1\}$ que obtém uma descrição parcial de $\bar{x}^{*}$ como entrada e retorna $d i\left(\bar{x}^{*}\right)=1$ se o exemplo descrito por $\bar{x}^{*}$ pertence a classe (default), e retorna $d i\left(\bar{x}^{*}\right)=0$, caso contrário. Dado um exemplo de teste $\left(\bar{x}^{*}, c\right)$, um CDI di realiza uma classificação correta se $d i\left(\bar{x}^{*}\right)=c$.

Vale ressaltar que $d i$ faz a classificação a partir de qualquer descrição possível para um exemplo (até mesmo $\bar{x}^{*}=(*, *, \ldots, *)$ ), assim, há $2^{3^{n}}$ CDIs possíveis para um conjunto de exemplos com $n$ atributos booleanos. Na prática, os CDIs têm sido implementados de diferentes modos, de acordo com as diferentes conceitualizações das estruturas de um classificador. A seguir serão mostradas algumas estratégias para a representação de classificadores a partir de dados incompletos.

\subsubsection{Classificadores para Dados Incompletos}

O modo mais simples de tratar dados incompletos é desconsiderar os exemplos que contenham valores não observados, classificando novos exemplos a partir, apenas, dos exemplos com valores de atributos conhecidos. Este é o método usado pelo algoritmo Predictor (White, 1987). Entretanto, essa estratégia apresenta bons resultados apenas quando o número de exemplos com valores ausentes é reduzido. Vale ressaltar que, apesar de ser bastante eficiente computacionalmente, faz um "uso" ineficiente dos dados.

Outra estratégia bastante utilizada para representar um CDI é baseada em primeiro "preencher" os valores ausentes com valores default, e então aplicar um CDC para a descrição 
"completada" (Quinlan, 1989). Este método, chamado de Imputação, representa um CDI di por um único CDC $d c$ e uma lista de valores de atributos default $v_{1}, v_{2}, \ldots, v_{n}$. Para classificar uma descrição $\bar{x}^{*}$, primeiro preenche cada atributo ausente $x_{i}^{*}=*$ com valores default $v_{i}$, obtendo uma completa descrição $\bar{x}$, e então determina $d c(\bar{x})$. Entretanto, esta técnica é bastante limitada em relação a faixa de CDIs que ela pode representar, o que leva muitos pesquisadores a considerarem alternativas de estratégias de representação mais gerais. Por exemplo, poder-se-ia representar implicitamente um CDI de $X_{n}$ definindo uma distribuição de probabilidade conjunta sobre o espaço dos exemplos que não possuam valores ausentes $X_{n} \times\{0,1\}$.

A Distribuição Conjunta representa um CDI di por uma distribuição probabilística do domínio. Assim, um exemplo $\vec{x}^{*}$ é classificado de acordo com a classe com máxima verossimilhança, dado os atributos observados $\bar{x}^{*}$ 's. Técnicas bastante utilizadas para representar a distribuição de probabilidade conjunta incluem Redes de Markov (Heckerman, 1997), Modelos de Mistura de Bernoulli (Ghahramani and Jordan, 1994) e Redes Bayesianas (Pearl, 1988). Estas representaçōes fornecem uma representação compacta e intuitiva de CDIs, apesar de, freqüentemente, apresentarem elevados custos computacionais.

Outro método utilizado para representar um CDI é considerá-lo como um mapeamento direto das descrições parciais $\bar{x}^{*}$ para as suas respectivas classes. Na realidade, esta abordagem pode ser implementada tratando o valor desconhecido * como um terceiro valor, e especificando uma classificação para cada descrição $\bar{x}^{*}$. Esta estratégia é freqüentemente adotada pelos algoritmos baseados em árvores de decisão para classificar conjuntos de dados incompletos (Quinlan, 1989). Este método, chamado de Regras Default, representam um CDI di como uma coleção de $3^{n}$ regras de classificação da forma $\bar{x}^{*} \rightarrow c$, no qual, para cada descrição $\bar{x}^{*} \in X_{n}^{*}, \bar{x}^{*} \rightarrow 1 \in d i$ ou $\bar{x}^{*} \rightarrow 0 \in d i$, mas não ambos. Uma descrição $\bar{x}^{*}$ é então classificada de acordo com a regra de matching $\bar{x}^{*} \rightarrow c \in d i$.

Para ilustrar o método Regras Default, considere o exemplo de um CDI de dois atributos, mostrado na Figura 4.2, no qual o primeiro atributo é "verde", o segundo é "planta", e a classe é "photosynthetic". Cada elemento no grafo representa uma regra (e.g. *1 $\rightarrow 1$ representa a regra de que uma planta, de uma cor näo especificada, é classificada como photosynthetic). É possivel notar que o conjunto de regras apresentam um comportamento não monotônico, visto que os conceitos de pertinência de um exemplo a uma classe podem mudar à medida que novos valores de atributo são especificados. Por exemplo, na Figura 4.2, 
quando os valores dos dois atributos estão ausentes $(* *)$, tem-se que a classe é $0(* * \rightarrow 0)$. Entretanto, quando se sabe apenas o valor do atributo planta $(* 1)$, observa-se que a classe é $1(* 1 \rightarrow 1)$. Finalmente, quando se sabe que o valor dois atributos (01), tem-se que a classe é igual a $0(01 \rightarrow 0)$. Isso demonstra que este classificador não pode ser especificado por um CDC.

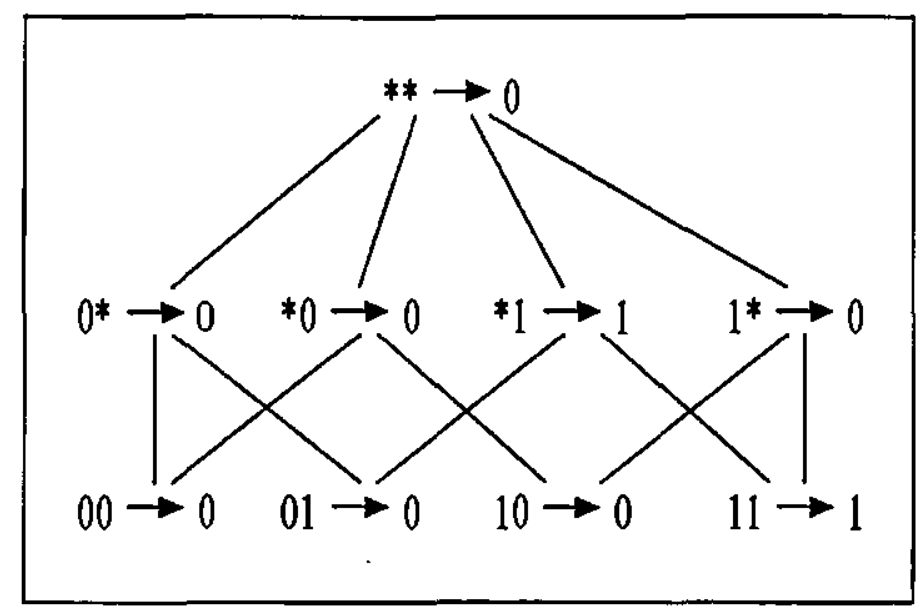

Figura 4.2: Representação da estratégia Regras Default para um CDI.

Uma representação alternativa de um CDI é imaginá-lo como uma coleção de CDCs definidos a partir de cada subconjunto de atributos observados. Este método, chamado de Classificador Lattice, representa um CDI di como um conjunto de $2^{n}$ CDCs, cada um deles definido por um subconjunto $s$ de atributos observados. Uma descrição $\bar{x}^{*}$ é classificada de acordo com o CDC $d i_{s}$ definido a partir do subconjunto de atributos observados. Para ilustrar essa estratégia, é mostrada na Figura 4.3 uma representação, pelo método Classificador Lattice, para o mesmo CDI dos dois atributos mostrados na Figura 4.2. Nesse exemplo, é possível observar que são estabelecidas algumas "regras" default. Assim, por exemplo, se os valores forem desconhecidos para ambos atributos, esse caso é classificado como $\neg$ fotossíntese. Em geral, representar explicitamente $2^{n}$ CDCs é inviável, mas uma representação possível pode ser baseada na escolha de apenas pequenos conjuntos de atributos relevantes e representar os CDCs tão somente a partir desses atributos. 
Atributos

Observados CDC Local

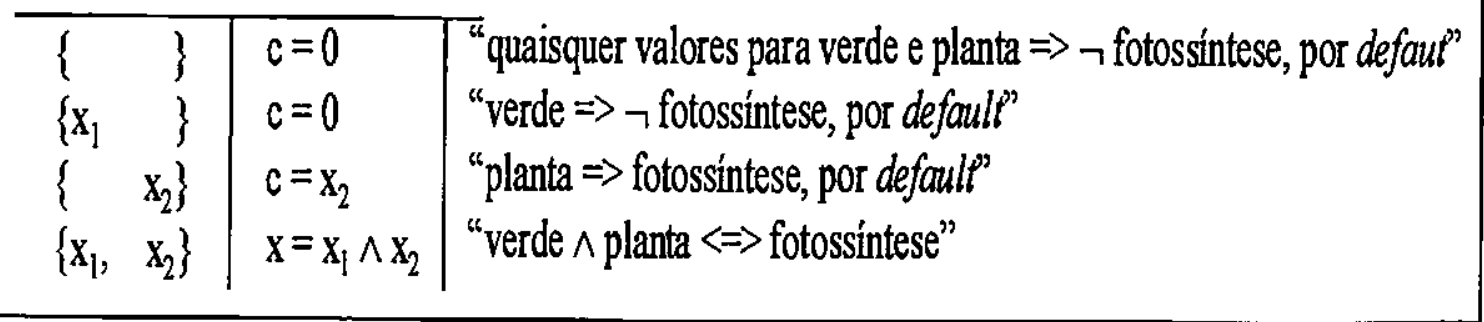

Figura 4.3: Representação da estratégia Classificador Lattice para um CDI.

\subsubsection{Aprendizado de Classificadores para Dados Incompletos}

O modelo de aprendizado supervisionado no contexto de dados incompletos é análogo ao caso do aprendizado a partir de conjuntos de dados completos: dado uma seqüência de exemplos de treinamento $\left(\overline{x_{1}}, c_{1}\right),\left(\overline{x_{2}}, c_{2}\right), \ldots,\left(\overline{x_{m}}, c_{m}\right)$, consistindo de descrições de objetos (possivelmente incompletos) e sua classe, o algoritmo de aprendizado deve, portanto, produzir um CDI $d i: X_{n}^{*} \rightarrow\{0,1\}$. A maioria dos algoritmos de aprendizado para CDI incluem dois componentes: uma técnica para representar o bias, que limita o espaço de busca a uma classe restrita de classificadores "apropriados" DI (Michell, 1980); e de uma regra de aprendizado para escolher algum di $\in D I$ dado os exemplos de treinamento. De fato, vários algoritmos de aprendizado que adotam as representações (vista na subseção anterior) e seus componentes têm sido desenvolvidos. A seguir são mostradas, de forma resumida, as representações e seus respectivos componentes:

\section{- Imputação:}

Bias: uma classe de CDCs $D C$ e um conjunto de possíveis vetores de valores-default $V$ (que implicitamente define uma classe de CDIs $D I$ ).

Regra de Aprendizado: usar o conjunto de treinamento para estimar o valor default mais comum para cada atributo individualmente, preencher os valores de atributos ausentes para cada exemplo no conjunto de treinamento, e então escolher um classificador $d c \in$ $D C$ com um erro mínimo (Little and Rubin, 1987), (Quinlan, 1989).

- Distribuição de Probabilidade Conjunta: 
Bias: uma classe de distribuições do domínio, usualmente definida por alguma arquitetura de rede de Markov ou rede Bayesiana, ou ainda por um Modelo de Mistura (que implicitamente define uma classe de CDIs $D I$ ).

Regra de Aprendizado: escolher uma distribuição do domínio (e.g. uma rede Bayesiana) com máxima verossimilhança de acordo com o conjunto de exemplos de treinamento. Na prática este problema de otimização pode ser bastante complexo e, portanto, alguns pesquisadores recorrem a técnicas de otimização heurísticas como, por exemplo, o Algoritmo EM (Ghahramani and Jordan, 1994).

\section{- Regras Default:}

Bias: uma classe de CDIs DI.

Regra de Aprendizado: escolher um classificador $d i \in D C$ com um erro mínimo (Quinlan, 1989).

\section{- Classificador Lattice:}

Bias: uma classe de CDCs $D C_{s}$ para cada subconjunto $s$ de atributos observados (que implicitamente define uma classe de CDIs $D I$ ).

Regra de Aprendizado: para cada subconjunto $s$ de atributos observados, escolher um classificador $d c \in D C$ com um erro mínimo.

Para analisar a eficácia dos algoritmos de aprendizado é necessário verificar a sua acurácia quando submetido a um novo conjunto de exemplos, chamado de exemplos de teste (que também podem apresentar valores de atributos ausentes). A acurácia de um CDI di representa a probabilidade que di classifica corretamente os exemplos de teste. A seguir será mostrado o tratamento de dados incompletos em conjunto de exemplos de teste.

\subsubsection{Manipulação de Valores Ausentes em Exemplos de Testes}

O outro lado do problema de classificação é o de como valores de atributos ausentes são manipulados durante a classificação dos exemplos de teste. Por exemplo, no caso dos algoritmos baseados em árvore de decisão, sem um método específico para tratar esses valores ausentes, não seria possível classificar um exemplo que apresenta um valor ausente para um atributo que foi ramificado na árvore, posto que não se saberia que caminho tomar nessa ramificação. 
Para efetuar a classificação mesmo quando atributos apresentam valores ausentes, alguns métodos alternativos têm sido usados.

Um método implementado por Breiman usa um atributo substituto quando um valor ausente é encontrado no atributo originalmente escolhido. $O$ atributo substituto é aquele que possui a maior correlação com o atributo original. A eficácia deste método obviamente depende da magnitude da correlação entre o atributo original e seu substituto (Breiman et al., 1984).

White propōe outro método, chamado Geração de Caminho Dinâmico, que pode oferecer flexibilidade na manipulação de valores ausentes. Ao invés de gerar a árvore de decisão completa de antemão, esse método produz apenas o caminho (i.e. a regra) requerida para classificar o caso corrente. Esta abordagem pode manipular com flexibilidade valores ausentes, uma vez que, se um atributo de um determinado exemplo do conjunto de testes não é observado, ele nunca será ramificado quando o algoritmo estiver classificando esse caso. Por exemplo, considere o processo de construção de um regra de decisão (um caminho na árvore de decisão) para classificar um novo exemplo $E_{1}$. Em cada passo, o algoritmo escolhe o atributo mais informativo (usando alguma heurística, e.g. entropia) para ramificá-lo. Entretanto, se o valor deste atributo está ausente para o exemplo $E_{1}$, então este atributo não pode ser ramificado e o algoritmo tenta com o segundo mais informativo. Assim, a geração do caminho é dinâmica (White, 1987). Naturalmente, essa abordagem pode apresentar um custo computacional elevado. Todavia, se a técnica de divisão de conjuntos de treinamento e teste leaving-one-out for utilizada, esse método pode ser otimizado (Liu et al., 1997). Essa otimizaçāo ocorre pois, como essa técnica constrói um modelo (classificador) para cada exemplo, apenas um caminho novo é necessário para a classificação de cada exemplo. Essa abordagem também é referida na literatura como método lazy decision tree (Friedman et al., 1996), visto que a criação da "melhor" árvore é adiada. Ao invés disso, é construída a "melhor" árvore para cada instância (de fato, apenas um caminho de classificação precisa ser gerado).

Nas próximas seções será enfatizado o paradigma Bayesiano, ponto central desse trabalho, para o tratamento de dados incompletos. 


\subsection{Estimativa de Dados Incompletos}

Neste trabalho a estimativa dos valores de atributos ausentes de um determinado conjunto de dados é realizado através de uma abordagem baseada na Teoria de Probabilidade Bayesiana. A partir de um conjunto de dados (com variáveis discretas) incompletos, os valores ausentes podem ser estimados de acordo com alguma função que descreva a distribuição de probabilidade desses dados. Baseado nessa suposição, é possível produzir uma distribuição de probabilidades para os possíveis "complementos" dos valores ausentes. Neste contexto, o "complemento" ideal para os valores ausentes pode ser obtido encontrando os valores que completam o conjunto de dados com máxima verossimilhança. Do ponto de vista teórico, maximizar essa probabilidade é o mesmo que minimizar a complexidade estocástica do conjunto de dados completo (Rissanen, 1989). Nesse caso, a complexidade estocástica representa o menor "esforço" necessário para codificar o conjunto de dados completo dentro do espaço de modelo escolhido. Intuitivamente, isto pode ser explicado pela natureza da complexidade estocástica: a complexidade estocástica mínima para o preenchimento do conjunto de dados é ótima desde que a mesma explore mais dos dados conhecidos nesse conjunto do que qualquer outro complemento dos dados. Um estudo mais aprofundado do critério de complexidade estocástica pode ser encontrado em (Rissanen, 1989).

A partir da definição de um critério de avaliação para a estimativa dos valores ausentes de um conjunto de dados, o problema de dados incompletos é reduzido a um problema de busca, no qual o objetivo é encontrar o "complemento" dos dados que minimize a complexidade estocástica do conjunto de dados completo. Para instanciar esse problema serão mostrados dois algoritmos bastante referenciados na literatura: algoritmo Expection Maximization (EM) (Dempster et al., 1977) e o Simulated Annealing (AS) (Aarts and Korst, 1989). Para compreender melhor esses métodos, é conveniente formalizar o critério de complexidade estocástica, o que será feito na próxima subseção.

\subsubsection{Critério de Complexidade Estocástica para Estimativa de Dados Incompletos}

Considere um conjunto de $N$ vetores de dados $d_{1}, \ldots, d_{N}$, no qual cada vetor de dados completo $d$ consiste de $m$ assinalamentos de valores $d=\left(X_{1}=x_{1}, \ldots, X_{m}=x_{m}\right)$, no qual cada 
valor $x_{i}$ pertence a um conjunto discreto $x_{i 1}, \ldots, x_{i n}$. Consequentemente, um conjunto de dados completo $\mathrm{D}$ pode ser considerado como uma matriz $N \times m$, na qual cada componente $d_{j i}$ é um assinalamento de valor na forma $X_{i}=x_{i}$. No caso dos dados incompletos, um ou mais dos seus assinalamentos são desconhecidos, e necessitam ser estimados. Em seguida, considere uma divisão de $\mathrm{D}$ em dois conjuntos: $D=\left(D_{o b s}, D_{a u s}\right)$, no qual $D_{o b s}$ denota os dados observados e $D_{a u s}$ representa os componentes ausentes de $D$, que devem ser estimados usando $D_{o b s}$.

Em seguida é necessário restringir o espaço de possíveis modelos $M$ que representam os possíveis complementos da partição $D_{a u s}$. Do ponto de vista Bayesiano a estimativa "ótima" para os valores ausentes pode ser obtida pela maximização da probabilidade $P(D \mid M)=$ $P\left(D_{o b s}, D_{a u s} \mid M\right)$. Dessa forma, $P(D \mid M)$ pode ser computada integrando todos os possíveis modelos (cenários de instanciações dos valores ausentes) $\Theta$, de acordo com a equação 4.1 abaixo:

$$
P(D \mid M)=P\left(D_{o b s}, D_{a u s} \mid M\right)=\int P\left(D_{o b s}, D_{a u s} \mid M, \Theta\right) P(\Theta \mid M) d \Theta
$$

Os cenários de instanciações dos valores ausentes são as possíveis estruturas que um conjunto de dados pode assumir se forem "completados" os dados ausentes. Na Figura 4.4 são mostrados os possíveis cenários de instanciações para o conjunto de dados $S$.

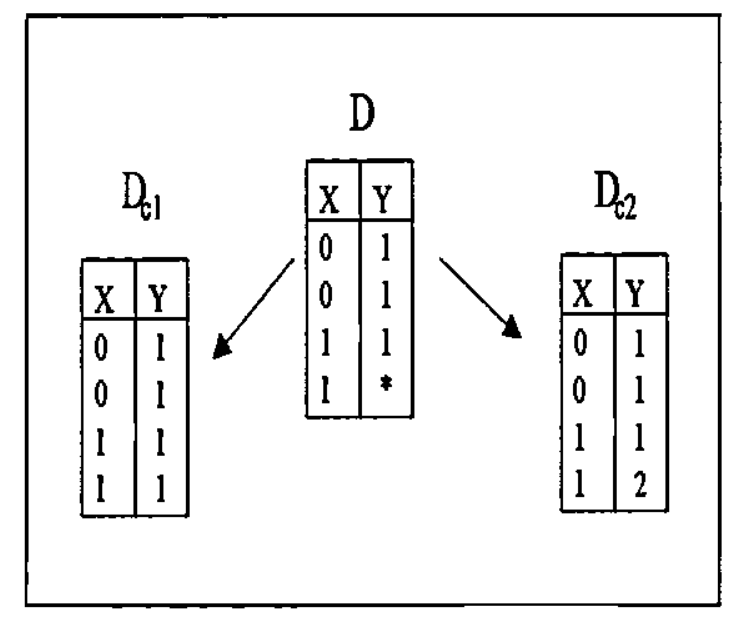

Figura 4.4: Possíveis cenários para o conjunto de dados $D\left(M=D_{c l}\right.$ e $\left.D_{c 2}\right)$.

Assim, a complexidade estocástica (CE) para os dados D, dado $M$, pode ser calculada ${ }^{5}$

\footnotetext{
${ }^{5} \mathrm{O}$ logaritmo é utilizado por conveniência matemática.
} 
por (Rissanen, 1989):

$$
C E(D \mid M)=C E\left(D_{\text {obs }}, D_{a u s} \mid M\right)=-\log C E\left(D_{\text {abs }}, D_{a u s} \mid M\right)
$$

Rissanem apresenta outras formas de calcular a complexidade estocástica (Rissanen. 1996), entretanto comparações entre os esquemas mais ou menos eficientes foge ao escopo deste trabalho.

Definido os critérios de validação da estimativa dos dados ausentes, o tratamento de dados incompletos pode ser considerado como um problema de busca, no qual o objetivo é encontrar uma estimativa de $D_{\text {aus }}$ que minimiza a complexidade estocástica ou, equivalentemente, maximiza a probabilidade $P(D \mid M)$ (Equação 4.1). Para efetuar essa busca são apresentadas duas alternativa, utilizando dois algoritmos bastante mencionados na literatura para realizar essa tarefa - Expection Maximization e o Simulated Annealing, que serão apresentados a seguir.

\subsubsection{Algoritmos Expection Maximization e Simulated Annealing}

Uma das formas mais utilizados para estimativa de valores ausentes é realizado por meio do algoritmo Expection Maximization, que consiste de dois passos, Esperança (valor esperado)(E) e Maximização (M) (Dempster et al., 1977). Esses passos podem ser apresentados, em alto nível, como se segue:

1. Considerar inicialmente $t=0$. Inicializar aleatoriamente os parâmetros (valores ausentes) $\Theta^{(t)}$.

2. Passo E: determinar $Q\left(\Theta, \Theta^{(t)}\right)=E\left[\log P\left(D_{o b s}, D_{a u s} \mid \Theta, M\right) P(\Theta \mid M) \mid D_{o b s}, \Theta^{(t)}, M\right]$, no qual $\Theta^{(t)}$ são as estimativas de parâmetro na execuçāo t.

3. Passo M: Estabelecer $\Theta^{(t+1)}=\operatorname{argmax}_{\Theta}\left\{Q\left(\Theta, \Theta^{(t)}\right)\right\}$ (Máxima verossimilhança).

4. Faça $t=t+1$. Ir para o passo 2 se não convergir.

É possível observar que o algoritmo EM não provê uma estimativa do valor ausente diretamente. O algoritmo EM maximiza $P\left(\Theta \mid D_{o b s}, M\right)$, e o resultado, obtido no passo M, da máxima probabilidade condicional do modelo $\hat{\Theta}$ pode ser usado para estimar os valores ausentes $D_{\text {aus }}$. Entretanto, a complexidade estocástica pode ser aproximada por: 


$$
C E\left(D_{\text {obs }}, D_{a u s} \mid M\right) \approx \log P\left(D_{o b s}, D_{\text {aus }} \mid \hat{\Theta}, M\right) P(\hat{\Theta}, M)-C
$$

na qual $C$ representa uma constante dependente do número de parâmetros do modelo, e o número de vetores de dados (Rissanen, 1989). Como a Esperança do primeiro termo dessa aproximação é maximizada durante o processo EM, a otimização da $\mathrm{CE}$ pode ser referida indiretamente pela otimização da aproximação apresentada na Equação 4.3.

O algoritmo Simulated Annealing é um método estocástico para otimização global pertencente a familia dos algoritmos de simulação estocástica Markov Chain Monte Carlo (MCMC). Uma versão comumente usada do SA segue os passos (Kontkanen et al., 1997):

1. Gerar uma suposição randômica dos dados ausentes $D_{\text {aus }}$. Estabelecer o parâmetro de "Temperatura" $T$ para seu valor inicial.

2. Repetir $L$ vezes:

(a) Gerar um novo candidato $\tilde{D}_{\text {aus }}$ para os dados ausentes, alterando a estimativa de um valor de atributo ausente escolhido aleatoriamente em $D_{\text {aus }}$ por outro valor também escolhido aleatoriamente.

(b) Se $P\left(D_{\text {obs }}, \tilde{D}_{\text {aus }} \mid M\right)>P\left(D_{\text {obs }}, D_{\text {aus }} \mid M\right)$ então faça $D_{\text {aus }}=\tilde{D}_{\text {aus }}$.

(c) Senão se $\left(\frac{P\left(D_{\text {obs }}, \tilde{D}_{\text {aus }} \mid M\right)}{P\left(D_{\text {obo }}, D_{\text {aus }} \mid M\right)}\right)^{1 / T}>\operatorname{Random}(0,1)$, então faça $D_{\text {aus }}=\tilde{D}_{\text {aus }}$.

3. $T=F * T$. Se não convergir, voltar ao passo 2 .

Neste esquema, o fator de "Resfriamento" $F$ é um parâmetro constante menor que um. $\mathrm{O}$ algoritmo SA converge quando $T$ se aproxima de zero. Segundo Aarts, se o valor inicial de $T$ é bastande grande, e o decremento do parâmetro é realizado lentamente, o processo converge quase sempre para o "optimum global" (Aarts and Korst, 1989). Na próxima seção é mostrado o aprendizado de redes Bayesianas, considerando o problema de dados ausentes.

\subsection{Aprendizado de Redes Bayesianas a partir de Con- juntos de Dados com Valores Ausentes}

A maioria dos métodos para aprendizado de redes Bayesianas, a partir de dados incompletos, são baseados em aproximações para efetuar o cálculo dos parâmetros (probabilidades) e 
das estruturas dessas redes (Heckerman, 1997). Nesta seção serão apresentados dois dos principais métodos para o aprendizado de redes Bayesianas a partir de conjuntos de dados incompletos. O primeiro, chamado de método Gibbs Sampling, aprende os parâmetros de uma rede Bayesiana cuja a estrutura é fornecida a priori. Enquanto que o segundo, Bound $e$ Collapse, aprende tanto os parâmetros quanto a estrutura de redes Bayesianas.

\subsubsection{Método Gibbs Sampling}

Um dos métodos mais utilizados para efetuar aproximações dos parâmetros de uma rede Bayesiana, baseado no método Monte-Carlo, é conhecido como Gibbs Sampling (Geman and Geman, 1984). Dadas as variáveis do domínio $X=X_{1}, \ldots, X_{n}$ com alguma distribuição de probabilidade conjunta $P(X)$, pode-se utilizar o Gibbs Sampling para aproximar a expectativa de uma função $f(x)$ com relação a $P(X)$ de acordo com os seguintes passos:

1. Escolher um estado inicial (valores) para as variáveis de $X$ (e.g. randomicamente).

2. Selecionar alguma variável $X_{i}$, não assinalada nesse estado corrente, computando sua distribuição de probabilidade dado o estado das outras $n-1$ variáveis.

3. Gerar um valor para $X_{i}$ baseado na sua distribuição de probabilidade, e computar $f(x)$.

4. Efetuar iterações dos dois passos anteriores, registrando o valor médio de $f(x)$, até que essas aproximaçōes possam convergir para a distribuição de probabilidade conjunta $P(X)$.

Para ilustrar esses quatro passos do método Gibbs Sampling, considere o cálculo de uma função $f(x)$ para aproximar a probabilidade de $P\left(\theta_{s} \mid D, S\right)$, onde $\theta_{s}$ são os parâmetros da rede (com variáveis discretas) de estrutura $S$, e $D$ um conjunto de dados incompletos. Primeiro, as variáveis com valores ausentes em cada exemplo são inicializadas de algum modo. Como resultado, tem-se uma amostra randômica (conjunto de dados) completa $D_{c}$. Segundo, é escolhida alguma variável $X_{i e}$ (variável $X_{i}$ no exemplo $e$ ) cujo valor não é observado no conjunto de dados original $D$, e determinado seu valor de acordo com a distribuição de probabilidade condicional mostrada na Equação 4.4: 


$$
P\left(x_{i l}^{\prime} \mid D_{c} \backslash x_{i l}, S^{h}\right)=\frac{P\left(x_{i l}^{\prime}, D_{c} \backslash x_{i l} \mid S^{h}\right)}{\sum_{x_{i l}^{\prime \prime}} P\left(x_{i l}^{\prime \prime}, D_{c} \backslash x_{i l} \mid S^{h}\right)}
$$

no qual $D_{c} \backslash X_{i l}$ denota o conjunto de dados $D_{c}$ com o valor $x_{i l}$ removido, e a somatória do denominador representa a execução sobre todos os estados (valores) da variável $X_{i l}$ (cálculos eficientes para os termos da Equação 4.4 são propostos por Heckerman (Heckerman, 1997)).

Terceiro, a determinação dos valores é repetida para todas as variáveis não observadas em $D$, produzindo um novo conjunto de dados completo $D_{c}^{\prime}$. Em seguida, é necessário computar a probabilidade $P\left(\theta_{s} \mid D_{c}^{\prime}, S\right)$ e, finalmente, os três passos anteriores são repetidos e a média dos valores de $P\left(\theta_{s} \mid D_{c}^{\prime}, S\right)$ é utilizada como uma aproximação.

Em resumo, o Gibbs Sampling gera um valor para o dado incompleto a partir de alguma distribuição de probabilidade condicional e provê uma estimativa estocástica para o cálculo dos parâmetros da rede Bayesiana (Ramoni and Sebastiani, 1997c). Uma implementação do método Gibbs Sampling é fornecida pelo programa BUGS (Thomas et al., 1992). Nesse programa, o usuário especifica a estrutura gráfica da rede Bayesiana e a forma da distribuição de probabilidade de cada nó dessa rede. O sistema então utiliza o método Gibbs Sampling para ajustar esse modelo de rede de acordo com o conjunto de dados de treinamento.

\subsubsection{Bound e Collapse}

A estratégia básica utilizada pelo método Gibbs Sampling para o aprendizado a partir de conjuntos de dados incompletos é baseada no Princípio da Informação Ausente (MLP - Missing Information Principle) - preencher os valores de atributos não observadas com base nas informações disponíveis (Little and Rubin, 1987). Métodos baseados nesse princípio apresentam alguns problemas como, por exemplo, tempo de execução fortemente dependente do número de dados ausentes, taxas de convergência frequentemente baixas, além de consumirem mais recursos para efetuarem as estimativas dos valores ausentes.

Ramoni e Sebastiani (Ramoni and Sebastiani, 1997c) desenvolveram um método determinístico para estimar os parâmetros de uma rede Bayesiana (com variáveis discretas) que não utiliza o MLP. Este método, chamado de Bound e Collapse (BC), estima as probabilidades condicionais de uma rede Bayesiana a partir de uma base de dados (possivelmente) incompleta. $\mathrm{O} \mathrm{BC}$ inicia com a delimitação (bound) do conjunto de possíveis estimativas para $\theta_{i j}$, consistentes com a base de dados, e então converge (collapse) o intervalo dessas 
estimativas para um ponto estimado através de uma combinação convexa das estimativas máxima e mínima, de acordo com o mecanismo de geração dos dados ausentes assumido (vistos na seção 4.2). Os mecanismos suportados pelo BC são o MAR e o NI.

Para um melhor entendimento de como esse método funciona, considere $n *\left(x_{i k} \mid p a_{i j}\right)$ a freqüência de casos na base de dados $D$ em que $X_{i}=x_{i k}$, dada a configuração (valores) de seus pais $p a_{i j}$ (diz-se $x_{i k} \mid p a_{i j}$ ), obtida a partir do possível "complemento" dos valores de atributos ausentes da base de dados ${ }^{6}$. Para ilustrar o cálculo desta freqüência, na Figura 4.6, é mostrado um exemplo das virtuais freqüências de $n *\left(x_{3 k} \mid x_{1}, x_{2}\right)$, dadas a rede Bayesiana da Figura 4.5 e uma base de dados incompleta $D$.

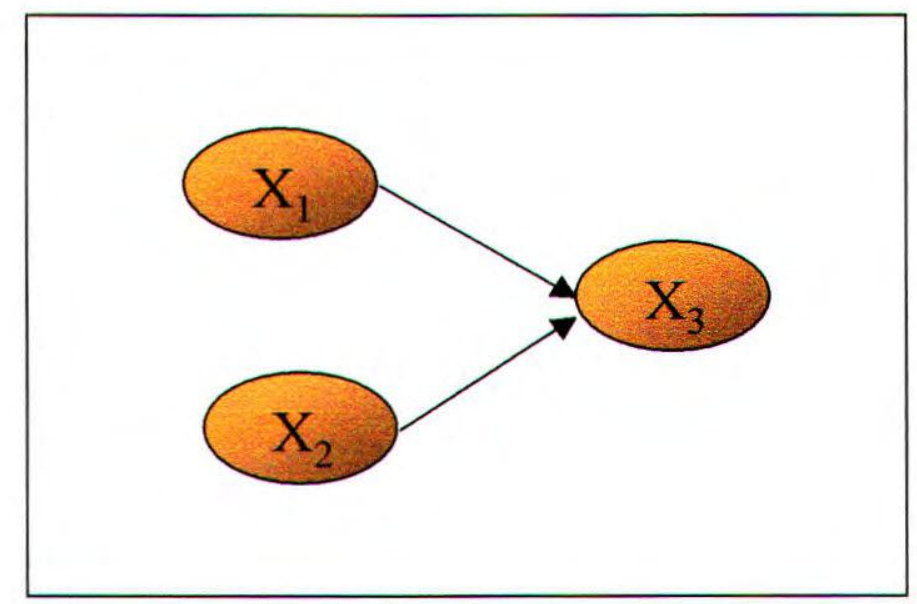

Figura 4.5: Exemplo da estrutura de uma rede Bayesiana fornecida como entrada para o Bound e Collapse.

Para cada caso incompleto na base de dados, são calculados os valores mínimo (lower bound) e máximo (upper bound) da probabilidade condicional $P\left(x_{i k} \mid p a_{i j}, D_{a u s}\right)$, na qual $D_{a u s}$ representa a parte incompleta da base de dados $D$. Caso o mecanismo de geração dos valores seja MAR, a estimativa de probabilidade pode ser calculada a partir da parte observada (que não possui valores de atributos ausentes) $D_{o b s}$. Entretanto, quando o mecanismo é conhecido, ou seja, NI, e, portanto qualquer padrão dos valores ausentes é igualmente comum, então a probabilidade condicional $P\left(x_{i k} \mid p a_{i j}, D_{\text {aus }}\right)$ pode ser entendida como sendo igual a $1 / c_{i}$, na qual $c_{i}$ representa o número de estados (valores) possíveis de $X_{i}$.

Avaliações experimentais mostram que as estimativas de probabilidades fornecidas pelo

\footnotetext{
${ }^{6}$ Os valores de atributos ausentes podem ser oriundos dos valores de uma variável, de seus pais, ou de ambos.
} 


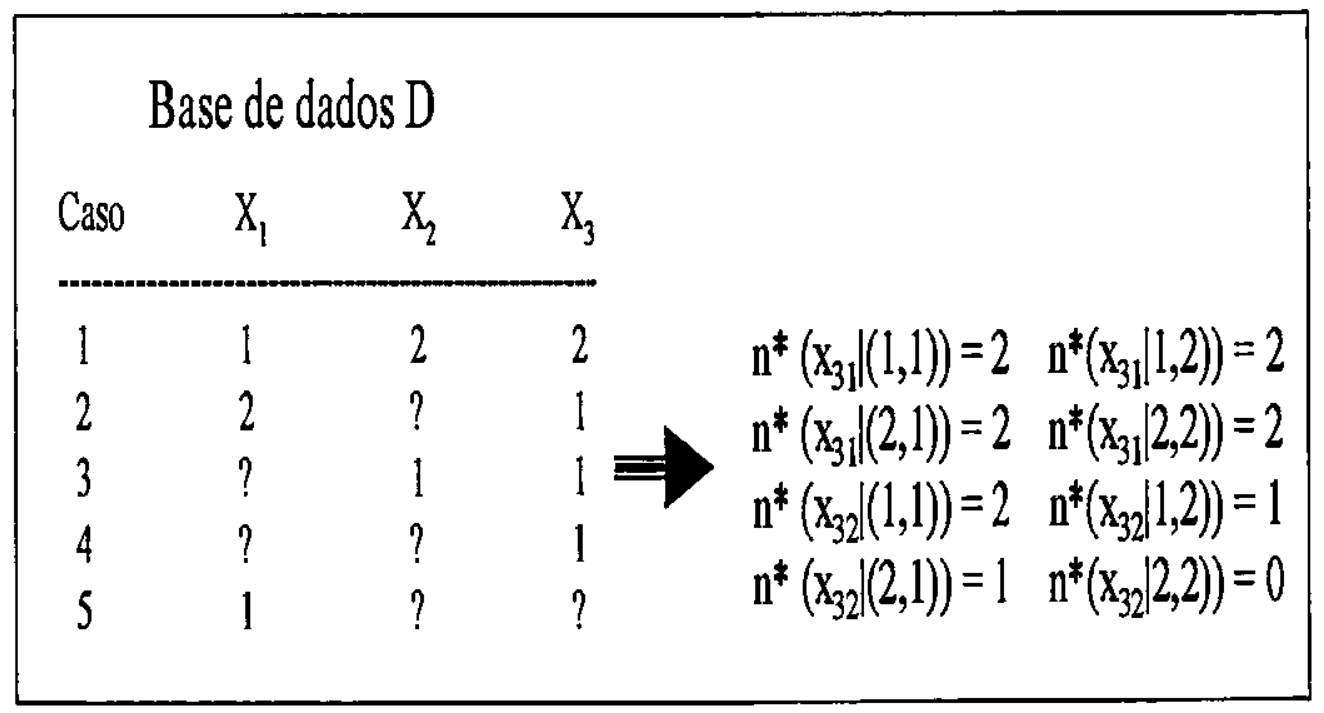

Figura 4.6: Freqüências virtuais de $n *\left(x_{3 k} \mid x_{1}, x_{2}\right)$ consistentes com a base de dados incompleta.

método BC são equivalentes às fornecidas pelo método Gibbs Sampling, quando a ausência dos dados é considerada aleatoriamente (MAR), e são mais robustas quando são considerados os verdadeiros padrões dos dados ausentes (NI) (Ramoni and Sebastiani, 1997b).

$\mathrm{O}$ método BC está implementado em um software, chamado BKD, capaz de extrair redes Bayesianas a partir de bases de dados (possivelmente) incompletas. O BKD recebe como entrada uma base de dados e uma ordem parcial das variáveis contidas nessa base (e.g. a própria ordem de entrada dos atributos da base de dados) e fornece como resultado uma rede Bayesiana (estrutura e parâmetros). Esse software realiza duas tarefas básicas: i) extrair um modelo gráfico a partir das informações disponíveis da base de dados e ii) avaliar as probabilidades condicionais a partir da estrutura extraída.

A primeira tarefa pode ser realizada utilizando uma extensão do algoritmo greedy search, proposto por (Cooper and Herskovits, 1992), para estimar o grau de dependência entre um nó $X_{i}$ e seus possíveis pais $P a_{i j}$. Assim, considerando que a ordem das variáveis é a mesma dos atributos da base de dados $\left(X_{i} \prec X_{j}\right.$ se $X_{i}$ não pode ser pai de $\left.X_{j}\right)$, que $P a_{i}$ representa o conjunto dos pais de $X_{i}$, e $P_{i}$ é um conjunto vazio se $X_{i}$ é um nó raiz. Então é verificada a "contribuição" do nó $X_{i}$ e de seus pais $P a_{i}$ para a probabilidade conjunta da estrutura $\mathrm{M}$ em relação a base de dados $\mathrm{D}$. $\mathrm{O}$ algoritmo adiciona um novo nó-pai ao conjunto $P a_{i}$ dos pais do nó $X_{i}$ que possua a maior "contribuição" e pára se a probabilidade conjunta 
$P a_{i}$ dos pais do nó $X_{i}$ que possua a maior "contribuição" e pára se a probabilidade conjunta não aumenta mais.

A segunda tarefa é realizada utilizando o método Bound e Collapse para estimar os valores de probabilidades condicionais das TPCs das rede Bayesiana gerada na tarefa um.

\subsection{Considerações Finais}

Em muitas aplicações reais os dados disponíveis são tipicamente incompletos, ou seja, contém usualmente elementos (atributos) com valores ausentes. Kontraknen considera os dados ausentes como um problema endêmico em se tratando de análise de dados (Kontkanen et al., 1997). A falta de alguns valores pode ser causada por imprecisões físicas ou limitações dos equipamentos de coleta de dados, ou pode simplesmente ser resultado de um erro humano, ou do computador, durante o processamento, armazenamento ou recuperação dos dados. Em particular, estes dados ausentes podem causar uma série de problemas para o processo de extração de padrões e regularidades nos dados, nos métodos de Data Mining.

Este capítulo enfatizou o tratamento de dados incompletos na Etapa de Data Mining, considerando o mecanismo pelo qual eles estão distribuídos nos dados e o paradigma de aprendizado utilizado pelos métodos dessa etapa do processo de KDD.

Quanto ao paradigma simbólico, foram abordadas várias estratégias utilizadas no tratamento de dados incompletos, bem como o aprendizado de classificadores a partir de dados incompletos, considerando o conjunto de treinamento e, com ênfase aos métodos de árvore de decisão, o tratamento dos valores de dados ausentes no conjunto de teste.

No que concerne ao paradigma estatístico-Bayesiano, foi enfatizado o aprendizado de redes Bayesianas a partir de conjunto de dados incompletos. Além disso, foi apresentado o problema de estimar os valores ausentes a partir dos valores de atributos observados, considerando o "melhor complemento dos dados", ou seja, que minimize a complexidade estocástica (máxima verossimilhança) do conjunto de dados completo. Para isso dois algoritmos foram mostrados - Expection Maximization e Simulated Annealing.

No próximo capítulo é apresentado um ponto bastante importante para a otimização e conseqüente sucesso do processo de KDD - a incorporação de conhecimento de fundo. 


\section{Capítulo 5}

\section{Incorporação de Conhecimento de}

\section{Fundo}

\subsection{Considerações Iniciais}

Na seção 2.3, foi enfatizada a importância da interação entre o especialista do domínio, o usuário final e o analista em todas as etapas do processo KDD. Dessa forma, a utilização de métodos e técnicas que possam incorporar o conhecimento prévio do domínio ${ }^{1}$ é de suma importância, principalmente no que tange a economia de esforços para "aprender" algo que poderia ser considerado a priori. $O$ fato de alguns sistemas comerciais (i.e. sistemas especialistas) poderem ser construídos a partir, apenas, do conhecimento do domínio atesta a utilização desses métodos (Heckerman, 1997).

Segundo Fayyad, apesar do uso do conhecimento prévio do domínio ser importante em todos os passos do processo KDD, a maioria dos métodos e ferramentas utilizadas nesse processo não são verdadeiramente interativas, por isso freqüentemente não oferecem mecanismos que facilitem a inclusão desse conhecimento de fundo (Fayyad, 1996).

A importância da combinação de conhecimento de fundo com o conhecimento embutido nos dados é proeminente em se tratando da etapa de Data Mining, especialmente quando se está trabalhando com poucos dados de treinamento ou com dados difíceis de serem obtidos. Um relevante passo tem sido dado pelo desenvolvimento de sistemas que aprendem a partir

\footnotetext{
${ }^{1}$ As expressões "conhecimento prévio", "conhecimento do domínio", "conhecimento a priori", "conhecimento especialista" e "conhecimento de fundo" são utilizadas, neste trabalho, indistintamente.
} 
de uma teoria do domínio, possivelmente incorreta ou incompleta (Pazzani, 1991), (Clark and Matwin, 1993a).

A proposta deste capítulo é apresentar duas formas de integrar o conhecimento de fundo com os métodos de aprendizado a partir de dados (na etapa de DM), enfatizando a incorporação de conhecimento de fundo em redes Bayesianas. Vale observar que, significantes avanços, principalmente na utilização de conhecimento a priori para diminuir o espaço de hipótese explorado, tem ocorrido em Programação Lógica Indutiva. Porém, os sistemas que contemplam essa tecnologia de aprendizado não serão tratados aqui, visto que os mesmos não estão inseridos no escopo deste trabalho.

A organização dos assuntos relacionados à incorporação de conhecimento de fundo é a que se segue. Na seção 5.2 , é mostrado um modo de integrar conhecimento de fundo com algoritmos simbólicos, usando o modelo qualitativo. Na seção 5.3 , é considerada a incorporação de conhecimento de fundo utilizando redes Bayesianas. Finalmente, na seção 5.4, são feitas algumas considerações finais acerca dos assuntos tratados neste capítulo.

\subsection{Incorporação de Conhecimento de Fundo no Apren- dizado Simbólico}

É notoriamente reconhecida a inabilidade da maioria dos algoritmos simbólicos (como ID3, C4.5 ou CN2) para a descoberta de padrões nos dados considerando algum conhecimento de fundo (Clark and Matwin, 1993b). Essa inabilidade acaba delegando ao analista o trabalho de gerar regras que tenham elevada acurácia, estejam de acordo com o conhecimento do especialista do domínio e não tenham sido induzidas pelo algoritmo de DM a partir, e tão somente, dos dados (exemplos) desse domínio.

Gillian Mowforth, da Intelligent Terminals Ltda e com larga experiência em aplicações comerciais que envolvem indução de regras, estima que, em aplicações comerciais típicas do sistema Extran (derivado do ID3), cerca de 30\% da árvore de decisão final é obtida via interação analista-especialista do domínio, ao invés de induzida por esse sistema (Mowforth, 1992). Essa interação envolve, portanto, o uso de conhecimento especialista, além do uso de ferramentas de indução a partir de exemplos. Assim, as regras justificadas estatisticamente (induzidas) são confrontadas com o conhecimento especialista do domínio e os resultados 
utilizados para refinar o processo de aprendizado. Vale ressaltar que, segundo Mowfort, essas evidências estatísticas podem, ainda, fazer (ou pelo menos sugerir) revisões na forma de modelar o conhecimento especialista.

Sob a luz desses indicativos, torna-se importante fornecer mecanismos que facilitem a indução de regras condizentes com o conhecimento especialista. Para instanciar o problema da incorporação de conhecimento de fundo em algoritmos simbólicos, será apresentado nas próximas duas subseções um modo de utilizar um modelo qualitativo, representando o conhecimento prévio do domínio, para restringir o espaço de busca de padrões (regras) a partir dos dados.

\subsubsection{Representação do Conhecimento de Fundo no Aprendizado Simbólico}

Clark e Matwin desenvolveram um método para guiar o aprendizado indutivo utilizando um modelo qualitativo, que representa o conhecimento de fundo de um domínio e restringe o espaço de hipóteses de regras a serem induzidas por um algoritmo (que no caso é o CN2) de aprendizado simbólico (Clark and Matwin, 1993b). A idéia é induzir regras que não apenas tenham elevada acurácia, mas que também possam ser explicadas (condizentes) por um conhecimento de fundo "qualitativo". Esse método pode ser visto como um caso especial do paradigma de aprendizado baseado em teoria, no qual a teoria é o modelo qualitativo (MQ) e o aprendizado é a indução de regras a partir dos dados.

Um MQ é composto por um conjunto de nós, que representam os parâmetros de um determinado domínio de aplicação, e setas, especificando a relação entre esses parâmetros (o sentido das setas indicam precedência temporal). Cada seta recebe um dos seguintes rótulos: $I+, I-, Q+$ ou $Q-^{2}$. A ligação $X \stackrel{Q+}{\rightarrow} Y$ denota que $Y$ varia monotonicamente com $X$ (e.g. se $X$ aumenta então $Y$ aumenta), enquanto $X \stackrel{I}{\rightarrow} Y$ significa que a taxa de mudança de $Y$ $d Y / d t$ varia monotonicamente com $X$. Similarmente, as ligaçōes $\stackrel{Q-}{\rightarrow}$ e $\stackrel{I-}{\rightarrow}$ indicam relaçōes monotonicamente inversas. Para efeito de simplificação, Clark e Matwin introduziram um terceiro rótulo - I*, para denotar um loop de auto-estabilização. Assim, $X \stackrel{I *+}{\rightarrow} Y$ indica que se $X$ é aumentado então incialmente $Y$ é aumentado; entretanto, como $Y$ é aumentado subseqüentemente, a taxa de aumento $d Y / d t$ eventualmente cai até que $Y$ alcance um novo

\footnotetext{
${ }^{2}$ Essas setas são rotuladas da mesma forma que na Teoria do Processo Qualitativo (Forbus, 1984).
} 
valor constante. Por exemplo, a posição do pedal do acelerador $P$ de um carro é relacionada com a velocidade do carro $V$ por $P \stackrel{I * t}{\rightarrow} V$. Inicialmente, o pressionamento do pedal causa um aumento de $d V / d t$; entretanto, a velocidade do carro não aumentará infinitamente, mas eventualmente alcançará uma nova e mais alta velocidade constante. Assim, para pequenas escalas de tempo a relação $I *$ procede como $P \stackrel{I t}{\rightarrow} V$ e para longa escalas de tempo, como $P \stackrel{Q+}{\rightarrow} V$ (uma determinada posição do pedal porduz uma correspondente velocidade para o carro). Essa situação pode ser visualizada na Figura 5.1.

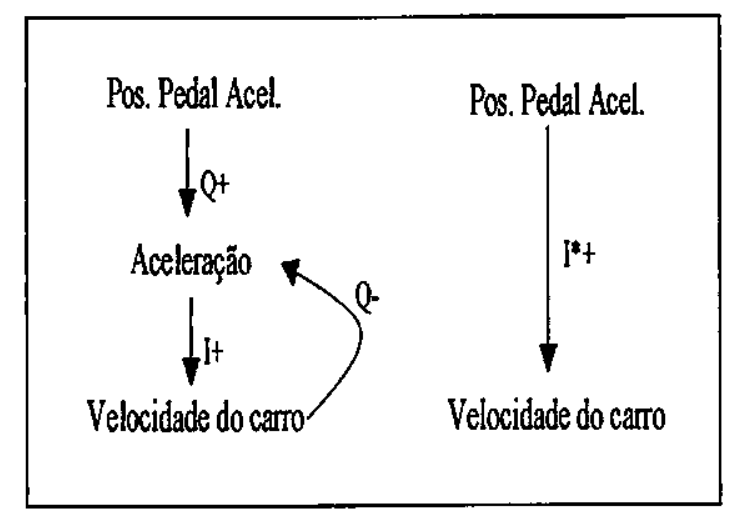

Figura 5.1: Exemplo da relaçāo $I *$.

Vale ressaltar que, apesar das semelhanças com a Teoria do Processo Qualitativo, o MQ proposto por Clark difere em função de não ser completamente especificado. O MQ não estabelece valores distintos para cada parâmetro, nem como resolver influências conflitantes durante a simulação. Como resultado, esse modelo, por si próprio, não pode ser usado para simulação ou predição. Ao invés disso, sua finalidade precípua é restringir o espaço de busca de regras e prover explicações dessas regras. Em outras palavras, o MQ representa o espaço de relacionamentos (regras) que são considerados "plausíveis" com o domínio pelo construtor do modelo.

\subsubsection{Combinação de Conhecimento de Fundo com Dados no Apren- dizado Simbólico}

A combinação do conhecimento de fundo (expressado por meio do MQ) e dos conceitos (regras) induzidos a partir dos dados é simples. Ao invés da ferramenta (algoritmo) de indução efetuar a busca em todo o espaço de regras possível, ela procura aquelas que são 
consistentes com o domínio. Portanto, são dois os passos a serem seguidos para indução de regras:

1. Definir quando uma regra é consistente com o MQ de um domínio.

2. Modificar a configuração de indução para buscar apenas as regras que satisfaçam esta definição.

O primeiro passo é realizado por um algoritmo de extração de regras que exaustivamente enumera todas as regras consistentes com o MQ. Estas regras são armazenadas em uma tabela lookup. Para realização do segundo passo, é utilizado um algoritmo para induzir regras a partir de um conjunto de dados, evitando a busca de regras que não estejam representadas nessa tabela. Dessa forma, esse algoritmo verifica, em cada hipótese de regra gerada, se a mesma está representada na tabela lookup; sendo desconsiderada em caso contrário.

A ferramenta de indução utilizado foi o $\mathrm{CN} 2$, que induz um conjunto de regras if...then a partir de um conjunto de dados, realizando uma general-to-specific beam search para uma regra em cada passo (Clark and Niblett, 1989), (Clark and Boswell, 1991). No caso particular do método proposto por Clark e Matwin, o algoritmo CN2 (implementado em Prolog) induz um conjunto desordenado de regras e utiliza como função de avaliação a estimativa de erro Laplace.

Uma abordagem semelhante pode ser pensada para o algoritmo ID3. Ao invés de avaliar todos os testes de atributos possíveis quando da expansão de um nó da árvore, o algoritmo avalia apenas aqueles cujo resultado da ramificação da árvore de decisão esteja contido na tabela de regras consistentes.

Maiores detalhes da construção de um MQ, extração de regras consistente com esse MQ, bem como alguns resultados da aplicação desse método, podem ser encontrados em (Clark and Matwin, 1993b).

A seguir será apresentado a incorporação de conhecimento de fundo utilizando métodos de aprendizado de redes Bayesianas. 


\subsection{Incorporação de Conhecimento de Fundo em Re- des Bayesianas}

A representação de conhecimento de fundo no sistema de aprendizado da seção 5.2 possui limitação no que concerne a representação de incerteza. Essa limitação advém da linguagem para expressar os conceitos aprendidos por esse sistema - proposicional. Por exemplo, é pouco provável que se consiga representar graus de crença de implicação probabilística, do tipo " $\mathrm{x}$ é usualmente verdadeiro", nesses sistemas.

Como forma de solucionar esse problema, as redes Bayesianas provêem um formalismo de representação e aprendizado capaz de cooperar amplamente para a combinação de conhecimento fundo e de conhecimento embutido nos dados para a extração de padrões a partir dos dados.

\subsubsection{Representação do Conhecimento de Fundo em Redes Baye- sianas}

Em função das redes Bayesianas constituirem um modelo do ambiente (do domínio de uma aplicação) e não apenas, como em muitos outros esquemas de representação (e.g. redes neurais e sistemas baseados em regras), um modelo de raciocínio, a representação do conhecimento de fundo é particularmente direta (Pearl, 1997). Dessa forma, o conhecimento a priori pode ser representado por meio da especificação dos elementos que compõem esse modelo. São vários os elementos que podem ser fornecidos previamente a um algoritmo de extração de redes Bayesianas a partir dos dados, sendo que os principais deles são:

1. Ordem completa: fornece a ordem de todos os nós da rede Bayesiana. Dessa forma, se um conjunto de nós precede um nó $Y$, este não pode ser um nó-pai de nenhum dos nós desse conjunto.

2. Ordem parcial: estabelece precedência de alguns nós sobre um outro subconjunto de nós da rede.

3. Causa e efeito: estabelece dependências entre pares de nós.

4. Impedimento de ligações entre nós: determina que um ou mais nós não podem ter relações de dependência com outros nós. 
5. Nós raizes e folhas: estabelece que um nó não possui nós-pais (raiz) e/ou que não pode ser um nó-pai (folha).

6. Grau de relação entre os nós: determina um threshold para que o algoritmo encontre apenas relações fortes (threshold alto) ou fracas (threshold baixo). Threshold baixos proporcionam processos de construção de redes Bayesianas mais lentos.

7. Valores de probabilidades condicionais: especifica os valores de probabilidades condicionais das TPCs dos nós de uma rede Bayesiana.

A observação desses itens varia de acordo com a ferramenta utilizada para extração de redes Bayesianas. Por exemplo, o software BKD implementa apenas os estabelecimentos de causa e efeito, e a entrada dos valores de probabilidade condicionais (Ramoni and Sebastiani, 1997b). Vale ressaltar que toda a rede, inclusive com os valores de probabilidades condicionais, pode ser fornecida a priori, caso, por exemplo, do Hugin System (Andersen et al., 1989) e do próprio BKD.

Em alguns sistemas Bayesianos, a observação do conhecimento de fundo é indispensável. Esses sistemas não aprendem a estrutura da rede Bayesiana, apenas atualizam os valores de probabilidades condicionais. Sendo, portanto, necessário o fornecimento a priori da topologia dessa rede.

É importante destacar que a facilidade da incorporação de conhecimento de fundo em redes Bayesianas muito se deve à facilidade de representação desse conhecimento. As redes Bayesianas possuem uma estrutura qualitativa, representando as dependências entre os nós, e quantitativa, avaliando (em termos probabilísticos) essas dependências, que facilitam a comunicação entre o especialista e o sistema de aprendizado Bayesiano (Heckerman et al., 1995), (Pearl, 1997).

\subsubsection{Combinação de Conhecimento de Fundo com Dados em Re- des Bayesianas}

As redes Bayesianas, juntamente com as tabelas de probabilidades condicionais, facilitam a combinação de conhecimento de fundo com os conceitos extraídos a partir dos dados, via técnicas largamente estudadas e aceitas na literatura, a partir da estatística Bayesiana (Heckerman et al., 1995). Em outras palavras, os métodos de aprendizado de redes Bayesianas a 
partir dos dados são utilizados para refinar o conhecimento (topologia e probabilidades das redes) fornecido a priori de acordo com os "conceitos" embutidos nesses dados. Na Figura 5.2, é mostrado um esquema básico do aprendizado de redes Bayesianas considerando o conhecimento prévio do domínio.

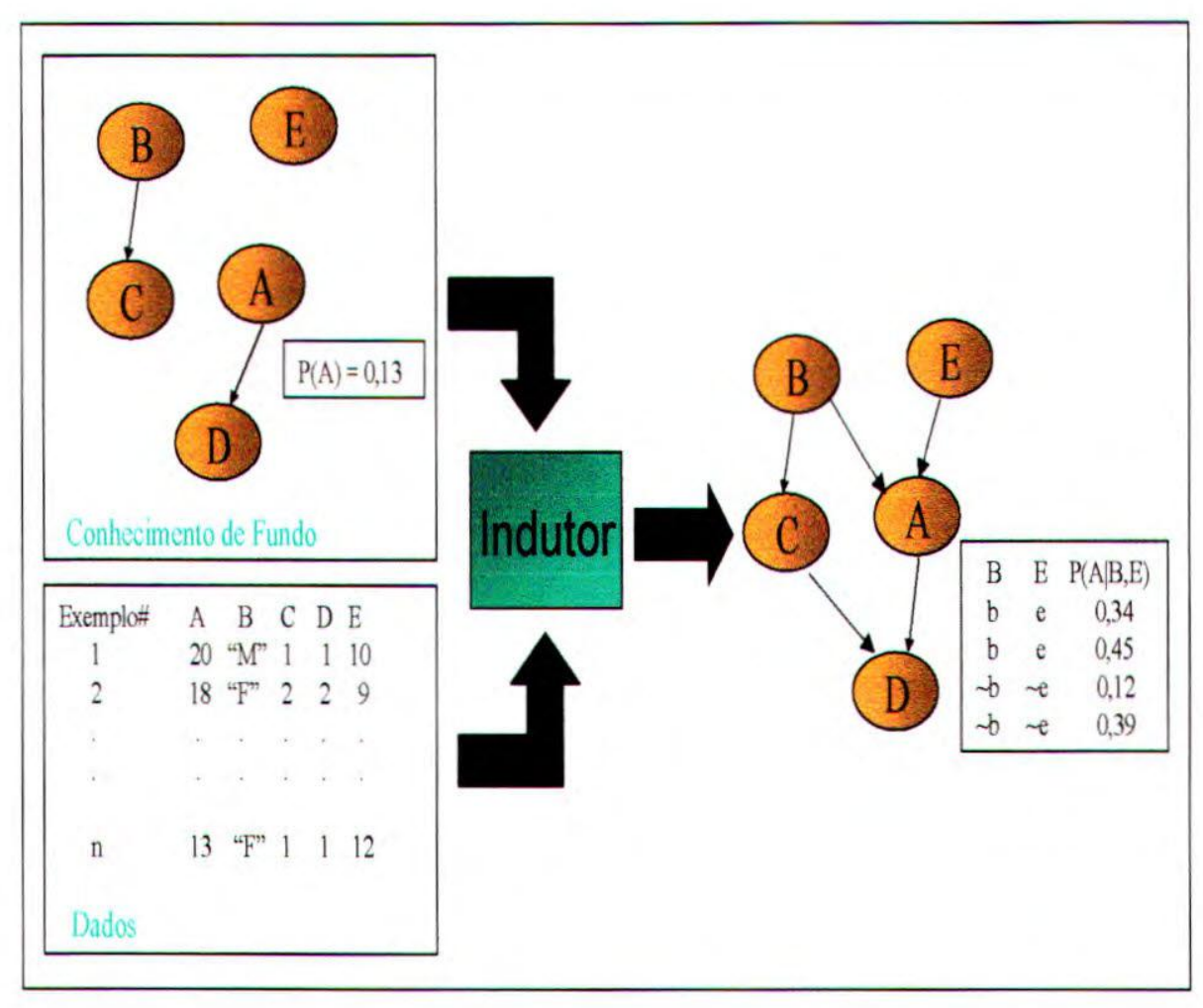

Figura 5.2: Esquema básico da combinação de conhecimento de fundo com dados em redes Bayesianas.

A combinação do conhecimento de fundo com os dados pode ocorrer basicamente de dois modos:

- Fornecimento a priori de toda a estrutura da rede.

- Atualização do conhecimento fornecido a priori.

No primeiro modo, o analista, por meio de interações com o especialista, fornece toda a estrutura da rede Bayesiana, em seguida submete ao algoritmo de aprendizado um conjunto de dados (com os atributos equivalentes aos nós da rede dada) com a finalidade de induzir os valores de probabilidades a partir desses dados. Uma variação desse modo é proposto por Heckerman. Neste método, toda a estrutura da rede Bayesiana é fornecida como entrada e 
o algoritmo, além de calcular os valores de probabilidades, utiliza os dados para "corrigir" a estrutura fornecida a priori (Heckerman et al., 1995).

No segundo modo, o especialista fornece algum conhecimento prévio (e.g. um ou mais elementos citados na subseção 5.4.1) e, em seguida, o algoritmo atualiza as probabilidades que por ventura foram fornecidas a priori, e/ou induz o que não foi fornecido (ligações entre nós e/ou probabilidades). Um exemplo desse modo de combinação é observado no algoritmo BKD (Ramoni and Sebastiani, 1997b).

Muitos dos algoritmos de aprendizado Bayesiano propostos na literatura possuem mecanismos para combinação de conhecimento de fundo com dados (e.g. BKD). Apesar disto, é importante destacar que alguns algoritmos não geram redes Bayesianas a partir dos dados; ao invés disso, trabalham (efetuando inferências) apenas com o conhecimento de fundo, ou seja, toda a rede Bayesiana (probabilidades e estrutura) é fornecida a priori. O Hugin constitui um exemplo destes sistemas.

\subsection{Considerações Finais}

A combinação de conhecimento de fundo com o conhecimento embutido nos dados merece ser observada antes mesmo do processo KDD iniciar, quando se deve efetuar um levantamento da quantidade e tipo do conhecimento a priori disponível. Esta combinação é freqüentemente realizada através das interações entre os envolvidos na aplicação desse processo.

Neste trabalho, a incorporação de conhecimento de fundo é enfatizada na etapa de Data Mining, sobretudo por proporcionar uma diminuição do esforço empregado na extração de padrões, haja vista que conhecimentos prévios do domínio podem ser incorporados a esse processo.

$\mathrm{Na}$ etapa de DM, a incorporação de conhecimento de fundo ocorre de acordo com o tipo e o paradigma de aprendizado que está sendo utilizado. Dessa forma, a potencialidade do que pode ser representado a priori depende muito da linguagem de descrição de conceitos do algoritmo de aprendizado. Por exemplo, alguns algoritmos permitem apenas a representação de conceitos sob o cálculo proposicional, sendo, portanto, muito difícil a representação de incerteza a partir dessa linguagem. Outro aspecto a ser sublinhado é a simplicidade (em termos humanos) da representação do conhecimento de fundo. Essa simplicidade é fundamental para facilitar a interação especialista-analista no provimento do conhecimento do domínio 
para facilitar a interação especialista-analista no provimento do conhecimento do domínio para os sistemas de aprendizado.

Neste capítulo, foram mostradas dois modos de manipular conhecimento de fundo na etapa de Data Mining do processo KDD, considerando dois paradigmas diferentes - simbólico e Bayesiano.

No que concerne ao aprendizado simbólico foi apresentado um exemplo do uso de métodos para guiar a indução de regras a partir dos dados. Esse método pressupõe a existência de um modelo qualitativo, representando o conhecimento de fundo, utilizado para que o algoritmo produza não apenas regras com alta acurácia, mas que sejam explicadas por esse conhecimento de fundo. Evidentemente, deve ser observado que o sucesso desse método depende da qualidade do MQ; um MQ mal definido implicará em um espaço de regras limitado ou muito amplo a ser "estudado" pelo algoritmo de aprendizado.

A incorporação de conhecimento de fundo em redes Bayesianas se caracteriza pela integração direta de elementos que constituem o modelo da rede. Segundo Dietterich, a incorporação de conhecimento de fundo representa uma das maiores motivações para o estudo de redes Bayesianas pelos pesquisadores de Aprendizado de Máquina. Enquanto a maioria dos métodos padrões de Aprendizado de Máquina alcançam esse objetivo por meio de alguma extensão, as redes Bayesianas efetuam essa incorporação de maneira direta (Dietterich, 1997). Vale ressaltar, entretanto, que alguns pesquisadores contestam a simplicidade da formulação de modelos probabilísticos para alguns domínios, haja vista a dificuldade de dimensionar, em termos probabilísticos, o conhecimento especialista (Clark and Matwin, 1993a).

No próximo capítulo serão apresentadas as principais ferramentas utilizadas neste trabalho. 


\section{Capítulo 6}

\section{Ferramentas Utilizadas}

\subsection{Considerações Iniciais}

Atualmente, existem várias ferramentas que podem ser utilizadas para auxiliar a execução das etapas do Processo de Extração de Conhecimento de Bases de Dados. O espectro de aplicação dessas ferramentas compreende desde programas para preparação e filtragem dos dados até as ferramentas de visualização do conhecimento extraído. Neste trabalho, algumas ferramentas foram utilizadas nas etapas de Seleção e Preparação dos Dados e de Data Mining. Primeiramente, são mostradas as ferramentas utilizadas na etapa de Seleção e Preparação dos Dados. Em seguida, na seção 6.3, são focalizadas as ferramentas utilizadas na etapa de Data Mining. E, por último, na seção 6.4, são feitas algumas consideraçōes finais a respeito de todas essas ferramentas.

\subsection{Ferramentas Utilizadas na Etapa de Seleção e Pre- paração dos Dados}

As ferrramentas mais utilizadas para apoiar a etapa Seleção e Preparação dos Dados são as próprias ferramentas de gerenciamento de Bases de Dados. Como os dados utilizados nos estudos de casos foram fornecidos pelo especialista no formato texto, a maioria das tarefas de preparação dos dados foram feitas no MSExcel, dada a simplicidade e disponibilidade desse software. Como exemplos dessas tarefas, podem ser citadas: seleção dos conjuntos de dados, e filtragem de atributos e registros. Entretanto, vale ressaltar que só foi possível utilizar o 
MSExcel a partir da divisão da base de dados em conjuntos de dados menores, posto que essa ferramenta trabalha com, no máximo, 65.536 registros (linhas).

No primeiro estudo de caso, referente ao Programa de Melhoramento Genético da Raça Nelore (Capítulo 7), a limitação da ferramenta não foi prejudicial mesmo trabalhando com a base de dados do PMGRN, composta por mais de 85.000 animais, em razão da mesma ter sido dividida, a pedido do especialista, em grupos de animais nelore nascidos no mesmo ano e submetidos à mesma condição de manejo.

Além do MSExcel, em algumas atividades específicas, foi necessária a elaboração, em C++Buider, de programas simples para a preparação dos dados. Assim, foram criados os programas NovaBase, utilizado no estudo de caso do Programa de Melhoramento Genético da Raça Nelore, cuja função é criar uma nova base de dados a partir da concatenação de registros da base original, e o ValAus, utilizado nos dois estudos de casos apresentados neste trabalho, que gera aleatoriamente valores ausentes em uma base de dados fornecida como entrada. Como esses programas foram criados exclusivamente para atender às necessidades dos estudos de casos apresentados nos Capítulos 7 e 8, um melhor entendimento será obtido quando da aplicação dos mesmos.

\subsection{Ferramentas Utilizadas na Etapa de Data Mining}

Na etapa de Data Mining foram utilizados o software Mineset ${ }^{T M}$, da Silicon Graphics e as ferramentas que implementam métodos Bayesianos - BKD e o Hugin System. O Mineset ${ }^{T M}$ foi utilizado para discretização e conseqüente visualização da distribuição dos valores dos atributos dentro das faixas resultantes dessas discretizações. Já o BKD foi utilizado para extração de padrões e pré-avaliação dos resultados. Enquanto que o Hugin System foi utilizado apenas para a pré-avaliação dos resultados obtidos. Esses softwares são apresentados a seguir.

\subsubsection{Mineset ${ }^{T M}$}

O Mineset ${ }^{T M 1}$ é um software da Silicon Graphics que congrega um conjunto de ferramentas para Data Mining, utilizando alguns dos principais algoritmos de Aprendizado de Máquina,

\footnotetext{
${ }^{1}$ Maiores detalhes sobre as propriedades e os recursos do Mineset $^{T M}$ podem ser encontrados em (Oliveira and Rezende, 1998) ou no próprio Guia do Usuário desse software.
} 
e um conjunto de ferramentas de visualização, que permite visões dos dados, das estatísticas geradas sobre esses dados e dos resultados obtidos pelas ferramentas de DM. Este software é constituído por três componentes básicos:

- Módulo de controle centralizado: consiste de uma interface gráfica chamada Tool Manager e um processo chamado Data Mover, que é executado no servidor todas as vezes que o Mineset ${ }^{T M}$ é executado.

- Ferramenta para Data Mining: possui quatro utilitários:

- Gerador de regras de associação.

- Classificador e indutor de árvore de decisão.

- Importância das colunas (atributos).

- Classificador e indutor de evidência.

- Ferramentas de visualização: consiste de oito módulos de visualização:

- Visualizador de árvores de decisão.

- Visualizador bidimensional e tridimensional.

- Visualizador de mapas.

- Visualizador de regras.

- Visualizador de evidências da classe dentro de cada atributo.

- Visualizador da base ou conjunto de dados.

- Visualizador de estatísticas geradas pelo Mineset ${ }^{T M}$.

- Visualizador difuso bidimensional e tridimensional.

O Mineset ${ }^{T M}$ utiliza uma biblioteca de algoritmos de aprendizado de máquina, chamada de $M L C^{++}$, para auxiliar nas tarefas de Data Mining. Essa biblioteca é de domínio público, e desde 1995 encontra-se sob a responsabilidade da Silicon Graphics. Maiores detalhes da disponibilidade, bem como das características da $M L C^{++}$podem ser encontrados em http: //www.sgi.com/Technology/mlc/indedx.html.

O Mineset ${ }^{T M}$ foi utilizado, em ambos os estudos de caso deste trabalho, na etapa de Data Mining. Mais especificamente, foram utilizadas as ferramentas de discretização e visualização da distribuição dos dados dentro das faixas de valores discretizados. 


\subsubsection{Bayesian Knowledge Discoverer}

O Bayesian Knowledge Discoverer (BKD), desenvolvido por Marco Ramoni e Paola Sebastiani na Open University em 1997, é uma ferramenta capaz de extrair redes Bayesianas a partir de bases de dados completas ou incompletas. O principal objetivo do BKD é prover a extração de conhecimento de base de dados na forma de redes Bayesianas, bem como as respectivas probabilidades condicionais entre as variáveis dessas redes (Ramoni and Sebastiani, 1997b).

Além disso, o BKD implementa um Algoritmo de Propagação Orientado a Metas que pode ser utilizado para apoiar um processo de tomada decisão quantificado através de probabilidades. Isto é, a partir da interface implementada para esse algoritmo, é possível efetuar inferências na rede bayesiana gerada, consultando as probabilidades condicionais, verossimilhança e variância, bem como as probabilidades marginais, dada a ocorrência de determinadas evidências nos estados (valores) das variáveis da rede.

As principais tarefas desempenhadas pelo BKD podem, portanto, ser resumidas em:

- Gerar redes Bayesinas a partir de informaçōes do usuário e/ou a partir de bases de dados completas ou que possuam valores ausentes.

- Estimar as distribuições de probabilidade condicional de uma dada estrutura de rede Bayesiana.

- Executar o Algoritmo de Propagação para inferência sobre as redes Bayesianas geradas.

Um exemplo de uma rede Bayesiana gerada pelo BKD, bem como de uma tabela de probabilidade condicional de um dos nós dessa rede, pode ser observado na Figura 6.1.

Uma vez gerada a rede Bayesiana e as respectivas TPCs, pode-se efetuar inferências por intermédio do Algoritmo de Propagação. Para um melhor entendimento da aplicação desse algoritmo considere a rede gerada pelo BKD mostrada na Figura 6.1, e a seguinte situação: deseja-se conhecer a probabilidade da variável $F$ assumir o valor $F 3$, dada a evidência de que a variável $E=E 2$. Essa situação é ilustrada na Figura 6.2.

Dessa forma, a probabilidade de $F$ ser igual a $F 3$ é de $36,9 \%$, dada a evidência de que $E=E 2$.

Vale ressaltar que o BKD trabalha apenas com variáveis discretas. Caso a base de dados possua atributos contínuos o próprio BKD os discretiza, automaticamente, por frequiência, 


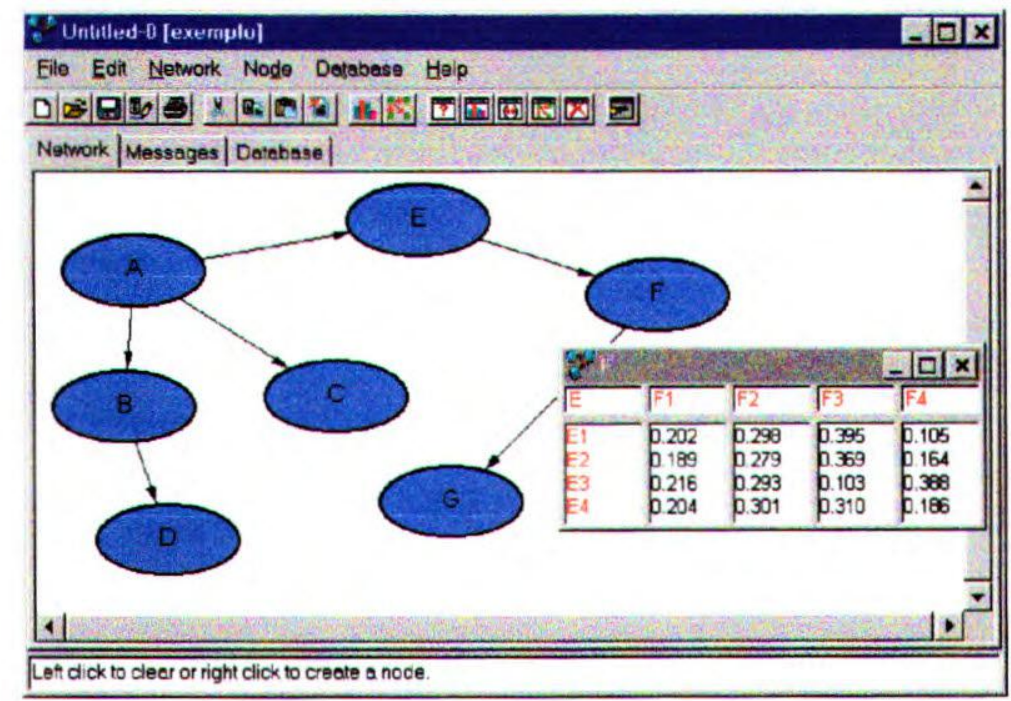

Figura 6.1: Exemplo de uma rede Bayesiana gerada pelo BKD.

em quatro faixa de valores.

Outra característica importante, permitida pelo BKD, é a possibilidade da combinação de conhecimento de fundo com o conhecimento embutido nos dados. Ou seja, antes da rede ser gerada a partir dos dados, é possível, por meio de intervenções do especialista, fornecer alguns conhecimentos a priori (e.g. estabelecer dependências ou atribuir valores às tabelas de probabilidades condicionais). As redes Bayesianas podem, ainda, serem criadas a partir, e tão somente, de informações do especialista.

O BKD também oferece a possibilidade de se obter redes Bayesianas mesmo a partir de conjuntos de dados incompletos, que é realizado por intermédio do método Bound e Collapse (visto na seção 4.5) implementado por esse software.

Neste trabalho, o BKD foi utilizado na etapa de Data Mining dos dois estudos de casos, que serão apresentados nos próximos capítulos, para extração de conhecimento tanto de conjuntos de dados completos como incompletos e conseqüente inferência sobre as redes Bayesianas. Além disso, foram utilizados os recursos desse software para combinação de conhecimento de fundo com o conhecimento embutido nos dados.

\subsubsection{Hugin System}

Em função da interface mais amigável e de apresentar mais recursos para inferências nas redes Bayesianas que o BKD, o Hugin System foi utilizado para a pré-avaliação do conhecimento 


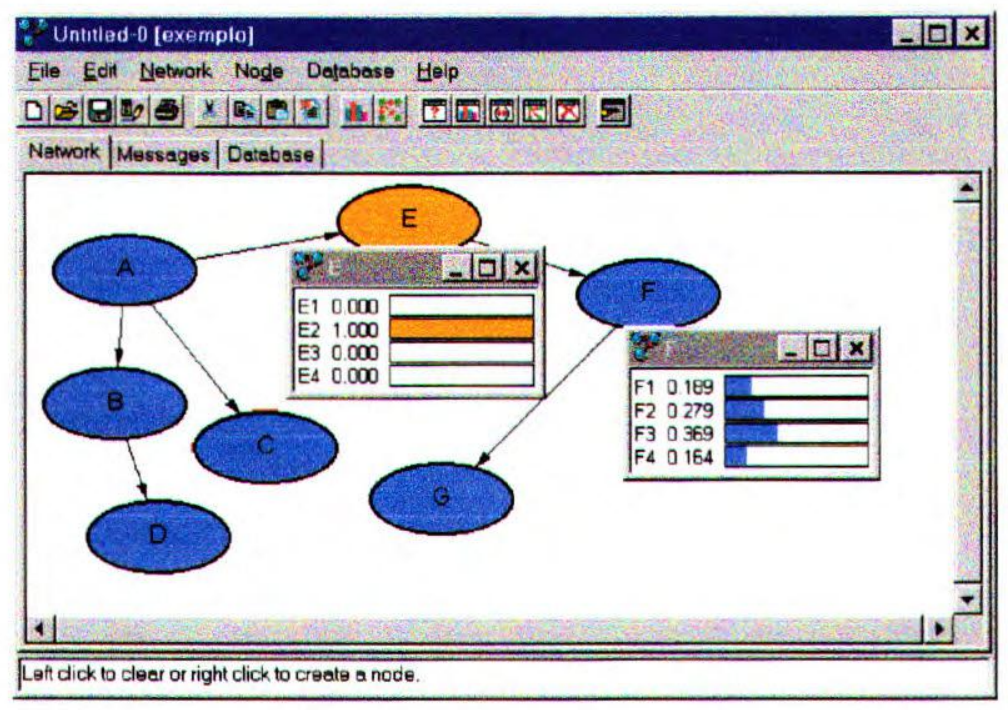

Figura 6.2: Exemplo da aplicação do Algoritmo de Propagação do BKD.

extraído.

O Hugin System é uma ferramenta capaz de construir modelos de apoio à tomada de decisão em domínios caracterizados por inerente incerteza. Os modelos suportados são redes Bayesianas e suas extensões, chamadas de diagramas de influência ${ }^{2}$. O Hugin é composto por dois módulos: o Hugin Runtime - um ambiente de edição, criação e inferência de redes Bayesianas e diagramas de influência; e o Hugin API (Application Program Interface) biblioteca (escrita em Linguagem C) que permite ao programador usar as redes Bayesianas e os diagramas de influência em suas próprias aplicações.

Ao contrário do BKD, o Hugin não permite a construção de redes Bayesianas a partir dos dados. Dessa forma, a criação da rede é feita por meio da interação com o especialista do domínio que deve fornecer as informações referentes às relações de dependência e às probabilidades condicionais dos nós dessa rede. Um outro modo de construir a rede, sem a interação direta com o especialista, é fornecer como entrada uma rede gerada, a partir dos dados, por outro método (e.g. BKD) e avaliada pelo especialista.

Em virtude do Hugin não criar a estrutura de uma rede Bayesiana a partir dos dados, neste trabalho, as mesmas foram construídas a partir das redes geradas pelo BKD, utilizando o ambiente de edição de redes Bayesianas oferecidas pelo Hugin. Além disso, todos

\footnotetext{
${ }^{2}$ Apenas as redes Bayesianas serão abordadas neste trabalho, pois os diagramas de influência fogem ao escopo do mesmo.
} 
os valores de probabilidade das TPCs também foram fornecidos como entrada para esta ferramenta. Este procedimento foi adotado em virtude, principalmente, do Hugin oferecer maiores recursos de interface e de inferência sobre redes Bayesianas.

Na Figura 6.3 é apresentada a rede Bayseana mostrado na Figura 6.1, desta vez construída no Hugin.

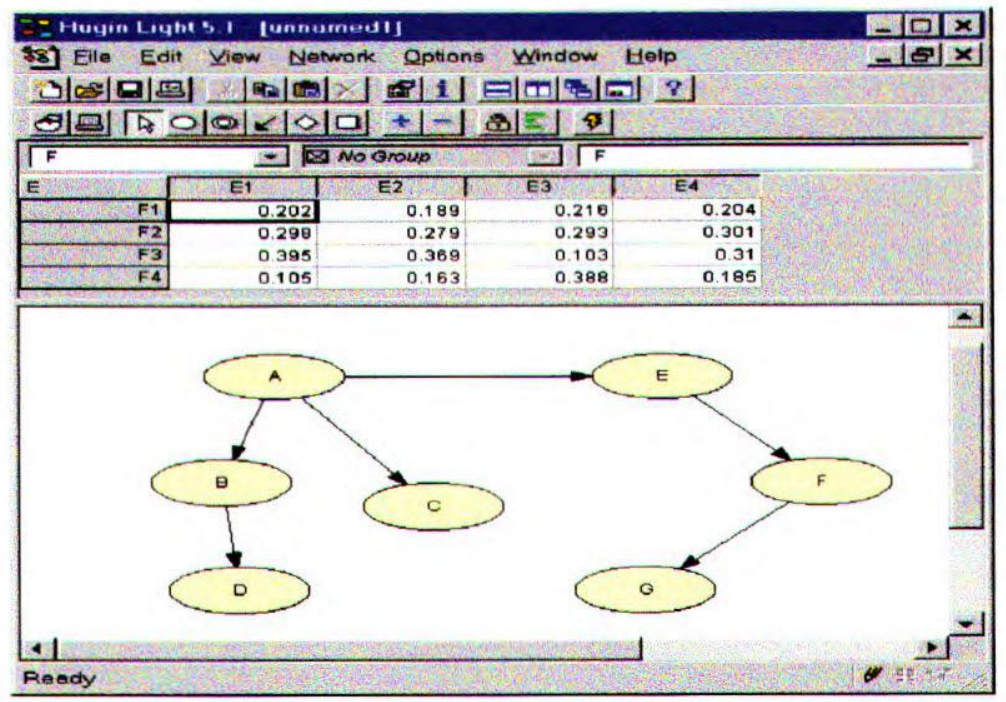

Figura 6.3: Exemplo de uma rede bayesiana criada no Hugin System.

Após a construção das redes e o fornecimento das respectivas probabilidades condicionais, pode-se efetuar inferências sobre as mesmas. Assim como a ferramenta BKD, o Hugin possui um algoritmo de propagação que pode ser utilizado para efetuar consultas às distribuições de probabilidade marginais das variáveis da rede. Na Figura 6.4 é mostrada a mesma situação do exemplo visto na Figura 6.2.

É possível observar na Figura 6.4 que a probabilidade $(36,9 \%)$ de $F$ assumir o valor $F 3$, dada a evidência de que a $E=E 2$, é a mesma obtida pelo BKD (Figura 6.2).

O método de propagação exemplificado na Figura 6.4 é o mais comum (método também implementado pelo BKD), chamado de sum normal. Esse método atualiza todas as probabilidades de acordo com as evidências dadas como entrada.

Além desse método de propagação, o Hugin oferece outros três tipos: max normal, sum fast retraction e max fast retract, que serão descritos a seguir.

O método max normal pode ser usado com o objetivo de encontrar quais os estados (valores) das variáveis pertencem à mais provável configuração (uma configuração é uma 


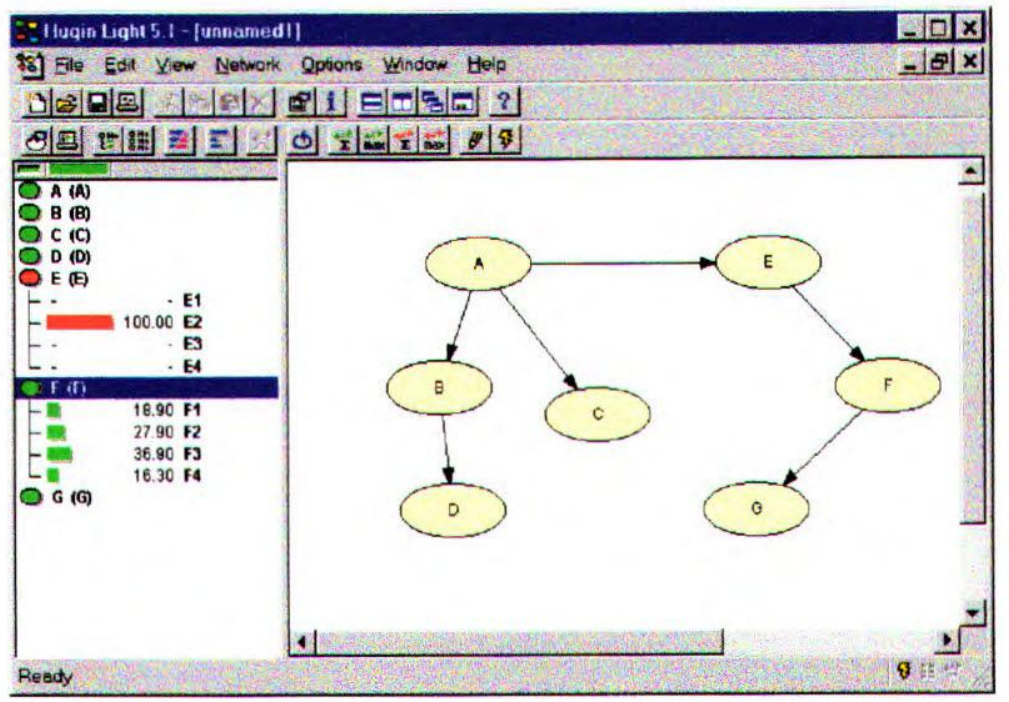

Figura 6.4: Exemplo da aplicação do Algoritmo de Propagação do Hugin.

lista de estados $\left(a_{1}, a_{2}, \ldots, a_{n}\right)$ de todos os nós de uma rede bayesiana $\left.\left(A_{1}, A_{2}, \ldots, A_{n}\right)\right)$. Se um estado de uma variável pertence à mais provável configuração, então o valor $100 \%$ é atribuído a ele. A todos os outros estados que não fazem parte dessa configuração são atribuídos valores relativos de probabilidade de acordo com a mais provável configuração. Na Figura 6.5, é apresentado um exemplo da mais provável configuração (estados das variáveis que apresentam valores iguais a 100\%) da rede bayesiana mostrada na Figura 6.3, dadas as evidências de que $D=D 1$ e $E=E 2$. Assim, a mais provável configuração mostrada nessa situação é $A=A 4, B=B 1, C=C 4, F=F 3$ e $G=G 1$, além, obviamente, das duas evidências para as variáveis D e E.

O método sum fast retraction é um tipo de propagação similar ao sum normal, exceto que ele mostra os nós que recebem evidência de maneira diferente. Ao invés de mostrar a probabilidade verdadeira dos estados de um determinado nó que recebe uma evidência, a probabilidade dos estados desse nó è mostrado como se ele não recebesse nenhuma evidência. Este método pode ser também usado para checar se há conflito na evidência de um estado de um determinado nó.

O método max fast retraction é semelhante ao max normal, exceto que ele mostra os nós que recebem evidência de maneira diferente. Ao invés de mostrar os valores dos estados do nó que recebe a evidência, as probabilidades dos estados desse nó são mostradas como se ele não recebesse nenhuma evidência. Este método pode ser também usado para checar se 


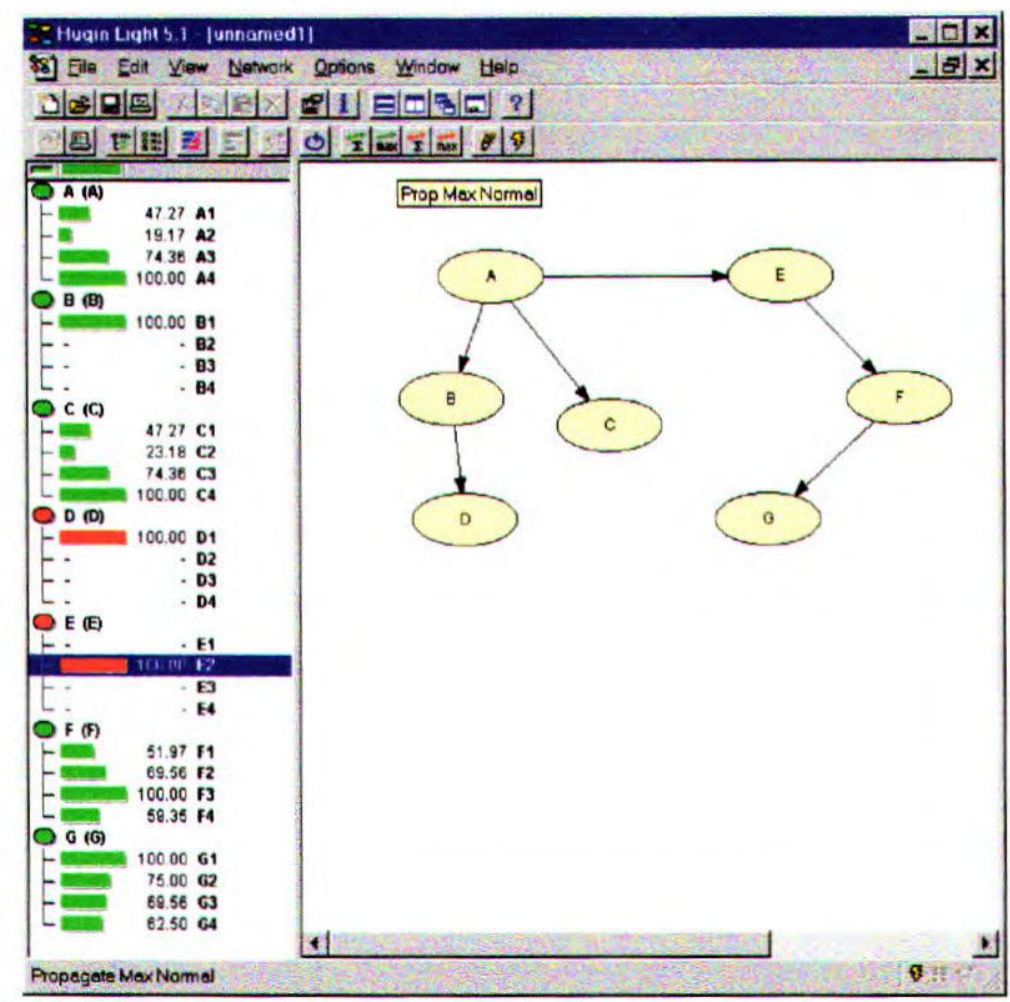

Figura 6.5: Exemplo do método de propagação max normal.

a evidência corresponde a(uma das) mais provável(éis) configuração(ões) ou se a evidência sugere que uma das configurações menos prováveis foi observada (se para um estado de um determinado nó foi observado que não ocorre o valor igual a $100 \%$ ).

\subsection{Considerações Finais}

Neste capítulo, foram apresentadas as ferramentas utilizadas para aplicação do processo KDD nos dois estudos de casos (que serão vistos nos Capítulos 7 e 8) apresentados neste trabalho.

$\mathrm{Na}$ escolha das ferramentas da etapa de Data Mining, procurou-se utilizar aquelas que cobrissem a maior quantidade de recursos providos pelo formalismo das redes Bayesianas. Como exemplos desses recursos podem ser citados: aprendizado causal, algoritmos de propagação, mecanismos para tratamento de dados incompletos e incorporação de conhecimento de fundo.

Neste trabalho, portanto, foram utilizadas ferramentas, sob o paradigma estatístico, que implementassem a maioria desses recursos, além de oferecerem uma interface amigável 
de edição e construçäo de redes Bayesianas. Outra característica destas ferramentas é a fácil compreensāo, por parte do especialista do domínio, dos resultados obtidos (conhecimento extraído).

Na Tabela 6.1, é apresentada uma síntese das principais propriedades e recursos implementados pelo BKD e Hugin.

\begin{tabular}{|c|c|c|}
\hline Propriedades/Recursos & BKD & Hugin \\
\hline $\begin{array}{l}\text { Linguagem de Descriçäo } \\
\text { de Exemplos }\end{array}$ & $\begin{array}{l}\text { atributo-valor/ } \\
\text { redes Bayesianas }\end{array}$ & redes Bayesianas \\
\hline $\begin{array}{c}\text { Linguagem de Descriçäo } \\
\text { de Conceitos }\end{array}$ & redes Bayesianas & redes Bayesianas \\
\hline $\begin{array}{c}\text { Linguagem de Descrição } \\
\text { de Conhecimento de Fundo }\end{array}$ & $\begin{array}{l}\text { relacionamentos } \\
\text { causais }\end{array}$ & $\begin{array}{c}\text { relacionamentos } \\
\text { causais }\end{array}$ \\
\hline $\begin{array}{l}\text { Tratamento de Dados } \\
\text { Incompletos }\end{array}$ & $\begin{array}{c}\text { sim (método } \\
\text { Bound \& Collapse) }\end{array}$ & não \\
\hline Algoritmo de Propagação & possui & possui \\
\hline $\begin{array}{c}\text { Ambiente Gráfico para } \\
\text { Ediçäo de Redes Bayesianas }\end{array}$ & possui & possui \\
\hline Bases de Dados Suportadas & texto & não suporta \\
\hline $\begin{array}{c}\text { API (Aplication Program } \\
\text { Interface) }\end{array}$ & não possui & possui \\
\hline $\begin{array}{l}\text { Principal site } \\
\text { relacionado }\end{array}$ & www.kmi.open.ac.uk & www.hugin.com \\
\hline
\end{tabular}

Tabela 6.1: Propriedades e recursos implementados pelo BKD e Hugin System.

No próximo capítulo é apresentado o estudo de caso do Programa de Melhoramento Genético da Raça Nelore, que faz uso de todas as ferramentas aqui abordadas. 


\section{Capítulo 7}

\section{Estudo de Caso - Base de Dados do Programa de Melhoramento Genético da Raça Nelore}

\subsection{Considerações Iniciais}

Em 1997, o Laboratório de Inteligência Computacional (LABIC), do Instituto de Ciências Matemáticas e de Computação (ICMC) da USP-São Carlos, em parceria com o Departamento de Genética da Faculdade de Medicina (DGFM), da Universidade de São Paulo (USP) -Ribeirão Preto, começou a trabalhar em um projeto de pesquisa que utiliza a tecnologia de Extração de Conhecimento de Bases de Dados com o objetivo de encontrar padrões e situaçōes de interesse na base de dados do Programa de Melhoramento Genético da Raça Nelore (PMGRN). A partir de informações iniciais e das interações com os especialistas, especialmente na pessoa do Prof. Dr. Raysildo Lôbo, Coordenador desse programa, foi traçado o objetivo específico de encontrar padrões de acasalamento entre os animais do PMGRN, considerando algumas funcionalidades como crescimento, habilidade materna e fertilidade do animal.

A finalidade deste capítulo é aplicar o processo KDD na extração de conhecimento da base de dados do PMGRN, visando auxiliar o processo de tomada de decisão dos especialistas e criadores de gado da raça nelore, principalmente no que se refere ao acasalamento de animais dessa raça. Além disso, dentro da aplicação do processo, é necessaário verificar a 
utilização dos métodos Bayesianos na etapa de Data Mining, considerando a incorporação de conhecimento de fundo e o tratamento de dados incompletos.

A organização deste capítulo segue as etapas do processo KDD, isto é, na próxima seção é apresentado um resumo das características do domínio da aplicação, bem como da descrição da base de dados do PMGRN, em seguida, na seção 7.3, é mostrada a etapa de seleção e preparação dos dados. Na seção 7.4, é focalizada a etapa de Data Mining - os métodos de aprendizado Bayesianos aplicados aos conjuntos de dados selecionados a partir da base de dados do PMGRN, bem como a incorporação de conhecimento de fundo e o tratamento de dados incompletos providos por esses métodos. Na seção 7.5, são realizadas as análises dos resultados obtidos na aplicação do processo KDD. Por último, na seção 7.6, são apresentadas algumas consideraçōes finais a respeito desse estudo de casos.

\subsection{Compreensão do Domínio da Aplicação}

O Programa de Melhoramento Genético da Raça Nelore teve seu início em junho de 1988, a partir da união de criadores, em busca de tecnologias modernas e de fácil aplicação na pecuária, e de pesquisadores do DGFM, da USP, que juntos definiram metas para viabilizar o aumento da produtividade do rebanho de corte nacional. O principal objetivo da utilização dessas tecnologias é avaliar touros, matrizes e animais jovens, a fim de permitir a obtenção das Diferenças Esperadas nas Progênies (DEPs), de características como peso e perímetro escrotal, padronizados para diferentes idades, com o apoio dos pesquisadores do DGFM.

Em outubro de 1994, o PMGRN começou a empregar a metodologia do Modelo Animal, uma das mais avançadas tecnologias disponíveis no mercado internacional, para predizer o valor genético, na forma de DEP, de todos os animais integrantes do programa (Lobo et al., 1998).

A Diferença Esperada na Progênie é usada em todo o mundo para comparar o mérito genético de animais para várias características, e prediz a habilidade da transmissão genética de um animal avaliado como progenitor. As DEPs são preditas para pesos, efeito materno e perímetros escrotais, padronizados para diferentes idades. Os efeitos dessas DEPs são as seguintes:

- A DEP pára efeito direto no peso indica a diferença esperada em quilogramas, de acordo com os genes para crescimento passados pelos seus pais. 
- A DEP para efeito materno prediz a diferença esperada em peso dos produtos (filhotes) das filhas do animal avaliado, devido às diferenças na habilidade maternal (produção de leite) apresentada por elas.

- A DEP para efeito direto no perímetro escrotal prediz a habilidade do animal em transmitir genes de crescimento testicular a sua progênie, sendo esta uma característica importante para a verificação da fertilidade e da precocidade sexual do animal.

As DEPs são mensuradas em várias fases da vida dos animais, sendo as medidas mais comuns realizadas aos 120,240,365 e 550 dias. Para efeito da aplicação do processo KDD no PMGRN, foram utilizadas DEPs para pesos aos 120, 240, 365 e 550 dias de idade, para perímetros escrotais aos 365 e 550 dias, e para efeito materno aos 120 e 240 dias de idade.

$O$ modelo geral inclui os efeitos fixos de grupo contemporâneo e classe de idade da vaca ao parto, e como aleatórios, os efeitos genéticos maternal e direto, além do efeito do ambiente permanente. Os grupos contemporâneos, para cada característica, foram definidos como sendo formado por animais do mesmo sexo, nascidos no mesmo rebanho, ano e trimestre, e submetidos ao mesmo sistema de manejo e alimentação. A idade da vaca ao parto foi agrupada em 6 classes: menor que 36, 36 a 47, 48 a 59, 60 a 71, 72 a 119 e maior que 119 meses de idade.

Atualmente, o PMGRN é formado por cerca de 60 rebanhos dos estados da Bahia, Goiás, Maranhão, Mato Grosso do Sul, Minas Gerais e Tocantins, totalizando cerca de 144.000 animais. Os animais participantes desse programa são submetidos a um controle periódico e bastante criterioso das características produtivas e reprodutivas. As informações referentes a essas características são colhidas e enviadas (em disquetes ou pela internet) pelo criador, mediante um programa de gerenciamento de rebanhos, ao Núcleo de Processamento de dados do PMGRN. Todos esses dados, junto com o número de registro do animal, do pai e da mãe do animal são armazenadas em uma base de dados para análises de interesse dos criadores e dos especialistas do DGFM.

Uma parte dessa base de dados resultante, composta por 69.573 animais, foi fornecida pelo Coordenador do Programa, com a finalidade de encontrar padrões de interesse nos dados, via processo KDD.

A descrição geral dessa base de dados é apresentada na Tabela 7.1. Para um melhor entendimento da composição da base de dados do PMGRN, é apresentada na Tabela 7.2 a 


\begin{tabular}{|c|c|c|c|c|c|c|c|}
\hline Nome & Registros & $\begin{array}{l}\text { Atributos } \\
\text { Contínuos }\end{array}$ & $\begin{array}{c}\text { Atributos } \\
\text { Discretos }\end{array}$ & Touros & Matrizes & Nelore & $\begin{array}{l}\text { Outras } \\
\text { Raças }\end{array}$ \\
\hline \hline BaseGeral & 69.573 & 18 & 17 & 26.128 & 43.445 & 56.068 & 13.505 \\
\hline
\end{tabular}

Tabela 7.1: Descrição da base de dados do PMGRN.

descrição de seus principais atributos.

Além dos detalhes da base de dados do PMGRN, foram considerados vários aspectos para a compreensão do domínio PMGRN (conforme foi especificado na subseção 2.3.1). Esses fatores foram levantados por meio da interação entre os dois grupos envolvidos (LABIC e DGFM), utilizando de expedientes como: entrevistas, reuniões e seminários; providos tanto pelo LABIC, quanto pelo DGFM. Um resumo desses aspectos pode ser observados na Tabela 7.3.

A partir do entendimento do PMGRN e dos dados que o compõem, bem como os objetivos a serem atingidos pela aplicação do processo KDD, a base de dados do programa foi submetida a um processo de seleção e preparação, a fim de atender aos requisitos dos métodos de Data Mining e/ou dos próprios especialistas.

\subsection{Seleção e Preparação dos Dados}

Para realizar os objetivos propostos para a análise dos dados do PMGRN, foi necessária a construção de uma nova base de dados, a partir da base original, considerando os dados do animal e de seus pais, ou seja, todos os atributos do animal e de seus pais foram postos lado a lado gerando uma nova base de dados. O modo como foi criada essa nova base é ilustrado na Figura 7.1.

Para construir esse novo conjunto de dados, foi utilizado o programa NovaBase, cuja função é construir uma nova tabela contendo em cada registro todos os atributos do animal, do pai e da mãe desse animal (105 atributos). Dessa base de dados, foram considerados apenas os animais nelore que possuiam pais e mães cadastrados (37.706). A distribuição dos animais em relação ao cadastro das informações de seus pais pode ser visualizada na Tabela 7.4 .

Vale ressaltar que o pré-processamento da base de dados resultante foi bastante simplificado. Essa facilidade foi proporcionada pelo fato da base de dados original ter sido 


\begin{tabular}{|c|c|c|}
\hline G_ANIM & Registro genealógico definitivo do animal & Inteiro \\
\hline G_PAI & Registro genealógico definitivo do pai & Inteiro \\
\hline G_MĀE & Registro genealógico definitivo da mãe & Inteiro \\
\hline NFA & Número da fazenda & Inteiro \\
\hline SERIE & Série fornecida pela $A B C Z$, identificadora de animais & Inteiro \\
\hline $\mathbf{R C}$ & Raça & Inteiro \\
\hline $\mathbf{S X}$ & Sexo do animal & Inteiro \\
\hline DT_NASC & Data de nascimento do animal & Data \\
\hline PAI_SER & Série fornecida pela $A B C Z$ relativa ao pai & Inteiro \\
\hline MAE_SER & Série fornecida pela $A B C Z$ relativa à mãe & Inteiro \\
\hline NOME & Nome do animal & String \\
\hline DDPP120 & Valor da DEP direta para peso aos 120 dias & Real \\
\hline ADPP120 & Acurácia da DEP direta para peso aos 120 dias & Real \\
\hline DMPP120 & Valor da DEP materna para peso aos 120 dias & Real \\
\hline AMPP120 & Acurácia da DEP materna para peso aos 120 dias & Real \\
\hline DDPP240 & Valor da DEP direta para peso aos 240 dias & Real \\
\hline ADPP240 & Acurácia da DEP direta para peso aos 240 dias & Real \\
\hline DMPP240 & Valor da DEP materna para peso aos 240 dias & Real \\
\hline AMPP240 & Acurácia da DEP materna para peso aos 240 dias & Real \\
\hline DDPP365 & Valor da DEP direta para peso aos 365 dias & Real \\
\hline ADPP365 & Acurácia da DEP direta para peso aos 365 dias & Real \\
\hline DMPP550 & Valor da DEP materna para peso aos 550 dias & Real \\
\hline AMPP550 & Acurácia da DEP materna para peso aos 550 dias & Real \\
\hline DDPE365 & Valor da DEP direta para perímetro escrotal aos 365 dias & Real \\
\hline ADPE365 & Acurácia da DEP direta para perímetro escrotal aos 365 dias & Real \\
\hline DDPE550 & Valor da DEP direta para perímetro escrotal aos 550 dias & Real \\
\hline ADPE550 & Acurácia DEP direta para perímetro escrotal aos 550 dias & Real \\
\hline MGT & Mérito genérico total expresso em unidades de desvio padrão genético & Real \\
\hline
\end{tabular}

Tabela 7.2: Descrição dos principais atributos da base de dados do PMGRN. 


\begin{tabular}{|c|c|}
\hline Aspectos a Considerar & Observação \\
\hline $\begin{array}{l}\text { Viabilidade da aplicação } \\
\text { do processo KDD }\end{array}$ & $\begin{array}{l}\text { Foi viável em função da parceria } \\
\text { entre o LABIC e os especialistas } \\
\text { do domínio }\end{array}$ \\
\hline Conhecimento a priori & $\begin{array}{c}\text { Foi possível por contar com o auxílio } \\
\text { direto dos especialistas }\end{array}$ \\
\hline $\begin{array}{l}\text { Objetivos do usuário } \\
\text { final / especialista }\end{array}$ & $\begin{array}{c}\text { Encontrar padrōes de acasalamento } \\
\text { nos animais da raça nelore }\end{array}$ \\
\hline Fonte dos dados & $\begin{array}{l}\text { Base de Dados gerenciada e } \\
\text { fornecida pelo especialista }\end{array}$ \\
\hline Gargalos do domínio & $\begin{array}{l}\text { Grande quantidade de dados } \\
\text { e valores eminentemente contínuos }\end{array}$ \\
\hline Critérios de avaliação & $\begin{array}{l}\text { Foram utilizados os próprios } \\
\text { recursos das ferramentas utilizadas }\end{array}$ \\
\hline $\begin{array}{l}\text { Modo de utilização do } \\
\text { conhecimento }\end{array}$ & Exploração \\
\hline
\end{tabular}

Tabela 7.3: Resumo dos aspectos a serem considerados para compreensão do PMGRN.

\begin{tabular}{|c|c|}
\hline Descrição & Número de Registros \\
\hline \hline Animais com pai e mãe cadastrados & 37.706 \\
\hline Animais só com pai cadastrado & 7.518 \\
\hline Animais só com mãe cadastrada & 4.796 \\
\hline Animais sem pai e mãe cadastrados & 6.048 \\
\hline
\end{tabular}

Tabela 7.4: Distribuição dos animais em relação ao cadastro dos dados de seus pais. 


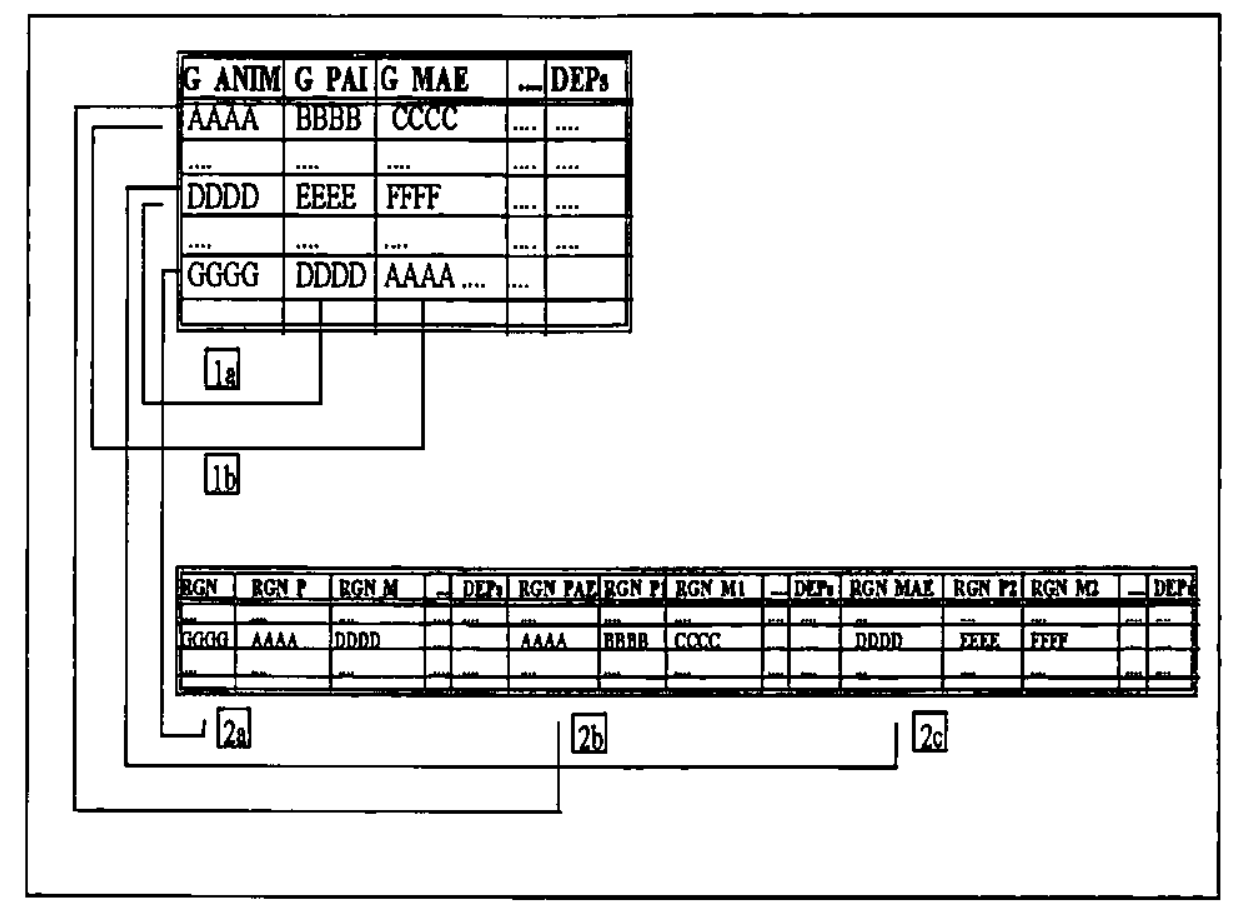

Figura 7.1: Nova base de dados gerada a partir do cruzamento dos dados dos animais e de seus pais.

fornecida no formato texto.

Uma vez selecionados e preparados ${ }^{1}$, os dados foram submetidos aos métodos de Data Mining. Neste trabalho, conforme já foi especificado, são utilizados os métodos de aprendizado Bayesianos para extração de padrões de acasalamento a partir dos dados do PMGRN.

\subsection{Data Mining}

Antes de se efetuar o processo de extração de padrōes, foram realizadas, por intermédio de interações com o especialista, reduções de atributos e instâncias no conjunto de dados resultante. Além disso, foram realizadas reduções por meio da discretizações dos valores desses conjuntos de dados, utilizando o Mineset ${ }^{T M}$.

\footnotetext{
${ }^{1}$ Após a etapa de seleção e preparação dos dados, a base de dados resultante é denominada, neste trabalho, de conjunto de dados.
} 


\subsubsection{Redução de Atributos e Instâncias}

Para efetuar as reduçōes de atributos e instâncias, foi estabelecido como filtro os grupos contemporâneos. Dessa forma, o conjunto de dados foi dividido, a pedido do especialista do domínio, em grupos contemporâneos, no qual cada conjunto de dados resultante é formado por animais nelore, nascidos no mesmo ano e submetidos as mesmas condiçōes de manejo. Partindo do pressuposto que os objetivos da análise dos dados do PMGRN se restringem aos valores das DEPs dos animais, foram considerados, para cada conjunto de dados formado por um determinado grupo contemporâneo, apenas os atributos de DEPs desses animais. Assim, foram utilizados apenas 22 atributos de DEPs dos 105 existentes para cada conjunto de dados de grupo contemporâneo. Na Tabela 7.5, esses atributos são especificados.

\begin{tabular}{|c|c|c|}
\hline Animal & Pai & Mãe \\
\hline \hline DMPP120 & DMPP120P & DMPP120_M \\
\hline DMPP240 & DMPP240P & DMPP240_M \\
\hline DDPP120 & DDPP120_ & DDPP120_M \\
\hline DDPP240 & DDPP240_P & DDPP240_M \\
\hline DDPP365 & DDPP365 P & DDPP365_M \\
\hline DDPP550 & DDPP550P & DDPP550_M \\
\hline DDPE365 & DDPE365 P & - \\
\hline DDPE550 & DDPE550P & - \\
\hline
\end{tabular}

Tabela 7.5: Relação de atributos de DEPs considerados para a análise dos grupos contemporâneos.

No que concerne a este estudo de caso, foram considerados para este estudo de caso os grupos contemporâneos de 1991, 1994, 1995 e 1996. A partir desses grupos, foram criados três conjuntos de dados, constituídos pelos grupos contemporâneos de 1991, o grupo de 1994 e, por último, um conjunto formado pela união dos animais dos grupos contemporâneos de 1995 e 1996. Na Tabela 7.6, são mostradas as descrições desses conjuntos de dados. A idéia de se trabalhar com vários grupos contemporâneos é justificada pela necessidade de se observar como varia as correlações dos valores das DEPs dos pais e de seus filhotes, ao longo dos anos.

Além da divisão por grupo contemporâneo, foi estabelecida, pelo especialista do domínio, 


\begin{tabular}{|c|c|}
\hline Nome do Arquivo & Número de Registros \\
\hline \hline Animais_1991 & 2.959 \\
\hline Animais_1994 & 6.844 \\
\hline Animais_1995_1996 & 15.808 \\
\hline
\end{tabular}

Tabela 7.6: Conjuntos de dados criados a partir dos grupos contemporâneos de 1991, 1994, 1995_1996.

a subdivisão dos três conjuntos de dados supracitados, obedecendo a três funcionalidades: crescimento, habilidade materna e fertilidade. Essas funcionalidades foram estudadas com objetivo de encontrar padrões na influência que os valores das DEPs dos pais exercem sobre determinadas DEPs dos filhotes. Para cada funcionalidade, foram consideradas apenas os atributos de DEPs mais relevantes (da coluna Animal mostrada na Tabela 7.5), além do sexo do animal condizente com essa funcionalidade. Os atributos de DEPs e o sexo dos animais considerados para o estudo das funcionalidades podem ser vistas na Tabela 7.7.

\begin{tabular}{|c|c|c|}
\hline Funcionalidade & Atributos dos Filhotes & Sexo dos Filhotes \\
\hline \hline Crescimento & DDPP120, DDPP365 e DDPP550 & Machos e Fêmeas \\
\hline Fertilidade & DDPE365 & Machos \\
\hline Habilidade Materna & DMPP120 & Fêmeas \\
\hline
\end{tabular}

Tabela 7.7: Atributos de DEPs e o sexo dos animais considerados para cada funcionalidade.

Dessa forma, foram criadas, para cada um dos conjuntos de dados mostrados na Tabela 7.6, três conjuntos de dados referentes a essas funcionalidades. Sendo cada um desses conjuntos formados apenas com animais de sexo e atributos de DEP relacionados com uma funcionalidade específica (conforme visto na Tabela 7.7), bem como todos os atributos de DEPs dos pais. A descrição desses conjuntos de dados pode ser visualizada na Tabela 7.8.

Outro aspecto que foi levado em consideração na reduçāo de atributos e instâncias, foi a discretização dos valores dos atributos dos conjuntos de dados utilizados neste estudo de caso. Apesar do BKD possuir um mecanismo para efetuar essa tarefa, foram realizadas discretizações, utilizando o Mineset ${ }^{T M}$, com a finalidade de confrontar os resultados obtidos (redes Bayesianas geradas utilizando o BKD) a partir de conjuntos de dados discretizados pelo BKD e pelo Mineset ${ }^{T M}$. Para efeito deste estudo de caso, foram discretizados os conjuntos de dados Crescimento_1991, Crescimento_1994, Hab_Materna_1991 e Hab_Materna_1994. 


\begin{tabular}{|c|c|c|}
\hline Nome do Arquivo & Número de Registros & Número de Atributos \\
\hline \hline Crescimento_1991 & 2.959 & 17 \\
\hline Fertilidade_1991 & 1.106 & 15 \\
\hline Hab_Materna_1991 & 1.853 & 15 \\
\hline Crescimento_1994 & 6.844 & 17 \\
\hline Fertilidade_1994 & 3.417 & 15 \\
\hline Hab_Materna_1994 & 3.427 & 15 \\
\hline Crescimento_1995_1996 & 15.808 & 17 \\
\hline Fertilidade_1995_1996 & 6.605 & 15 \\
\hline Hab_Materna_1995_1996 & 7.555 & 15 \\
\hline
\end{tabular}

Tabela 7.8: Conjuntos de dados criados a partir dos conjuntos de dados Animais_1991, Animais_1994 e Animais_1995_1996, considerando as funcionalidades sugeridas pelo especialista.

Na Figura 7.2, podem ser observadas, como exemplo, as distribuições de valores, dentro das faixas discretizadas pelo Mineset ${ }^{T M}$, para o conjunto de dados Crescimento_1991. O método de discretização usado, no Mineset ${ }^{T M}$, foi o stand-alone baseado na distribuição por frequência especificando 4 intervalos de discretização.

As faixas de valores geradas pelo Mineset ${ }^{T M}$, para os conjuntos de dados da Tabela 7.8, foram bastante semelhantes às faixas geradas pelo BKD. As Tabela 7.9 e Tabela 7.10 apresentam, como exemplo, as faixas de valores resultantes das discretizaçōes realizadas pelo Mineset $^{T M}$ e BKD para o conjunto de dados Crescimento_1991.

Outro recurso importante do Mineset ${ }^{T M}$, utilizado neste estudo de caso, foi o levantamento de alguns indicadores estatísticos dos conjuntos de dados. A seguir, na Figura 7.3, são apresentados alguns desses indicadores para o conjunto de dados Fertilidade_1991.

\subsubsection{Extração de Padrões}

Nesta etapa, os conjuntos de dados da Tabela 7.8 foram submetidos ao BKD. O objetivo da aplicação do BKD foi extrair conhecimento da base de dados do PMGRN, na forma de dependências entre as DEPs dos pais e de seus filhotes, além disso, efetuar inferências para quantificar essas dependências, mediante valores de probabilidades. A seguir são mostradas algumas das redes Bayesianas geradas pelo BKD a partir dos conjuntos de dados completos 


\begin{tabular}{|c|c|}
\hline Atributo & Faixas de Valores \\
& (m e M assumem, respectivamente, o maior e menor valor do atributo) \\
\hline \hline DDPP120_P & $(\mathrm{m}, 0.05],(0.05,1.45],(1.45,3.35],(3.35, \mathrm{M}]$ \\
\hline \hline DDPM120_P & $(\mathrm{m},-0.85],(-0.85,0.25],(0.25,1.35),(1.35, \mathrm{M}]$ \\
\hline \hline DDPP240_P & $(\mathrm{m}, 0.65],(0.65,2.8],(2.8,6.7],(6.7, \mathrm{M}]$ \\
\hline \hline DMPP240_P & $(\mathrm{m},-1.25],(-1.25,0.35],(0.35,1.95],(1.95, \mathrm{M}]$ \\
\hline \hline DDPP365_P & $(\mathrm{m}, 1.45],(1.45,4.75],(4.75,8.3],(8.3, \mathrm{M}]$ \\
\hline \hline DDPP550_P & $(\mathrm{m}, 2.45],(2.45,5.25],(5.25,9.55],(9.55, \mathrm{M}]$ \\
\hline \hline DDPE365_P & $(\mathrm{m},-0.25],(-0.25,-0.05],(-0.05,0.35],(0.35, \mathrm{M}]$ \\
\hline \hline DDPE550_P & $(\mathrm{m},-0.75],(-0.75,-0.25],(-0.25,0.25],(0.25, \mathrm{M}]$ \\
\hline \hline DDPP120_M & $(\mathrm{m},-0.75],(-0.75,0.05],(0.05,0.95],(0.95, \mathrm{M}]$ \\
\hline \hline DMPP120_M & $(\mathrm{m},-0.45],(-0.45,0.15],(0.15,0.85],(0.85, \mathrm{M}]$ \\
\hline \hline DDPP240_M & $(\mathrm{m},-1.15],(-1.15,0.25],(0.25,1.75],(1.75, \mathrm{M}]$ \\
\hline \hline DMPP240_M & $(\mathrm{m},-0.55],(-0.55,0.35],(0.35,1.35],(1.35, \mathrm{M}]$ \\
\hline \hline DDPP365_M & $(\mathrm{m},-1.65],(-1.65,0.65],(0.65,3.15],(3.15, \mathrm{M}]$ \\
\hline \hline DDPP550_M & $(\mathrm{m},-2.35],(-2.35,0.65],(0.65,4.15],(4.15, \mathrm{M}]$ \\
\hline \hline DDPP120 & $(\mathrm{m},-0.25],(-0.25,0.75],(0.75,1.95],(1.95, \mathrm{M}]$ \\
\hline \hline DDPP365 & $(\mathrm{m}, 0.15],(0.15,2.85],(2.85,5.65],(5.65, \mathrm{M}]$ \\
\hline \hline DDPP550 & $(\mathrm{m},-0.05],(-0.05,2.75],(2.75,6.15],(6.15, \mathrm{M}]$ \\
\hline \hline
\end{tabular}

Tabela 7.9: Faixas de valores das discretizações realizadas pelo Mineset $^{T M}$ para o conjunto de dados Crescimento_1991. 


\begin{tabular}{|c|c|}
\hline Atributo & $\begin{array}{c}\text { Faixas de Valores } \\
\end{array}$ \\
\hline \hline DDPP120_P & $(\mathrm{m}, 0],(0,1.4],(1.4,3.3],(3.3, \mathrm{M}]$ \\
\hline \hline DMPP120_P & $(\mathrm{m},-1],(-1,0.3],(0.3,1.6],(1.6, \mathrm{M}]$ \\
\hline \hline DDPP240_P & $(\mathrm{m}, 0.6],(0.6,2.9],(2.9,6.9],(6.9, \mathrm{M}]$ \\
\hline \hline DMPP240_P & $(\mathrm{m},-1.4],(-1.4,0.4],(0.4,2.3],(2.3, \mathrm{M}]$ \\
\hline \hline DDPP365_P & $(\mathrm{m}, 1.4],(1.4,4.9],(4.9,8.6],(8.6, \mathrm{M}]$ \\
\hline \hline DDPP550_P & $(\mathrm{m}, 2.4],(2.4,5.3],(5.3,9.6],(9.6, \mathrm{M}]$ \\
\hline \hline DDPE365_P & $(\mathrm{m},-0.3],(-0.3,-0.1],(-0.1,0.3],(0.3, \mathrm{M}]$ \\
\hline \hline DDPE550_P & $(\mathrm{m},-0.7],(-0.7,-0.2],(-0.2,0.3],(0.3, \mathrm{M}]$ \\
\hline \hline DDPP120_M & $(\mathrm{m},-0.8],(-0.8,0],(0,0.9],(0.9, \mathrm{M}]$ \\
\hline \hline DMPP120_M & $(\mathrm{m},-0.4],(-0.4,0.2],(0.2,0.9],(0.9, \mathrm{M}]$ \\
\hline \hline DDPP240_M & $(\mathrm{m},-1.2],(-1.2,0.2],(0.2,1.8],(1.8, \mathrm{M}]$ \\
\hline \hline DMPP240_M & $(\mathrm{m},-0.6],(-0.6,0.3],(0.3,1.4],(1.4, \mathrm{M}]$ \\
\hline \hline DDPP365_M & $(\mathrm{m},-1.8],(-1.8,0.7],(0.7,3.3],(3.3, \mathrm{M}]$ \\
\hline \hline DDPP550_M & $(\mathrm{m},-2.5],(-2.5,0.7],(0.7,4.3],(4.3, \mathrm{M}]$ \\
\hline \hline DDPP120 & $(\mathrm{m},-0.3],(-0.3,0.8],(0.8,2.1],(2.1, \mathrm{M}]$ \\
\hline \hline DDPP365 & $(\mathrm{m}, 0],(0,2.8],(2.8,5.8],(5.8, \mathrm{M}]$ \\
\hline \hline DDPP550 & $(\mathrm{m}, 0],(0,3],(3,6.6],(6.6, \mathrm{M}]$ \\
\hline \hline
\end{tabular}

Tabela 7.10: Faixas de valores das discretizações realizadas pelo BKD para o conjunto de dados Crescimento..1991. 


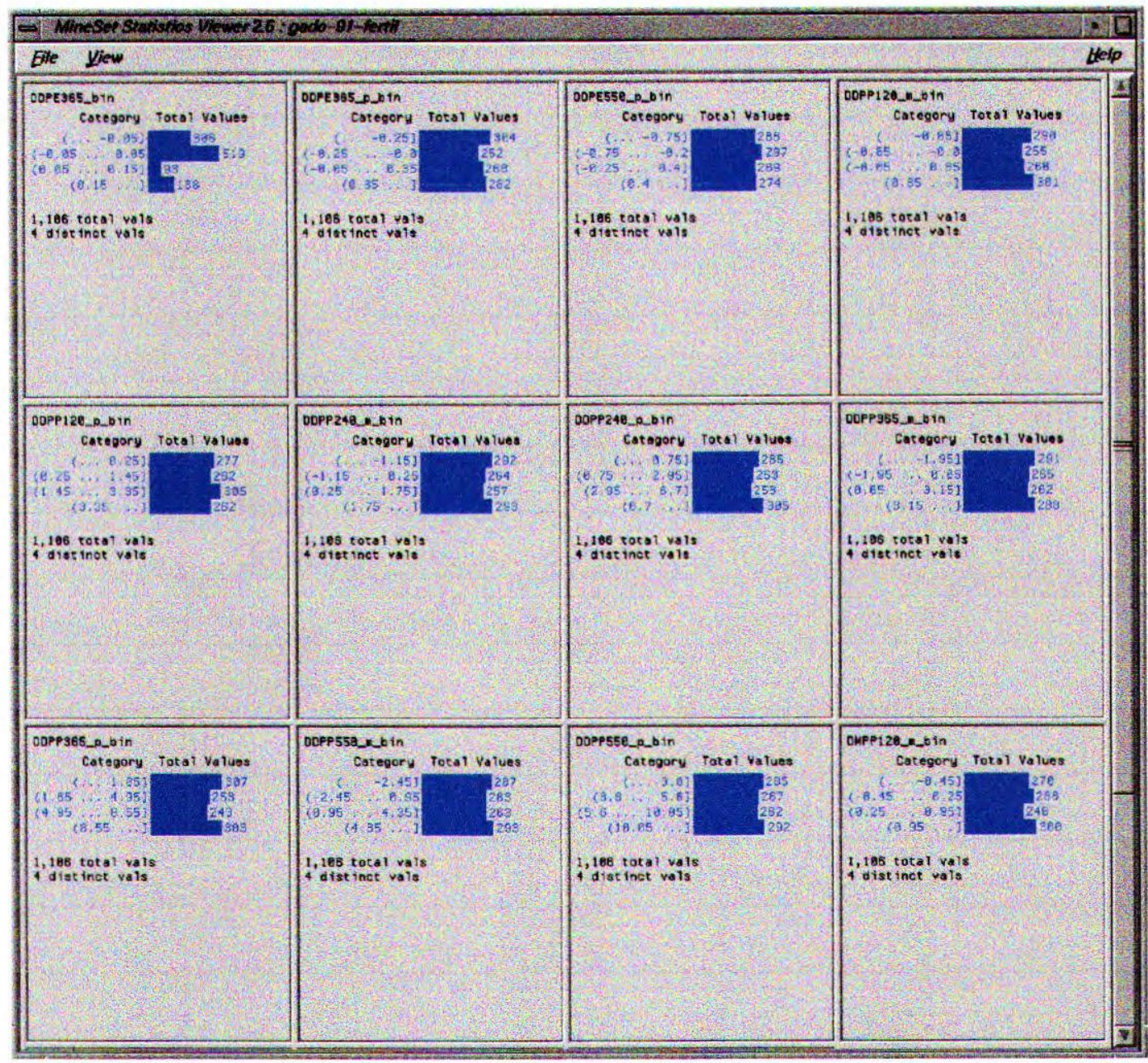

Figura 7.2: Distribuição dos valores nas faixas discretizadas pelo Mineset $^{T M}$, para os atributos do conjunto de dados Crescimento_1991.

e com valores ausentes do PMGRN, bem como a incorporação de conhecimentos a priori fornecidos pelo especialista.

\section{Redes Bayesianas Geradas pelo BKD}

Todos os nove conjuntos de dados da Tabela 7.8 foram fornecidos como entrada ao BKD e, por conseguinte, geradas nove redes Bayesianas medindo as correlações existentes entre as DEPs dos pais e de seus filhotes. Na Figura 7.4, é apresentado, como exemplo, a rede Bayesiana gerada a partir do conjunto de dados Hab_Materna_1994, bem como um exemplo da influência, medida em termos probabilísticos, que as DEPs dos pais exercem sobre a DMPP120 dos filhotes. 


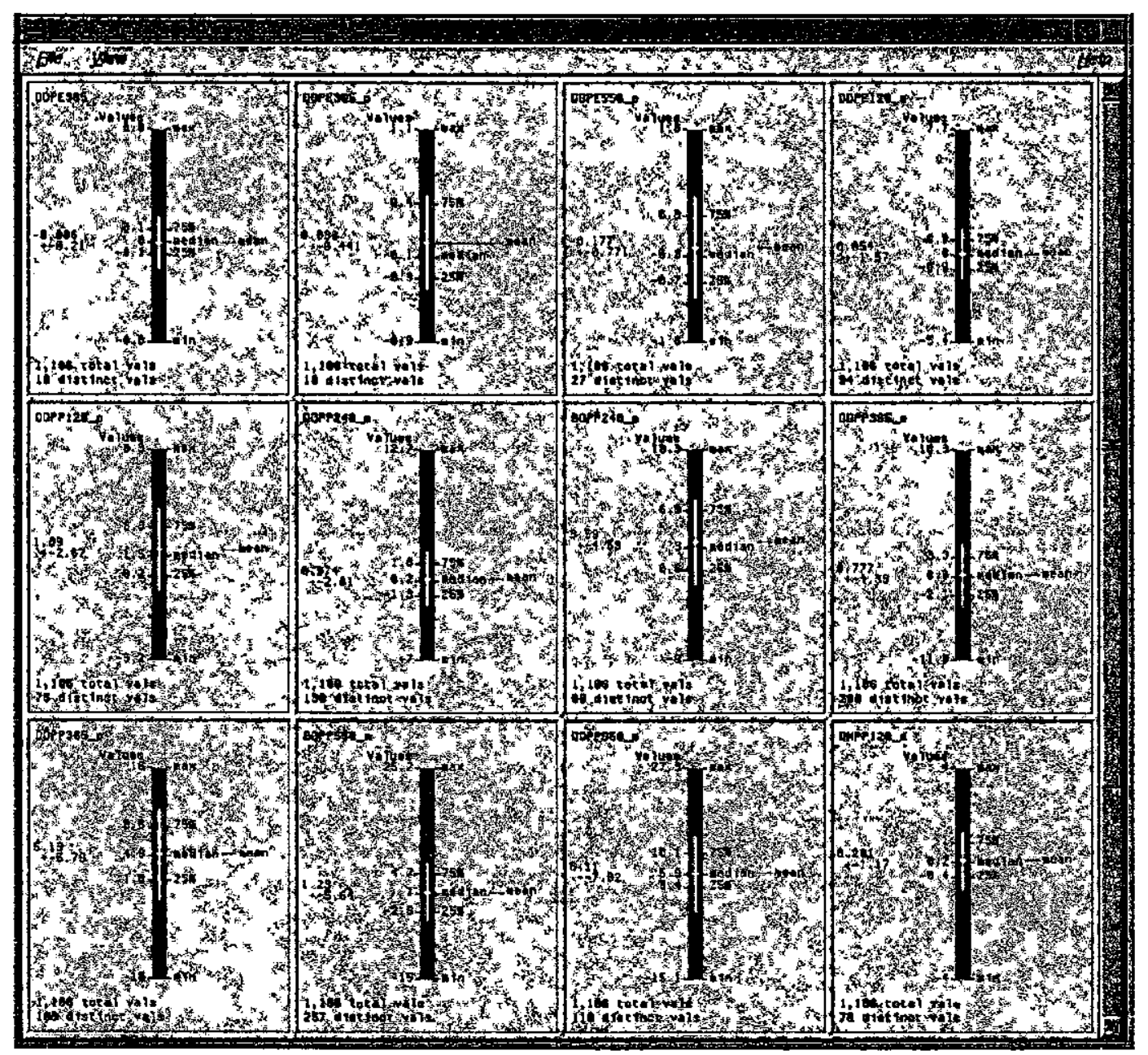

Figura 7.3: Indicadores estatísticos, levantados pelo Mineset $^{T M}$ para o conjunto de dados Fertilidade_1991.

Vale ressaltar, conforme foi visto na subseção 6.3.2, que o BKD discretiza todos os valores de atributos contínuos. Assim, a leitura da tabela mostrada no exemplo da Figura 7.4 é realizada da seguinte forma: os intervalos de valores possíveis para a DMPP120 são de $[-4,-0,4),[-0,4,0,2),[0,2,0,9)$ e $[0,9,3,6) ;$ e, de acordo com o conjunto de dados Hab_Materna_1994, é possível observar que, se não há evidência na rede, a distribuição dos animais nesses intervalos é de $25,2 \%, 23,1 \%, 26,5 \%$ e $25,2 \%$, respectivamente.

De acordo com o que foi mostrado na subseção 7.4.1, alguns conjuntos de dados (da Tabela 7.8) foram discretizados pelo Mineset $^{T M}$ e, então, submetidos ao BKD. Na Figura 7.5 , é apresentada, como exemplo, a rede Bayesiana gerada a partir do conjunto de dados Hab_Materna_1994, discretizado pelo Mineset ${ }^{T M}$. Nessa Figura, é mostrada também a influência, medida em termos probabilísticos, que as DEPs dos pais exercem sobre a DMPP120 


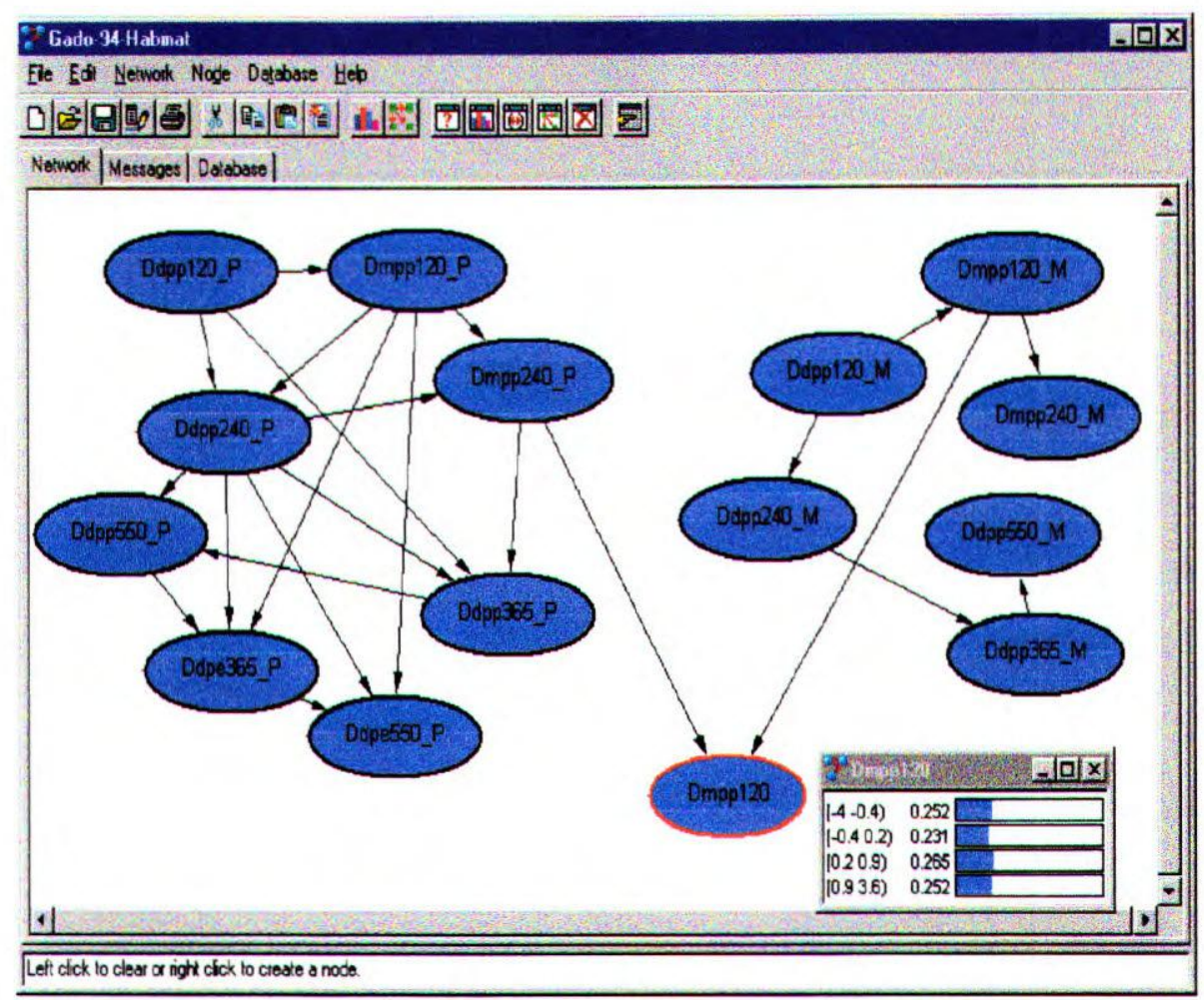

Figura 7.4: Rede Bayesiana gerada pelo BKD a partir do conjunto de dados Hab_Materna_1994.

dos filhotes.

Na Figura 7.5, é possível observar que ocorreram poucas mudanças nas influências diretas dos nós da rede, em relação a estrutura apresentada na Figura 7.4. Essas mudanas se restringiram às DEPs dos pais, visto que a relação de dependência direta entre as DEPs da mãe e das DEPs do pais com os filhotes se mantiveram. Vale ressaltar que essas alterações são oriundas da nova distribuição dos valores de DEPs nos intervalos discretizados pelo Mineset $^{T M}$.

Após a geração das redes Bayesianas, foi possível utilizar o algoritmo de propagação do BKD para efetuar inferências sobre essas redes. Para exemplificar as inferência realizadas sobre as redes Bayesianas resultantes desse estudo de caso, considere a rede mostrada na Figura 7.4 e a seguinte situação: deseja-se conhecer a probabilidade de um animal fazer parte do intervalo de valores mais altos para a DMPP120 [0,9,3,6), dadas as evidências de que a DDPP120_P está na faixa de valores entre [2,1, 4,3), e a DMPP120_M possui valores entre [-4,2 e -0,5). Essa situação pode ser visualizada na Figura 7.6. 


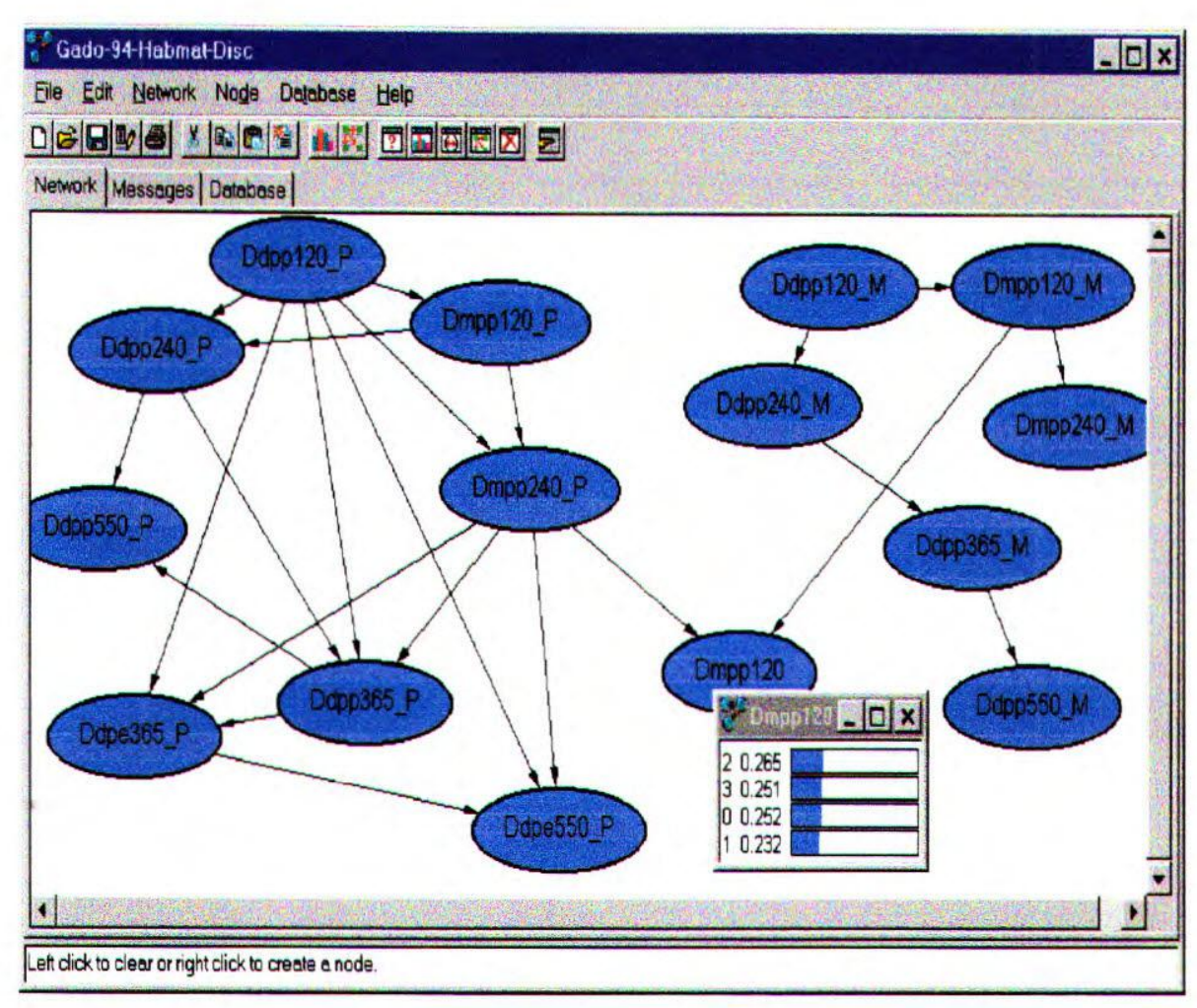

Figura 7.5: Rede Bayesianas gerada pelo BKD, a partir do conjunto de dados Hab_Materna_1994 discretizado pelo Mineset ${ }^{T M}$. Sendo $0=(\mathrm{m},-0.45], 1=(-0.45,0.15]$, $2=(0.15,0.85]$ e $3=(0.85, \mathrm{M}]$

Portanto, a probabilidade de um animal possuir valores para DMPP120_M entre [0,9, $3,6]$ é de $11 \%$, dadas as evidências supracitadas.

Além das redes Bayesianas para os conjuntos de dados completos, foram geradas redes a partir de conjuntos de dados com valores ausentes. A seguir são mostrados os resultados obtidos pelo BKD para estes conjuntos de dados.

\section{Tratamento de Dados Incompletos}

Com o intuito de avaliar as mudanças ocorridas nas relações de dependências entre as DEPs, dada a existência de valores ausentes no conjunto de dados, foram retirados, aleatoriamente, desses conjuntos, mediante o programa ValAus, $20 \%$ e $40 \%$ dos valores dessas DEPs. Na Figura 7.7, é apresentado, como exemplo, a rede Bayesiana gerada do conjuntos de dados Hab_Materna_1994 (Figura 7.4), com 20\% de valores ausentes.

As redes Bayesianas geradas a partir de todos os conjuntos de dados com valores 


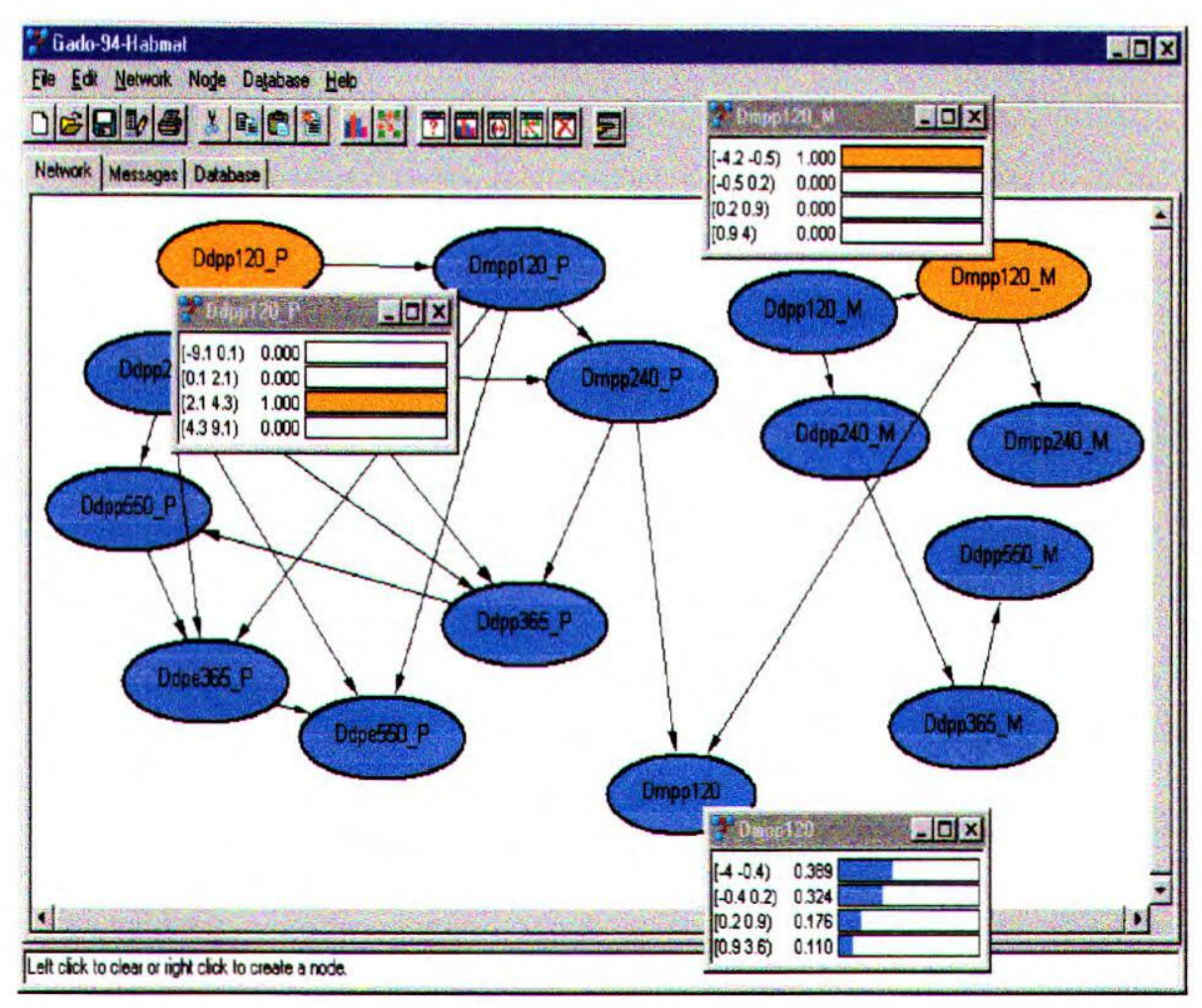

Figura 7.6: Exemplo de inferência, via algoritmo de propagação, sobre redes Bayesianas geradas pelo BKD.

ausentes foram comparadas com as redes geradas de conjuntos de dados completos. A análise desses resultados será apresentada na seção 7.5.

Conforme pode ser observada na Figura 7.7, a rede Bayesiana gerada a partir do conjunto de dados Hab_Materna_1994, com 20\% de valores ausentes, possui basicamente a mesma estrutura da rede Bayesiana extraída do conjunto de dados Hab_Materna_1994 completo. Houve apenas inclusões de novas dependências (setas) entre os nós da rede. Por exemplo, foi acrescentada a influência da DDPP120_M sobre a DDPP550_M, não observada na rede Bayesiana da Figura 7.4. Vale destacar que as dependências diretas das DEPs dos pais em relação as DEPs dos filhotes não foram alteradas, ou seja, a DMPP120 continuou recebendo influência direta apenas das DEPs DMPP240_P e DMPP120_M. Evidentemente, houve uma alteração considerável dos parâmetros da rede (valores de probabilidade das TPCs), visto que a freqüência de ocorrência dos valores de DEPs no conjunto de dados, fornecido como entrada, foi alterado ( $20 \%$ de valores ausentes).

Para efeito de verificação das mudanças ocorridas a partir do aumento do número de 


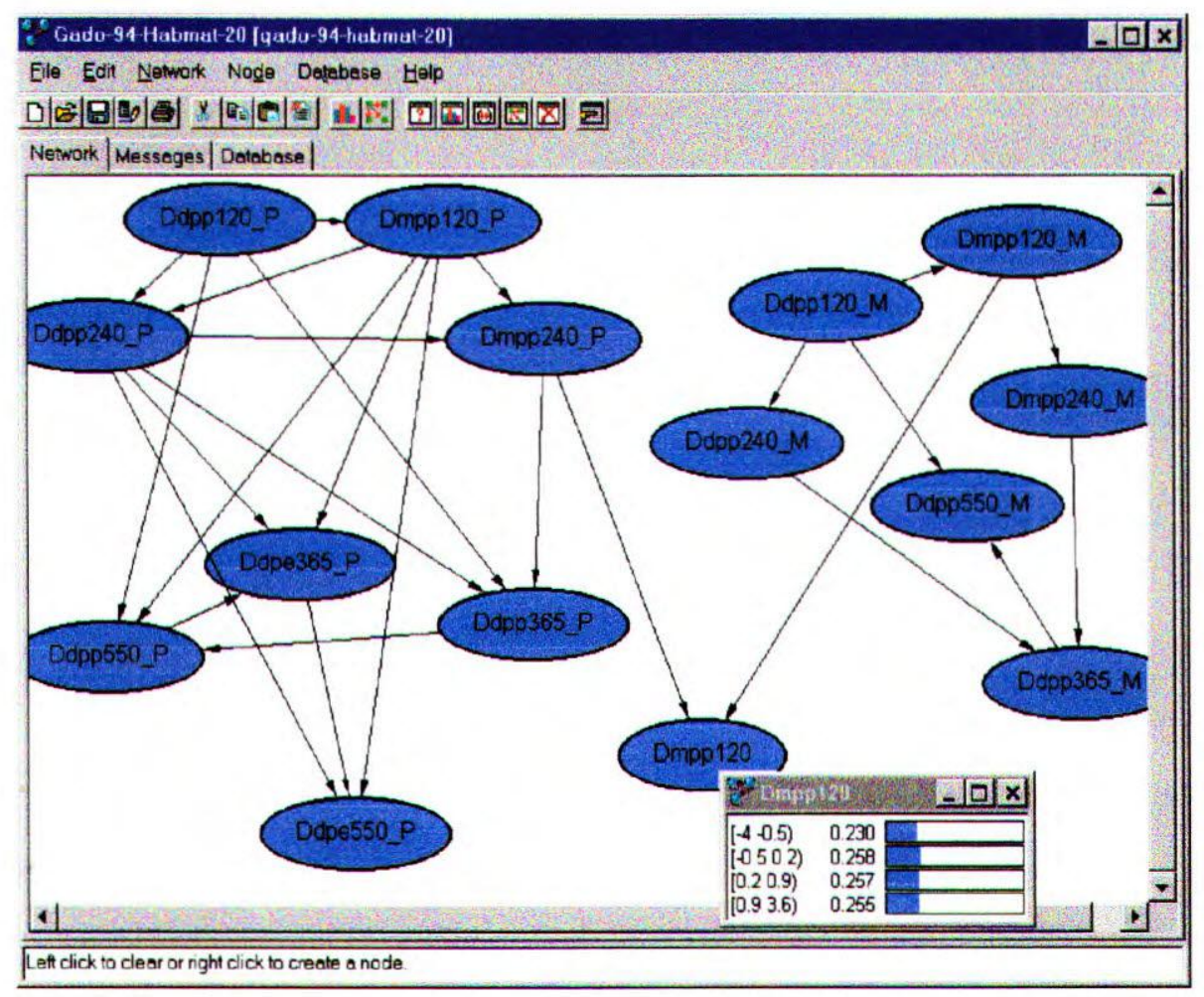

Figura 7.7: Rede Bayesiana gerada pelo BKD a partir do conjunto de dados Hab_Materna_1994, retirando-se 20\% de seus valores.

valores ausentes, é mostrada na Figuras 7.8, a rede Bayesianas gerada a partir do conjunto de dados Hab_Materna_1994, com 40\% de valores ausentes.

A rede Bayesiana gerada a partir do conjunto de dados Hab_Materna_1994, com 40\% de valores ausentes, já apresentou uma estrutura bastante diferente da rede gerada do conjunto de dados completo Hab_Materna_1994 (Figura 7.4). Dentre as principais alterações estão: inclusão da dependência direta da DMPP120_P a DMPP120; surgimento de dependências diretas entre as DEPs dos pais (DDPP120_P e DMPP120_P) e das mães (DMPP120_M); inclusões de várias dependência diretas entre os nós de DEPs dos pais e entre as DEPs das mães.

Outra situação também observada, neste estudo de caso, foi a submissão dos conjuntos de dados com valores de atributos ausentes, aproveitando as estruturas de redes Bayesianas geradas a partir de conjuntos de dados completos. Dessa forma, foram fornecidos como entrada, para o BKD, a estrutura da rede Bayesiana (gerada a partir de conjuntos de dados completos) e os conjuntos de dados incompletos. A partir dessas entradas, o BKD atualiza os 


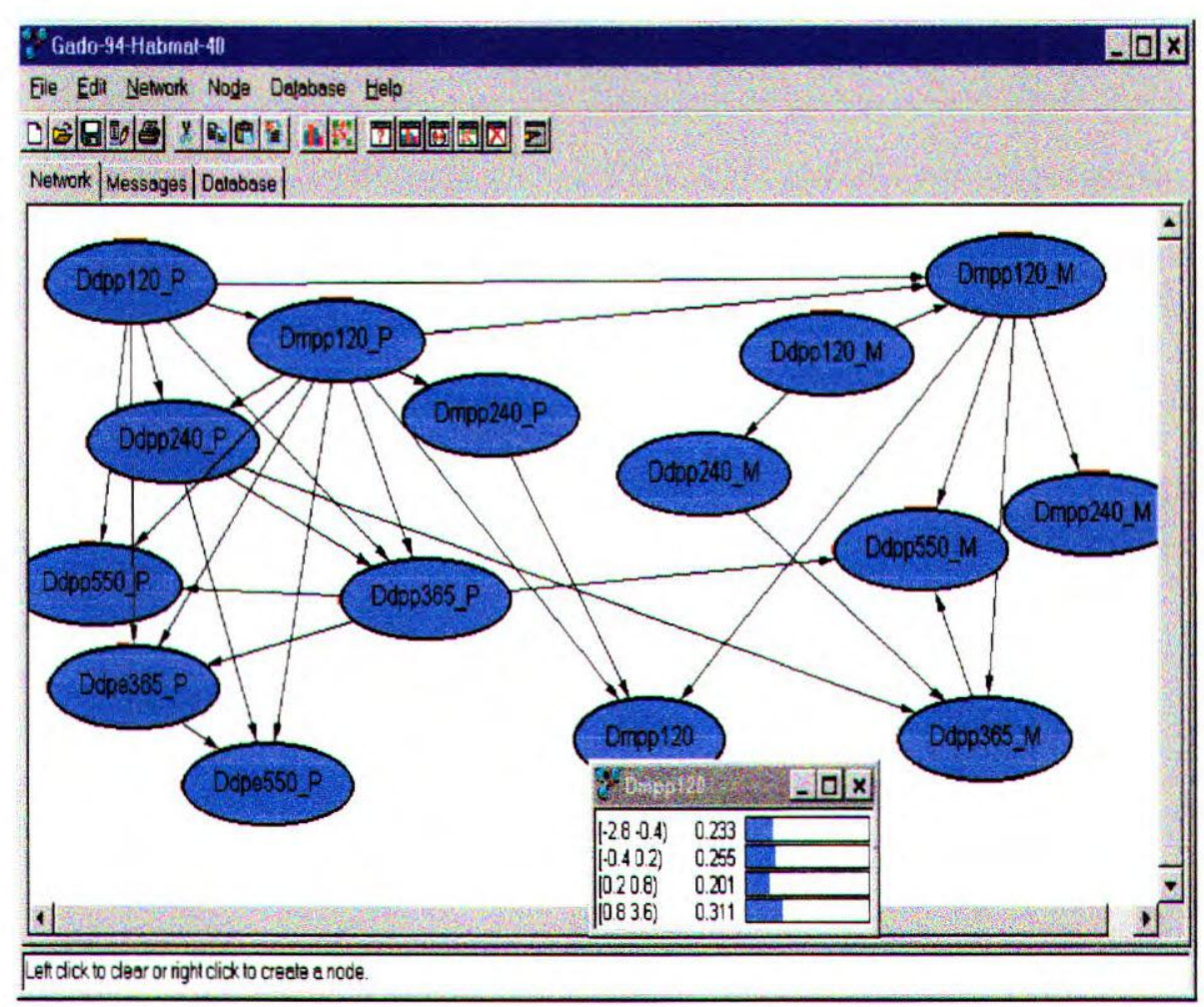

Figura 7.8: Rede Bayesiana gerada pelo BKD a partir do conjunto de dados Hab_Materna_1994, retirando-se 40\% de seus valores.

parâmetros da rede Bayesiana. Este tipo de estudo é interessante, quando se deseja analisar os limites da distribuição de probabilidade condicional dos valores ausentes no conjunto de dados, a partir de uma estrutura de rede fornecida a priori. Além disso, se o especialista fornece como entrada a rede Bayesiana, o tempo gasto para estimar os valores de probabilidades, a partir de conjuntos de dados incompletos, é bastante inferior ao tempo gasto para extrair a rede Bayesiana e estimar os parâmetros. Nas Figuras 7.9 e 7.10, são apresentados exemplos, nos quais a estrutura da rede Bayesiana da Figura 7.4 e o conjunto de dados Hab_Materna_1994, com 20\% e 40\% de valores ausentes, são fornecidos como entrada.

A partir dessas figuras, é possível analisar os valores mínimos e máximos (bounds) de cada um dos parâmetros dessas redes Bayesianas. No exemplo mostrado na Figura 7.10, os valores mínimos e máximos da probabilidade condicional da DMPP120_P estão no intervalo $[-4,6,-0,7)$, dado que DDPP120_P possui valores no intervalo $[-9,1,0,2)$, é de $6,1 \%$ e 83,5\%, respectivamente. Sendo que a estimativa (collapse) para a TPC do nó DMPP120_P é de $27,1 \%$. 


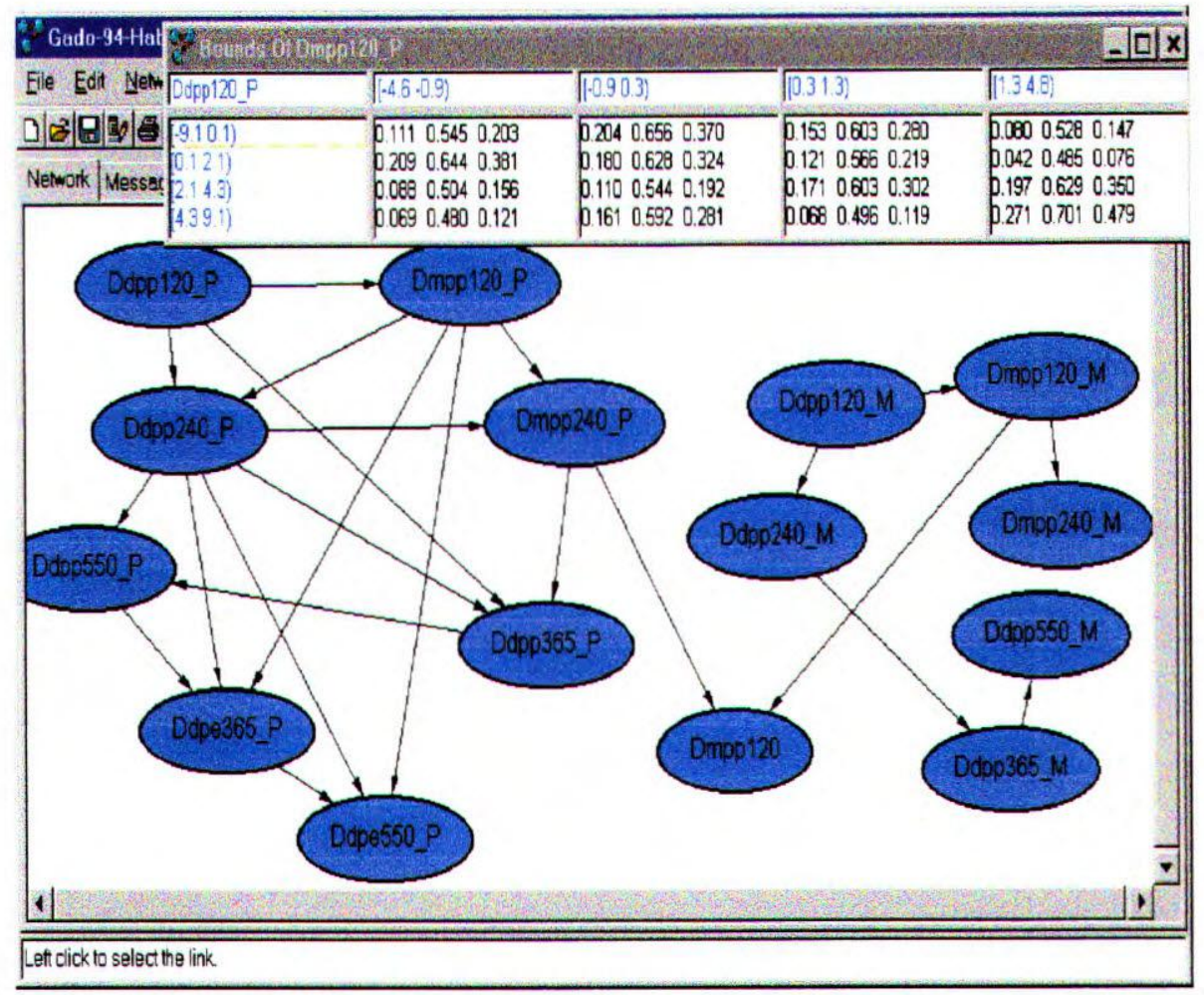

Figura 7.9: Atualização dos parâmetros da rede Bayesiana gerada pelo BKD a partir do conjunto de dados Hab_Materna_1994, com 20\% dos valores de seus atributos ausentes .

\section{Incorporação de Conhecimento de Fundo}

A partir das redes Bayesianas geradas dos conjuntos de dados completos e com valores ausentes, foram considerados alguns conhecimentos a priori, fornecidos pelo especialista, para a geração das redes Bayesianas deste estudo de casos. O propósito da incorporação desse conhecimento de fundo foi analisar e medir, por meio de probabilidades, algumas influências diretas de determinados valores de DEPs dos pais em relação aos seus filhotes, não observadas pelo BKD, mas assumidas pelo especialista do domínio. Na Figura 7.11, é mostrado um exemplo da inclusão de um conhecimento sugerido a priori. Neste exemplo, baseado na rede Bayesiana gerada a partir do conjunto de dados Hab_Materna_1994 (Figura 7.4), apesar de não ser observado pelo $\mathrm{BKD}^{2}$, foi sugerido pelo especialista a observação da influência direta da DDPP240_P sobre a DMPP120 do filhote. Dessa forma, foi colocada uma seta ligando os nós da rede Bayesiana, utilizando o próprio ambiente de edição do BKD,

\footnotetext{
${ }^{2}$ Essa relação direta não foi observada, de acordo com especialista, porque a DMPP120 possui dependência maior em relação a DMPP240_P.
} 


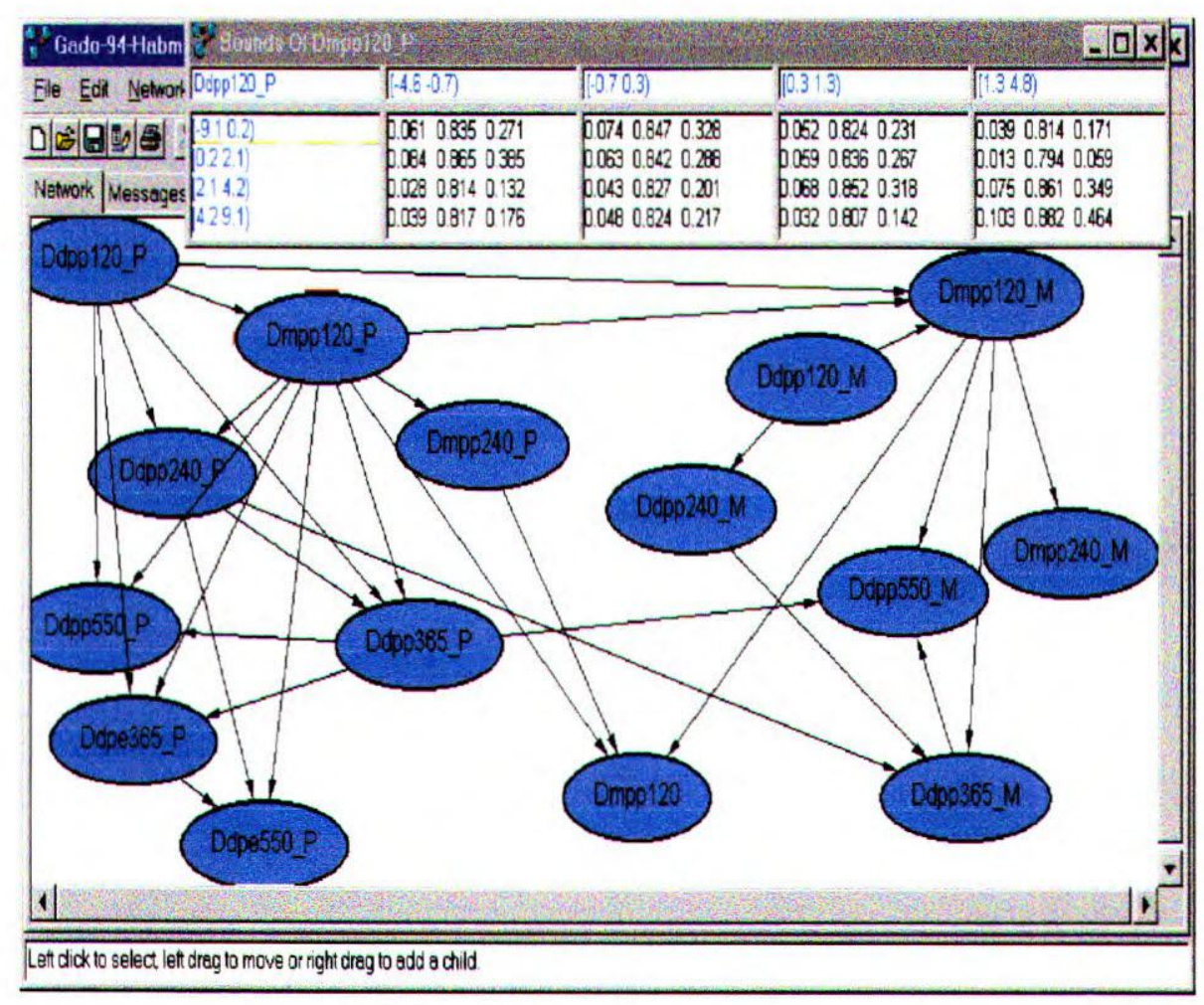

Figura 7.10: Atualização dos parâmetros da rede Bayesiana gerada pelo BKD a partir do conjunto de dados Hab_Materna_1994, com 40\% dos valores de seus atributos ausentes .

e recalculados os valores das TPCs da rede.

É possível observar que os valores da TPC do nó DMPP120 foi alterado, o que ocorre em função da mudança de influência direta dos atributos. Vale sublinhar que, como o BKD possui recursos de edição apropriados, várias sugestões, oriundas das interações com o especialista, foram fornecidas a priori. Isso permitiu explorar várias situações de interesse, além de proporcionar, entre outras vantagens, a otimização do tempo de construção da rede e uma maior confiabilidade dos resultados obtidos.

\subsubsection{Pré-Avaliação dos Resultados}

Para efetuar a pré-avaliação dos resultados obtidos a partir das redes Bayesianas geradas pelo $\mathrm{BKD}$, foram utilizados os recursos de visualização e inferência do próprio BKD e do Hugin System. 


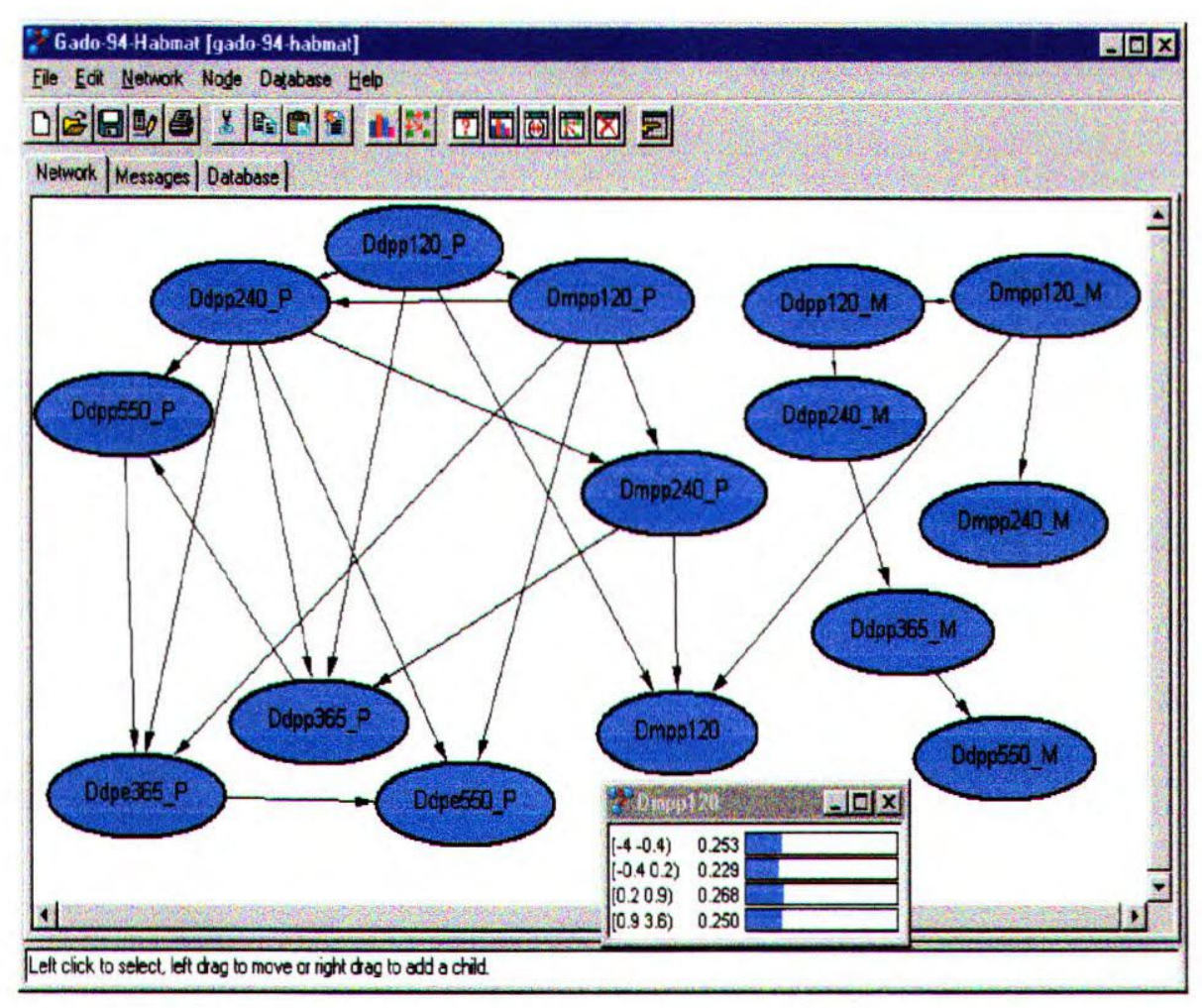

Figura 7.11: Rede Bayesiana gerada pelo BKD a partir de Hab_Materna_1994, considerando o conhecimento a priori de que há dependência entre a DDPP240_P e a DMPP120.

\section{Pré-Avaliação dos Resultados Utilizando o BKD}

A pré-avaliação dos resultados obtidos na aplicação do BKD foi realizada a partir dos próprios recursos desse software. Dessa forma, foi utilizado o próprio ambiente gráfico do BKD para verificar as dependências entre os nós das redes Bayesianas. Por exemplo, a partir da rede Bayesiana da Figura 7.4, é possível analisar as dependências entre os nós, bem como quantificar essas dependências, consultando as probabilidades cobndicionais, marginais, verossimilhança e variância. Além disso, foi utilizado o algoritmo de propagação para efetuar as inferências desejadas, a fim de se verificar várias situações de interesse, dada a ocorrência de determinadas evidências nos estados (valores) dos nós (DEPs) da rede. Um exemplo da utilização do algoritmo de propagação do BKD é mostrado na Figura 7.6.

A aplicação do algoritmo de propagação, provido pelo BKD, possibilitou efetuar uma série de inferências sugeridas pelo especialista. Assim, o caráter exploratório dessa ferramenta propiciou, por meio da informação de evidências para alguns valores de DEPs, a verificação, de forma bastante interativa, de várias situações de interesse, 
Como forma de aperfeiçoar as inferência realizadas pelo $\mathrm{BKD}$, propiciando um auxílio ainda maior ao processo de tomada de decisão dos especialistas do domínio, bem como de melhorar a pré-avaliação dos resultados, foi utilizado, neste estudo de caso, o Hugin System, cuja aplicação será apresentada a seguir.

\section{Pré-Avaliação dos Resultados Utilizando o Hugin System}

Conforme visto na subseção 6.3.3, o Hugin System é utilizado, na etapa de Data Mining, para auxiliar a pré-avaliação dos resultados obtidos. Dessa forma, a criação das redes bayesianas foi baseada em interações com o especialista do domínio e nas redes Bayesianas geradas pelo BKD, utilizando o ambiente de edição de redes Bayesianas oferecido pelo Hugin. Na Figura 7.12, é mostrada a rede criada no Hugin a partir da rede Bayesiana gerada pelo BKD (Figura 7.4) do conjunto de dados Hab_Materna_94, bem como o exemplo da TPC de um nó (DMPP120_M).

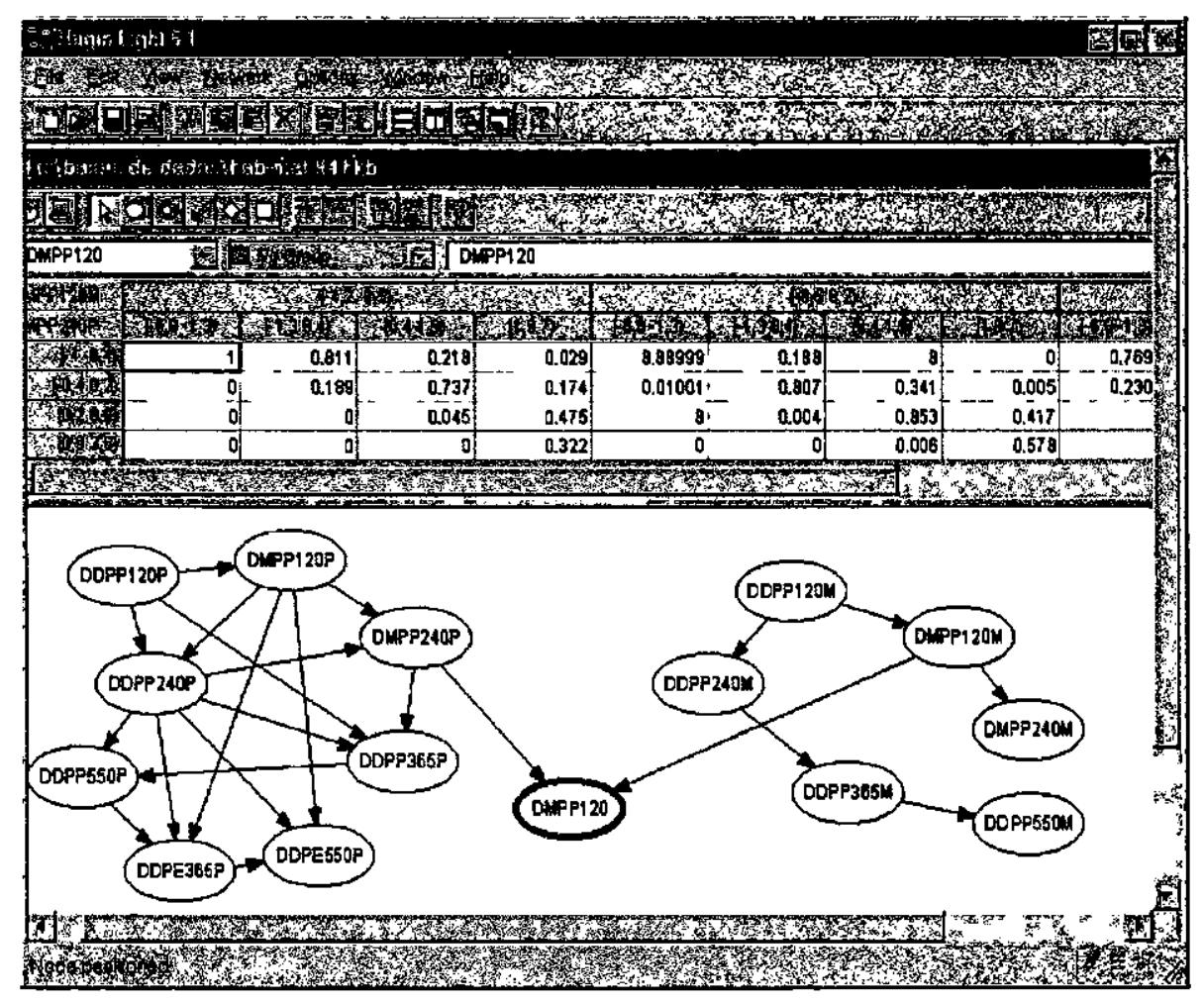

Figura 7.12: Rede Bayesiana criada no Hugin System a partir da rede gerada pelo BKD da base de dados Hab_Materna_1994.

Após a construção das redes e o fornecimento das respectivas probabilidades condi- 
cionais, foram efetuadas as inferências sobre as redes criadas. Um exemplo da aplicação desse algoritmo, utilizando o método sum normal, pode ser visto na Figura 7.13, na qual é mostrada a mesma situação do exemplo visto na Figura 7.6.

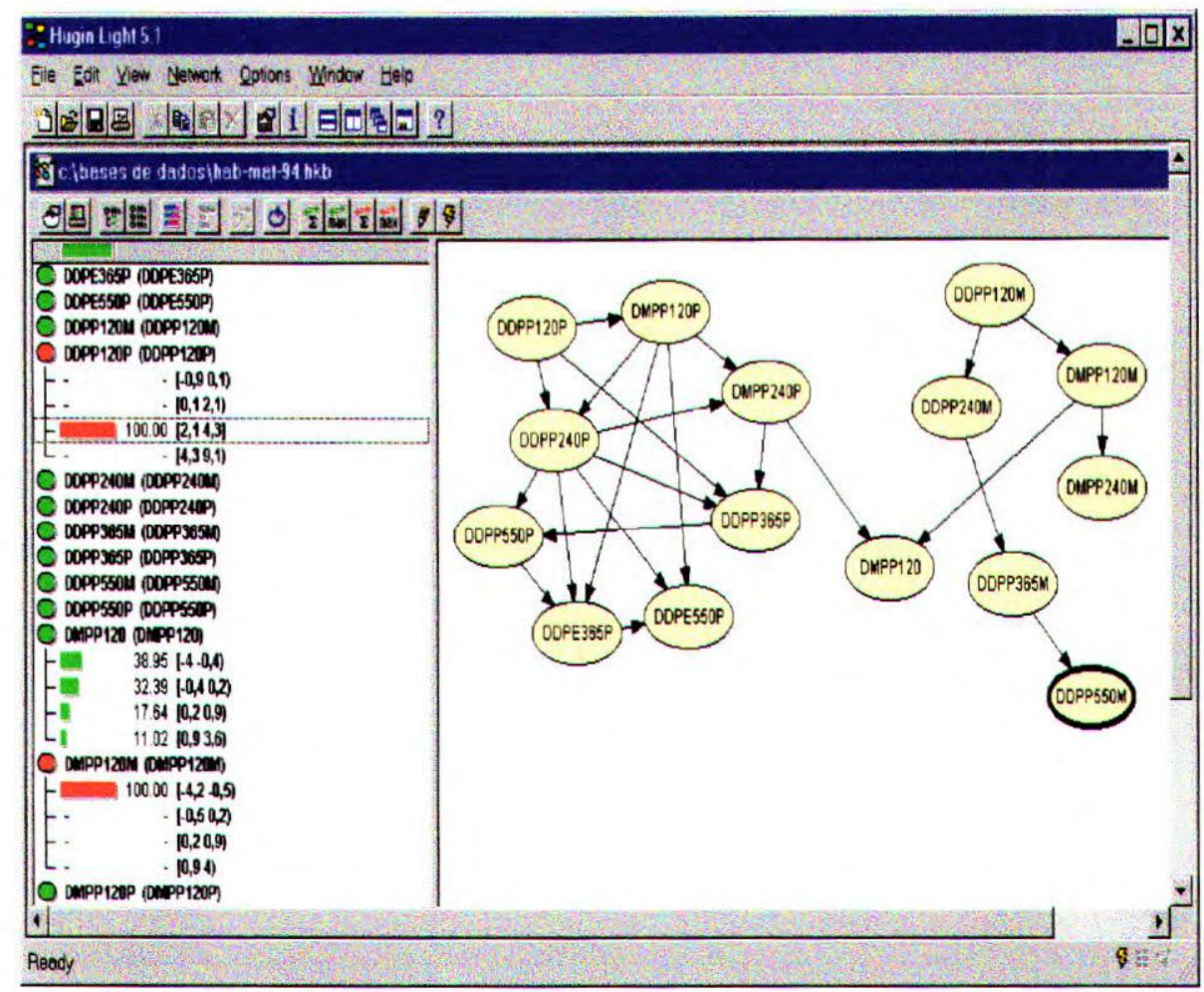

Figura 7.13: Exemplo da aplicação do Algoritmo de Propagação do Hugin.

É possível observar na Figura 7.13 que a probabilidade (11,02\%) de um animal possuir valores de DMPP120 entre [0,9, 3,6), dadas as evidências de que a DDPP120_P está na faixa de valores entre $[2,1,4,3)$, e a DMPP120_M possui valores entre $[-4,2$ e $-0,5)$, é aproximadamente a mesma obtida pelo BKD (11\%).

Um outro exemplo da aplicação do algoritmo de propagação do Hugin, desta feita utilizando o método max normal, é mostrado na Figura 7.14. Nessa Figura, pode ser observado que a mais provável configuração da situação mostrada no exemplo anterior (i.e. as evidências de que $2,1 \leq D D P P 120 \_P \leq 4,3$ e $\left.-4,2 \leq D M P P 120 \_M \leq-0,5\right)$, é a de que os valores das DEPs estejam entre os intervalos apresentados na Tabela 7.11.

A partir deste exemplo é possível verificar que a máxima configuração, para o caso em que o pai do animal apresenta valores baixos para DMPP120_M e médios para a DDPP120_P, indica que as demais DEPs assumem valores regulares (entre a primeira e a terceira faixas 


\begin{tabular}{|c|c|}
\hline DEP & Intervalo de Valores \\
\hline \hline DMPP120_P & {$[-4,6-0,9)$} \\
\hline DMPP240_P & {$[-6,8-1,3)$} \\
\hline DDPP240_P & {$[0,63,8)$} \\
\hline DDPP365_P & {$[0,75,3)$} \\
\hline DDPP550_P & {$[1,46,8)$} \\
\hline DDPE365_P & {$[0,10,4)$} \\
\hline DDPE550_P & {$[00,5)$} \\
\hline DMPP240_M & {$[-6,1-0,8)$} \\
\hline DDPP120_M & {$[-5,3-0,7)$} \\
\hline DDPP240_M & {$[-7,6-1)$} \\
\hline DDPP365_M & {$[-14,3-1,2)$} \\
\hline DDPP550_M & {$[-15,5-1,9)$} \\
\hline DMPP120 & {$[-40,2)$} \\
\hline
\end{tabular}

Tabela 7.11: Configuração mais provável para que um animal possua valores de DMPP120 entre $[0,9,3,6)$, dadas as evidências $\left(2,1 \leq D D P P 120 \_P \leq 4,3\right)$, e $(-4,2 \leq$ $\left.D M P P 120 \_M \leq-0,5\right)$. 


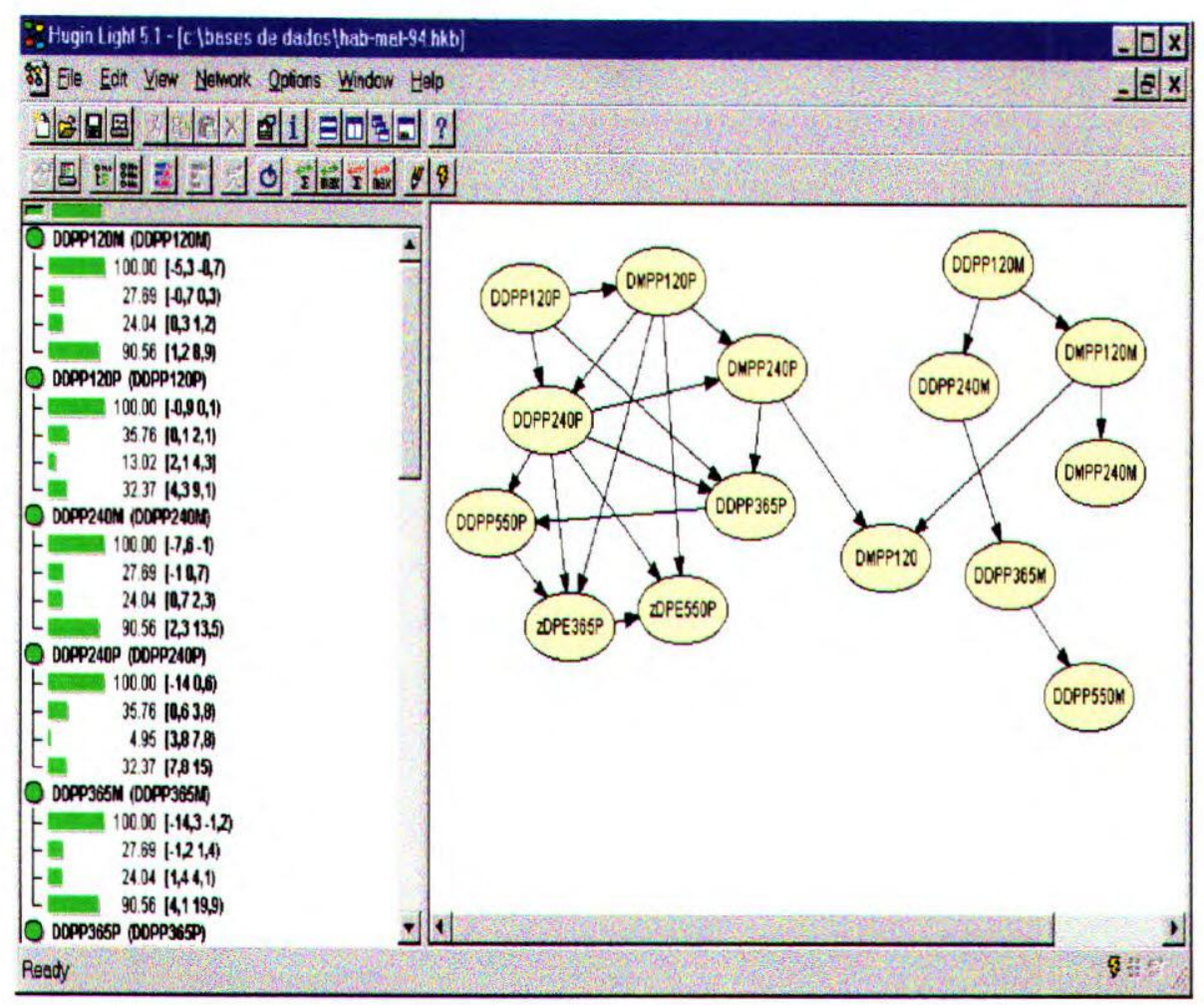

Figura 7.14: Exemplo da aplicação do Algoritmo de Propagação do Hugin usando o método max normal.

de valores para cada DEP).

A aplicação dos algoritmos de propagação do Hugin, assim como ocorreu na aplicação do $\mathrm{BKD}$, foi de muito valia para a análise de várias situações de interesse do especialista do domínio. Outro aspecto que deve ser destacado na aplicação do Hugin é o seu ambiente de edição de redes Bayesianas, o qual permitiu efetuar interações com o especialista, com o intuito de se obter respostas imediatas, via algoritmo de propagação, para cada sugestão fornecida por estes.

A seguir serão apresentadas algumas considerações finais acerca dos resultados obtidos a partir da aplicação do processo KDD na base de dados do PMGRN.

\subsection{Considerações Finais}

Neste capítulo, foi focalizado a aplicação do processo KDD na base de dados do PMGRN, com o objetivo precípuo de encontrar padrões no acasalamento de animais da raça Nelore. Dessa forma, procurou-se observar a maioria dos aspectos envolvidos na execução de cada uma 
das fases desse processo - do levantamento das metas a serem alcançadas até as avaliações preliminares dos resultados obtidos.

Para analisar os padrões de acasalamentos, foi necessário estabelecer alguns filtros para a base de dados do PMGRN. Esses filtros, sugeridos pelos especialistas do domínio, contemplam os grupos contemporâneos e algumas funcionalidades animais. Assim, foram criados vários conjuntos de dados, com o propósito de encontrar relaçōes entre as DEPs dos pais e as DEPs (condizentes com a funcionalidade em questão) dos filhotes. Por ser um processo centrado na interação usuário/especialista/analista, a aplicação do KDD nesse estudo de caso, só foi possível em virtude da participação dos especialistas, em todas as etapas desse processo.

Para encontrar as relações supracitadas, foram utilizadas redes Bayesianas, que modelam graficamente essas relações, além de quantificá-las em termos probabilísticos. Foram observadas várias situações de interesse para análise dos dados do PMGRN. Dentre essas situações, destacam-se:

- Extração de padrōes de acasalamento por meio da relação de dependência entre as DEPs dos pais e de seus filhotes, para os vários conjuntos.

- Exploração das várias redes geradas, por meio dos mecanismos de inferência, para quantificar as dependências que os pais exercem sobre os filhos, em termos dos valores das DEPs.

- Potencialização do aprendizado das redes Bayesianas, incorporando conhecimento de fundo a esse aprendizado.

- Verificação da influência dos valores ausentes sobre o aprendizado das redes Bayesianas a partir da base de dados do PMGRN.

Os principais resultados obtidos na aplicação do processo $\mathrm{KDD}$, considerando as situaçōes acima, foram:

- A interação com os especialistas do domínio propiciou uma maior compreensão do domínio da aplicação, bem como da identificação dos objetivos da aplicação. Outrossim, em função da interface amigável dos métodos de aprendizado utilizados, além da facilidade de compreensão dos modelos (redes Bayesianas) gerados para o domínio, 
foi possível verificar a utilidade desses métodos no auxilio à tomada de decisão dos envolvidos no PMGRN. Prova disso, foi a inclusão de alguns resultados preliminares deste trabalho no Sumário anual desse Programa (Lobo et al., 1998).

- Foi possível observar que a as estruturas das redes Bayesianas mudaram pouco ao longo dos anos estudos aqui (1991 a 1996). Dessa forma, as relações de dependência permaneceram basicamente as mesmas neste período.

- Há um indicativo de influência maior dos valores das DEPs dos pais, comparado aos das mães, sobre as DEPs dos filhotes.

- A facilidade da incorporação de conhecimento de fundo, provida pelos métodos utilizados neste trabalho, proporcionou a extração de redes Bayesianas mais próximas do modelo, pretendido pelo especialista, para os dados do PMGRN.

- No tratamento de dados incompletos, foram observados que apesar de serem retirados $20 \%$ e $40 \%$ dos valores dos conjuntos de dados originais, as dependências direta entre as DEPs dos pais e dos filhotes, na maioria dos vezes, mantiveram-se.

Vale ressaltar que os resultados obtidos com a aplicação do processo KDD, a partir da base de dados do PMGRN, ainda estão na fase de avaliação. 


\title{
Capítulo 8
}

\section{Estudo de Caso - Base de Dados da}

\author{
Swiss Life
}

\subsection{Considerações Iniciais}

O estudo de caso envolvendo os dados de seguro da Swiss Life não representa uma instância típica da aplicação do processo KDD, posto que não há a participação de especialistas desse domínio. Apesar disso, esses dados foram utilizados com o objetivo precípuo de encontrar relações de dependências, representadas por intermédio de redes Bayesianas, entre os atributos pertencentes a esse conjunto de dados. A aplicação de métodos de aprendizado Bayesianos a este estudo de caso envolve, ainda, a inferência sobre as redes Bayesianas geradas a partir dos dados e, em função do grande número de valores de atributos ausentes, o tratamento de dados incompletos.

Este capítulo está organizado conforme é especificado a seguir. Na seção 8.2, é apresentada a descrição do conjunto de dados utilizado neste estudo de caso. Na seção 8.3, é focalizada a preparação dos dados. Na seção 8.4, são mostradas as redes Bayesianas geradas a partir dos dados de seguro da Swiss Life na etapa de Data Mining. Finalmente, na seção 8.5, são feitas algumas considerações finais acerca deste estudo de casos. 


\subsection{Descrição do Conjunto de Dados}

O conjunto de dados utilizado no estudo de caso proposto neste capítulo foi extraído de um sistema de data warehouse chamado $M A S Y$, da companhia de seguro Swiss Life. Este sisterna realiza o armazenamento e a análise dos dados dessa empresa. O conjunto de dados foi preparado pelo grupo de Sistema de Informação dessa empresa. Esse conjunto de dados consiste de arquivos de dados em formato ASCII, cada qual contendo registros na forma Prolog-like (parecidos com a representação utilizada pela linguagem Prolog) e organizados em uma tupla por linha. A organização dos registros pode ser entendida como sendo da seguinte forma:

$$
<\text { relação > (componente1, componente } 2, \ldots, \text { componenteN })
$$

na qual < relação > representa o nome de uma relação existente na base de dados, formada por vários componentes representados por componente ${ }_{1}$, componente com $_{2}, .$. componente $_{N}$.

Os arquivos que formam o conjunto de dados possuem registros de relaçōes específicas. Existem ao todo 10 (dez) relações que descrevem os parceiros ou clientes da Swiss Life, endereços, contratos de seguros, apólices de seguros, domicílios e componentes de tarifas de seguros. As relações existentes na base de dados são:

- PART - relação que representa os parceiros da Swiss Life.

- EADR - relação que contém endereços eletrônicos de parceiros.

- PADR - relação que contém endereços postais de parceiros.

- HHOLD - relação que armazena os dados sobre os domicílios dos parceiros

- VVERT - relação que representa a apólice de seguro.

- PARROL - relação que representa o papel que os parceiros fazem com relação a uma determinada apólice de seguros.

- TFROL - relação que representa os papéis de tarifa e especifica maiores informações caso um parceiro seja uma pessoa segurada. 
- TFKOMP - relação que está associada aos papéis de parceiros.

- PROD - relação que representa os produtos.

- LVTARF - relação que representam tarifas dedicadas de seguro.

A base de dados disponibilizada possui ao todo 340.573 registros, distribuídos nas relações existentes. O número de registros em cada relação é mostrado na Tabela 8.1.

\begin{tabular}{|c|c|c|}
\hline Relação & Registros & Atributos \\
\hline \hline VVERT & 34.986 & 18 \\
\hline PARROL & 111.077 & 5 \\
\hline PART & 17.267 & 9 \\
\hline HHOLD & 12.934 & 43 \\
\hline EADR & 505 & 3 \\
\hline PADR & 17.970 & 4 \\
\hline TFKOMP & 73.502 & 26 \\
\hline PROD & 184 & 3 \\
\hline TFROL & 73.332 & 8 \\
\hline LVTARF & 239 & 9 \\
\hline
\end{tabular}

Tabela 8.1: Distribuição dos registros da base de dados da Swiss Life, por relação.

A empresa descreveu três problemas possíveis para serem atacados, utilizando-se algoritmos de Aprendizado de Máquina. Um dos problemas, denominado de TaskC, trata da procura de agrupamentos (clusters) existentes na relação HHOLD, que possui os dados referentes aos domicílios dos clientes da seguradora. Apesar das redes Bayesianas não se enquadrarem no tipo de aprendizado de clusters, as mesmas foram utilizadas com intuito de verificar o modo como os atributos desse conjunto de dados se relacionam. Outrossim, efetuar o tratamento de dados incompletos, visto que há uma grande ocorrência de valores ausentes do conjunto de dados da relação HHOLD. Na Tabela 8.2 é apresentada a descrição dos atributos da relação HHOLD, objeto desse estudo de caso.

Utilizando a ferramenta Statistic Visualizer do Mineset ${ }^{T M}$, foram levantados alguns indicadores estatísticos. apresentados na Figura 8.1, a fim de se obter uma noçāo melhor da distribuição dos dados da relação HHOLD. 


\begin{tabular}{|c|c|c|}
\hline Atributo & Tipo & Descrição \\
\hline \hline hhid & Numérico & Identificador de domicílio \\
\hline Atributo $_{2}, \ldots$, Atributo $_{43}$ & String & $\begin{array}{c}\text { Sem descrição (para proteger } \\
\text { informações privadas) }\end{array}$ \\
\hline
\end{tabular}

Tabela 8.2: Relação HHOLD.

\subsection{Preparação dos Dados}

A preparação dos dados foi bastante simplificada, visto que os mesmos já estavam no formato texto, seguido por tabulaçōes, aceito pelo BKD. A única alteração realizada no conjunto de dados, fornecido para este estudo de caso, foi a retirada do atributo que identifica o domicílio do segurado, visto que essa informação representa apenas a chave estrangeira desse arquivo de dados.

Além disso, para este estudo de caso, foram considerados dois fatores: o primeiro, para a extração de redes Bayesianas a partir de conjuntos de dados sem valores ausentes; e o segundo, para extração de redes, considerando a ocorrência desses valores ausentes. Como o conjunto de dados da relação HHOLD apresenta exemplos com valores de atributos ausentes, o estudo de caso foi realizado considerando dois conjuntos, apresentados na Tabela 8.3.

\begin{tabular}{|c|c|}
\hline Conjunto de Dados & Instâncias \\
\hline \hline HHOLD_comp & 5.192 \\
\hline HHOLD & 12.934 \\
\hline
\end{tabular}

Tabela 8.3: Conjuntos de dados utilizados para extração de redes Bayesianas.

A idéia de submeter a parte completa do conjunto de dados (HHOLD_comp), bem como todo o conjunto de dados da relação HHOLD, foi motivada pela análise comparatória das redes Bayesianas geradas pelos dois conjuntos e pela verificação da representatividade da parte dos exemplos que contém dados incompletos.

\subsection{Data Mining}

Nesta etapa, os conjuntos de dados HHOLD_comp e HHOLD foram submetidos ao BKD, com o objetivo de encontrar as relações de dependência, na forma de redes Bayesianas, entre 


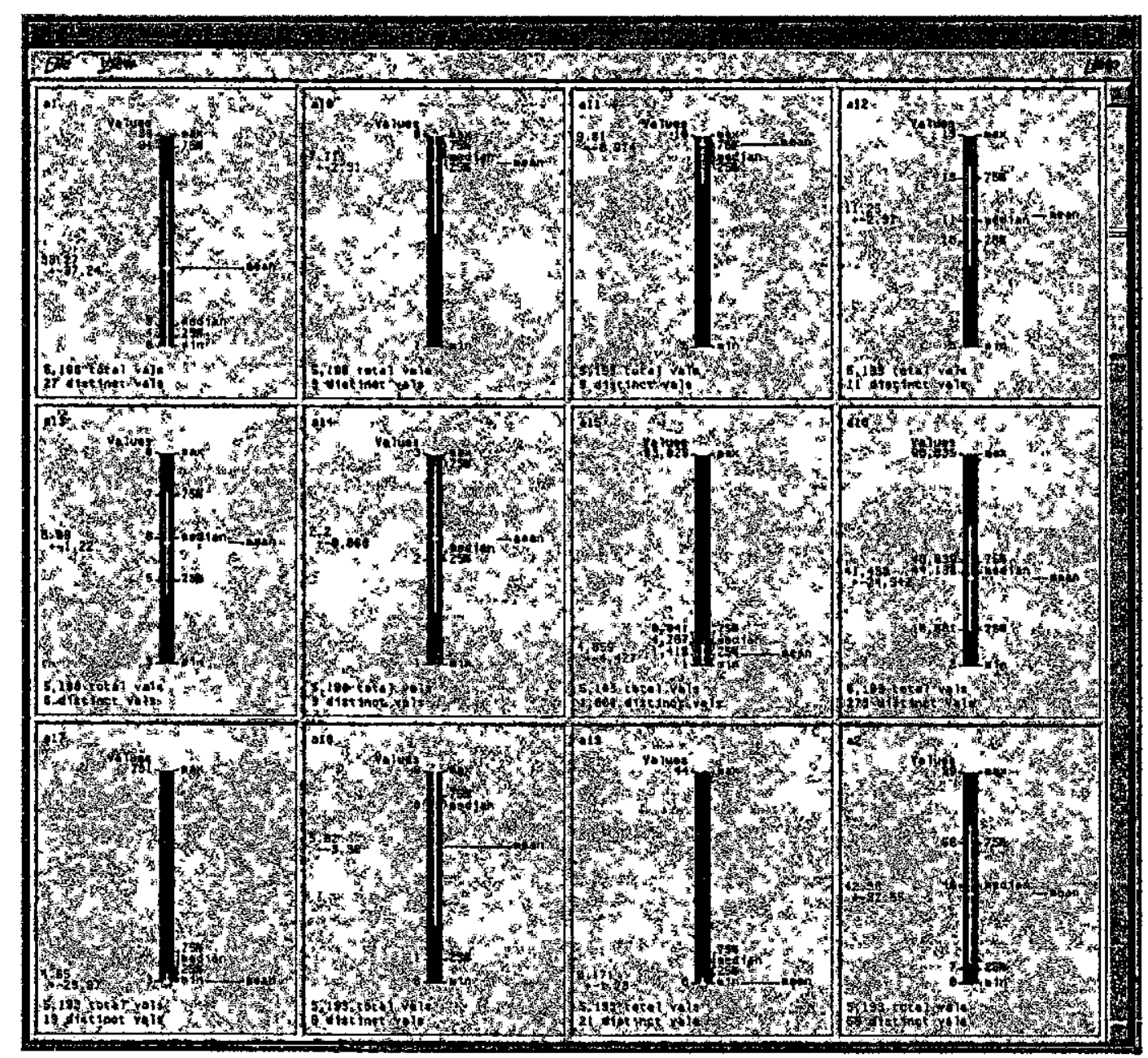

Figura 8.1: Indicadores estatísticos, levantados pelo Mineset $^{T M}$, para o conjunto de dados da relação HHOLD.

os atributos desses conjuntos. Os resultados obtidos são apresentados a seguir.

\subsubsection{Redução de Atributos e Instâncias}

Como não houve a interação direta com especialistas do domínio ora estudado, a única redução de atributos e instâncias realizada foi a discretização dos valores, utilizando o Mineset ${ }^{T M}$. O objetivo dessa discretização, assim como no estudo de caso apresentado no Capítulo 7, é avaliar as mudanças ocorridas em função das discretizações. Vale destacar que as discretizações ocorreram sobre o conjunto de dados HHOLD_comp.

Na Figura 8.2, pode ser visualizada a distribuição dos valores, dentro das faixas discretizadas pelo Mineset $^{T M}$, para alguns atributos do conjunto de dados HHOLD_comp. 


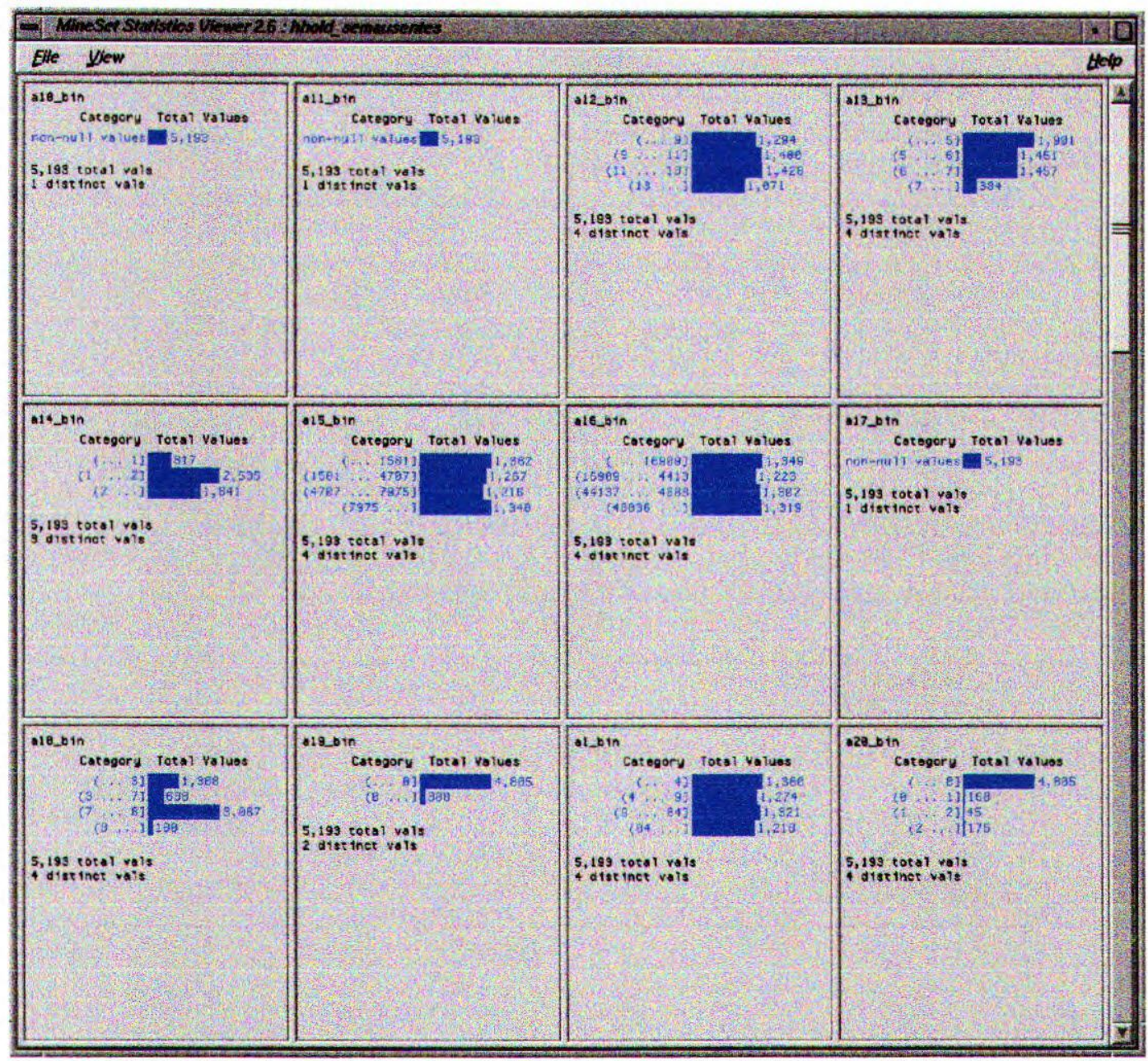

Figura 8.2: Distribuição dos valores nas faixas discretizadas pelo Mineset $^{T M}$, para os atributos do conjunto de dados HHOLD_comp.

\subsubsection{Extração de Padrões}

O conjunto de dados HHOLD_comp foi submetido ao BKD para geração das redes Bayesianas correspondentes, considerando duas situações:

- Extração de redes Bayesianas considerando as discretizações realizadas pelo Mineset $^{T M}$.

- Extração de redes Bayesianas a partir das discretizações feitas pelo próprio BKD.

Nas Figuras 8.3 e 8.4, são apresentadas, respectivamente, as redes Bayesianas gerada a partir do conjunto de dados HHOLD_comp, considerando as duas situações supracitadas.

Comparando as redes Bayesianas mostradas nas Figuras 8.3 e 8.4, é possível observar que poucas mudanças ocorreram nas relações de dependência entre os nós dessas redes, o que 


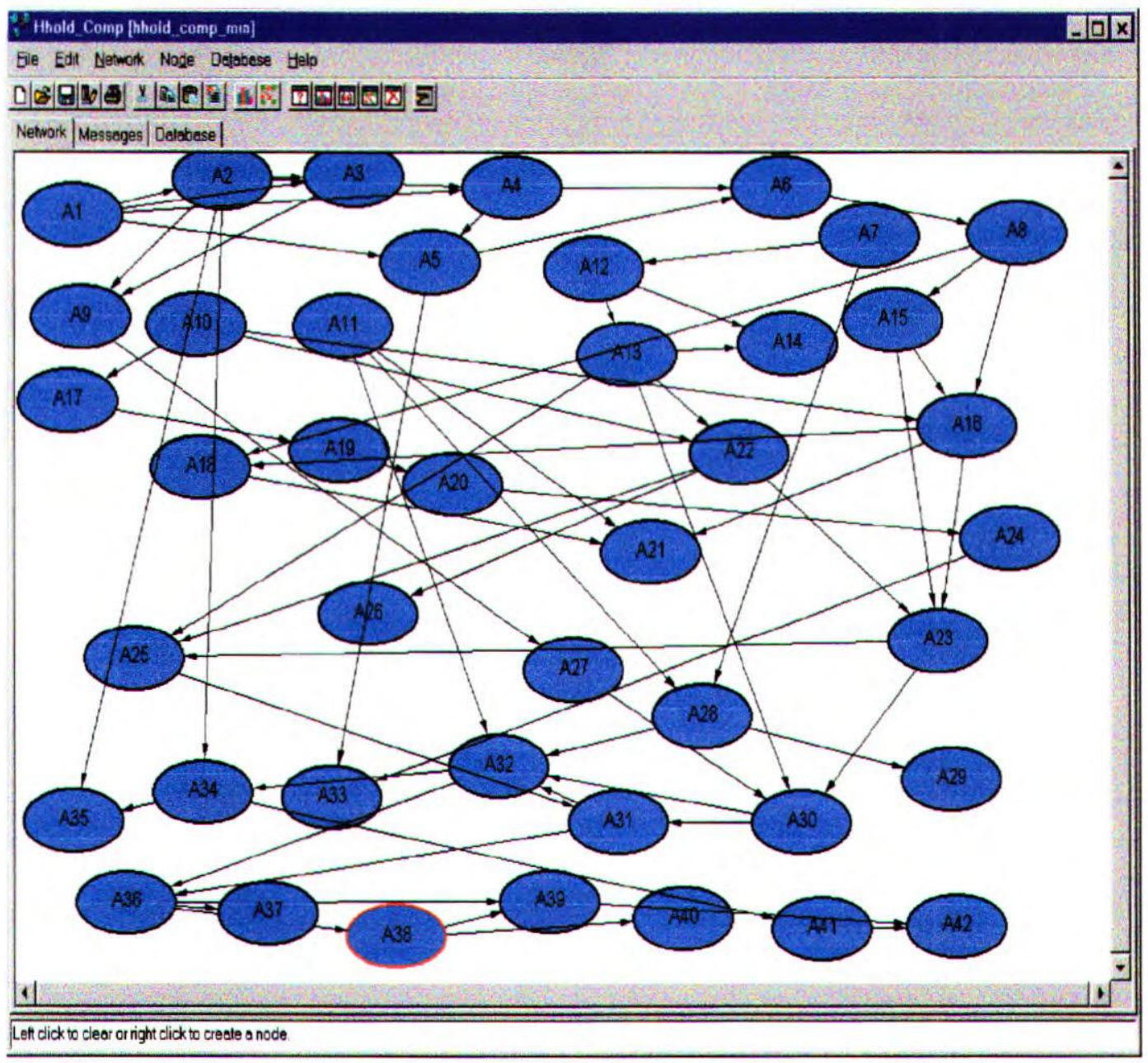

Figura 8.3: Rede Bayesianas gerada pelo BKD, a partir do conjunto de dados HHOLD_comp discretizado pelo Mineset ${ }^{T M}$.

indica que a diferença de distribuição dos valores nas faixas categorizadas pelos métodos de discretização, utilizados pelo Mineset $^{T M}$ e BKD, não foram traduzidas em grandes alterações nas estruturas das redes.

Para efeito deste estudo de caso, foi considerado também o tratamento de dados incompletos, que será abordado a seguir.

\subsubsection{Tratamento de Dados Incompletos}

O tratamento de dados incompletos foi realizado sobre todo o conjunto de dados da relação HHOLD. Assim, esses dados foram submetidos ao BKD com o objetivo de avaliar o comportamento desse método em relação a um conjunto com grande ocorrência de valo- 


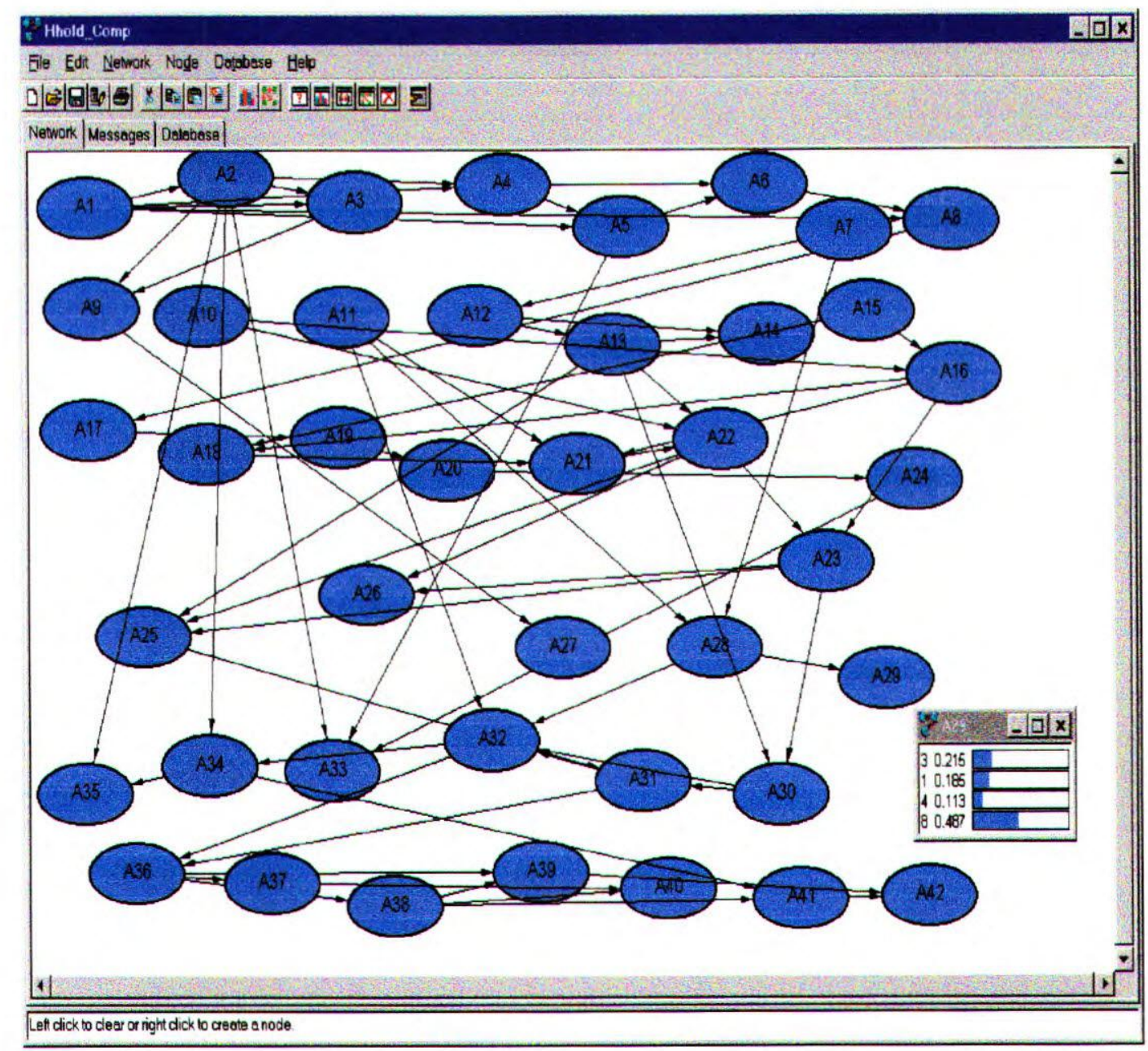

Figura 8.4: Rede Bayesiana gerada pelo BKD a partir do conjunto de dados HHOLD_comp.

res ausentes, além de verificar as possíveis mudanças em relação à rede gerada a partir do conjunto de dados completo (HHOLD_comp). A rede Bayesiana resultante da aplicação do BKD, considerando os dados incompletos, pode ser visualizada na Figura 8.5.

Na Figura 8.5, é possível observar que as dependências entre os atributos de HHOLD não apresentaram mudanças muito acentuadas em relação ao modelo da rede Bayesiana gerada para HHOLD_comp. Vale ressaltar que a falta de um especialista no domínio, além do caráter sigiloso das informações contidas no conjunto de dados da relação HHOLD, impediram que se pudesse efetuar avaliações mais precisas dos resultados obtidos, não apenas para o conjunto de dados com valores ausentes, mas de todos os resultados deste estudo de caso. 


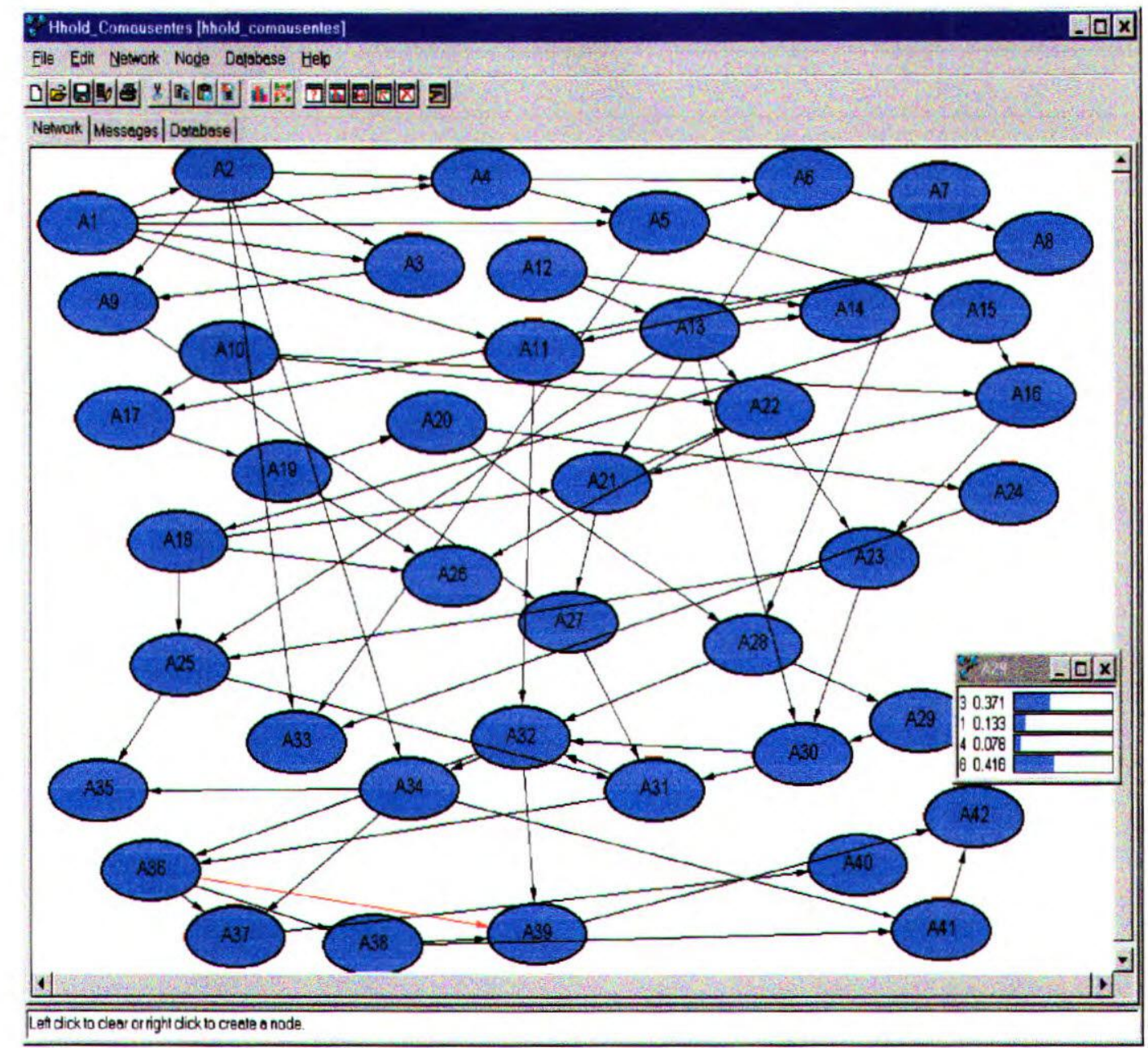

Figura 8.5: Rede Bayesiana gerada pelo BKD a partir do conjunto de dados HHOLD.

\subsection{Considerações Finais}

Neste capítulo, o conjunto de dados referente a relação HHOLD, da base de dados da Swiss Life, foi submetido ao método de aprendizado de redes Bayesianas utilizado neste trabalho. Apesar de não representar um caso eminente de aplicação do processo KDD, este estudo de caso foi realizado, principalmente, com o objetivo de encontrar (e quantificar) relações de dependências entre os atributos desse conjunto de dados, além de avaliar o comportamento das redes Bayesianas no tratamento de conjuntos de dados com grande volume de valores de atributos ausentes. Vale ressaltar que esses valores representam ocorrência reais e não, como no estudo de caso do PMGRN, "retiradas" aleatorias do conjunto de dados.

Dentre os principais resultados obtidos neste estudo de caso destacam-se: 
- Identificação de relações entre os atributos do conjunto de dados da relação HHOLD ${ }^{1}$. Como o número de atributos desse conjunto de dados é bastante elevado, torna-se imperativo o uso de métodos que modelem eficientemente essas relações, de forma que possa ser utilizado para apoiar um processo de tomada de decisão. As redes Bayesianas mostraram-se um modelo eficiente para esse propósito.

- Avaliação do grau de influência que um atributo tem sobre os demais. Foram realizadas várias inferências, por intermédio do algoritmo de propagaçāo do $\mathrm{BKD}$, sobre as redes geradas, a fim de quantificar essas influências.

- As redes Bayesianas geradas a partir de todo conjunto de dados (considerando os valores ausentes) não sofreram grandes alterações em relação a rede Bayesiana gerada a partir do conjunto de dados HHOLD_comp.

Um ponto comum em relação aos resultados enumerados acima, é que, como não houve a participação do especialista do domínio neste estudo de caso, o grau de coerência das relações geradas pelo BKD não pôde ser avaliada.

\footnotetext{
${ }^{1}$ Como não se conhece o que representa cada um dos atributos não foram apresentados aqui resultados muito específicos, do tipo $a_{34}$ têm um alto grau de dependência com $a_{41}$.
} 


\section{Capítulo 9}

\section{Conclusão}

O constante avanço dos mecanismos de coleta e armazenamento de dados, além da preocupação das empresas públicas e privadas em visualizar a informação como seu maior patrimônio, tem direcionado várias pesquisas para o estudo da transformação desses dados em conhecimento, o que pode proporcionar um auxílio efetivamente inteligente ao processo de tomada de decisão.

A transformação de dados em conhecimento tem utilizado métodos eminentemente manuais para análise e interpretação de dados, o que torna o processo de extração de padrões em bases de dados muitas vezes caro, lento e altamente subjetivo, além de inviável em se tratando de grande volume de dados.

Como forma de solucionar esse problema, o processo KDD desponta como uma tecnologia capaz de cooperar amplamente na busca do conhecimento embutido nos dados. $O$ KDD pode ser entendido como um processo de extração de conhecimento de bases de dados com o objetivo de compreender esses dados, adquirindo relações de interesse não observadas pelo especialista do domínio, bem como auxiliando a validação de conhecimento extraído por esse especialista.

A extração de conhecimento de bases de dados deve ser vista como um processo interativo, e não como um sistema de análise automática. Dessa forma, sem uma forte ênfase na interação entre os usuários do processo (identificados neste trabalho como usuários finais, especialistas do domínio e analistas do processo), é pouco provável que se consiga encontrar padrões válidos e potencialmente úteis nos dados.

A busca de padrões pode ser realizada sob vários paradigmas, utilizando os mais va- 
riados métodos de aprendizado. Neste trabalho, esses padrōes foram extraídos utilizando métodos baseados no aprendizado de redes Bayesianas, amplamente aplicadas na análise de relações de dependências entre os dados. As redes Bayesianas constituem um modelo do ambiente (domínio de uma aplicação) e não apenas, como em muitos outros esquemas de representação (e.g. redes neurais e sistemas baseados em regras), um modelo de raciocínio.

Apesar de já existirem várias representações (e.g. árvores de decisão e regras de produção) e técnicas (e.g. classificação e clustering) para análise de dados, as redes Bayesianas têm sido alvo de pesquisas por várias razões. Este trabalho enfatizou duas das mais proeminentes razões - incorporação de conhecimento de fundo e tratamento de dados incompletos.

A incorporação de conhecimento de fundo merece ser destacada, principalmente, por proporcionar uma diminuição do esforço computacional no processo KDD, uma vez que conhecimentos prévios do domínio podem ser incorporados a esse processo. E tratamento de dados incompletos é de relevante interesse, basicamente, por razão das bases de dados comerciais apresentarem, com muita freqüência, valores de atributos ausentes.

Diante desse panorama, a principal contribuição deste trabalho foi investigar os métodos de aprendizado Bayesianos a fim de explorar suas potencialidades no tocante a:

- Identificação de relações de dependências entre os atributos de uma base de dados. Sendo essas relações modeladas na forma de redes Bayesianas e medidas em termos probabilísticos.

- Utilização dos recursos de inferências sobre redes Bayesianas, que, pela própria facilidade de entendimento e praticidade dessas redes, podem ser utilizados para auxílio efetivo à tomada de decisão

- Incorporação de conhecimento de fundo.

- Tratamento de dados incompletos.

Além disso. podem ser destacadas algumas outras contribuições em caráter mais específico:

- Levantamento dos requisitos de cada uma das etapas do processo KDD enfatizando a interação entre os envolvidos nesse processo, identificando problemas e apresentando possíveis soluçōes. 
- Investigação das redes Bayesianas no contexto de extração de conhecimento de dados, estabelecendo interseções entre a abordagem estatístico-Bayesiana e a manipulação de incerteza, aprendizado de máquina e ao próprio processo KDD.

- Análise do estado da arte dos métodos para tratamento de dados incompletos e incorporação de conhecimento de fundo.

- Aplicação do processo KDD em um estudo de caso real, utilizando os dados do Programa de Melhoramento da Raça Nelore, com o objetivo precípuo de encontrar padrões de acasalamentos nos animais dessa raça. Vale destacar que alguns resultados preliminares deste estudo de caso foram publicados na seção de pesquisa do sumário anual desse programa (Lobo et al., 1998).

Baseado no que foi investigado nesta dissertação, os seguintes trabalhos futuros podem ser sugeridos:

- No âmbito geral:

- Investigar o uso de diagramas de influências (que podem ser vistos como extensões de redes Bayesianas) no contexto de extração de conhecimento de bases de dados.

- Investigar e avaliar outros métodos de incorporação de conhecimento de fundo, especialmente, os que envolvam Programação Lógica Indutiva.

- Analisar outros métodos de tratamento de dados incompletos não contemplados neste trabalho.

- Utilizar outras bases de dados para avaliar os requisitos de cada uma das etapas do processo KDD.

- No que tange ao estudo de caso do PMGRN:

- Analisar mais explicitamente os efeitos do ambiente sobre a produtividade dos animais da raça nelore.

- Propor uma rede Bayesiana "ideal" para cada uma das funcionalidades animais, independente do grupo contemporâneo. A fim de que o criador possa utilizá-la, efetivamente, para apoio a um processo de tomada de decisão. 
- Investigar formas de identificar erros, dolosos ou não, cometidos pelos criadores, durante a mensuração das DEPs dos animais de seu rebanho.

- No que tange ao estudo de caso da Swiss Life:

- Avaliar outros métodos de tratamento de dados incompletos para o conjunto de dados HHOLD.

- Utilizar os métodos de aprendizado de redes Bayesianas para outras relações da base de dados da Swiss Life. 


\section{Referências}

Aamodt, A. and Plaza, E. (1994). Case-based reasoning: Foundational issues, methodological variations and system approaches. AI Communications, 7(1):39-59.

Aarts, E. and Korst, J. (1989). Simulated Anneling and Boltzmann Machines: A Stochastic Approach to Combinatorial Optimization and Neural Computing. John Wiley \& Sons.

Andersen, S. K., Olsen, K. G., Jensen, F. V., and Jensen, F. (1989). Hugin - a shell for building bayesian belief universes for expert system. In Proceedings of the 11th International Joint Conference on Artificial Intelligence, pages 1080-1085. SpringerVerlag.

Batista, G. E. A. P. A. (1997). Um ambiente de avaliação de algoritmos de aprendizado de máquina utilizando exemplos. Dissertação de Mestrado, ICMC-USP.

Breiman, L., Friedman, J. H., Olshen, R. A., and Stone, C. J. (1984). Classification and Regression Trees. Wadsworth.

Buntine, W. (1996). A guide to the literature on learning probabilistic networks from data. IEEE Transactions on Knowledge and Data Engineering, 8(3):111-134.

Carbonel, J. G. and Langley, P. (1987). Machine Learning - Encyclopedia of Artificial Intelligence. Ed. John Wiley \& Sons.

Casella, G. and Berger, R. L. (1990). Statistical Inference. Wadsworth and Brooks.

Cheeseman, P. and Stutz, P. (1990). Autoclass: A bayesian classification system. pages $431-441$.

Clark, P. and Boswell, R. (1991). Rule induction with CN2: Some recent improvements. In Kodratoff, Y., editor, Proceedings of the 5th European Conference (EWSL 91), pages 151-163. Springer-Verlag. 
Clark, P. and Matwin, S. (1993a). Learning domain theories uning abstract background knowledge. In Prazdil, P., editor, Proceeding Sixth European Conference on Machine Learning, pages 360-365. Springer-Verlag.

Clark, P. and Matwin, S. (1993b). Using qualitative models to guide inductive learning. In Utgoff, P., editor, Proceedings Tenth Int. Machine Learning Conference (ML-93), pages 49-56. Morgan Kaufmann.

Clark, P. and Niblett, T. (1989). The cn2 induction algorithm. Machine Learning, $3(4): 261-283$.

Codd, E. F. (1993). Provinding OLAP (On-Line Analytical Processing) to User-Analyst: An IT Mandate. E. F. Codd and Assoc.

Cooper, G. and Herskovits, E. (1992). A bayesian method for induction of probabilistic networks from data. Machine Learning, (9):309-347.

Dantas, C. A. B. (1997). Probabilidade: Um Curso Introdutório. Editora USP.

Dawid, P. (1984). Statistical theory - the prequential approach (with discussion). Journal of the Royal Statistical Society, (147):178-292.

Decker, K. M. and Focardi, S. (1995). Technology overview: A report on data mining. Technical Report 02, CSCS-ETH, Swiss Scientific Computer Center, 1995.

Dempster, A. P., Laird, N. M., and Rubin, D. B. (1977). Maximum likelihood from incomplete data via the EM algorithm. Journal of the Royal Statistical Society, 39(1):1-38.

Dietterich, T. G. (1997). Machine learning research: Four current directions. $\mathrm{ftp}: / / \mathrm{ftp}$.cs.orst.edu/pub/tgd/papers.

Fayyad, U. (1996). Data mining and knowledge discovery: Making sense out of data. IEEE Expert, 11(5):20-25.

Fayyad, U., Piatetsky-Shapiro, G., and Smith, P. (1996). The KDD process for extracting useful knowledge from volumes of data. Communications of $A C M, 39(11): 27-34$.

Félix, L. C. M. (1998). Data mining no processo de extração de conhecimento de bases de dados. Dissertação de Mestrado, ICMC-USP.

Forbus, K. D. (1984). Qualitative process theory. Artificial Intelligence, 24:85-168. 
Friedman, H. F., Kohavi, R., and Yun, Y. (1996). Lazy decision tree. In Proceedings of the 13th National Conference on Artificial Intelligence, pages 717-724. AAAI and MIT.

Geman, S. and Geman, D. (1984). Stochastic relaxation, gibbs distribuitions and the bayesian restoration of images. IEEE Transactions on Pattern Analysis and Machine Intelligence, (6):721-742.

Ghahramani, Z. and Jordan, M. I. (1994). Learning from incomplete data. Technical Report 108, Artificial Intelligence Laboratory - Massachusetts Institute of Technology.

Glymour, C., Madigan, D., Pregibon, D., and Smyth, P. (1997). Statistic themes and lessons for data mining. Data Mining and Knowledge Discovery, 1(1):11-28.

Han, J. (1998). Towards on-line analytical mining in large databases. ACM SIGMOD Record, 27(1).

Haykin, S. (1994). Neural Networks - A Comprehensive Foundation. Macmillan College Publishing Company.

Heckerman, D. (1997). Bayesian networks for knowledge discovery. Data Mining and Knowledge Discovery, 1(1):79-119.

Heckerman, D., Geiger, D., and Chickering, D. (1995). Learning bayesian networks: The combination of knowledge and statistical data. Machine Learning, (20):197-243.

Hertz, J., Krogh, A., and Palmer, R. G. (1991). Introduction to Theory of Neural Computation. Addison-Wesley.

Howard, R. and Matheson, J. (1983). The Principles and Applications of Decision Analysis. Strategic Decision Group.

Inmon, W. H. (1996). The data warehouse and data mining. Communications of ACM, $39(11): 49-50$.

Jensen, F. (1994). Implementation aspects of various propagation algorithms in hugin. Technical Report 94-2014, AalBorg University.

Jensen, F., lauritzen, S., and Olsen, K. (1990). Bayesian updating in recursive graphical models by local computations. Computational Statisticals Quaterly, (4):269-282.

Kerber, R. (1991). Learning classification from examples. In Proceedings AAAI Workshop on Knowledge Discovery in Databases. Springer-Verlag. 
Kerber, R., Livezey, B., and Simoudis, E. (1995). A Hybrid System for Data Mining (Chapter 7). John Wiley \& Sons Ltd.

Kietz, J. and Staudt, M. (1998). Private life insurance business at swiss life. http://www.swisslife.ch/.

Kliber, D., Livezey, B., and Simound, E. (1988). Machine learning as a experimental science. Machine Learning, 3(1):5-8.

Kontkanen, P., Myllymäki, P., Silander, T., and Tirri, H. (1997). Comparing stochastic complexity minimization algorithms in stimating missing data. In Proceedings Workshop on Uncertainty Processing - WUPES'97, pages 81-90.

Langley, P., Iba, W., and Thompson, K. (1992). An analysis of bayesian classifiers. In Proceedings of the 10th Conference on Artificial Intelligence, pages 223-228. AAAI and MIT.

Lauritzen, S. (1992). Propagation of probabilities, means and variance in mixed graphical association models. Journal of American Statistical Association, (87):1089-1992.

Li, B. (1996). Data mining now - a survey and thesis proposal.

Ling, C. X. and Wang, H. (1997). Computing optimal attribute weight setting for nearest neighbor algorithms. Artificial Intelligence Review, pages 255-272.

Little, R. J. A. and Rubin, D. B. (1987). Statistical Analysis With Missing Data. Wiley.

Liu, W. Z., White, A. P., Thompson, S. G., and Bramer, M. A. (1997). Techniques for dealing with missing values in classification. pages $527-536$.

Lobo, R. B., Bezerra, L. A., Oliveira, H. N., and de los Reyes, A. (1998). Avaliação genética de animais jovens, touros e matrizes. Ribeirão Preto, FMRP-USP/GEMAC.

Madigan, D. and Raftery, A. (1994). Model selection and accounting for model uncertainty in graphical models using occam's window. Journal of the American Statistical Association, (89):1535-1546.

Mannila, H. (1997a). Data mining: Machine learning, statistic and databases. http://www.cs.helsinki.fi/ mannila.

Mannila, H. (1997b). Methods and problems in data mining. In Proceedings International Conference on Database Theory, Delphi, Greece. Springer-Verlag. 
Michell, T. M. (1980). The need for biases in learning generalizations. Technical Report 117, Rutgers University.

Michell, T. M. (1997). Machine Learning. McGraw-Hill.

Mowforth, G. (1992). Personal communication. Interview.

Oliveira, R. B. T. and Rezende, S. O. (1998). Ferramentas de visualização de dados do mineset. Technical Report 71, ICMC-USP.

Pazzani, M. (1991). The utility of knowledge in indutive learning. Technical report, Department of Information \& Computer Science - University of California.

Pearl, J. (1988). Probabilistic Reasoning in Inteligent System. Morgan Kaufmann Publishers, Inc., San Mateo, California, USA.

Pearl, J. (1997). Bayesian networks. Technical Report 246, Cognitive Systems Laboratory - University of California.

Porter, B. W., Bareiss, R., and Holte, R. C. (1990). Concept learning and heuristic classification in weak-theory domains. Artificial Intelligence, 45(1-2):229-263.

Quinlan, J. R. (1986). Induction of decision trees. Machine Learning, (1):81-106.

Quinlan, J. R. (1989). Unknown attribute values in induction. In Machine Learning.

Quinlan, J. R. (1993). C4.5: Programs for Machine Learning. Morgan Kaufmann Publishers, Inc., Los Altos, California, USA.

Ramoni, M. and Sebastiani, P. (1997a). Bayesian inference with missing data using bound and collapse. Technical Report 58, Knowledge Media Institute - The Open University.

Ramoni, M. and Sebastiani, P. (1997b). Discovering bayesian networks in incomplete database. Technical Report 46, Knowledge Media Institute - The Open University.

Ramoni, M. and Sebastiani, P. (1997c). Parameter estimation in bayesian networks from incomplete database. Technical Report 57, Knowledge Media Institute - The Open University.

Reither, R. (1987). Nonmonotonic reasoning. Annual Review of Computer Science, (2):147-186. 
Rezende, S. O., Oliveira, R. B. T., Félix, L. C. M., and da Rocha, C. A. J. (1998). Visualization for knowledge discovery in database. In Ebecken, N.F.F. (ed.) Data Mining. WIT Press, England, pages 81-95.

Rezende, S. O. and Pugliesi, J. B. (1998). Aquisição de conhecimento explícito ou manual. Technical Report 37, ICMC-USP.

Rich, E. and Knight, K. (1993). Inteligência Artificial - 2a Edição. Makron Books.

Rissanen, J. (1989). Stochastic Complexity in Statistical Inquiry. World Scientific Publishing Company.

Rissanen, J. (1996). Fisher information and stochastic complexity. IEEE Transactions and Information Theory, 42(1):40-47.

Russell, S. and Norvig, P. (1995). Artificial Intelligence - A Modern Approach. Prentice Hall.

Salzberg, S. L. (1997). On comparing classifiers: Pitfalls to avoid and a recommended approach. Data Mining and Knowledge Discovery, 1(3).

Schuurmans, D. and Greiner, R. (1995). Learning to classify incomplete examples. Technical report, Department of Computer Science - University of Toronto.

Shatcher, R. (1988). Probabilistic inference and influence diagrams. Operations Research, (36):589-605.

Shatcher, R. and Andersen, S. (1989). Gaussian influence diagrams. Management Science, (35):527-550.

Silberschatz, A., Stonebraker, M., and Ullman, M. (1996). Database research: Achievements and opportunities into the 21 century. SIGMOD Record.

Thomas, A., Spiegelhalter, D., and Gilks, W. (1992). Bugs: A Program to Perform Bayesian Inference Using Gibbs Sampling. Oxford University Press.

Tukey, J. (1977). Exploratory Data Analysis. Addison-Wesley.

Weiss, S. M. and Kulikowski, C. A. (1991). Computer Systems that Learn: Classification and Prediction Methods from statistic, Neural Nets, Machine Learning and Expert System. Morgan Kaufmann Publishers, Inc. 
White, A. P. (1987). Probabilistic induction by dinamic path generation in virtual trees. In Bramer, M. A., editor, In Research and Development in Expert System III, pages 35-46. 